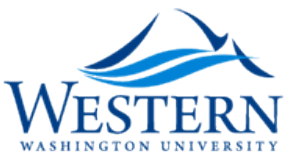

Western Washington University

Western CEDAR

East Asian Studies Press

Books and Monographs

1991

\title{
A Change in Dynasties: Loyalism in Thirteenth- century China
}

Jennifer W. Jay

Follow this and additional works at: https://cedar.wwu.edu/easpress

Part of the Asian History Commons

\section{Recommended Citation}

Jay, Jennifer W., "A Change in Dynasties: Loyalism in Thirteenth-century China" (1991). East Asian Studies Press. 4. https://cedar.wwu.edu/easpress/4

This Book is brought to you for free and open access by the Books and Monographs at Western CEDAR. It has been accepted for inclusion in East Asian Studies Press by an authorized administrator of Western CEDAR. For more information, please contact westerncedar@wwu.edu. 


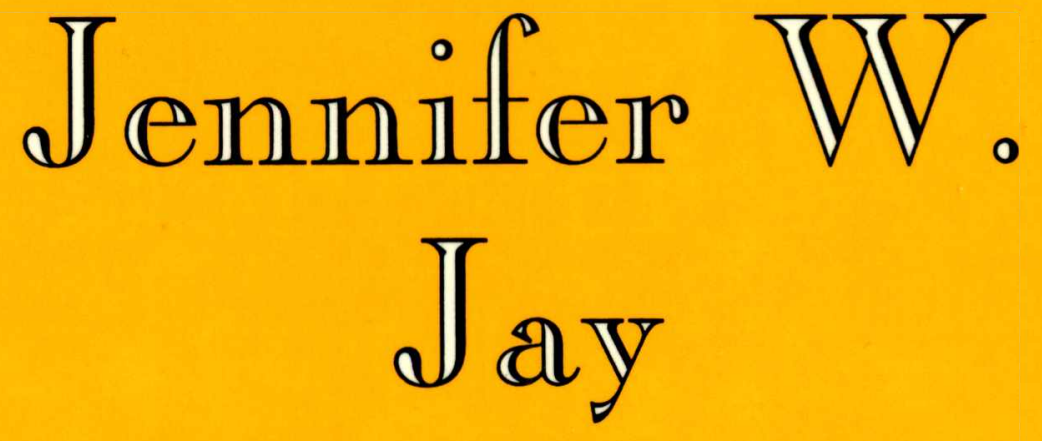

Al Change

in

Dynasties 
Jay / A Change in Dynasties 
Center for East Asian Studies

Western Washington University

Studies on East Asia, Vlume 18

A Change in Dynasties: Loyalism in Thirteenth-Century China, by Jennifer W. Jay

The Center for East Asian Studies publishes scholarly works on topics relating to China, Japan, Korea, and Mongolia.

Editor:

Professor Henry G. Schwarz 


\title{
A CHANGE IN DYNASTIES:
}

\section{LOYALISM IN THIRTEENTH-CENTURY CHINA}

\author{
by \\ Jennifer W. Jay
}

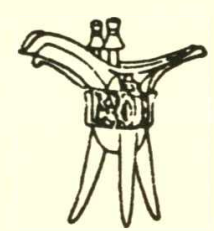

Western Washington 
Copyright 1991

by

CENTER FOR EAST ASIAN STUDIES

Western Washington University

Bellingham, Washington 98225

All rights reserved. No part of this publication may be reproduced or transmitted in any form or by any means, electronic or mechanical, including photocopy, recording, or any information storage or retrieval system, without permission in writing from the publisher.

Library of Congress Cataloging-in-Publication Data

Jay, Jennifer W.

A change in dynasties : loyalism in thirteenth-century China /

by Jennifer W. Jay.

p. cm. -- (Studies on East Asia ; v. 18)

Includes bibliographical references and index.

ISBN 0-914584-18-9; \$30.00 (est.)

1. China--History--Sung dynasty, 960-1279. 2. China--History

--Yüan dynasty, 1260-1368. 3. Loyalty. I. Title. II. Series.

DS751.J38 1991

951'.024--dc20

91-14475

CIP

Printed in the United States of America

on acid-free paper 
To my late grandfather, Jay Bon Ming 


\section{CONTENTS}

Acknowledgments vii

Guidelines viii

Abbreviations ix

Preface $x i$

One / Introduction

Two / The Surrender of the Southern Song and Loyalist

Resistance

Three / The Hagiography and Historiography of Song Loyalism

Four / The Zhongyi Tradition of Loyalty: Wen Tianxiang and the Martyrs, 1273-1279

Five / Regional Loyalist Centers and Personalities, ca. $1276-1300$

Six / Zhou Mi and Marginal Loyalism in Hangzhou and Huzhou

Seven / The Transformation of Song Loyalism

Appendixes

Bibliography of Works Cited

About the Author 


\section{APPENDIXES AND MAPS}

\section{APPENDIXES}
A. Songshi Biographies of Zhongyi Men
B. Zhongyi Biographies Throughout the Dynasties
C. Wen Tianxiang's Career Before the Resistance
D. Zhongyi Loyalists in Wen Tianxiang's mufu
E. Loyalist Centers and Major Personalities
F. Zhou Mi's Traveling Companions

MAPS

1. Song-Yuan China, ca. 1276

xiv

2. Song-Yuan Military Campaigns, ca. 1273-1279

3. Loyalist Centers, ca. 1276-1300 


\section{ACKNOWLEDGMENTS}

Both the research and writing of this monograph took place at the Australian National University in Canberra. I would like to thank the Australian National University for granting me a postgraduate scholarship and in providing research facilities during 1979-83. Professor Wang Gungwu guided me through difficult stages of research; for this and for personal encouragement I indeed owe him an immense debt of gratitude. To Dr. Igor de Rachewiltz, I am likewise indebted for guidance and assistance, as well as for generously lending me source materials. I thank Drs. Ho Hon-wai, Jennifer Holmgren, and L. W. Preston for reading through the entire draft and making valuable suggestions for improvement. Thanks are also due to Mr. William Mills, who proofread the manuscript and assisted with the maps. I am fortunate to have the expert guidance and abundant patience of Dr. Henry G. Schwarz, the editor and publisher of my book. I would also like to express a special gratitude and enduring respect to Professor E. G. Pulleyblank, who initiated me into the field of medieval Chinese history and who continued to provide ample encouragement.

Parts of Chapters Three and Six have appeared in different form in Papers on Far Eastern History 28 (1983) and Harvard Journal of Asiatic Studies 50:2 (1990), respectively. Permission to include the material in these two articles is much appreciated.

My children, Trevor and Graham, deserve a mention for putting up with babysitters to enable me to work undisturbed.

For any errors and misinterpretations in this study, however, I am solely responsible. 


\section{GUIDELINES}

1. Pinyin is used to romanize personal names and place names with the following exceptions: i) actual references, titles and names used by the authors of works in Western languages (e.g. Chang Fu-jui); ii) Tsin for the dynasty to distinguish it from the Jin 金 and Foochow for from Fuzhou 热州. Modern equivalents of place names are given in brackets.

2. The dates for Song and Yuan men are in accordance with Chang Bide $e t$ al., Songren zhuanji ziliao suoyin (Taibei, 1976) and Wang Deyi et al., Yuanren zhuanji ziliao suoyin (Taibei, 1981). In some cases I have amended the dates using the Songshi or Yuanshi, and in reference to an individual's collected writings (for example, Shu Yuexiang [1217-1298], not [1236-1298] as given in Wang Deyi). For individuals from other periods, the dates are drawn from Jiang Liangfu's Lidai mingren nianli beizhuan zongbiao (Taibei, 1970).

3. The translations of offices are mostly from E. A. Kracke, Translation of Sung Civil Service Titles (Paris, 1957) and supplemented by Chang Fu-jui, Les Fonctionnaires des Song: Index des Titres (Paris, 1962). Some exceptions are such as translating chengxiang as "chief minister" and not "grand councillor."

4. The maps were prepared from Tan Qixiang's Zhongguo lishi ditu ji (Shanghai, 1982), vols. 6 and 7.

5. Unless otherwise indicated, the translations in this monograph are my own. 


\section{PREFACE}

This book is a study of loyalists during the transition from the Song to Yuan dynasties, from about 1273 to 1300 . By means of an examination of their background and loyalist activities, and a reconstruction of relationships between individual loyalists, I obtain a broad view of Song loyalism and its significance to contemporaries and their response to alien rule. After a critical examination of official histories and the writings of the Song loyalists, I suggest that Song loyalism should be observed in terms of a spectrum of relative rather than absolute values. In addition, the intensity and duration of loyalty changed over time and through circumstances. I delineate three traditions of Song loyalists in this spectrum: the zhongyi loyalists who died during or for the Song cause; the yimin loyalists who survived the collapse of the dynasty and/or loyalist resistance and lived some years under Mongol rule, and the marginal loyalists (a subgroup of the yimin) whose conduct during their later years drew strong criticism from traditional historians. Contrary to traditional views of Song loyalists as individuals totally uncompromising to the new government, evidence indicates that after the defeat of loyalist resistance in 1279 , even among the exemplars accommodation was more often the case than resistance.

In the introductory chapter I briefly outline the divergent interpretations of Mongol rule and its impact on the structure of Chinese society, and indicate the lack of a broad and comprehensive view of the Song loyalists. Chapter Two is a reappraisal of the events of the end of the Southern Song and the political circumstances under which the leaders of the loyalist movement planned and carried out their resistance from 1276 to 1279 . I offer some new interpretations, such as showing Wen Tianxiang to have been a newcomer rather than the leading personality of the Southern Song court and 


\section{Preface}

the loyalist movement, contrary to traditional misconceptions that he had single-handedly planned and executed the resistance. In this reconstruction, Chen Yizhong and Li Tingzhi are found to be the senior officials who emerged as the unchallenged leaders in 1275-76.

Chapter Three examines some aspects of both official and unofficial historiography of the Song loyalists. Wen Tianxiang's writings, along with his prejudices, are shown to have influenced both the Songshi and the works of the Song loyalists, and accounted for certain discrepancies among the sources. I also discuss the possibility of censorship under the Yuan, concluding that more likely the Song loyalists, their descendants and editors were cautious and censored themselves. I then look at later writings reflecting a local concern, which produced favorable accounts at the expense of historical objectivity. One example raised is Quan Zuwang's research into the contributions his local district and his ancestors made in connection with Song loyalism. In this chapter I also deal with several myths in the traditional portrayal of the Song loyalists.

The next chapter deals with the zhongyi loyalists (martyrs); in particular, the participation in the loyalist resistance by Wen Tianxiang, Li Tingzhi, Lu Xiufu, Chang Shijie, and Xie Fangde are discussed in more detail. I also examine the relationships between these key personalities and their loyalist followers, and suggest that the organization and structure of their support was within the traditional mufu (tent government) system.

Chapter Five reconstructs nine yimin loyalist groups (survivors) in the first generation of Mongol rule: Annam, Beijing, Kuaiji, Wuzhou, Luling, Ningbo, Raozhou, Suzhou, and Dongguan. The key loyalist figures active in these centers--Wang Yuanliang, Jia Xuanweng, Wang Yingsun, Lin Jingxi, Xie Ao, Fang Feng, Wang Yinglin, Hu Sanxing, Liu Chenweng, Ma Tingluan, Zheng Sixiao, Gong Kai, and Zhao Bixiang--are discussed with respect to their attitudes towards the conquest and life under Mongol rule. I indicate that in most cases the loyalism of these individuals became less intense as they socialized with Yuan officials and gave tacit approval for their sons to seek employment in the new government.

The Hangzhou and Huzhou loyalists such as Deng Mu and Mou Yan are examined in Chapter Six, which is concerned with the relationships of Zhou Mi, a versatile writer and artist. Among Zhou Mi's extensive circle of 


\section{Preface}

friends were many in the employ of the Yuan government and a young generation of artists and scholars who later, with deep regret, accepted official appointments. This change was evident in the late 1280s and 1290s, by which time their loyalty had become transformed into accommodating positions disapproved of by some contemporaries and later historians. The concluding chapter summarizes my findings on the essence and duration of Song loyalism and looks at its impact on later generations experiencing dynastic collapse. 


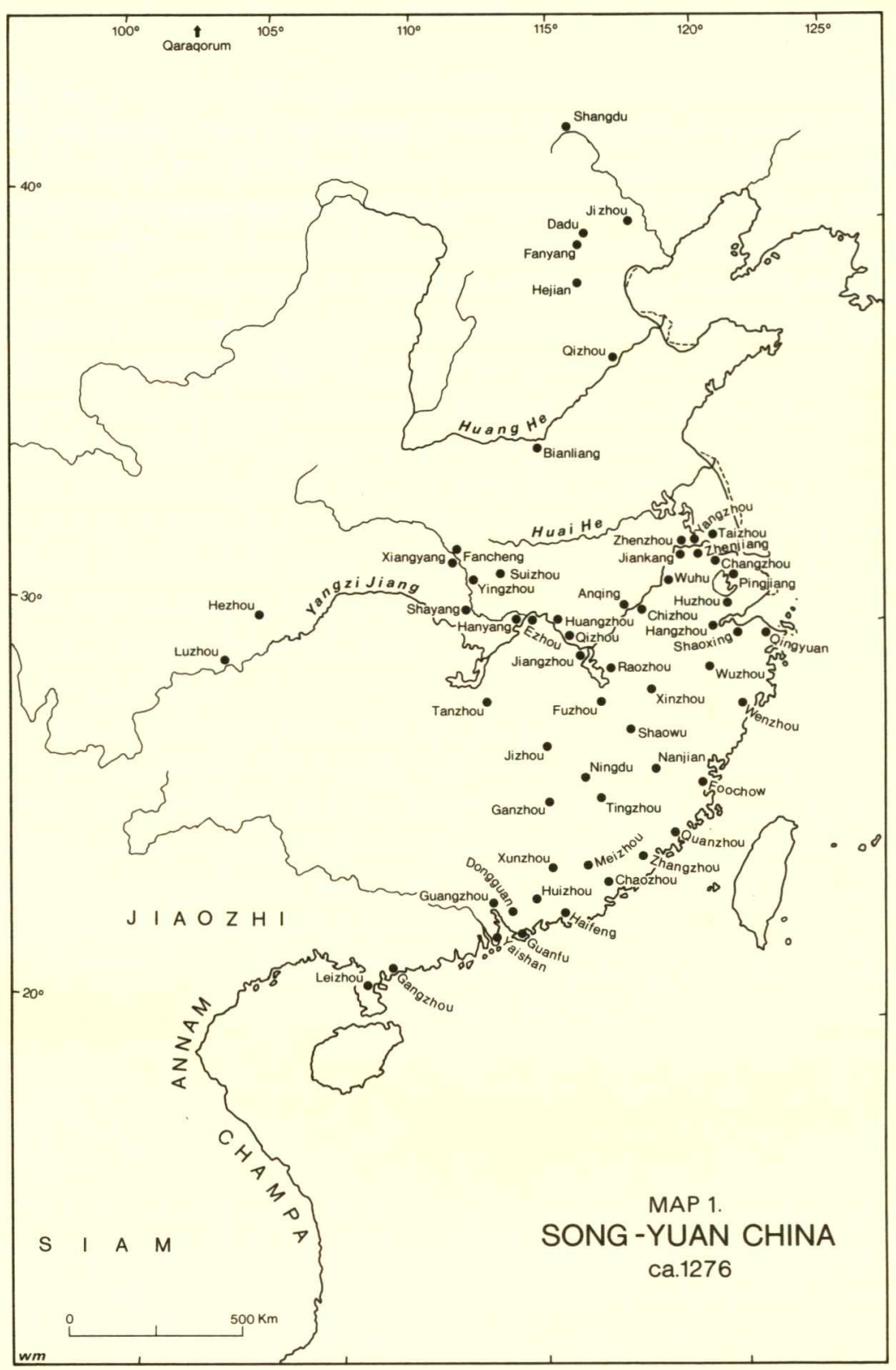




\section{ONE / INTRODUCTION}

In February 1276, Mongol armies occupied Hangzhou, the capital of the Southern Song (1127-1276) and reunified China under foreign rule. It took another three years to suppress the last traces of loyalist resi vance in the southeastern provinces. In contrast to North China which had by then undergone several foreign regimes, Jiangnan (i.e., South China, the territory of the Southern Song south of the Huai and Yangzi rivers) had never before been conquered by foreigners. ${ }^{1}$ In the process of conquest and assimilation, the Mongols had become less destructive than the earlier reputation for which they were remembered. ${ }^{2}$ Nevertheless, the double crisis of the collapse of the Song and its replacement by a foreign dynasty left an indelible mark on the educated elite of South China. Many officials and scholars collaborated with and surrendered to the Mongol Yuan (1276-1368), but not a few felt intense loyalty to the fallen dynasty and resisted the conquest by engaging in military combat, committing suicide or withdrawing into self-imposed exile.

The pacification of South China raises other questions. Did the response of the southern Chinese differ from that of the northern Chinese forty years earlier, when the Mongols supplanted the Jurchen Jin (1125-1234)? To what extent did ethnicity and culturalism dictate the varying types of response among the southern intellectuals? How was the Chinese perception of foreign

1. These foreign dynasties are the Toba Wei (386-534), Northern Qi (550-577), Khitan Liao (916-1125), Tangut Xixia (1038-1227), and Jurchen Jin (1125-1234).

2. On the process of Mongol conquest and assimilation patterns, seen from the perspective of Mongolian history, see Thomas A. Allsen, Charles Halperin, David Morgan, Morris Rossabi, and Zhou Liangxiao. 


\section{Chapter One}

rule modified and rationalized over time? And, what effects did the Yuan government have on the social, cultural, economic, and political structures of society in South China?

Chinese historians have traditionally viewed the Mongol period in history as a disastrous and uprooting century that brought not only economic exploitation and suffering to the Chinese people, but a drastic interruption in Chinese culture and civilization as well. Those embracing such views dwell on the Yuan practice of dividing its subjects into four social classes in descending order of political and legal privileges: Mongols; Semu (Central Asians); Hanren (Tanguts, Khitans, Jurchens, northern Chinese); and Nanren (former subjects of the Southern Song). These writers claim that such discrimination based on ethnic origins and the order of submission to Mongol rule relegated the Confucian scholars and former officials of the Song to society's lowest strata, one rank above the paupers and one below the prostitutes. ${ }^{1}$ Furthermore, social unrest and widespread rebellions in the late Yuan are interpreted as racially instigated uprisings against the Yuan administration. Likewise, the success of Zhu Yuanzhang (Ming Taizu, r. 1368-98) in establishing the Ming dynasty (1368-1644) is attributed to its indigenous origins. ${ }^{2}$ The Ming scholar Wang Zhu (fl. 1521) took an extremist position: he ignored the entire Yuan period and represented Zhu Yuanzhang's ancestors as the legitimate heirs of the Song mandate. ${ }^{3}$ Modern Chinese nationalist critics of Western and Japanese imperialism and, until recently, most authors of general histories of China also deny that the Yuan period had any positive

1. See Zheng Sixiao, Xinshi, 129, and Xie Fangde, Dieshan xiansheng wenji, 6.3b. Cf. Chen Yuan, Western and Central Asians, 290-91, and Xiao Qiqing, "Yuandai de ruhu, " 169. Chen Yuan and most modern historians now dismiss the statements of Zheng Sixiao and Xie Fangde as exaggerated complaints of frustrated scholars.

2. For example, see Jian Bozan, 338-44, and Jin Yufu, Song Liao Jin shi, 115.

3. Wang Zhu's Songshi zhi is discussed by Hok-lam Chan in his "Chinese official historiography," 95-105. See also Wang Deyi, "You Songshi zhi tandao Mingchao ren de Songshi guan," 510-25. 


\section{Introduction}

features. ${ }^{1}$

Alternative views have not been absent. After recognizing the permanence of Manchu power, some Ming loyalist scholars in the seventeenthcentury looked back at the Yuan period and acknowledged that culture and civilization had actually survived Mongol rule. ${ }^{2}$ Therefore, they somewhat confidently hoped that the same would prevail during the Manchu Qing dynasty (1644-1911).

In more recent times, Meng Siming's pioneer study concludes that, contrary to previous opinions, the Mongol conquest did not fundamentally upset the socio-economic organization of Chinese society in the South. ${ }^{3}$ Meng argues that although the Yuan government superimposed political control over the gentry and former Song officials who had submitted, it more or less allowed them to retain their economic power and regular administrative functions at the local level. Being economically powerful, this Chinese elite of large landowners and wealthy merchants was placed in an advantageous position to exercise political influence over some destitute Mongol nationals. Meng also dismisses the view that reaction against racial discrimination had been responsible for the final destruction of Mongol power in China. He points out that it was the Chinese elite who quickly volunteered aid to the Yuan court when indigenous rebels threatened the central government. Only when the Yuan formulated policies that antagonized the Chinese elite in the 1350s did the latter switch sides to join forces with Zhu Yuanzhang. Meng feels that to regard the late Yuan uprisings as a nationalist resistance to foreign rule was tantamount to using the outcome of history to determine the nature of the uprisings. He and the Japanese scholar Yanai Watari concur in the view that although Yuan regulations were discriminatory, the law was sometimes flexible, and many northern Chinese in fact reached prominent government posts. They argue further that the four social classes had not

1. See Jacques Gernet, 18, and Witold Rodzinski, vol. 1, 184-85.

2. For a comparative view of the Qing situation, see John D. Langlois, Jr., "Chinese culturalism," 355-56.

3. Meng Siming, Yuandai shehui jieji zhidu, 1-2, et passim. 


\section{Chapter One}

necessarily been perpetuated by ethnic differences and were less exclusive and rigid than previously assessed. ${ }^{1}$ They both assert that economic factors, and not racial and ethnic hostilities, had primarily been responsible for the fall of the Yuan in 1368.

Recent regional studies have yielded varied conclusions about ruptures in the socio-economic structure of Chinese society in the South. Davis' study of a prominent lineage in Qingyuan (Ningbo) shows its drastic social and political decline after the Song demise. In contrast, Hymes' research demonstrates that the local elite in Fuzhou (Jiangxi province) emerged essentially intact through the Song to Yuan transition. ${ }^{2}$ Likewise, Langlois not only contradicts traditional claims of a stagnancy during this period, but shows unbroken traditions and innovations in Chinese civilization, arts and culture in the light of the reunification of the country. ${ }^{3}$ In Taiwan Yao Congwu's favorable views about the employment of Confucian scholars by the Yuan government have been adopted by Li Zefen, whose assessment of the Yuan dynasty as a constructive period also drew upon Western studies. ${ }^{4}$ Mainland Chinese historians previously subscribed to Soviet historiography, which viewed the Mongols as aggressive and expansionist, laying waste whatever territory they conquered. Since the 1960s, however, they have interpreted the Mongol reunification of China to be a progressive and positive measure, a view that is now very much in accordance with the government's present policy to win the goodwill of ethnic minorities and to emphasize the multi-

1. See Yanai Watari, 97-101.

2. On Qingyuan (Mingzhou), see Richard L. Davis, and on Fuzhou, Robert P. Hymes.

3. Langlois, ed., China Under Mongol Rule, contains the theme of Yuan contribution to Chinese culture. I had completed my research and formulated my conclusions when the book came out, but I am still indebted to this volume which confirms some of my conclusions presented in this study.

4. See Yao Congwu, "Cheng Jufu, " 353-79. See also Li Zefen's five-volume work which, however, should be cautiously used, as factual errors (e.g. Zhou Mi, in vol. 5, 409-10) and tenuous views of the Yuan dynasty occur frequently. 


\section{Introduction}

ethnic nature of the Chinese population. ${ }^{1}$

These two conflicting interpretations of the impact of Mongol rule on South China reflect in general the divergent focuses of the authors. Alternative views are more interested in the collaborators and cooperators while traditional writings emphasize the role of the loyalists who resisted Mongol rule. In this study, the term "loyalists" is used in the same sense as the United Empire Loyalists and the Spanish Loyalists, in which loyalty to the existing order and authority was retained even when both were about to be toppled and replaced; ${ }^{2}$ the term "loyalism" refers to a specific type of loyalty exhibited during dynastic change. ${ }^{3}$ "Song loyalists" (similarly, "Ming loyalists") describe men who embraced a lingering loyalty to the former dynasty, and refer specifically to a subgroup of loyal men who defended the state against various hostile forces during different periods of the dynasty (e.g., bandits, usurpers, rebels, and alien conquerors). The term "loyalist" incorporates two groups of men: the zhongyi 忠我 (loyal and righteous martyrs) and the yimin tained their loyalty to the end, dying during or shortly after the Mongol conquest; thus the term carried the sense of martyrdom. ${ }^{4}$ In contrast, the yimin

1. See David M. Farquhar; Yuanshi gangyao bianxie zu; Shu Zhenbang; and Zhou Liangxiao.

2. This usage is in accordance with Webster's International Dictionary (1971), p. 1342: "A person who is or remains loyal to a political cause, party, government or sovereign." The Shorter Oxford Dictionary on Historical Principles (1980), p. 1245, also states: "One who is loyal; one who adhered to his sovereign or to constituted authority, especially in times of revolt; one who supports the existing form of government." The use of the term "loyalist" to describe loyal men at the end of the dynasty, i.e., a subgroup of all loyal men throughout the dynasty, is conventional, as applied to the Ming loyalists.

3. This usage concurs with Laurence A. Schneider, 78. On the term "Ming loyalists," see Lynn A. Struve, "Ambivalence and action," 327.

4. Other terms are zhonglie (loyal and brave), yishi (righteous men), and zhongchen (loyal subjects). The zhongyi biographies have been included in dynastic histories since the Tsinshu, compiled by Fang Xuanling. It should be noted, however, that the distinction between zhongyi and yimin is not always consistent, nor are the terms mutually exclusive. Even in the Songshi, compiled by Toghto (hereafter SS), the zhongyi biographies include several individuals who did not die, but withdrew from society or disappeared. 


\section{Chapter One}

loyalists survived the Song demise and withdrew from public office as a form of protest against the new government. In its original sense, the term yimin generally meant survivors or a population remaining after large-scale natural disasters or after a dynasty became defunct. ${ }^{1}$ By the time Yuan replaced Song, however, it was used in both this general sense and a more specific one to refer to subjects of a former dynasty who refused to serve the new government. The term yimin from the term yimin 冕民(recluse). I should point out that the zhongyi, yimin (surviving subject), and yimin (recluse) were not exclusive from each other: for instance, a zhongyi who did not die immediately during the dynastic collapse could have lived the life of a surviving subject for the period before he died a martyr; and a surviving subject could have become a recluse during his period of passive protest to the new dynasty. ${ }^{2}$

What is generally ignored by the authors of traditional views is the fact that the Song loyalists comprised a minority of the southern Chinese elite, while those who surrendered or collaborated with the Mongols made up the majority. The loyalists, however, left an indelible imprint on the history of the transitional period between the Song and Yuan. The active participants of the resistance mobilized local and popular forces formidable enough to keep the Mongol army and navy fully employed for three years. Even after final defeat at the sea battle of Yaishan and the death of virtually all the leaders, the survivors joined with other loyalists who had already engaged in passive protest since the fall of the Song capital. Among the literati of southern Chinese society in the first generation of Yuan rule, the loyalists constituted a visible social group. Many rejected public office under the new government and immersed themselves in poetry, art, scholarship, and teaching.

The legacy of the loyalists is a large volume of extant writings in fields ranging from history to art connoisseurship. These writings provide

1. The term yimin was first used in the Zuozhuan and by Mencius. See James Legge, vol. 5, 127, and vol. 2, 353. The Mencius quotation makes a reference to the Yunhan poem in the Shijing.

2. This distinction is also referred to by Langlois in his "Chin-hua Confucianism under the Mongols," 48, 339, note 77. 


\section{Introduction}

documentation on their response to dynastic change. In addition, they constitute primary sources on the last years of the Southern Song, the loyalist resistance, and the plight of Confucian scholars in the early years of Yuan domination in South China. Through teaching, the loyalists also exerted strong influence on their children and students--the second generation of southern Chinese intellectuals under the Yuan. The Song loyalists excelled in scholarship: Wang Yinglin (1223-96) in classical studies, Ma Duanlin (12541325) in bibliographical work, Zhou Mi (1232-98) in biji (random jottings) miscellanies, and Liu Chenweng (1232-97) and Wang Yuanliang (fl. 12701300 ) in poetry. As a social and cultural group, the loyalists inspired a large body of literature that idealized and glorified the spirit and activities of Song loyalism. Ming loyalists, in particular, found ideological precedents from this period of history for moral support of their fierce resistance to the Qing dynasty. Therefore, the Song loyalists justify a monographic study on the basis of their significance as a political threat during the loyalist resistance of 1276-79 and as a visible social group during the first generation of Yuan rule, not to mention their ideological impact on loyalists of subsequent periods.

Traditional, i.e. pre-1900, Chinese scholarship on the Song loyalists was involved in three overlapping areas: editing and prefacing literary collections of the loyalists, adding biographies of local loyalists to gazetteers and genealogies, and compiling biographies of loyalists as separate works or as sections to be included in private and official histories. In some cases the authors were themselves Song loyalists or loyalists of later periods, and in all cases they were sympathizers and admirers of loyalist figures. Their chief concern lay in adding entries of those men whom they felt had been left out in previous compilations, and thus their approach was neither critical nor analytical. Modern Chinese historians, affected by a deep admiration for the patriotic spirit, have been prolific in studies of the legendary loyalist hero Wen Tianxiang (1236-83), and there exist separate articles on less known loyalists, 


\section{Chapter One}

but to date the group has not been studied in its entirety. ${ }^{1}$

In the 1950s several prominent scholars in Hong Kong debated the actual routes taken by the refugee Song court during the loyalist resistance and the site of its last lookout tower. ${ }^{2}$ Their interest was in the significance and role of Kowloon in Song history and not in the overall perspective of the loyalists. Another aspect of Song loyalism Chinese scholars have paid attention to is the poetry of the loyalists which mourned the demise of the dynasty and which reflected the poetic trends during the transition from Song to Yuan. Several separate studies of these poets have appeared. ${ }^{3}$ In the West, scholarship on the topic has also been selective and limited. ${ }^{4}$ Mote's study of eremitism under the Yuan provides brief profiles of Wen Tianxiang, Xie Fangde (1226-89) and Zheng Sixiao (1241-1318). ${ }^{5}$ Art historians have shown interest in the loyalist painters Qian Xuan (ca. 1235-aft. 1300), Zheng Sixiao, and Gong Kai (1222-1307). ${ }^{6}$ In addition, Franke's biographical dictionary of the

1. See, for example, Yang De'en and $\mathrm{Li}$ An. There are also several separate articles on $\mathrm{Li}$ Tingzhi, Zheng Sixiao, Ma Tingluan, Xie Fangde and a few others. Sun Kekuan, "Yuanchu Nan Song yimin chushu," ignores the zhongyi loyalists and looks at only the yimin. It lists and categorizes ninety-five yimin loyalists but does not analyze personal relationships and individual loyalists. Japanese scholarship has contributed little to the topic, except for studies on Wen Tianxiang, such as by Kamegei Ryo, and on poetry in Yoshikawa Kôjirô, Genminshi gaisetsu, 50-86.

2. This debate will be discussed in Chapter 3.

3. Anthologies of Song literature usually include the poetry of the Song demise. Recently theses by Su Wenting and Wang Weiyong have been published in Taiwan. On Liu Chenweng, see Huang Xiaoguang; and on Zhou Mi, see Wang Yinghua. These works are mostly annotations of the poetry and contain little analysis.

4. William Andrews Brown's dissertation is essentially a translation of Wen's SS biography. See also C. Bradford Langley.

5. Frederick W. Mote, "Confucian eremitism in the Yuan period."

6. See James Cahill, Hills Beyond a River, 15-37; Sherman E. Lee and Wai-kam Ho, 92-95. 


\section{Introduction}

Song period includes a sizable number of biographies of Song loyalists. ${ }^{1}$

These previous studies either focused on several prominent loyalist figures whose exemplary conduct won the exaggerated praise and idealization of Chinese historians up to the present century, or else dealt with some aspect of an individual loyalist's achievement in certain fields. Accounts of the Song loyalists and the resistance battles are brief in most general histories of China, and our picture of Song loyalism is still vague and incomplete. The popular image sees the loyalists as totally self-righteous men who gathered only in each other's company and had no contact at all with any part of the Yuan government, but it is merely a myth with some grains of truth. The myth becomes more distant from reality when the virtues of the loyalists are embellished and their faults ignored to serve new circumstances and events through the writings of the traditional historians.

The entire group of loyalists and the full spectrum of their activities and personal relationships need to be presented in order to gain a broad perspective on Song loyalism's influence and role in the Song-to-Yuan transition and its significance for subsequent periods of dynastic collapse. Through critical use of official sources and the loyalists' own writings, I reassess the last years of the Southern Song, the sequence of events leading to its surrender by Empress Dowager Xie (1208-82), and the rise and defeat of loyalist resistance in 1276-79. By examining the nature of loyalist writings and the particular aspects of Yuan historiography in regard to the Song loyalists, I explain certain discrepancies among the sources and discuss the myth-making mechanism of the exemplary figures. By studying this group of intellectuals, highly sensitive to their political and cultural environment, I hope that we can acquire some new insights on Song loyalism, particularly on the impact of, and the Chinese response to, foreign rule in South China.

My initial approach to the topic was to identify as broadly as possible the subjects of the study, that is, to decide whom to include and whom to exclude under the term "Song loyalists." From both primary and secondary

1. Herbert Franke, ed. Sung Biographies, particularly the biographies of Zhang Shijie, Chen Zhongwei, Chen Wenlong, Chen Yizhong, Zhou Mi, Xie Fangde, Lu Xiufu, Ma Tingluan, Ma Duanlin, Du Hu, Wang Yinglin, Wang Yuanliang, Wen Tianxiang, Zheng Sixiao, Gong $\mathrm{Kai}$, and Wen Riguan. 


\section{Chapter One}

sources I compiled about three hundred biographical sketches of men whose loyalist conduct during and after 1273-79 earned them a degree of commendation. These were individuals who fought in the military resistance, died or committed suicide because of the Song collapse; the survivors of the resistance battles; and former Song officials and commoners who withdrew from society or politics and declined to take up office under the Yuan government. Loyalty to the Song and refusal to serve in the Yuan were the criteria I used to identify and define the group. This seemed straightforward enough, but I soon noticed that the same individuals considered as loyalists in one source are criticized as collaborators in another. Their loyalty was doubted because they either served the Yuan under coercion before retiring or accepted office towards the latter part of their life. While some sources still classify them as loyalists on the basis that the offices held were merely teaching positions and did not entail taking orders from the throne, others condemn this conduct as failure to maintain integrity to the end and relegate them to the class of collaborators. ${ }^{1}$ Among the sources there exists a general inconsistency as to whether such individuals should be included as loyalists. To exclude this subgroup from a discussion of Song loyalism would amount to concentrating on exemplary loyalists and ignoring less absolute manifestations of loyalism; a broad and comprehensive perspective on the Song loyalists would therefore not be achieved. Furthermore, it would succumb to the shortcomings of traditional scholarship on the topic--resorting to merely listing the individuals whose conduct ought to be extolled by future generations.

As I worked my way through the mass of loyalist literature, I became increasingly convinced that this group of marginal loyalists constituted an important part of the research, for it is through this middle-ground of loyalism that we can see that the Song loyalists were not a homogeneous group with absolute values and flawless conduct. They were, in fact, a loose gathering of individuals who defined their loyalism and life-style according to personal circumstances and experiences. The core of this study is thus concerned with identifying and describing three types or traditions of Song loyal-

1. Ming scholars were especially critical of individuals who served the Yuan, regardless of the nature of the position. 


\section{Introduction}

ists: the zhongyi martyrs who died for the Song cause, the yimin who survived and largely maintained their loyalty by not serving the new dynasty, and the marginal loyalists, a subgroup of the yimin, whose loyalty was doubted by contemporaries or later critics because at some time they reemerged into public office. The chapter on the martyr tradition deals with heroic examples of loyalism, as exhibited in Wen Tianxiang and Li Tingzhi (d. 1276), followed by an analysis of the relationship between these leaders of military resistance and their followers and supporters. My main purpose in the chapter on the loyalist survivors is to identify loyalist groups and leading personages, in addition to reconstructing personal relationships and major activities in Annam and Champa, Dadu (Beijing), Kuaiji (Shaoxing), Wuzhou and Jiande (Yanzhou), Qingyuan (Ningbo), Luling, Raozhou and Wuyuan, Pingjiang (Suzhou), and Dongguan (near Guangzhou). The marginal loyalists in Huzhou (Wuxing) and Hangzhou revolved around Zhou Mi; this group of friends and acquaintances is taken as a case study of the middle-ground of Song loyalism.

From these three traditions I discuss approximately ninety individuals, who either left collected writings or whose loyal conduct featured particular and unique characteristics of Song loyalism. These men belonged to the adult generations (over twenty years old at the time of the Song demise) who may or may not have been in Song office, but who physically and/or emotionally suffered through the fall of Hangzhou and/or the defeat of loyalist resistance in 1279, and afterwards for a period of time still considered themselves men of the Song. The backgrounds, activities, and experiences of these individuals before and after the dynastic crisis, together with their motivations, aspirations, and personal relationships are the central concern of this study. The Song loyalists were a product of their time and the crises they perceived, thus in the next chapter I first probe and reconstruct the political background with particular emphasis on the experience of the loyalists themselves. The period under research is limited to ca. 1273-1300 in order to focus on the first generation of Yuan rule in South China. By 1300, many loyalists had died, or their loyalism had in most cases become insignificant or transformed into a more accommodating acceptance of the new dynasty. 


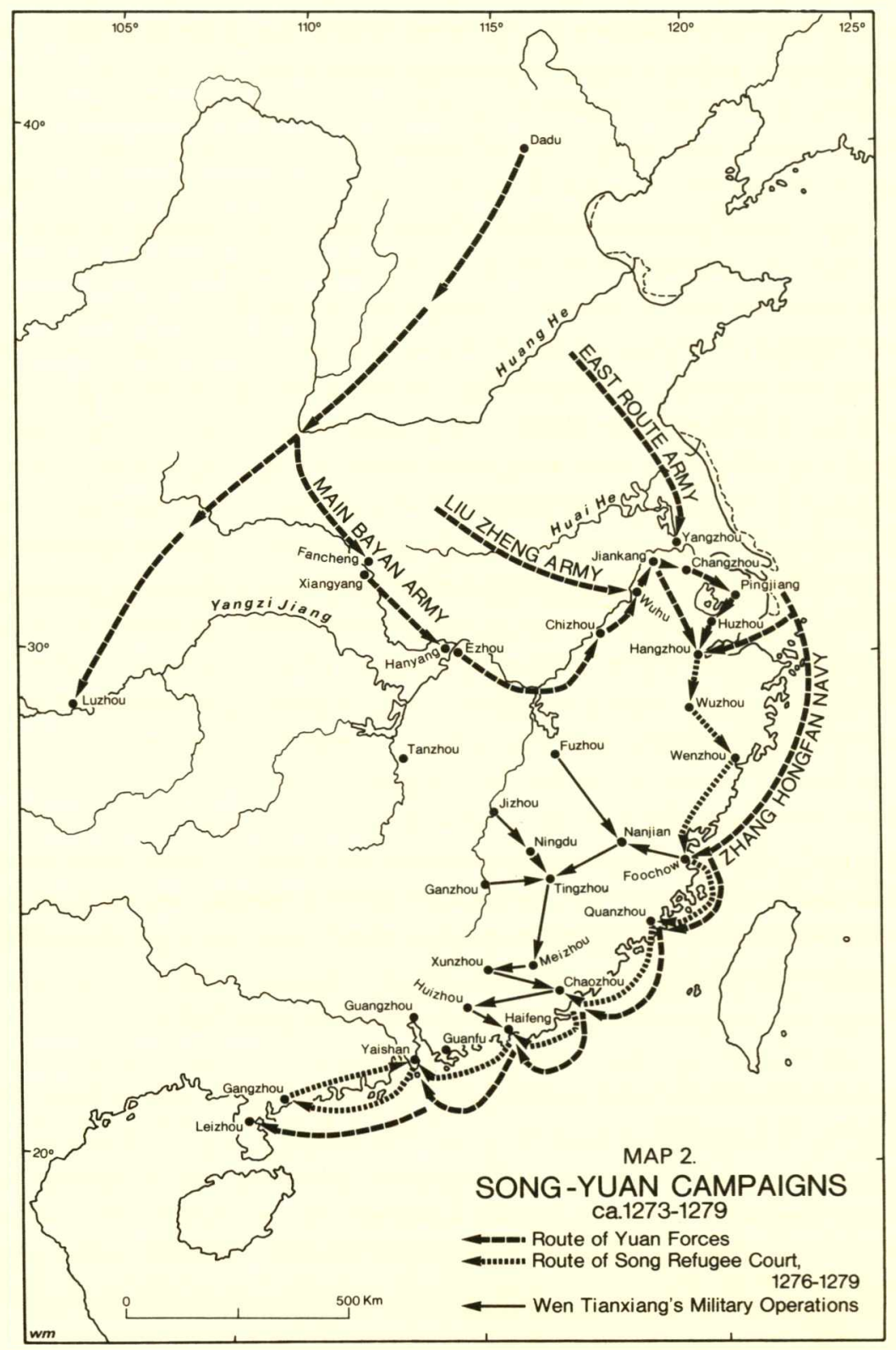




\section{TWO / THE SURRENDER OF THE SOUTHERN SONG AND LOYALIST RESISTANCE}

\section{Background to the Fall of Hangzhou}

Since its founding in 960 , the Song dynasty was sporadically plagued by its neighboring states: Tangut Xi Xia (1038-1227) in Ningxia and Gansu, the Khitan Liao (916-1125) in Inner Mongolia and Manchuria, the Jurchen Jin (1126-1234) who supplanted the Khitans, and the Mongols who in turn took over Jurchen territory before occupying the whole of China by 1276 . Due to the weak military foundations of the state, Song foreign policy from the very beginning resorted to appeasement. ${ }^{1}$ Under the terms of the Treaty of Shanyuan in 1005, the Song acknowledged the Khitan Liao as an equal state, opened up trade, and submitted annual tribute payments. ${ }^{2}$

A century later the Song collaborated with the Jurchens and crushed

1. Song foreign policy was a controversial topic among Qing scholars. Wang Fuzhi felt that the external menace should have been nipped right from the start: that is, had the Khitans been dealt with severely, the Jurchens and Mongols would not have had successive turns at invading China. See his Songlun, 15.262. A contrary opinion was expressed by Zhao Yi, who argued in his Nian'er shi zhaji, 26.501, that the Song had been able to survive only by relying on appeasement policies.

2. This peace treaty is only briefly mentioned in the $S S$ annals (SS 7.127). See Wang Gungwu, "Rhetoric of a lesser empire," and Jin Shi. The initial amount of tribute to the Liao was 100,000 ounces of silver and 200,000 bolts of silk, later increased to 200,000 ounces of silver and 300,000 bolts of silk. The Song also sent a total of 255,000 units of silver, silk, and tea to Xi Xia. The Jin first demanded 250,000 ounces of silver and 250,000 bolts of silk; the amounts were later changed to 200,000 and then 300,000 each. Apart from these official amounts, the Jin envoys also received lavish gifts. In 1234 the Song refused to comply with the Mongol request for 200,000 ounces of silver and 200,000 bolts of silk. See Zhao Yi, 26.499 . 


\section{Chapter Two}

the Liao, but in 1126-27 it ceded to them the Liao tribute as well as North China, the nuclear center of Chinese civilization. ${ }^{1}$ The ultimate humiliation was inflicted with the capture and abduction to the North of the two Song emperors, Huizong (r. 1101-25) and Qinzong (r. 1126-27), along with some two thousand imperial relatives and three thousand officials and escorts. Huizong's ninth son, Gaozong (r. 1127-62), escaped and mustered enough support from court officials and military men to bring about a restoration that prolonged the Song house for another century and half (subsequently known as the Southern Song). ${ }^{2}$ Yue Fei (1103-41), the legendary patriotic general, regained some lost territory but was stopped short and put to death by Gao-

zong, who at the time was inclined towards a peace with the Jurchens. ${ }^{3}$ As a condition for peace, the border between the Song and Jurchen Jin was drawn more or less along the Huai River. Against the choice of Jiankang (Nanjing), Hangzhou was renamed Lin'an (Approaching peace) and made the seat of the Song court. Although soon established in the rich economic zone of the southeastern provinces, the Song court for the remainder of its existence regarded Hangzhou as merely the temporary residence. ${ }^{4}$ Nostalgia for the former capital of Bianliang (Kaifeng) was assuaged by Hangzhou's meteoric rise to a cultural metropolis rivaling its predecessor, but the desire to recover the Central Plain was voiced fervently by statesmen and patriotic poets. ${ }^{5}$ In

1. For the immediate background to this crisis, see John Winthrop Haeger, "1126-27."

2. Despite its removal to the south, the dynasty continued to call itself the Song, but the Khitans, Jurchens, and Mongols often referred to it as Nanchao (Southern dynasty). A differentiation between Northern and Southern Song was not made until at least the Yuan dynasty.

3. On Yue Fei, see Edward H. Kaplan.

4. For the layout of Hangzhou, see A.C. Moule, Quinsai, 1-53, and Etienne Balazs, 85-86.

5. Lu You (1125-1209) and Xin Qiji (1140-1207) were the foremost patriotic poets who advocated an aggressive policy against the Jin for the recovery of the north and the reunification of China. Xin was a northerner who in his youth brought an army with him to the south. His biography is in SS 401.12161-67; see also Irving Yucheng Lo. Lu You's best-known patriotic poem, "Instructions to my sons, " requested his descendants to inform him of the reunification at his grave. For a translation, see Burton Watson, 68. 


\section{The Surrender of Southern Song}

1234 a Song-Mongol alliance eradicated the Jin dynasty thus offering the Song final revenge against the Jurchens, but it also removed the crucial buffer state needed to ensure its own security against the Mongols, who annexed the Jurchen territory.

The inherent conflict of interests between these two unlikely allies inevitably precipitated hostilities lasting almost half a century. The Southern Song was ideologically compelled to recover the North, or at least the Northern Song capitals and imperial mausolea. On the other hand, the Mongols were likewise committed to continue an expansionist policy, now directed against the Southern Song itself. Initial skirmishes began when the Southern Song refused to pay tribute to the Mongols and withdraw its forces from former Jin territory, thereby allowing the Mongols an excuse to raid Sichuan, Jing-Hu, and the Liang-Huai regions. These clashes were relatively minor and amounted to the Mongols exploiting and looting territory. However, the second stage of warfare in 1258-60 was executed with more organization and intensity. Interested in both occupying territory and collecting war spoils, Möngke Qaghan (Xianzong, r. 1251-59) led the main force from Qaraqorum to Hezhou in Sichuan. One column branched off to Xiangyang in the Jing-Hu area, and Qubilai (Shizu, r. 1260-94) led a column from Kaiping (later Shangdu, near Tulun) to Ezhou (Wuchang), where he was to join with the army of Uriangqatai (1211-72), which was then advancing north from Jiaozhi (Tonkin). ${ }^{1}$ Both the Song and Mongol forces were suffering heavy losses at Ezhou when the latter beat a hasty retreat. Möngke had suddenly died and Qubilai immediately hastened north to stake his claim to the throne. Just before this new turn of events, it appears that at the Song fort the general in charge of the Huai region, Jia Sidao (1213-75), had proposed a peace treaty.

In 1260 Qubilai realized that rivalry for the khanate succession and the consolidation of his power would preoccupy him and his army for a long period. He decided, therefore, to delay the Song campaigns and dispatched

1. For Möngke's Song campaigns, see Yuanshi, 3.51-54 (hereafter YS). See also Allsen. Uriangqatai's biography is found in YS, 121.2979. The strategy of fighting simultaneously on three fronts was a traditional Mongol policy used by Chinggis and Ögödei in north China. This strategy was repeated in the Xiangyang and Hangzhou campaigns. 


\section{Chapter Two}

Hao Jing (1223-75) and several emissaries to the Song court. ${ }^{1}$ Ostensibly it was a friendly mission to proclaim to the Song his accession to the Mongol throne, to conclude a cease-fire agreement, and to warn Mongol generals at the borders to refrain from looting. Hao Jing was, however, not permitted to proceed to the Song court, in spite of the numerous letters he addressed to Emperor Lizong (r. 1225-65), Jia Sidao, Li Tingzhi, and various government departments threatening Mongol reprisals. ${ }^{2}$ Jia Sidao had by then become chief minister and handed over the administration of the Huai to the veteran general Li Tingzhi. For sixteen years Hao Jing and his companions were detained in Huai territory, allegedly under the irresponsible orders of Jia Sidao. Jia has been accused of conceiving such a foolhardy measure to keep secret an agreement to cede Song territory and annual tributes to Qubilai, and to claim full credit and honors for the retreat of the Mongols in 1259 from Ezhou. ${ }^{3}$ In a favorable reappraisal of Jia, Franke convincingly dispels this myth on both counts: there exists no evidence of such an agreement, and primary sources indicate that the central government and emperors were well aware of the situation at the front. ${ }^{4}$

Franke, however, does not explain why Jia Sidao insisted on such an ill-conceived and fruitless strategy. I suggest that Li Tingzhi, rather than Jia, played the crucial role during the entire duration of Hao Jing's captivity. Li Tingzhi, the veteran official and general in command of the Huai region in 1260-76, was responsible for reporting to the Song court on developments at the front. It was Li's responsibility to assess Hao Jing's mission and he, therefore, on his own initiative detained the luckless envoy pending an inves-

1. Hao Jing's biography is in YS 157.3698-3709. For the official statement of Hao Jing's mission, see YS 4.65, 157.3708; Hao Jing, 37.1a. On Hao Jing's relationship to Qubilai, see Rossabi, Khubilai Khan, 70-71.

2. These long letters are found in Hao Jing, 37-39.

3. SS 45.878, 474.13782; Songji sanchao zhengyao, 3.37, 4.4.

4. Franke, "Chia Ssu-tao," 226-28. A brief biji work by Jia survives as the Yuesheng suichao. 


\section{The Surrender of Southern Song}

tigation. ${ }^{1}$ To Hao Jing's request for an audience with the Song court, $\mathrm{Li}$ Tingzhi simply responded that he dared not convey the message. Perhaps through an espionage network which evidently existed on both sides, Li discovered that Hao Jing had previously submitted to Qubilai a plan to conquer the Song and on that basis perceived the mission to be hostile. Below is a summary of Hao's strategy:

There are two ways to conquer countries--by the use of force and by the use of strategy. Although other countries have quickly submitted to our rule, the Song has not been conquered even after twenty years. It is therefore advisable to use strategy in this case, which will require a great deal of patience. The fact that the Mongol army is not skilled in fighting on plains, as well as other reasons, call for a delaying tactic. We should thus buy time and gain the confidence of the Song and request that they cede to us some territory and present us annual tributes of cash. When the time is ripe for the conquest we should then first take the Jing, the Huai, and the Yangzi respectively. The attack should be three-pronged in order to weaken progressively Song fortifications. The Song must be regarded as a powerful opponent: their ruler and ministers are on friendly terms, there exists no current internal chaos, and since 1234 it has been engaged in rigorous recruitment of soldiers. ${ }^{2}$

Li was also skeptical about Hao's background: he was a protégé of the general Zhang Rou (1190-1268), who had gone over to the Mongols during the Jin collapse. ${ }^{3}$ Li most likely recommended further detention, and Jia

1. See Hao Jing, 37.16b. Li visited Hao and presented him with hortensia flowers (Hao Jing, 1.25b-27a). He also read Hao Jing's essays and commented on his scholarship.

2. This was the "Stategy for the eastern campaign" that Hao submitted to Qubilai in early 1255 , shortly after he was recommended to his service. See Hao Jing, 37.1a-11b.

3. See Zhang Rou's biography in YS 147.3471-76. 


\section{Chapter Two}

Sidao concurred. Detaining Hao was actually consistent with Li's suspicion of emissaries in general; later he even doubted Wen Tianxiang, his loyalist colleague, and executed other envoys. Li's name, however, has not been drawn into this event due to the efforts of historiographers to preserve his historical image as an exemplary loyalist.

During his captivity, Hao Jing was not imprisoned in the true sense, nor subjected to ill treatment. He admitted to receiving generous material comfort and food, and he wandered freely in the spacious gardens in the company of his five or six subordinates. He continued to communicate with Li Tingzhi and wrote prolifically. ${ }^{1}$

The detention and execution of foreign envoys were not unusual occurrences in the history of Song foreign relations; at times such acts were sanctioned and praised as loyal behavior by the Song court. ${ }^{2}$ The Hao Jing incident has drawn particular censure hy Chinese historiographers because it provided the Mongols with a ready excuse to attack the Song, and for the Song with an immediate explanation and scapegoat for the collapse of the dynasty. Had the outcome of the incident been different, the Song and Yuan entanglement would not have teen resolved by a friendly pact. Hao Jing's offer of a peace treaty would have ceded territory and cash to the Mongols, and such terms, if concluded, would have amounted to merely a cease-fire, not an end, to the Song conquest. That much Hao Jing made clear in his advice to Qubilai Qaghan. These terms suggested a sort of coexistence the Song

1. The Lingchuan ji contains serious scholarship on the Confucian classics, mostly written during the early years of Hao's captivity; from 1269 to 1276 there exists only one piece of writing dated 1273. By that time Hao had lost hope of ever returning to the north to see his only son. Hao's writings show hatred of the Jin dynasty but passionate sympathy for the Northern Song and for loyal men and women during its collapse. He sincerely wanted to avoid bloodshed, as he tried to convince Li Tingzhi of Qubilai's enlightenment (Hao Jing, 37.13a).

2. In 1004 an imperial edict promised that those who killed Khitans would be sheltered and rewarded (SS 7.125). In 1231 the Song killed a Mongol envoy (YS 2.31); in 1275 the Yuan envoy Lian Xixian and his entire party were put to death, although the Song court denied having ever sanctioned the action (YS 8.164). Li Tingzhi also slaughtered a few emissaries who tried to entice him to surrender. 


\section{The Surrender of Southern Song}

had with the Liao and Jin states, but coexistence was incompatible with the Chinggisqanide heritage of tengri-ordained world conquest. ${ }^{1}$ Thus whether Hao Jing returned to the Mongol court with or without a treaty or, as it happened, did not return until sixteen years later, was in the long run inconsequential to Qubilai's resumption of campaigns against the Song after he had settled internal disputes.

During the period of relative calm in 1260-68 there were nonetheless some clashes at the border, with the Song attempting to reconquer lost territory and the Mongols defending their gains. An incident advantageous to the Mongol side occurred in 1261: the defection of a high-ranking Song commander, Liu Zheng (1213-75), and his surrender of fifteen commanderies and 300,000 households in Luzhou (in Sichuan province). ${ }^{2}$ Liu Zheng was a northern Chinese who had first defected from the Jin to the Song. Using discrimination by Jia Sidao and southern Chinese generals as his reason for defecting, he divulged military secrets to the Mongols. In particular, he advised them about the strategic importance of Xiangyang and built up the Mongol navy which was at that time inferior to the Song fleet. At the same time, the Song welcomed the defection of Li Tan (d. 1262), who submitted three prefectures in Shandong. ${ }^{3}$ He was the adopted son of Li Quan (d. 1231), who forty years earlier had gone over from the Jin to the Song and then defected to the Mongols. In just a few months' time, the Mongol forces crushed Li Tan's army, executed the traitor, and recovered the Shandong region. While

1. Hao Jing's memorial clearly shows that a treaty, if concluded, was to be understood only as a temporary measure. See also Igor de Rachewiltz, "Some remarks," 24, and Franke, From Tribal Chieftain to Universal Emperor and God, 15.

2. SS 47.877. For Liu Zheng's biography, see YS 161.3785. Liu Zheng was regarded as a victim of both discrimination against northerners by southerners and of the slighting of military men in favor of civilian officials in the Song court under Jia Sidao's influence. See Yao Congwu, "Hubilie ping Song yihou de nanren wenti," 11-13.

3. The biographies of both $\mathrm{Li}$ Tan and his father $\mathrm{Li}$ Quan are located in the section for panchen (renegades). See, respectively, YS 206.4591-94 and SS 476.13817-477.13851. See also SS 45.880-82; YS 5.82-83; Bi Yuan, 174.4819-177.4824; Chen Bangzhan, Songshi jishi benmo, 104.1123-25; Sun Kekuan, "Yuanchu Li Tan shibian de fenxi," in his Menggu Hanjun yu Han wenhua yanjiu, 44-78. 


\section{Chapter Two}

Li Tan's defection gave little lasting advantage to the Song, the efforts of Liu Zheng and other Song defectors and collaborators facilitated the Mongol conquest of the Song.

When the Mongols resumed war with the Song, they first attacked Xiangyang and Fancheng, the cities on the upper and lower banks of the Yangzi in the Jing-Hu region. This strategy took into account the lessons learned in Möngke's disastrous campaign in Sichuan, and aimed to acquire access to the Yangzi River from the Jing and Huai regions before launching a pincer attack on the Song capital, Hangzhou. The Xiangyang fortifications had been rebuilt after the Mongol onslaught in 1234-35, and had then become almost impregnable to enemy forces. After a siege of six years with catapults made by Muslim engineers, the twin cities crumbled one after the other, mostly because the Mongols effectively cut off supplies of food, especially salt and firewood. In spite of some relief measures rendered by Li Tingzhi and the veteran generals Xia Gui (1197-79) and Fan Wenhu (fl. 1260-80), the defending commander of Xiangyang, Lü Wenhuan (d. ca. 1297), surrendered in March 1273 and subsequently fought on the Mongol side. ${ }^{1}$ Meanwhile at the Mongol court, Qubilai had firmly eliminated challenges to his position on the throne and surrounded himself with competent Chinese advisers such as Liu Bingzhong (1216-74). ${ }^{2}$ Dadu (Beijing) was designated as the capital and in 1271 "Yuan" was declared the official name of the dynasty.

The Song court now had on its throne Duzong (r. 1265-74), and Jia Sidao had dominated the government for fourteen years. In 1273, the court that dealt with the collapse of Xiangyang was not united but divided by personal grievances against state policies. There was a general lack of confidence in the ability of the central government to deal with the Mongol threat. Jia Sidao has been traditionally denounced for being reckless, unconcerned, and inattentive to the Mongol crisis during his entire term in office. He did, however, introduce in 1262 two fundamental measures designed to increase

1. SS 46.911; YS 8.147; Zhou Mi, Guixin zazhi, bie b.37a-48a. See also Moule, Quinsai, 70-78 for a discussion of Marco Polo's alleged but doubtful role in the Xiangyang battle.

2. On Liu Bingzhong, see Hok-lam Chan, "Liu Ping-chung." For Qubilai's use of Confucian advisers, see Yao Congwu, "Hubilie ping Song." 


\section{The Surrender of Southern Song}

revenues for military defense: the limitation of private landownership and the investigation into embezzlement and other abuses of military generals. The principle behind the first measure, the public-land reform policy, was to prevent private hoarding of grain by the large landowners. ${ }^{1}$ One-third of privately owned land exceeding the set quota allowed in accordance with official rank and other criteria was to be converted into state land, the revenues of which were to go directly to the army. The owners of the confiscated land were compensated with cash and/or offers of official ranks. To show his sincerity and personal sacrifice in the matter, Jia surrendered to this scheme some ten thousand mou of his own estates in Zhexi, an example followed by an imperial relative and several prominent men. In spite of loud protest and resentment by the large landowners, who had the most to lose and who were substantially represented among the powerful local elite and central bureaucracy, Lizong repeatedly sanctioned the scheme. ${ }^{2}$ In the thirteen years of its implementation, this land reform did indeed generate a considerable amount of revenue.

While the large landowners were the victims of the public-land policy, military personnel were singled out in the auditing regulation policy, a scheme to make individual generals account for in detail all expenditures of previous campaigns. ${ }^{3}$ Not a few top military leaders were spending part of their allocated funds in forbidden private transactions such as trade and commerce; some were even drawing extra salaries for fictitious names of nonexistent soldiers. After close scrutiny any amount overspent or spent in an unauthorized manner had to be repaid to the state from the generals' own pockets. This measure ruined some innocent victims, including the loyalist hero Xie Fangde. ${ }^{4}$ Although these two schemes were originally conceived to

1. On the public-land reform, see SS 173.4194-95, 474.13782-83; Bi Yuan, 177.4831-32; Xianchun yishi, a.1a-2b; Songji sanchao 3.39-3.41; Franke, "Chia Ssu-tao," 226-28.

2. Xianchun yishi a.1b.

3. Bi Yuan, 176.4812-13; Liu Zijian (James T.C.), "Luelun Songdai," 483-84.

4. SS 425.12688; Bi Yuan, 176.4813. 


\section{Chapter Two}

strengthen Song defense, they alienated many central and local officials.

To Jia Sidao's credit, as his contemporary critic Zhou Mi admitted, ${ }^{1}$ it must be said that when Jia was in power the Song court was not menaced by the abuses of imperial relatives, eunuchs, and university students--a situation that had affected his predecessors. ${ }^{2}$ There is also little evidence that he resorted to nepotism: few of his blood relatives and friends obtained high positions in the Song court. Not until 1275 was the court plagued by fierce struggles between the peace and war factions that had characterized and immobilized earlier administrations. While the war faction advocated an aggressive military policy, the peace advocates potentially exposed the Song to renewed Mongol attacks. Nevertheless, Jia was more inclined to favor this passive policy, and from 1259 to 1274 there existed in the Song court no apparent opposition in this regard. Intense criticism of his appeasement policy began only after his disgrace in early 1275 . Jia, however, had no illusions about the permanence of the relative peace from 1260 to 1273 . It was in anticipation of a protracted struggle with the Mongols that he instituted the two schemes outlined above.

What caused dissent in the Song court may have been the resentment military officers felt against civilian officials. They seem to have encountered some discrimination in dealings with their civilian superiors, especially Jia, who despite his military background, from 1260 acted in the capacity of a civilian official, made high level decisions and handed out rewards and punishments according to merit or demerit. But if Jia had shown preferential treatment to civilian officials, that attitude was consistent with general Song policy to undermine and control the military sector. As a result, military officials sought to overcome their social stigma by emulating the civilian officials in dress and customs, and even aspired to convert their military status to civil

1. Zhou Mi, Guixin zazhi, hou.11a-13b.

2. Shi Songzhi (d. 1256) and Ding Daquan suffered abuses by the students of the three universities. Their biographies are in SS 414.12423-28, 474.13778-79. 


\section{The Surrender of Southern Song}

ranks. ${ }^{1}$ Although a few officials managed to combine a military and civilian career, as did Jia Sidao, Li Tingzhi, Wen Tianxiang, and Xie Fangde, the majority did not. The military was itself split by internal jealousies affecting their morale. Military and civil officials accused Jia Sidao of protecting his former subordinates like Fan Wenhu, who was not severely punished after his failure to rescue Xiangyang from the Mongol siege. Generals with northern origins like Liu Zheng, who later defected to the Mongols, and the loyalist Zhang Shijie felt discriminated against by the southern generals. The military sector also regarded the auditing regulations, introduced in 1262 , as inequitable. Furthermore, the steep demotions and heavy penalties which often accompanied defeat in battle built up resentment with the central government. In 1258 and in 1275 , even Jia was threatened with serious punishment for military defeat but the death penalty was mitigated by his long service to the state. $^{2}$

The Song court appears to have recognized these grievances of the military officials, and sought to remedy the situation. To open up channels of communication with the generals at the front, it frequently lavished generous rewards on the top and bottom ranks after each successful battle. Generals were often asked to propose strategies and review maps at the court. These half-hearted measures, however, did not greatly improve military morale.

Apart from the chasm between military and civilian officials, factionalism revolving around Jia Sidao weakened the Song court. Traditional and secondary sources allege that Jia purged anyone who did not support him. Indeed, as soon as he became chief minister in 1259, having been an acting chief minister since 1254 , he engineered the disgrace and dismissal of his ri-

\footnotetext{
1. A recent study of the northern Song military indicates that upward mobility was also possible, as shown by not a few cases of promotion from soldier to general occurring within one generation. Only one-quarter of military families was able to retain the status of general for three generations. See He Guanhuan. It seems that many military families either fell into obscurity or sought status in the civil service. See also Liu Zijian (James T.C.), "Lüelun Songdai, " 480-82.
}

2. $S S 44.863,474.13786$. 


\section{Chapter Two}

vals Ding Daquan (d. 1263) and Wu Qian (d. 1262). ${ }^{1}$ Ding is known in Chinese history as a treacherous official in the same category as Jia, and Wu is regarded as a good minister. However, it is not strictly true that Jia monopolized state power, for only in 1261-66 and again in 1273 was Jia the sole chief minister, and even during those years he might have been restrained by at least three acting ministers at any one time, such as Ma Tingluan (122389), Jiang Wanli (1197-1275), and Wang Yue (d. 1276). ${ }^{2}$ During the other years in power, he actually shared the chief ministership with the just-mentioned acting ministers who were then promoted to chief ministers. ${ }^{3} \mathrm{Ma}$, Jiang, and Wang are considered benevolent and loyal ministers and not blamed for the country's misfortune. Their biographies and those of almost every upright official invariably contain the statement that they had opposed Jia and consequently suffered setbacks in their careers. Apart from the protest against Jia's land reform, the details of such dissent are vague and never provided in the biographies--an omission that could well indicate their general tacit support of Jia during his administration. After his downfall, one would be hard pressed to find anyone, or any of his opponents' biographers, admitting to this support. The loyalties shown to Jia by his protégé Liao Yingzhong (d. 1275) and an obscure monk were rare exceptions. ${ }^{4}$

Other than Jia's alleged crimes, a more fundamental problem confronting the Song court during that period was the lack of competent alternatives to Jia and the reluctance of men in high-ranking positions to commit themselves to the state. Reading through the Songshi annals of that period,

1. Wu Qian's biography is in SS 418.12515-20.

2. The biographies of Ma, Jiang, and Wang are in SS 414.12436-39, 418.12523-25, 418.12525-28.

3. SS $214.5632-53$.

4. See Bi Yuan, 181.4959, and Zhou Mi, Guixin zazhi, hou.21b-22b. In the 1290s Deng Mu met an old Buddhist monk, formerly patronized by Jia, who still wept for Jia's tragic death. Deng remarked that this monk's gratitude was sufficient to shame the eminent statesmen who had previously been helped by Jia but who abused Jia immediately after the latter's disgrace in 1275. See Deng Mu, "Traveling from Taoshan to Yunmen," Boya qin, buyi.2b-3a. 
one is struck by the numerous requests from almost all top civilian and many military officers to retire on pension, citing old age or illness as the reason. ${ }^{1}$ Except in a few cases (such as that of Ma Tingluan who was genuinely ill), most of the reasons were pretexts and did not reflect Confucian humility appropriately associated with declining high appointments. Even Jia many times pleaded to be relieved of his duties, but he alone was accused by his critics of faking modesty while secretly bribing censorate officials to memorialize against his resignation. Nor should such pleadings for retirement be equated with the Confucian practice of withdrawal in adverse times, for the Song emperors were considered beyond reproach by being frugal themselves but generous to officials. For some, the reasons for seeking retirement was the desire to lead a life of leisure; for others, it was due to anxiety and uncertainty about the future in the wake of the Mongol crisis. But in all cases, there was great envy for the ideal life of the upper middle-class official in retirement. This life was replete with wine and women, shared in idyllic settings with friends and traveling companions while they composed poems and made excursions to historical and scenic sites. In essence this life-style reflected extravagance and frivolity in everyday life shared by both the well-to-do and the lower strata of society. It was a by-product of economic prosperity and cultural attainments of a highly urbanized society in the last years of the Southern Song. This pleasure-seeking life was blamed for selecting Hangzhou, a city endowed with spectacular landscapes, as the capital, against the choice of Jiankang, a city which was better fortified against invasions. ${ }^{2}$ A Hangzhou contemporary felt that the beauty of the city made scholar-officials forget about the urge to recover the North. In fact, however, this life-style was highly popular and familiar to even loyalists such as Zhou Mi in Hangzhou and Huzhou, and Wen Tianxiang in Jizhou.

The surprisingly calm and unperturbed society of Hangzhou just prior to the Mongol crisis was possible because military disturbances over the last

\section{SS 42-46.807-916, et passim.}

2. Liu Yiqing, preface.1, 1.3. 


\section{Chapter Two}

forty years had taken place far away from the southeast. ${ }^{1}$ Moreover, a sense of deceptive security had been strengthened by the prosperity of the region. In spite of occasional outbursts of panic, the scholar-officials, like the lower classes, had learned to live with sporadic military incursions at the borders, feeling that the dynasty, although long threatened, could not really be in immediate danger of total conquest.

It was during this period of apparent peace that $\mathrm{Li}$ Tingzhi reported the fall of Xiangyang to the court. The first reaction was panic, followed by the sudden realization of the irretrievable state of affairs. For individuals and the court, the vulnerability of the capital and nearby cities was truly experienced for the first time. The imperial court immediately canceled scheduled festivities for a forthcoming state occasion and directed the savings to be used for the defense of the Yangzi River. ${ }^{2}$ The Huai region was alerted to possible attacks by the Mongols, and the court issued strict warnings to border generals to hold their defense posts, promising rewards and punishments in accordance with individual performance. It also invited officials and commoners from both the central and local ranks to present strategies of defense. ${ }^{3}$ To raise morale, immediate and posthumous rewards were generously bestowed on individuals who distinguished themselves in the Xiangyang battles. The generals responsible for the direction and course of the lost battles--Li Tingzhi, Fan Wenhu, and Xia Gui--were merely demoted a rank or two. The strict policy of penalizing defeated generals, as was the rule from the 1230 s to the 1260 s, no longer applied because the court wanted to retain their support rather than alienate it. Even the relatives and friends of Lü Wenhuan, who surrendered Xiangyang, were reassured of the throne's confidence in their loyalty. If the Song court expected gratitude to motivate the

1. For a description of this life, see Gernet, passim.

2. SS 46.912 .

3. One response came from the eminent Confucian scholar Jin Lüxiang (1232-1303) who proposed to dispatch a naval force along the seacoast to Hebei in order to relieve Xiangyang. Later the Song defectors and pirates Zhu Xuan and Zhang Qing used this plan to help the Mongols conquer the Song. See Jin's biography in YS 189.4316. 


\section{The Surrender of Southern Song}

relatives to remain loyal, it was to be greatly disappointed. Lü's nephew Lü Shikui (d. ca. 1300), his cousin Lü Wenfu (d. ca. 1300) and his son-in-law Fan Wenhu--all three top-ranking generals--soon thereafter defected to the Mongol side. ${ }^{1}$

To raise the morale of the troops and generals, Jia repeatedly requested to be allowed to lead a force to the front, but was dissuaded by Emperor Duzong. ${ }^{2}$ Instead, an ad-hoc department was set up to handle the abuses of the Bureau of Military Affairs, security leaks of campaigns, and delays of reports from the front. ${ }^{3}$ At the front, propaganda was stepped up to encourage northern Chinese to defect to the Song side and to counteract Song defections to the Mongols. The measure was successful in winning over many defectors, but while the Mongols appointed defectors to important military positions, the Song government offered only modest sinecures. Consequently, it failed to attract high-ranking defectors. The Song did not make use of informers and defectors from the Jin and Yuan, who consequently did not play a key role in the campaigns against their former commands. ${ }^{4}$

These minor changes did not amount to an overhaul of the military after the Xiangyang collapse. In the civil service, however, there was a definite turnover in key personnel, if not in policy. Jia Sidao was still in the limelight, but by 1274 , resignations by Jiang Wanli, Ma Tingluan, and others had been accepted by the court. Wang Yue, Zhang Jian (d. after 1276), and Chen Yizhong (d. after 1285) now held the reins of government. ${ }^{5}$ Jia's policies were by and large continued, and rewards and honors were bestowed on those who showed valiant loyalty in defending cities against the Mongol army. The new ministers also had to cope with the natural disasters which co-

1. SS 46.913-14. The two Lüs had earlier submitted their resignations to the Song court in anticipation of their guilt by association when Lü Wenhuan surrendered.

2. SS 46.912 .

3. SS 46.912; Zhou Mi, Guixin zazhi, bie b.48a-49a.

4. SS 46.913-15.

5. SS 46.916-18. 


\section{Chapter Two}

incided with the Mongol advances: the floods in Hangzhou and Wuzhou, and the drought in Fujian province.

In August 1274 Emperor Duzong died, and his four-year old son Xian came to the throne with Empress Dowager Xie (Lizong's empress) designated as regent. ${ }^{1}$ Xian, posthumously known as Gongdi (r. Aug. 1274-Feb. 1276), was actually younger than his brother Shi, but was chosen as successor because his mother, née Quan, was the empress. Advice was sought from retired veteran officials, but none responded. In the same month at the Mongol Yuan court, Bayan (1237-95) and Shi Tianze (1202-75) were appointed to the general command of combined forces to liquidate the Song. ${ }^{2}$ Bayan was assisted by high-ranking officers such as Uriangqatai's son Aju (1234-87), Arigh Qaya (1227-86), Dong Wenbing (1217-78), and Zhang Rou's son Hongfan (1236-80), in addition to the defectors Lü Wenhuan and Liu Zheng. The major campaigns were planned for the Jing-Hu and Hangzhou areas, while a less intense battle was to be fought in Sichuan under Li Dehui (1218-80). ${ }^{3}$ In October, Bayan assembled land and naval forces, some 200,000 strong, in the newly conquered Xiangyang for a three-pronged attack. ${ }^{4}$ The main force was led by Bayan along the Yangzi River; an eastern wing advanced from the Huaixi region; and a third unit fought in the Jingnan area.

From the start the Mongols had prepared for a difficult campaign, and indeed the first attack on Yingzhou was fraught with difficulties, for the Song had garrisoned this city with over 100,000 men. Quite unexpectedly, Bayan

1. SS 47.921-22; Bi Yuan, 180.4926-27.

2. YS 8.156; Bi Yuan, 180.4928-29.

3. On the Sichuan battles, which were separate from Bayan's campaigns, see the biographies of the Yuan general Li Dehui in YS 163.3817-19 and the loyalist general Zhang Jue in SS 451.13280-84.

4. SS 47.922-24; YS 8.157; Bi Yuan, 180.4929-34. For a laudatory account of Bayan's role in the conquest of the Song, see an official contemporary source: Liu Minzhong, Ping Song $l u$. This work is the principal source for Bayan's biography in the YS which has been translated by Francis W. Cleaves, "The biography of Bayan." 


\section{The Surrender of Southern Song}

abandoned this siege for the time being and moved along the Han tributary, taking possession of Shayang and Xincheng after crushing prolonged local resistance. The next important battle took place at the Yangluo fort and Hanyang, both of which protected Ezhou. After a siege of ten days, the Song defender Cheng Pengfei (d. after 1303) surrendered in January 1275 and joined the ranks of the Song defectors. At this point Bayan's forces crossed the Yangzi and moved with relative ease from city to city along the river.

The fall of Ezhou and the crossing of the Yangzi by the Mongols forced the Song to undertake several measures. In order to generate revenues for the army, the property and estates of the imperial relatives, the aristocracy, monasteries and temples were taxed. The court next followed popular demand for Jia Sidao, as commander-in-chief of the empire's forces, to halt the Mongol advance along the Yangzi. ${ }^{1}$ Confidence in Jia Sidao's military ability as demonstrated twenty years earlier in the Huai seems to have remained strong even at this time. The army led by Jia was 70,000 strong with many generals recruited from the capital reserves. As a result, the defense of the capital was much weakened, leading Empress Dowager Xie to promulgate an empire-wide appeal to raise armies for the defense of the emperor (qinwang). In particular, the edict appealed to the general populace to rise against total foreign conquest.

\footnotetext{
The late emperor [Duzong] has died, and the successor is but an infant. [In spite of] my old age and decrepitude, I reluctantly took charge of state affairs from behind the curtain . . . . How infuriating are these ugly caitiffs who have trespassed the Yangzi River! Bypassing our barricades and reaching our hilltops, they seduced our recalcitrant subjects and violated the obedient. Since ancient times there has not yet been an age of total barbarian conquest. How has it come to this present state that deviates from the constants of Heaven and Earth? . . . Three hundred years of virtuous rule--surely that has made an
}

1. SS 47.924. 


\section{Chapter Two}

impression on the people. The souls of $100,000,000$ pray for the protection of Heaven. In profound grief, I proclaim this edict in order to reverse the precarious state of the country. I have esteem for, and rely on you civilian and military officials, who having received the benefits and generosity of the late emperors, will presently not shy away and try to escape from this plight. Those worthy men with loyal livers and righteous galls [i.e., hearts], come forth and combat the forces that plague the throne and submit your skills. The country must exist before the family can exist. Mutual protection leads to the protection of all. I now proclaim these intents as ordained by Heaven, to raise the banner for the various circuits to rise to the salvation of the emperor. Be encouraged by fine strategies and illustrious names; nobility and rewards will be bestowed generously. This edict is thus proclaimed to reassure the empire. I trust you will understand it all. ${ }^{1}$

Simultaneous with the direct appeal to both officials and private citizen to come to the assistance of the empire, veteran generals were appointed to coordinate the qinwang armies raised in each of the nine circuits. ${ }^{2}$ Information and details about the armies recruited were to be reported to the court, which would confer ranks and offices on the leaders and communicate to them whether they should await orders from the local centers or proceed directly to the capital. The edict made no provisions for financial resources, but the qinwang units did not appear to have been short of funds. The sources are vague about the details of recruitment but are emphatic about the immediate response by veteran officials and newcomers alike who offered their services to the country. In Hu-Guang, Li Fei (d. 1275) organized 20,000 men; in Yangzhou, Ruan Kesi (d. 1276) under Li Tingzhi's command mobi-

1. Wen Tianxiang quotes this text in full in his Jinian lu. See Wen Tianxiang, 17.10a-b.

2. Liu Yiqing, 6.8; Songji sanchao, 4.53 . 


\section{The Surrender of Southern Song}

lized 30,000; Wen Tianxiang in Jizhou and Ganzhou brought together 10,000; and Xie Fangde in Raozhou and Xinzhou, and many others in various parts of the country assembled troops ranging in size from handfuls to thousands. ${ }^{1}$ By March 1275, a few months after the edict was issued, at least 200,000 men had been recruited.

By this time, however, the military crisis had reached an irreversible point, and Bayan and his forces were increasingly helped by the surrender of Song generals and the rapid erosion of Song morale. Huangzhou, Qizhou, Anqing, and Chizhou were taken by the time Jia Sidao arrived with his forces to halt the Mongol advance. ${ }^{2}$ Just before cannons were fired and arrows shot, Jia sent an envoy to negotiate with Bayan for peace, but the latter quickly rejected the offer. In the ensuing battles at Dingjiazhou (near Wuhu), Bayan inflicted a crushing defeat on Jia's army and naval forces. Jia then hastened to Lugang, where Xia Gui, the commander of Huaixi, had already fled without even engaging in battle. Jia's entire force was dispersed, and over two thousand ships, along with supplies, maps and seals were captured. ${ }^{3}$

To obtain immediate relief from the Yuan onslaught, the Song then released the long detained Hao Jing and sent him home with proper protocol. ${ }^{4}$ But Bayan continued his attacks through Jiankang and Zhenjiang. There, he left behind forces to safeguard the gains along the Yangzi, and after instructing the eastern circuit army to continue campaigns in the Huai region, he departed for Dadu and Shangdu to deal with Qaidu's (d. 1301) uprising. He did not return to supervise the Song conquest until November $1275 .^{5}$

1. In Songji sanchao 4.56, an imperial relative who was a student memorializes against the transfer of the capital, suggesting that the large size of the qinwang armies was strong enough to oppose the Mongols.

2. SS 47.925-26 and 474.13785-86; YS 8.160-63; Bi Yuan, 181.4940-42.

3. SS 47.926; YS 8.162; Bi Yuan, 181.4942-43. The figure of 130,000 , given as the size of Jia's army (Songji sanchao 5.55), is most likely an exaggeration.

4. SS 47.926; YS 8.163; Bi Yuan, 181.4945.

5. Liu Minzhong, b.1a-2b. 


\section{Chapter Two}

During his absence, the Song restored control over Changzhou and several other cities, and the Huai region continued to hold out under the intrepid $\mathrm{Li}$ Tingzhi.

Meanwhile, in the Song court the vilification of Jia Sidao began almost immediately after his defeat at Dingjiazhou and Wuhu. Memorials from commoners, National University students, and all ranks of officials flooded the court demanding that Jia and his supporters be executed. Reluctantly Empress Dowager Xie finally bowed to public pressure and demoted Jia, revoked his honors, confiscated his property, and exiled him to the remote South. In October 1275 Jia was violently murdered in Fujian by a minor official acting on his own initiative. By then Jia had been accused of crimes ranging from wrongly possessing an imperial gift to inviting the Mongols to conquer the Song. His former friends did not hold high military and political positions, yet they were stripped of all ranks and at least one of them committed suicide. ${ }^{1}$

The crushing blow on Jia's large and well-equipped armies increased panic at the Song court and the rate of desertion. Even well-respected and high-ranking officials such as Zhang Jian, Wang Yinglin and Wen Jiweng (1236-91) deserted the court. ${ }^{2}$ The problem was so acute that a rescript was issued chastising central government officials who fled without permission and local officials who abandoned cities under their charge. The edict stipulated that those remaining in office would be promoted two ranks, while those who deserted would be investigated by the censorate and their names posted for ignominious conduct. ${ }^{3}$

Among the officials who remained at the court were Chen Yizhong and Wang Yue, the chief ministers now promoted to commanders-in-chief of

1. SS 47.927, 927-35; Zhou Mi, Guixin zazhi, hou.13b-14b and hou.21b-22b.

2. SS 47.935-37; Liu Yiqing, 7.8. However, many of these officials (e.g. Chen Wenlong and $\mathrm{Xu}$ Zongren) shown by the $S S$ to have fled the court in fact went to join the loyalist movement. Zeng Yuanzi did not flee the court, but had in fact been exiled to Leizhou for being implicated in Jia Sidao's proposal to transfer the capital.

3. SS 47.928. See the full text of the edict in Liu Yiqing, 7.8; Bi Yuan, 181.4950. 


\section{The Surrender of Southern Song}

the army and navy. They did not get along well, and while Wang Yue's activities did not go beyond criticizing Jia, Chen Yizhong emerged as the most forceful personality at the Song court. Chen, in fact, now brought about a shift in policy in the civil service for the first time since the Jia Sidao administration. Chen's policies were essentially motivated by the obvious need to unite dissident factions and to regain support for the Song house in the face of alarmingly large defections to the Mongols. To placate the large landowners, he abolished the public-land reform that had been in effect for thirteen years. Land forcefully bought by the state was returned to the landowners on the condition that they lead their tenants into battle. ${ }^{1}$ To win the financial support of merchants and overseas traders, he restored less rigorous regulations on the tea and salt monopolies and the commission of ships and overseas trade. In the armed forces, he injected new enthusiasm for the qinwang campaigns and dispatched envoys to generals who had surrendered to the enemy in an effort to win back their loyalty. He acknowledged that they had cause for discontent under Jia's administration and promised to absolve them of their crime of surrendering if they would return to the Song. The court would then reappoint them to their former posts; those who reconquered a lost prefecture or county would be offered its administration, with rewards promised to everyone from the generals to the enlisted men. ${ }^{2}$ Chen also ordered Jia's dispersed troops to return to their duties and instructed local magistrates to provide cash and rice to soldiers and civilians passing through, in return for a suspension of taxes. An amnesty was proclaimed for all but the most dangerous criminals, including military and civilian officials who had been banished and their property confiscated. ${ }^{3}$ Chen even urged bandits and rebels to join forces with the central government in repelling the Mongol armies. All these measures, however, were conceived too late and implemented in too short a time to regain support for the Song state.

\section{SS 47.927.}

2. SS 47.928. For the letter to and reply from Lü Wenhuan in regard to his return to the Song, see Liu Yiqing, 8.3-5.

3. SS 47.926 . 


\section{Chapter Two}

In August 1275 Chen Yizhong left the capital for his native prefecture, Wenzhou, in Zhejiang province. When he returned in October, the Song defenses were in ruins and his own position at the Song court was challenged by Zhang Shijie and Liu Mengyan (1219-99), the newly appointed chief minister. ${ }^{1}$ In contrast to the incompetence and confusion of Song defense, Bayan coordinated a cautious and highly successful strategy in Zhenjiang where he had returned from the North in November. This strategy, to advance simultaneously on three fronts as earlier applied in 1274 from Xiangyang, now aimed for Hangzhou as the point of convergence. The western wing under Ajirghan (d. 1282) proceeded rapidly to Jiankang and attacked the Dusong pass, while the eastern wing under Dong Wenbing and Zhang Hongfan sailed to the mouth of the Yangzi and advanced along the seacoast. ${ }^{2}$ The central army led by Bayan pushed through Changzhou and Huzhou.

In a month, Changzhou, the Dusong pass, and Pingjiang (Suzhou) had fallen in rapid succession. Changzhou had been taken by the Mongols before, but during Bayan's absence had reverted to Song control. To punish the city for its obstinate resistance and dubious loyalty, Bayan had the entire population massacred. ${ }^{3}$ If he had intended to intimidate Hangzhou into quick capitulation by instilling terror, he was immediately successful, at least as far as Empress Dowager Xie was concerned. She was determined at all costs to avoid actual fighting in the capital, and offered increasingly more concessions in suing for peace, but in each case the Mongols turned a deaf ear. In one mission, the Yuan envoy Lian Xixian (d. 1275) was murdered, but the Song court disclaimed responsibility and blamed unruly generals and bandits. ${ }^{4}$ In January Lu Xiufu headed a Song mission to have the Song emperor relegated

1. SS 47.934, 418.12530. Both Chen Yizhong and Wang Yue had recommended this appointment (SS 47.931).

2. SS 47.934; YS 8.170; Bi Yuan, 182.4966. See Ajirghan's biography in YS 129.3147-49.

3. SS 47.935; YS 8.170; Bi Yuan, 182.4968; Liu Minzhong, b.2b-3a.

4. SS 47.935-36; Bi Yuan, 182.4970. The Song had also killed several other Yuan envoys in 1275 (YS 8.165). 


\section{The Surrender of Southern Song}

to the inferior status of nephew to the Yuan emperor, and to promise annual tributes. When this offer was rejected, the Song court sought the lower status of grandson, but that too was turned down. Then the empress dowager agreed to surrender as a vassal on the condition that a piece of territory be granted to ensure the perpetuation of the Song imperial family. This message and the official seals were sent to Bayan, who by then had pressed on to the Gaoting mountain, just thirty $l i$ northeast of Hangzhou. Bayan was still not impressed by this proposal for conditional surrender. In January 1276, to further demonstrate her genuinely good faith in seeking negotiations, the empress dowager issued edicts to Wen Tianxiang and other generals to cease fighting and disband recruited units. ${ }^{1}$

The Song court was not unanimous in supporting peace negotiations with the Mongol authorities, and this dissent not only confused the generals at the front, but seriously undermined the credibility of Song proposals to the Mongol side. In seeking appeasement at all costs the empress dowager played a personal role: she was not manipulated, but only supported, by officials such as Wu Jian (d. after 1276), Xie Tang (fl. 1260-80) and others who were soon promoted to ministerial ranks. Contrary to traditional accounts which identify Chen Yizhong with the faction advocating surrender and single out Wen Tianxiang as the one strongly opposed to the move, a close examination of the sources indicates a different situation. I suggest, and will later show, that Chen Yizhong and Zhang Shijie represented the faction that advocated continued hostilities with the Mongols and even made preparations in the event that the capital collapsed. ${ }^{2}$

In February 1276, the empress dowager's peace negotiations were leading to unconditional surrender, and a few days before that event Chen Yizhong, Zhang Shijie, Lu Xiufu, and Chen Wenlong (d. 1276) took their forces and left the capital. ${ }^{3}$ Gongdi's brothers Shi and Bing had just been ap-

1. Liu Yiqing, 8.10.

2. Chen Yizhong and Zhang Shijie, despite their differences, apparently planned the escape route of the refugee court from beginning to end.

3. SS 47.937-39; YS 9.177; Bi Yuan, 182.4978, 4982. 


\section{Chapter Two}

pointed pacifying commissioner of Fujian in charge of Foochow and administrator in charge of the Court of Imperial Relatives in the South, respectively. The two princes were escorted out of the capital by their maternal uncles and headed for Wenzhou, where they were to be met by Chen Yizhong, Zhang Shijie, and Lu Xiufu.

At about this time, Wen Tianxiang returned to Hangzhou after an aborted attempt to defend the Dusong pass. The court was then virtually deserted by the departure of those who accompanied the two princes to the southeast and by the extensive evacuation of civilian officials to their native homes. In the absence of veteran officials, Wen, despite his relatively junior status, and Wu Jian, despite his old age, were appointed chief ministers and dispatched to resume peace negotiations with Bayan. ${ }^{1}$ In this mission, Wen was one of five or six envoys sent by the empress dowager, the others being Jia Xuanweng (1213-98), Xie Tang, Jia Yuqing (d. 1276), and Liu Ba (d. after 1280). Rather than completing the details of the surrender, as had been the empress dowager's instructions, Wen reviled both the Yuan generals and the Song defectors in Bayan's camp. While the other envoys were permitted to return to report to the Song court, Wen was detained.

Altogether, the negotiations for surrender extended over three months, from December 1275 to February 1276. This protracted period was responsible for the unhurried and rather orderly submission of the capital. Fighting was avoided in the city itself, concurring with Empress Dowager Xie's firm determination not to have the Changzhou massacre of the entire population repeated. On February 21, 1276 the young Song emperor assembled the few remaining officials to make obeisance to the North, the direction of the Yuan capital. The final unconditional surrender statement pleaded only

1. SS 47.938; YS 9.177. When he was asked by Qubilai in 1276 why he was still chief minister despite his old age, Wu Qian replied that no one else was willing to assume the post (Liu Yiqing, 9.15). 


\section{The Surrender of Southern Song}

for the lives of the people of Hangzhou and the Song house. ${ }^{1}$ Concurrent with the statement were edicts issued to the entire Song empire to cease fighting. One edict was addressed to Li Tingzhi ordering him to surrender all the Huai commanderies and prefectures; another was dispatched to return the two young princes in flight. ${ }^{2}$

The actual transfer of power to the Mongol forces also turned out to be a regulated process in the gathering of war spoils, transfer of administration, and pacification of the population. This was in stark contrast to the arbitrary massacres and rampant looting of earlier Mongol campaigns that took place in other cities. ${ }^{3}$ Dong Wenbing was first sent inside the city walls to take inventory of the troops, civilians, cash and food supplies. Only then did the Mongol party enter the palaces and collect the seals, art objects and valuable treasures. In the government offices and ancestral temples, appointment notices and government seals, sacrificial and archive material were assembled. The important items were selected for immediate shipment to Dadu, while other pieces were stored in trunks and left temporarily outside the respective offices. ${ }^{4}$

1. SS 47.937-38; YS 9.178; Liu Yiqing, 8.11-12, record the edict ordering the surrender: "The roots [i.e. Hangzhou] have already been pulled out, and even if the various cities continue to resist, how the population will [become] innocent victims! As soon as this edict arrives, surrender immediately and the population will be spared of calamity." The surrender statement of Empress Dowager Xie might have included an inventory list of court treasures in addition to official records on the landmarks of the capital. Marco Polo (1254-1324) claims to have seen a copy on which he based his account of the Song capital. His version of the Song conquest and the Song emperor and empress is strikingly inaccurate, indicating that the facts of the conquest were not clear to foreigners in the empire. For Marco Polo's account, see A.C. Moule and Paul Pelliot, Marco Polo, 139.309-13, 152.326-27.

2. See SS 47.938-39, 421.12602, and Liu Minzhong, c.1a-b. Empress Dowager Xie and Gongdi both addressed edicts to Li Tingzhi, urging him to submit and spare the population from further bloodshed. Li burned the edicts and slew the messengers.

3. For example, Changzhou, Chizhou and cities in Sichuan.

4. YS 9.179-80; Liu Minzhong, b.7a-9a. A decade later, Zhou Mi visited the former Song imperial library and found paintings stored in big trunks, an indication that much of the material never reached Dadu. See his Yunyan guoyan lu, 3.6b-7a, and R.H. van Gulik, 201-2. 


\section{Chapter Two}

Soldiers, in general, were not permitted to enter the city, but patrols kept peace inside the former Song capital. Wen Tianxiang's volunteer troops were disbanded and told to go home, while the regular Song forces were incorporated into the Mongol army. Weapons were confiscated from everyone not allowed to carry them. All Song offices and departments were dissolved and imperial guards dismissed, but many former civilian and military officials subsequently offered their services to the new administration, which was proclaimed as the Regional Government of Zhedong and Zhexi, under the control of Fan Wenhu and Mangquat (d. 1290). The Pacification Bureau of Zhedong and Zhexi was provisionally set up to attend to affairs relating to the former Song government. Following the Yuan practice of conciliation, Song officials who had surrendered and collaborated were assigned to head the bureau. ${ }^{1}$

In spite of the orderly change of administration, the anticipation of Hangzhou's collapse nevertheless created restless apprehension at all levels of society, from the imperial family to the common people. Local bandits took advantage of anarchy to plunder and loot. The Mongol temporary government was not able to prevent unruly generals and soldiers from demanding sahua (bribes). ${ }^{2}$ The surrender notice was circulated extensively to inform the public of the change of administration and to curtail speculation about Mongol intentions. Soon Qubilai sent an edict to former officials, clerks, civilians, and soldiers of the Song. It ordered all social and economic classes to continue with their normal professions and refrain from arousing unnecessary suspicion and fear. An amnesty was declared on criminals who had committed offenses prior to the submission of Hangzhou. Former Song officials were reassured that they would not be punished, and archival material, court sacrificial and musical instruments, genealogies, astrological charts and geo-

1. YS $9.178-79,9.182-83$. In June 1276 the pacification bureau was dissolved, but the regional government of the Zhedong and Zhexi remained under the control of Mangquai (biography in YS 131.3186) and Fan Wenhu. A month later, the provincial government (xing zhongshu sheng) was set up in Ezhou and Hangzhou.

2. On the Mongols demanding sahua, see Zheng Sixiao, Xinshi, 123, and "Drunken song," in Wang Yuanliang, Shuiyun ji, 13b. 


\section{The Surrender of Southern Song}

graphical maps were collected for safekeeping. Descendants of Confucian sages and virtuous men, illustrious Confucian scholars, medical experts, Buddhist monks, Daoist priests, fortunetellers and shamans, astrologers, and recluses in the mountains and forests were required to register their names with officials in Hangzhou. Famous mountains, great rivers, monasteries and temples, as well as sites commemorating distinguished men were to be preserved. Widows, orphans, and the disadvantaged were to be assisted with public funds. ${ }^{1}$

The edict also informed the people of Hangzhou that the Song house, in accordance with precedents set by defeated rulers, would be required to go to the Yuan capital. In essence, this meant that the Song imperial family was taken into captivity and abducted to the North. Two main entourages journeyed to Qubilai's court, one consisting of chief ministers (the "mercybegging officials") and the other of members of the Song imperial family. The first one left on February 25, 1276, a few days after the surrender of Hangzhou, and included Wen Tianxiang (who escaped after three weeks), Jia Xuanweng, Wu Jian, Jia Yuqing, and Liu Ba. Altogether there were about three hundred former officials and clerks, and three thousand carriers and escorts of gifts and war spoils. ${ }^{2}$ The purpose of this journey was to submit seals and the surrender statement to the Yuan emperor. After entering Dadu, the gifts were acknowledged and the gift-bearers rewarded with positions in the Yuan government. Jia Yuqing died shortly upon arrival and an accompanying official, Gao Yingsong (d. 1276), starved himself to death; ${ }^{3}$ the remaining former Song chief ministers awaited the arrival of the imperial entourage which had left Hangzhou on March 28, 1276.

The imperial entourage was escorted by Bayan and consisted mainly

1. For the surrender notice and the text of Qubilai's proclamation to the conquered people of Song, see YS 9.178-79; Liu Minzhong, b.7b.

2. SS 47.938; YS 9.178; Bi Yuan, 182.4979-90. The diary of one Yan Guangda, a member of the chief minister's entourage, provides a day-by-day account of the journey to the Yuan capital. See Liu Yiqing, 9.1-15. It has been translated in Moule, "Hang-chou to Shang-tu, A.D. 1276."

3. See Gao Yingsong's biography in SS 454.13347; see also Bi Yuan, 183.4985. 


\section{Chapter Two}

of Gongdi, his mother Empress Dowager Quan, his grandfather Prince Fu, princesses and imperial concubines and relatives. Empress Dowager Xie left Hangzhou several months later due to serious illness. ${ }^{1}$ Palace maids, former officials, and students from the three universities also formed part of the large retinue. Some officials volunteered to accompany the imperial family hoping to acquire positions in the new dynasty, but it appears that the students were compelled to embark on the journey. ${ }^{2}$ Included in the former category was Liu Mengyan, the former Song chief minister who later reached high ranks in the Yuan bureaucracy; in the latter category the National University student $\mathrm{Xu}$ Yingbiao (d. 1276) committed suicide with his family of three rather than witness what he described as the shameful capitulation of the imperial family in the Yuan capital. ${ }^{3}$

When the imperial entourage arrived in Yangzhou, the loyalist general Jiang Cai (d. 1276), under the orders of Li Tingzhi, attempted but failed to rescue the hostages. ${ }^{4}$ In a little over two months the entourage arrived in Dadu, where the Song family joined the chief ministers to proceed to Shangdu, Qubilai's summer residence. There, they were received at court by Qubilai and his empress in a grand feast, and the young Gongdi was formally stripped of his title of emperor and given the title Duke of Yingguo. ${ }^{5}$ The Duke of Yingguo and the two empress dowagers were each granted tax-free property in Dadu, where they subsequently lived. Compared to the hardships to which the Jurchens subjected Huizong and Qinzong in the takeover of

1. YS 9.180-81; Bi Yuan, 182.4981.

2. YS 9.180; Bi Yuan, 182.4981; Songji sanchao 5.62-63. While the last source states that there were several hundreds of students, the YS $(9.182)$ indicates that only forty-six arrived at Dadu; Zhou Mi records ninety-nine. In 1278 only eighteen were left, each of whom had been appointed instructor in a prefecture (Guixin zazhi, $x u$ b.9b-10a).

3. SS 451.13277; Bi Yuan, 182.4981.

4. SS 451.13268; Bi Yuan, 182.4982.

5. YS 9.182; Bi Yuan, 183.4985. The generosity of Qubilai towards the Song imperial family has been praised, for example, by Zhao Yi. See Zhao Yi, 30.634-37. 


\section{The Surrender of Southern Song}

North China in 1126-27, Qubilai's treatment of Song royalty was strikingly compassionate. Empress Dowager Xie died in 1282 and Empress Dowager Quan entered a monastery soon after. In 1288 the Duke of Yingguo set out for Tibet to become a Lama priest; it seems that in 1323 he was ordered by Shidebala (Yingzong, r. 1321-23) to commit suicide. ${ }^{1}$ Some palace ladies accompanying the imperial family on the journey hanged themselves rather than sacrifice their virtue by remarrying; those remaining were married off to craftsmen in the North. ${ }^{2}$ Imperial relatives, officials, and students who were part of the imperial retinue were given positions in the government. ${ }^{3}$

Arriving in Shangdu, Bayan also had an audience with Qubilai in which he presented a laudatory address about the surrender of the city to proclaim the conquest of the Song to Heaven, Earth, and his ancestors. ${ }^{4}$ Arrangements were also made for the traditional Chinese sacrifices to the sacred mountains and rivers to indicate the legitimate succession of the Yuan to the Song, again only by proxy, as Qubilai, like his predecessors, did not wholly subscribe to the traditional Chinese concept of legitimate succession. ${ }^{5}$ These sacrificial rituals nevertheless show that as far as the Mongols were concerned, the conquest of the Song was completed in February 1276 with the fall of Hangzhou. Likewise, many Song generals and officials undoubtedly thought the Song had perished when news of the Hangzhou collapse reached them. Thus following many other Song commanders, Xia Gui, the veteran general in Huaixi, and Fang Hui (1227-1307), the prefect of Jiande, immedi-

1. YS 15.316. The death of Gongdi occurred in 1323; see Wang Guowei, 21.1060-61. Wang quotes from Nianchang, 22.734.

2. Bi Yuan, 183.4985; Wang Yuanliang, Shuiyun ji, 19a-b.

3. See Liu Yiqing, 9.9-10, for offices awarded to members of the ministers' entourage. Of these men, only Liu Mengyan rose to high office in the Yuan bureaucracy.

4. YS 9.182.

5. Franke, From Tribal Chieftain, 32-33. 


\section{Chapter Two}

ately halted their operations and surrendered to the Mongol forces. ${ }^{1}$ The general opinion in 1276 was that the Song had ended: the Song court had disintegrated, the imperial family had been taken captive, and edicts had been issued ordering the entire empire to capitulate. ${ }^{2}$

Bayan's role in the surrender of the Song imperial family has been overwhelmingly praised in Yuan official sources. He was commended for following Qubilai's instructions to exercise mercy and strategy rather than rely on force and killing, ${ }^{3}$ and to a certain extent Bayan did avoid some bloodshed by attracting many defections. He applied firmly the policy of conciliation, which rewarded lavishly those who capitulated and punished harshly those who resisted. The surrendering officials were, in turn, effectively used as envoys to persuade their friends and relatives to cross over to the Mongol side. Destruction was thus not arbitrary nor total in some cities, but elsewhere there were indeed acts of violence and ruthlessness, ranging from cutting off the enemies' ears and displaying them at the city gates to exterminating the entire population of Changzhou. ${ }^{4}$ Loyalist writings may have exaggerated or even fabricated stories of Bayan putting diehard Song loyalists in boiling water to extract oil and grease for catapults. ${ }^{5}$ But, when Yuan sources report that "when the troops were sent to occupy the city [i.e., Hangzhou] and when the imperial family was dispatched to the North, the people

1. SS 47.938; YS 9.179; Bi Yuan, 182.4980.

2. Ming efforts to rewrite Song and Yuan history resulted in treating the period from 1276 to 1279 as part of the Southern Song.

3. YS 8.156 and other sources quote Qubilai's instructions to Bayan to follow the precedent of merciful conquest as exemplified by Cao Bin in the reign of the founder of the Song dynasty, Taizu (r. 960-76).

4. Liu Minzhong, b.3b, et passim.

5. For accounts of these atrocities, see Songji sanchao 5.60; Bi Yuan, 182.4968; Wang Yinglin, Siming wenxian ji, 5.14b. 


\section{The Surrender of Southern Song}

did not even know, ${ }^{11}$ the poetry of the captives speak otherwise of the huge piles of stinking bodies and the heart-rending weeping of bystanders watching the imperial family embark on the journey to the North.

Another myth perpetuated by Yuan sources is the ease with which the conquest was carried out: "Taking Xiangyang and the Huai was as easy as picking up mustard seeds, and pacifying south of the Yangzi was as easy as turning the palm. "2 This misrepresentation is refuted by the fact that the conquest took over forty years, the last two requiring the Mongols' total armed forces in China. Among the 123 generals who received rewards and honors for meritorious service ${ }^{3}$ were many Song defectors who subsequently distinguished themselves in inflicting defeat on the Song forces as well as in luring over defectors.

Both Song and Yuan official sources abound in anecdotes and records of loyalist deeds of Song military and civilian officials in the face of impending defeat. Jiang Wanli, a former Song chief minister, drowned himself when the Mongol army entered his native place of Raozhou; his brother Wanqing and son also perished. ${ }^{4}$ Zhao Maofa (d. 1275) of Chizhou and Li Fei of Tanzhou killed themselves and their families rather than surrender. ${ }^{5}$ After Jia Sidao's defeat in early 1275, Wang Lixin (d. 1275) searched for an "uncontaminated plot of Song soil" on which to die. ${ }^{6}$ There were numerous others who refused to capitulate, citing their debt to the Song as the reason; others declared in a most uncompromising manner: "Alive, I am a subject of the

1. This passage is in Liu Minzhong, b.10a. For differing accounts by the captives, see, e.g., Wang Yuanliang, Hushan leigao, 2.1a.

2. Liu Minzhong, preface.1a.

3. Cleaves, "Biography of Bayan," 259.

4. SS 418.12525 .

5. See the biographies of Li Fei and Zhao Maofa in SS 450.13255-60; see also Bi Yuan, 182.4972-73.

6. See Wang Lixin's biography in SS 416.12475-76. 


\section{Chapter Two}

Song; dead, I will remain a ghost of the Song. " 1 In fury some killed the envoys sent to persuade them to surrender and berated the enemy until their tongues were cut off. ${ }^{2}$ These examples of martyrdom and endurance for the Song cause and for preserving honor in the family continued to be emulated among resistance circles in 1276-79. No longer receiving the sanction of the abducted Song imperial family and court, the loyalists operated independently in the southeastern provinces where the Mongol forces had not fully penetrated.

\section{Loyalist Resistance in 1276-79}

In spite of Empress Dowager Xie's edicts ordering the total submission of the Song empire, fighting did not cease in parts of Huai, Sichuan, Fujian, Jiangxi, and Guangdong. ${ }^{3}$ Remnant Song forces were soon joined by newly recruited armies to engage in militant resistance to the Mongols. The rise and sustenance of this movement can be attributed to two important events: the qinwang edict promulgated in January 1275 and the flight of the two Song princes to the southeastern provinces just days before the young Song emperor formally capitulated in Hangzhou. The qinwang edict had immediately led veteran officials and commoners alike to volunteer their assistance to the emperor by raising armies. For some, the summons was interpreted as a personal appeal to save the dynasty from total conquest. By the middle of the year, combined efforts by officials and commoners had recruited a total of over 200,000 men, with operations in the Huai region under Li Tingzhi and Ruan Kesi, in Jiangxi under Wen Tianxiang and Xie Fangde, in Hunan under Li Fei, and in Sichuan and elsewhere. However, these new armies had hardly begun to fight when Empress Dowager Xie ordered their disbandment in De-

1. Liu Minzhong, a.5a; see also Fan Tianshun's biography in SS 450.13250.

2. For example, Zhao Liangchun (d. 1275) of Huzhou (SS 451.13266) killed some Yuan envoys. Another loyalist had his tongue and nose cut off when he would not yield ( $S S$ 454.13343).

3. I am indebted to Paul Buell for making available to me his working paper, now published as "The Sung resistance movement, 1276-1279. " Buell's central focus is on the local perspective of the resistance movement in the southeastern provinces. 


\section{The Surrender of Southern Song}

cember 1275 and January 1276, during which time she was deeply involved in peace negotiations with the Mongol Yuan forces. This order was largely ignored and even when the capital surrendered, a substantial part of the qinwang forces was still intact and recruitment was continuing. These units were still under the control of local leaders and scattered throughout Song territory. It remained an immense task for the loyalist leaders from the central Song court to rally their support and organize, assimilate, and administer the armies as a single massive force.

While the qinwang campaigns provided the military base, it was the presence of the two young Song princes, Shi and Bing, that gave the resistance movement the legitimacy, credibility, and popularity it received in Jiangxi, Fujian, and Guangdong. ${ }^{1}$ Traditional accounts unanimously credit Wen Tianxiang with the initial conception and leadership of the movement, but evidence suggests that Chen Yizhong and Li Tingzhi played the primary roles in both the evacuation of the two princes from Hangzhou and the assembling of loyalist forces at Wenzhou. In 1275, while Empress Dowager $\mathrm{Xie}$ and some officials were suing for peace, contrary to traditional views Chen Yizhong advocated continued hostilities towards the Yuan and even considered alternative plans to restore the Song state should it perish. From April 1275, after Jia's disgrace, Chen's main effort was to reverse Jia's policies in order to restore the government's confidence and to strengthen its defenses. Jia at that time had memorialized the throne to transfer the capital from Hangzhou to a less vulnerable location, but Chen in an effort to dissociate himself from Jia, executed Jia's messenger who had conveyed the proposal. ${ }^{2}$ While agreeing with Jia and even making preparations to transfer the Song court, Chen pretended to concur with general public opinion not to

1. In early February 1276, Shi (Prince Ji) became Prince Yi, and Bing (Prince Xin) became Prince Guang. In June, Shi was enthroned (posthumously Di Shi and Duanzong); Bing became Prince Wei (SS 47.937, 940). The YS, Wen Tianxiang's Wenshan xiansheng quanji, and other sources are in accordance with the $S S$ titles for the Song princes. However, the Songji sanchao (6.65-75) erroneously refers to Shi as Prince Guang and to Bing as Prince Wei (both titles, in fact, belonged to Bing). Shi is given an alternative reading of Xia in $\mathrm{Ci}$ hai.

2. This was Han Zhen (d. 1275); see SS 47.927. 


\section{Chapter Two}

relocate the capital on the grounds that the army had just been replenished with qinwang forces and that the Mongol army could well pursue the fleeing Song court. ${ }^{1}$ In August 1275, he left for his home in Wenzhou. ${ }^{2}$ This departure is inadequately explained by the sources as the outcome of the power struggle between Chen and Wang Yue, whose son criticized Chen in a petition. Evidence indicates that Chen's trip to Wenzhou from August to October 1275 was intended to inveștigate the prefecture as a possible temporary capital or as a base for military operations.

Chen was in a position to plot with Li Tingzhi, the veteran military and civil official in charge of the Huai region. Li at that time had been given ministerial ranks and often came when summoned to the Song court to report the situation at the front; thus ample opportunities existed for the two men to have consulted each other. Li's connection with the Hao Jing affair has earlier been discussed, and now his more elusive role was most likely to supply Huai troops to support Chen's evacuation plan. Indeed, Huai troops were conspicuously present among the loyalist forces. $\mathrm{Li}$ also provided Chen with the able supporters Lu Xiufu and Su Liuyi (d. 1279), both of whom had been his own protégés in the Huai region and who later became central personali-

1. This opinion was voiced by a student who was an imperial relative. See Songji sanchao 5.56 .

2. Liu Fu's biography (SS 405.12249) states that Chen Yizhong had planned to take the two princes to seek refuge in the sea via Wenzhou. According to traditional accounts, Chen Yizhong, Zhang Shijie, and other high-ranking officials disagreed among themselves and simply fled the court at the same time that the two Song princes departed from Hangzhou. The presence of Chen, Zhang, and the others in Wenzhou, where the princes also arrived, is then seen as coincidental. Chen is portrayed as irresponsible and untrustworthy, always disappearing at crucial moments, as in 1275 from a meeting with Bayan and in 1277 from the loyalist court. In one unreliable anecdote, a summons had to be sent to Chen's mother to persuade him to return to the Song court. Another unlikely story has Zhang Shijie order the coffin of Chen's mother to be carried with the refugee court to make Chen take part in the loyalist resistance. Chen's absence from the Song court in August to October 1275 is naively explained as hurt pride! My reconstruction of this event attempts to explain the Wenzhou and $\mathrm{Li}$ Tingzhi connections. In the next chapter I shall deal with the role of Wen Tianxiang in the historiography of the event. 


\section{The Surrender of Southern Song}

ties in the resistance movement. ${ }^{1}$ Li was later summoned as chief minister at the enthronement of Prince Shi in June 1276, an indication of his im- portance at the initial planning stage of the restoration.

The original plan might have been the total evacuation of the Song court, but as Empress Dowager Xie wavered and until the last days of surrender refused to leave Hangzhou, the flight of the two princes was substituted. In order not to arouse the Mongols' suspicion, the plan was to depart by different routes and to reassemble in Wenzhou. This prefecture, apart from being Chen's home, had ideological significance as the temporary refuge of Gaozong's restoration of the Song dynasty a century and a half before. Wenzhou was also in close proximity to Foochow and Quanzhou, which could potentially serve as naval bases for the loyalists and obtain support from the imperial clansmen based in the two prefectures. ${ }^{2}$

A day or two before the official surrender of Hangzhou, Chen Yizhong, Zhang Shijie, Lu Xiufu, Chen Wenlong, and other supporters took their forces and fled from the court as planned. At the same time, the princes' maternal uncles and imperial relatives escorted them to Wenzhou via Wuzhou; they were followed by a rearguard sent by Chen Yizhong. ${ }^{3}$ The two princes were accompanied by their mothers, a sister, and other relatives. As soon as Bayan was notified of the two Song princes' flight, Yuan forces were alerted but the princes managed a narrow escape. Less than two months later, all parties arrived in Wenzhou: Chen Yizhong came from his home in Wenzhou with some land forces; Zhang Shijie descended from Qingyuan (Ningbo) where he had just attacked in vain the Yuan occupation forces; and Lu Xiufu and Su Liuyi arrived along other routes. At the Jiangxin monastery on a chair on which Gaozong had once sat, Prince Shi was proclaimed com-

1. Li Tingzhi and his "little court" of talented protégés are dealt with in Chapter 4.

2. Foochow and Quanzhou were respectively the seats for the Western and Southern Courts of Imperial Clansmen. See SS 164.3889.

3. SS 47.939-40; Bi Yuan, 182.4982. The rearguard was led by Zhang Quan, who had been protected by Chen Yizhong but criticized by Wen Tianxiang after his defeat at Changzhou in December 1275. An imperial son-in-law, Yang Zhen, attempted to decoy the Yuan forces to allow the princes to escape. He was later taken captive to Dadu. 


\section{Chapter Two}

mander-in-chief of the empire's infantry and cavalry, and Prince Bing his assistant. ${ }^{1}$ An appeal to revitalize support for the Song princes was directed specifically at territories that had not yet surrendered to the Mongols. Several Song clansmen in the retinue were sent into Fujian to reassure its officials and people, as well as to drum up support from other clansmen. Response to these appeals was instantaneous; many prefectures and counties about to surrender in Fujian, Guangdong, and Sichuan quickly reversed their decision, and some places which had already submitted reverted to loyalist control. ${ }^{2}$ Pressured by Mongol generals, Empress Dowager Xie recalled the two princes, but Chen Yizhong ignored her instructions and drowned her envoys. $\mathrm{He}$ then sailed along the coast to Foochow with the two young princes and most of the loyalist forces.

In June 1276 Prince Shi (posthumously Di Shi) was proclaimed successor to the abducted Gongdi, and his mother, Imperial Concubine Yang, was appointed regent. A xingchao (refugee loyalist court) was formed with Chen Yizhong as commander-in-chief and chief minister of the Left, Li Tingzhi as chief minister of the Right, Chen Wenlong and Liu Fu (d. 1276) as assistant ministers, Zhang Shijie as vice-commissioner of Military Affairs, Su Liuyi as attendant of Palace Affairs, and Lu Xiufu as signatory official of Military Affairs. ${ }^{3}$ Among other central government officials who rallied to the enthronement were Deng Guangjian (1232-1302) and Chen Zhongwei (1212-83), who later wrote eyewitness accounts of the resistance. ${ }^{4}$ The generals Wu Jun, Zhao Jin, Fu Zhuo, Li Jue (all died 1277), and Di Guoxiu (fl. 1275-90, who later defected) were dispatched to various circuits to recover

1. SS 47.939-40; Bi Yuan, 182.4982.

2. SS 47.940. Some of these cities were Fuzhou, Guangzhou, and Tingzhou.

3. SS 47.940; Bi Yuan, 183.4984-86.

4. Deng wrote Wen Tianxiang's biography (extant only in fragments, in Wen Tianxiang, juan 17) and the biographies of Wen's followers (in ibid., 19.42b-52a). Chen Zhongwei wrote the Erwang benmo, which became juan 6 of Songji sanchao. 


\section{The Surrender of Southern Song}

Jiangxi, Zhejiang, and the Huai region from Mongol control. ${ }^{1}$ This group of officials and generals who withdrew from Hangzhou may be said to have constituted the faction in favor of continuing hostilities with the Mongols, a course of action that Empress Dowager Xie had opposed since 1275.

Wen Tianxiang was not a key member of this faction at the time. Prior to the qinwang campaign, he was virtually unknown among decisionmakers of the Song court; furthermore, he was in the Song capital only for brief periods in August 1275 and January 1276, hardly long enough to have made his presence felt. ${ }^{2}$ Wen might have been aware of the evacuation plan and even expressed agreement in principle with the removal to the South of the two princes, but he was neither involved in nor entrusted with the details of the flight. ${ }^{3}$ Instead, a day before the official surrender of Hangzhou, he found himself in the company of the other envoys in the Mongol camp, detained and forced to make the journey to the North with the ministers' entourage. During the trip Wen struck up a close relationship with Jia Xuanweng and declared his antiforeign sentiments to Wu Jian. ${ }^{4}$ After twenty days, with the help of eleven followers, he made a desperate escape at Zhenjiang, after which the Mongol forces launched an extensive search for him. ${ }^{5}$ But in the Huai region he was not welcomed by loyalist forces under Li Tingzhi in Yangzhou, who was convinced that Wen was a collaborator who wanted

\section{SS 47.940; Bi Yuan, 183.4986.}

2. In January 1275 Wen Tianxiang raised troops in his native province of Jiangxi, arriving at the capital only in September. In October he was sent to Pingjiang, and in December he was in Huzhou defending Dusong Pass (SS 418.12534-36).

3. Traditional and secondary accounts, however, credit Wen with first proposing the evacuation of the two princes. But even Wen on one occasion admitted to only helping Chen Yizhong plan for the transfer of the imperial family (Wen Tianxiang, 13.1a).

4. On Wu Jian, see Wen Tianxiang, 13.13a-b. Jia Xuanweng is said to have refused to sign the surrender statement, thus earning Wen's praise. Jia also bought and freed Wen's younger sister after she was enslaved by the Yuan government. See Jia's biography in SS 421.1259899.

5. SS 47.940; YS 9.180; Bi Yuan, 183.4983-84; Wen Tianxiang, 13.23b-28b, 17.18a-b. 


\section{Chapter Two}

them to surrender to the Mongols. Distressed at Li's instructions to have him killed and despairing over the death and defection of his followers, Wen heard about the arrival of the Song princes in Wenzhou and hastened south to join the loyalist court. ${ }^{1}$

After a failed attempt to rescue the entourages of Gongdi and his mother passing through Zhenjiang, Li Tingzhi, accompanied by Jiang Cai, also set out for Wenzhou to assume the chief ministership at the refugee Song court. But while passing through Taizhou, both were captured by their subordinates who surrendered Huaidong the moment they departed. Unflinching in their loyalty to the Song, the two men were executed in September $1276 .{ }^{2}$ After his death Li's influence on Song resistance continued to be felt through his protégés Lu Xiufu and Su Liuyi, who remained with the refugee court to the end.

In June 1276 Wen Tianxiang reached Wenzhou and continued on to Foochow, where the loyalist party had moved. Because Li Tingzhi was captured and did not assume the chief ministership, Wen was appointed to take his place but did not accept. His companions Du Hu (d. 1277) and Lü Wu (d. 1277) were dispatched to Wenzhou and Jiang-Huai respectively to recruit local bandits and ruffians. ${ }^{3}$ Almost immediately after Wen's arrival, discord arose over personal and strategic issues. As discussed earlier, Wen Tianxiang was relatively new to the court, and did not participate in decision-making until 1275 , whereas the other loyalist leaders had been in the political lime-

1. Wen Tianxiang, 13.30b-57a and 17.18a-b; Bi Yuan, 180.4983-84. Li Tingzhi was suspicious of Wen because the latter's signature was forged on the pacification statement sent to persuade Li to surrender. Wen thought that the Mongols had fabricated and circulated a story that a certain Song chief minister (presumably Wen) was about to request $\mathrm{Li}$ to submit to the Mongols. Li simply could not be convinced that Wen was able to escape his Mongol guards with eleven followers. Wen was alerted to Li's intention to kill him and helped to safety by Miao Zaicheng, the defense general of Zhenzhou.

2. See the biographies of Li Tingzhi and Jiang Cai in SS 421.12602, 451.13268-69; YS 9.183-85; Zhaozhong lu, 26.

3. SS 47.940; Bi Yuan, 183.4986. 
light since the 1250 s and some even earlier. ${ }^{1}$ Wen was arrogant, blunt and overbearing, and simply could not get along with the other officials of the refugee loyalist court. His sharp criticism threatened their position in the loyalist movement, and even Lu Xiufu, a rather mild-mannered personality known for his integrity, would not take sides with him. ${ }^{2}$ Lu Xiufu himself was incompatible with Chen Yizhong and was soon exiled to Chaozhou and writing to Chen Wenlong for reinstatement. ${ }^{3}$ To further complicate matters, Zhang Shijie and Chen Yizhong also disagreed with each other. Chen was suspicious of Zhang, who many years earlier had defected from the Mongols to the Song. To contain Zhang's power, he put him in control of troops which were not Zhang's own, and in charge of naval forces although his expertise was in land warfare. Instead, the naval expert Liu Shiyong (d. 1277) was assigned to land operations. ${ }^{4}$

Strategic considerations, however, finally turned all the other loyalist leaders against Wen Tianxiang. Both Zhang Shijie and Chen Yizhong considered it most important to take the coastal regions and secure a strong fleet, but Wen insisted on restoring the interior province of Jiangxi (where he was a native) as the base of loyalist power. ${ }^{5}$ No compromise could be reached in

1. In the $S S$ annals, Wen is mentioned only once before 1274 , as top graduate of the 1256 examination. Li Tingzhi, Xie Fangde, Chen Yizhong, Chen Wenlong, and Lu Xiufu appear much earlier and more frequently before 1276 (SS 45-47.871-920, et passim).

2. Immediately after his arrival at the loyalist court, Wen antagonized both Chen and Zhang by his criticism of Chen's irresponsibility and Zhang's inadequate forces. See Zhaozhong lu, 19.

3. Lu Xiufu, 2792-93; Bi Yuan, 183.4987.

4. SS 418.12531. Liu Shiyong later died of excessive drinking caused by grief over the irretrievable state of the Song. His biography is attached to that of Zhang Shijie, in SS 451.13274-75. Chen's suspicion of Zhang was responsible for rejecting a strategy conceived by both Zhang and Wen in December 1275 (SS 451.13273). Zhang was a relative of Zhang Rou, who had defected from the Jin to the Mongols. Thus Zhang Shijie and his counterpart from the Yuan camp, Zhang Hongfan, were related.

5. Bi Yuan, 183.4990; Zhaozhong lu, 19; Wen Tianxiang, 16.20a. On the dispute over strategy, see also Buell, 151. 


\section{Chapter Two}

this regard, and in August 1276 Wen left for Nanjian prefecture in Fujian province to recruit men and recover Jiangxi. From that point on Wen's xing dudu fu (mobile military government or military headquarters) more or less operated independently from the refugee court of the two Song princes, which was controlled by Chen Yizhong and Zhang Shijie. Wen was not permitted to join the refugee court during the next three years of loyalist resistance, and thus there existed in fact two major components of the movement: the refugee court which took with it all the loyalist forces rallied by mid1276, and Wen's mobile headquarters which in August 1276 did not yet have a substantial army. Virtually no communication and coordination occurred between the two. ${ }^{1}$

Apart from the loyalist court and Wen's headquarters which operated in the southeastern provinces, there were at the time other pockets of resistance, the most significant being in Sichuan under the stubborn general Zhang Jue (d. 1279), who did not surrender until $1278 .^{2}$ In fact, Sichuan was not totally subdued until shortly before the Yaishan defeat in March $1279 .{ }^{3} \mathrm{Al}$ though Zhang Jue and other centers had sent assistance to the refugee court, because of the collapse of the south-central region following the fall of Hangzhou, communication was completely cut off from Chen Yizhong, Wen Tianxiang, and the other leaders.

The loyalist resistance suffered severe leadership problems but, curiously enough, there was no evidence of financial difficulties. Both the refugee court and Wen's military headquarters had sufficient funds to pay the large number of mercenaries and to reimburse the local people for food and

1. Wen blamed Chen for spoiling plans for Tongzhou to join in the resistance by not trusting Wen's earlier arrangements with the defense general there. See Wen Tianxiang, 16.19b.

2. See the biographies of Zhang Jue and Li Dehui, the Yuan general in charge of Mongol campaigns in Sichuan, in SS 451.13280-84; YS 163.3815-19. See also Zhaozhong lu, 28-29.

3. Hezhou surrendered only in February 1279 (YS 10.208). 


\section{The Surrender of Southern Song}

supplies. Money was also liberally used to bribe informers. ${ }^{1}$ After the final defeat of the loyalist movement, the Mongols still found large sums of gold and treasures in the defeated Song fleet. The sources are unclear about the financial aspect of the resistance, but a great amount of wealth was brought to the South by the two princes. In addition, loyalist leaders and participants contributed their family fortunes to the cause; the local population also provided resources. ${ }^{2}$

In Nanjian prefecture, as soon as the word spread about Wen's recruitment efforts, his former subordinates who had dispersed at the Mongol takeover of Hangzhou flocked back with renewed enthusiasm. ${ }^{3}$ There were numerous new personalities who swiftly raised troops and joined forces with Wen. In four to five months' time Wen amassed tremendous support, and thus moved the headquarters to Tingzhou where he could supervise more directly the operations to recover Jiangxi. From April to August 1277, he brought under loyalist control Meizhou, Xingguo county and Yudu, while his generals reconquered Ji and Gan counties. Loyalist response was also overwhelming from Hengshan and Fuzhou. ${ }^{4}$ Initial victories were, however, short-lived as Yuan forces soon caught up with the loyalist movement. By September all of Wen's troops again disintegrated, as did those of his subordinate generals Zou Feng (d. 1277) and others. At Kongkang, a locality between Jiangxi and Fujian, his family and almost all of his followers were captured, and some were put to death after torture. With the help of a follower who impersonated Wen and got captured, the real Wen fled to Xunzhou in

1. YS 10.208-09. For example, Wen Tianxiang offered large sums of gold to a crew member and a Mongol soldier, among others, to help him escape in March 1276. See Wen Tianxiang, 13.22a, 23a.

2. For example, Wen and Xie Ao donated entire family inheritances to the cause. Ma Nanbao was a local magnate who also contributed financial support. On Ma, see Wan Sitong, Songji zhongyi lu, 7.15-17.

3. Wen had first considered Guangzhou as his headquarters, but when that city was occupied by the Mongol forces, he decided on Nanjian as an alternative. See Wen Tianxiang, 16.20a.

4. See Wen's biography in SS 418.12537-38; Wen Tianxiang, 16.20a-22b. 


\section{Chapter Two}

Guangdong province. ${ }^{1}$

Wen continued within Guangdong to Chaozhou and Huizhou in March 1278; in Huizhou he again set up his military headquarters, beginning with only a few survivors. He pleaded desperately to join the refugee court but, although granted honors for his resistance efforts, was again turned down. ${ }^{2}$ Left on his own, Wen nevertheless soon received renewed support from freshly enlisted troops. He also subdued the local bandits, Chen Yi (fl. 12701300) and his four brothers, and earned the gratitude of the local population which had long been plagued by banditry. ${ }^{3}$ Chen Yi had been recruited earlier to join the loyalist effort, but shortly after this clash with Wen he turned into an informer and led the Yuan general Zhang Hongfan to wipe out the newly recruited armies in January 1279. After fighting in various parts of Guangdong, Wen was finally defeated at Haifeng. He quickly swallowed poison to avoid being captured alive but did not die; he was then abducted to Yaishan, the final site of loyalist resistance. ${ }^{4}$

Meanwhile, from mid-1276 the refugee court and the two Song princes were relentlessly pursued by Yuan forces. The Mongols had expected some resistance in the southeastern provinces which had not submitted, and as early as February 1276 Bayan had invited the Muslim Pu Shougeng (d. ca. 1296), commissioner of Overseas Trade and Ships in Quanzhou, to surrender, but $\mathrm{Pu}$ did not immediately reply. ${ }^{5}$ In spite of some initial successes, the loyalist units sent to Zhedong and Zhexi met with disastrous reverses. In December 1276 the refugee court and its forces were forced to sail from

\section{SS 418.12538 .}

2. Wen thought that Zhang Shijie had spoken against his request (Wen Tianxiang, 16.22a).

3. $S S 418.12538$.

4. SS 418.12538-39; Wen Tianxiang, 16.23. The poison that Wen took cured him of constipation and eye trouble instead of killing him.

5. YS 9.180. On Pu Shougeng, see Luo Xianglin, Pu Shougeng zhuan and Kuwabara Jitsuzo. 
Foochow to Quanzhou. ${ }^{1}$ Upon arrival, Pu Shougeng invited the loyalist forces to land, but Zhang Shijie suspected Pu's intentions and rejected the offer. Pu then refused to supply Zhang with grain and ships, after which Zhang confiscated Pu's property and vessels. Pu retaliated by a massacre of Song clansmen, officials, and Huai soldiers in Quanzhou. He also formally surrendered to the Mongol forces in January $1277 .^{2}$

As Foochow and Xinghua collapsed, the refugee court lost an important leader, Chen Wenlong, who starved to death after capture. ${ }^{3}$ It then sailed south along the Fujian and Guangdong coast to Chaozhou, Haifeng, and Guanfu (Qianwan, Hong Kong). Parts of Guangdong were then recovered by local loyalist efforts. ${ }^{4}$ In August 1277 Zhang Shijie left Chen Yizhong and Lu Xiufu to guard the imperial retinue, and himself launched an attack on Quanzhou while his generals recovered Shaowu. The Huai troops in Foochow which were loyal to Zhang Shijie mutinied and attempted to kill Wang Jiweng (d. 1285), the Foochow administrator who defected to the Mongols. They were, however, totally annihilated by Mongol forces. By October Zhang Shijie had suffered utter defeat, as the Mongol army arrived to relieve Pu Shougeng; Shaowu was also recaptured. Returning to Qianwan by December 1277 and moving to Xiushan, Zhang Shijie found the refugee court divided over the next course of action. Chen Yizhong could not obtain a consensus to transfer the refugee court and the two Song princes to Champa in Indochina and subsequently left with some forces to first investigate the feasibility of such action. Perhaps because the entire loyalist movement was soon obliterated, Chen never returned to the refugee court; he died in Thailand a few years later. ${ }^{5}$

Meanwhile Zhang Shijie continued to steer the imperial retinue away

1. SS 47.942 .

2. Ibid.

3. Chen Wenlong's biography is in SS 451.13279-80.

4. SS 47.942-44.

5. Chen Yizhong's biography in SS 418.12532. 
from incessant attacks: they reached Jing'ao in January 1278 and Gangzhou (southwest Guangdong province) in April. In the months immediately before Yuan forces massacred the populations of Chaozhou and Guangzhou in order to punish them for their prolonged resistance. At this time the refugee court was joined by a former Song official, Zeng Yuanzi (d. 1285), who had been exiled to Leizhou (near Gangzhou) in early 1275 after having been implicated with Jia Sidao. ${ }^{1}$ In May 1276 Di Shi nearly drowned during the flight at sea; he soon died of fright. The remaining officials and generals of the refugee court were about to disperse, but Lu Xiufu convinced them to continue the resistance. The younger Song prince, Bing (posthumously Di Bing), was then enthroned as the successor to Di Shi. ${ }^{2}$ In July 1278, Zhang Shijie took all the loyalist forces to Yaishan in Xinhui county, near Guangzhou. Yaishan was situated on the sea between two mountains; its highly inaccessible harbor impressed Zhang Shijie as strategically important: it could camouflage the loyalist fleet and at the same time prevent the enemy from entering. ${ }^{3}$ For the next few months the refugee court prepared the Song fleet for naval warfare. Temporary lodgings were built for the imperial retinue and accompanying personnel and troops, an operation that involved a large number of local inhabitants. ${ }^{4}$

By late February 1279, however, the Mongol army had forced all remaining loyalist forces and the refugee court to retreat to the sea. Zhang Shijie now made preparations for the Song fleet to withstand a long siege. One thousand large loyalist vessels were tied together in the form of a long line, in order to stiffen morale and prevent desertion. ${ }^{5}$

In early March 1279, the Yuan generals, Li Heng (1236-85) and

1. SS 47.944 .

2. SS $47.944,451.13276$.

3. SS 451.13273-74.

4. Zhang Yi, 15a.

5. SS 47.945, 451.13274; Wen Tianxiang, 16.9a-10b; Zhang Yi, 15a-20b; Zhaozhong lu, 3436; Bi Yuan, 184.5025-28. 


\section{The Surrender of Southern Song}

Zhang Hongfan with Wen Tianxiang as hostage, reached Yaishan from opposite directions. Together they had at their disposal only five hundred vessels, which were smaller and swifter than the Song fleet. The Yuan crews were unfamiliar with naval warfare and suffered from seasickness. Anticipating this disadvantage and wishing to avoid a violent confrontation, Zhang Hongfan ordered Wen Tianxiang to persuade Zhang Shijie to surrender without fighting. Wen refused and replied with a poem that has since become famous: ". . . In this life since antiquity who can escape death / Better to preserve a pure heart to illuminate the pages of history. ${ }^{1}$

For three weeks the Mongol forces encircled the loyalist fleet and effectively blocked off food supplies and fresh water. Many soldiers in desperation drank sea water and became incapacitated. On March $19 \mathrm{Li}$ Heng took advantage of the low morning tide to attack the northern tip of the loyalist fleet, and in the high afternoon tide Zhang Hongfan blasted the southern end. The loyalist soldiers were soon tired out and could fight no longer. ${ }^{2}$ After one boat lowered its banner to surrender, virtually the entire loyalist fleet followed suit. The battle was lost for the loyalist forces in less than a day--quite a surprise for both sides--as Wen Tianxiang, who witnessed the fiasco, wrote about the collapse:

Suddenly this morning the sky darkened and the wind and rain manifested evil,

Catapults and thunder flashed; arrows descended.

Only yesterday morning the Song vessels decked the

Yaishan sea,

Today only the Mongol boats remain!

Last night ships on both sides drummed and clanged, But today all the boats snore lazily away. ${ }^{3}$

1. "Passing through Lingding ocean, " Wen Tianxiang, 14.1a.

2. SS $47.945,451.13274$.

3. "On the sixth day of the second month [March 19, 1279]," Wen Tianxiang, 14.1b-2b. 


\section{Chapter Two}

The young emperor's boat was the largest vessel and securely attached to the entire loyalist fleet, and therefore could not break out of the Mongol encirclement. Realizing that the end had come, Lu Xiufu forced his wife and children to jump off the boat before he threw himself and the young Di Bing into the sea and died. ${ }^{1}$ The body of the last claimant to the Song throne, Di Bing, was discovered the next day loaded with gold and official seals to help him sink. Many imperial relatives, officials and soldiers are said to have drowned as well. The Mongol forces rescued some of these men, including Deng Guangjian (1232-1303), who subsequently became Zhang Hongfan's family tutor. ${ }^{2}$ Zhang Shijie managed to escape and land with sixteen vessels and some remnant forces. Imperial Concubine Yang also survived the fiasco but upon hearing that Di Bing, her son, had drowned, ended her own life. Zhang was still determined to reorganize the dispersed loyalist forces and seek another Song imperial clansman to enthrone. But a hurricane capsized his boat and he drowned, dashing any hopes of joining up with Chen Yizhong in Champa. ${ }^{3}$ Su Liuyi, another survivor of Yaishan, also attempted to restore the resistance with Zeng Yuanzi and a remnant force; however, only Zeng reached Annam because Su was soon captured and executed. ${ }^{4}$

The Yaishan battle thus ended with the annihilation of the refugee court and loyalist forces. Over 100,000 lives out of an estimated total of 200,000 were wiped out in this confrontation alone, and over the last three years of resistance greater numbers of men had been mobilized and killed. ${ }^{5}$ Damage to the society, economy, and landscape of the Southeast must have been devastating, in view of the fact that some cities changed back and forth

1. SS 451.13276; Zhang Yi, 19a-b; Bi Yuan, 184.5027.

2. Wen Tianxiang, 14.14a-b; see also the biography of Zhang Hongfan in YS 156.3682-83.

3. Zhaozhong lu, 35-36; Zhang Yi, 19b-20a.

4. Wen wrote that Su Liuyi and his son had rescued Zeng Yuanzi from the ocean, all of whom afterwards sailed to the south (Wen Tianxiang, 16.11b-12a).

5. SS 47.945; Bi Yuan, 184.5027; Buell, 167. 


\section{The Surrender of Southern Song}

from loyalist to Mongol control. Whole families were involved in the resistance, and whole families died one way or another. Popular loyalist accounts of the recruitment and composition of the loyalist forces are vague and tend to generalize. The participants, leaders, and the people are too often seen as keenly aware of the country's predicament and as taking it upon themselves to salvage the situation. The facts were considerably less glorious.

The loyalist forces had consisted of two major components: the residual Song regular forces that had been brought to the Southeast by Chen Yizhong and Zhang Shijie, and the qinwang units that were continuously augmented during the three years of resistance and mostly comprised Wen Tianxiang's forces. The qinwang forces were sometimes regarded as volunteer corps, but that is not entirely correct. One large group of these forces were aboriginal peoples, the Yao and the She, who inhabited the interiors of Jiangxi, Guangdong, and Guangxi provinces. ${ }^{1}$ Together with the Huai soldiers, they were essentially mercenaries. ${ }^{2}$ A third group was formed by local bandits who were persuaded to join forces with the loyalists. One such unit was led by Xiong Fei (d. 1278) of Dongguan who fought the Yuan forces until his death. ${ }^{3}$ Many soldiers had already been in local defense units, and were reorganized by local leaders and presented as a single force to the loyalists. Some units were formed by civilians and tenants forcibly abducted by gentry members; many more were tricked by local leaders posing

1. The exact role of the She and Yao peoples is unclear, as references to them in loyalist writings are sparse. For a brief note on the loyalist connection with the Dan people, see E.N. Anderson, Jr., 250. For background studies of the Dan, Yao, and She people, see Xu Songshi, 143-53, et passim; He Ge'en; and Jiang Bingzhao. See also Buell, 140-41.

2. Wen ordered his subordinate Chen Jizhou to mobilize adventurers of the district and to join up with the aboriginal people; see Wen's biography in SS 418.12534. The Zhaozhong lu (p. 34) states that many boats belonging to the She people were involved with Zhang Shijie's forces at Yaishan. Wang Yanwu's funerary inscription to Wen Tianxiang records that the Huai troops were mercenaries; see Wang Yanwu, 4.1b.

3. Xiong Fei was persuaded by an imperial clansman, Zhao Bixiang, to attach his unit to Wen and avoid being labeled as bandits. See Chen Botao, 1a.1b-2a. 


\section{Chapter Two}

as merchants recruiting for labor. ${ }^{1}$ Some of these leaders praised in their biographies as loyalists who organized armies for the Song cause were opportunists. They responded to Chen Yizhong's promise that if they led their tenants into battle, their lands which had been confiscated during Jia Sidao's land reform would be returned to them. Thus many so-called loyalists were merely tenants and slaves forced into the barracks by their landlords and masters. $^{2}$ Of other participants in the resistance, some admired righteousness and wanted to emulate the heroes; some simply wanted to collect material rewards and titles. Still others were town ruffians and adventurers whose sole aim was to loot.

In sum, among the loyalist troops few had responded from an innate sense of culture and ethnicity. Such disparate elements could hardly be expected to remain together without constant leadership and reinforcement of morale. Indeed, after each battle, these troops dispersed, but once summoned, they reassembled again. In particular, the She aboriginals and bandits proved to be unreliable. During the later months of the resistance they were easily enticed to join the Mongol forces. Wen Tianxiang's capture was facilitated by the defection of some bandits whom he had earlier recruited. After the defeat at Yaishan, some of these forces rebelled against the Yuan; ironically, these revolts have been later viewed as loyalist uprisings. ${ }^{3}$ As a combat force, these troops were almost useless because they were incompetent, poorly trained and inefficient. The people's heroic support of the Song cause, presented in local traditions and folklore as history, thus turns out to be closer to myth. This reappraisal of the last years of the Song has also shown that such myths include depicting Wen Tianxiang as the key organizer of the resistance and undermining the integrity and importance of some of his colleagues such as Li Tingzhi and Chen Yizhong.

1. SS 193.4822 .

2. Wang Fuzhi, 10.194.

3. For these uprisings in the early 1280 s by men who had submitted to the Yuan, see Huang Qinglian, 51-52, 85-86. 


\section{THREE / THE HAGIOGRAPHY AND HISTORIOG- RAPHY OF SONG LOYALISM}

In traditional Chinese history-writing, as Professor Twitchett puts it, biographies of individuals and groups were intended to "illuminate the actions of men as 'subjects and ministers' and present precepts and examples for future generations of Confucian officialdom. ${ }^{1}$ As such, a didactic and moralistic concern is particularly striking in both the official and unofficial historiography of the Song loyalists, who became exemplars to be emulated by contemporaries and those who experienced subsequent dynastic collapses. This chapter examines Wen Tianxiang's collected writings, a major source for the Songshi (History of the Song) biographies of the loyalists. ${ }^{2}$ It also discusses discrepancies which have survived in present accounts of Song loyalism, followed by an assessment of the social and political climate under which loyalist writings were produced and circulated. After examining later loyalist writings reflecting a local and limited perspective, we unravel the myth-making mechanism that has contributed to the hagiographical tradition of Song loyalism.

\section{Wen Tianxiang's Writings and Influence on Loyalist Literature}

Sources on the Song loyalists are disparate and voluminous, often unsystematized and mutually conflicting. They yield both a confusing picture of the last years of the Southern Song and a traditional, incomplete account of

1. D.C. Twitchett, 109.

2. For additional information on the primary sources cited in this monograph, see Yves Hervouet; Franke, Sung Biographies; Franke, "Some aspects," 117-29; Rao Zongyi, Jiulong yu Songji shiliao. 


\section{Chapter Three}

the events and personalities of the resistance movement. The Song loyalists themselves were the first to record their experiences and feelings about the demise of the Song; about fifty of these men left extant writings in the form of prose and poetry collections, group biographies of fellow loyalists, and notebook miscellanies. ${ }^{1}$ The predominant literary collection is Wen Tianxiang's Wenshan xiansheng quanji (Complete writings of Wen Tianxiang), particularly the sections entitled Zhinan lu (Record pointing to the south), Ji Dushi (Rearranged Du Fu poems), Yinxiao ji (Collection of whistling and humming) and Jinian lu (A chronological record). ${ }^{2}$ The Zhinan $l u$ is a collection of poems with long prefaces and in two parts. The first covers the period from September 1275 to May 1276, and recounts Wen's arrival from his native Jiangxi province at the Song capital of Hangzhou, his detention by $\mathrm{Ba}$ yan and escape from captivity, and his eventual arrival in Wenzhou to join the loyalist forces. The sequel, the Zhinan houlu, extends from January 1279 to June 1282 , covering the period of his second incarceration through to his captivity and imprisonment in Dadu. The dates and content of the Yinxiao ji coincide with the Zhinan lu. The Ji Dushi is a collection of two hundred fiveword stanza poems with prefaces, completed in 1280. Wen composed these poems by rearranging random lines from Du Fu's (712-70) poetry to describe his experience in the loyalist resistance and to praise the loyalist men under his personal command. Lastly, the Jinian $l u$ is a chronological account of his life from birth to the spring of 1282 , when he was still in Dadu awaiting execution. ${ }^{3}$

In these writings Wen's primary objective was to express for posterity his thoughts on the events and personalities of the collapse of the dynasty and the resistance, and thus a highly self-centered and personal tone pervades ev-

1. See the Bibliography for the extant writings of the loyalists cited in this study.

2. For various editions of the Wenshan ji, see Brown, 6-11. In the SBCK edition, the sections which have particular relevance to the resistance appear as follows: Zhinan qianlu, 13; Zhinan houlu, 14; Yinxiao ji, 15; Ji Dushi, 16; Jinian lu, 17.

3. The SBCK edition of the Jianian lu contains commentaries by a member of the Yuan Bureau of Inspection as well as parts of Wen's biography by Deng Guanjian. 


\section{Hagiography and Historiography}

ery page. Wen repeatedly provides minute details of his narrow escape from death and records in full his eloquent conversations with the Yuan officials Bolot (fl. 1270-1300), Zhang Hongfan, and Bayan. All too often Wen passes moral judgment on the conduct of other loyalists. To his own followers, friends, and the obscure men who assisted the Song cause or himself and died in the process he is generous with praise, often devoting an entire poem and preface to each personality or event. To his rivals in loyalist circles he is unfair and overly critical. He says that Li Tingzhi "had been in Yangzhou for over ten years: a coward without long-range plans, he could only close his gates and rely on defensive measures. He was no help in saving the country." ${ }^{1}$ Although Wen admits that Zhang Shijie was indispensable in restoring Fujian to loyalist control, he pointedly blames Zhang for lacking any "longrange ambition; surrounding himself with large armies and extraordinary wealth, he aspired only to flee far away, thus courting defeat." ${ }^{2}$ Su Liuyi is seen as "sulking because his ambitions were not realized; his quick temper made him unapproachable." ${ }^{3}$ Wen claims that Chen Yizhong had neither moral principles nor political skills, but disappeared at critical moments. ${ }^{4}$ Chen's disagreement with Wen's plans to restore the Jiangxi region is illogically interpreted as a selfish attempt to redeem himself for fleeing from the Song capital earlier. ${ }^{5}$

Apart from being a highly subjective and emotional account, Wen's work suffers from another fundamental weakness: the selective nature of its material. Wen's activities were limited to his military headquarters, and he received only second- or third-hand accounts about the refugee loyalist court. We are thus merely informed in detail about Wen's personal experiences, which did not in fact involve other resistance centers and cannot be relied

1. Wen Tianxiang, $16.7 \mathrm{~b}$.

2. Ibid., 16.11a-b.

3. Ibid., 16.11b-12a.

4. Ibid., 16.5a, 16.15b-16a.

5. Ibid., 16.20a. 


\section{Chapter Three}

upon to yield a comprehensive account of the entire resistance movement. It was Lu Xiufu who recorded the events of the loyalist court in a diary which he had entrusted to a fellow loyalist, Deng Guangiian, before leaping into the sea with the infant emperor Di Bing (d. 1279). Unfortunately the diary is not extant, but Deng's Tianhai lu (Record of filling the sea) was based on it and survives in excerpts. ${ }^{1}$

Deng Guangjian, a fellow townsman of Wen Tianxiang, had earlier joined the loyalist court after his whole family perished at the hands of bandits. After the Yaishan defeat he had tried to drown himself, but was rescued and later became family tutor to Zhang Hongfan, the Yuan general who captured Wen Tianxiang. Deng later found himself making the journey to Dadu with Wen Tianxiang in 1279, and the two captives composed poetry to each other's rhymes and shared despondent feelings about the collapse of the Song. They became such close friends that Wen instructed his younger brother to request Deng Guangjian to inscribe his epitaph because Deng "entirely knew his mind and intent." 2 To fulfill this objective, Deng undoubtedly had complete access to Wen's writings.

Deng Guangjian's biography of Wen and the Wen chengxiang dufu zhongyi zhuan (Collection of biographical notices of the loyalists in Chief Minister Wen's military headquarters) were in fact completed years later. ${ }^{3}$ Deng was to a large extent faithful to Wen's records, particularly in the choice of subjects to be covered and in the selection of information on their fate. All the loyal men commemorated by Wen in his writings were incorpo-

1. Parts of the Tianhai lu, together with Huang Jin's comments, are in "Postscript to the biography of Lu Xiufu," in Huang Jin, 3.6a-8b.

2. Wen Tianxiang, $17.40 \mathrm{~b}$. Deng Guangjian also wrote an encomium for Wen. See Zheng Yuanyou, 1.15.

3. Parts of Deng's biography of Wen survive scattered in Wen Tianxiang's Jinian lu (Wen Tianxiang, 17). They appear in scattered form in Yang De'en, and in $\mathrm{Li} \mathrm{An,} \mathrm{49,} \mathrm{128,} \mathrm{132,}$ 135-36, 156, 160. Deng Guangjian's Wen Chengxiang dufu zhongyi zhuan is in Wen Tianxiang, $19.41 \mathrm{a}-52 \mathrm{~b}$. 


\section{Hagiography and Historiography}

rated into Deng's work but the order of listing was not followed. ${ }^{1}$ For some unknown reason Deng Guangjian chose not to use Lu Xiufu's diary in these biographies and refused to release it to a fellow loyalist and friend of $\mathrm{Lu}$, Gong Kai (1222-1307). ${ }^{2}$ Besides, Deng's family did not submit his Tianhai $l u$ to the Yuan history bureau until after the Songshi was completed. ${ }^{3}$

Gong Kai, however, had no difficulty obtaining from Deng a handwritten copy of Wen's Jinian lu, on which he subsequently based biographies of Wen and Lu Xiufu. ${ }^{4}$ Zheng Sixiao (1241-1318) of Pingjiang also owned copies of Wen's Zhinan lu and drew upon it for a biography of Wen in his controversial Xinshi (History from the heart). ${ }^{5}$ In Annam, where he had fled after the Yaishan defeat, another loyalist survivor, Chen Zhongwei, wrote a postscript to the anonymous Songji sanchao zhengyao (Essential policies of the last three reigns at the end of the Song). This postscript, the Erwang benmo, was brought back to China in the early $1280 \mathrm{~s}^{6}{ }^{6}$ Numerous internal inconsistencies and several stages of editing have rendered the work useless as a historical source. Some editing took the form of direct copying from

1. Deng Guangjian followed the list supplied by Wen so closely that no biography was provided for the valiant general Ma Shilong, who fought in the same capacity as Yin Yu, who was given a biography. The $S S$ also relied on Deng's biographies so exclusively that it, likewise, omitted Ma Shilong. See Zhao Yi, 26.520.

2. See Gong Kai's biography of Lu Xiufu, in Cheng Minzheng, 10.10b-11a.

3. Huang Jin, 3.6a.

4. In his biography of Wen, Gong Kai says that it was based on a manuscript of Wen's $J i$ nian lu, which he saw in Deng Guangjian's house. See Cheng Minzheng, 10.7b.

5. "Account of Chief Minister Wen," in Zheng Sixiao, Xinshi, 92.

6. Rao Zongyi, Jiulong yu Songji, 3-6. The Songji sanchao used the wrong titles to refer to the Song princes. Wan Sitong and the publisher of Siming congshu have also expressed doubt about this work's reliability. See Wan Sitong, Songji zhongyi lu, 2.23. 


\section{Chapter Three}

Wen's Ji Dushi. ${ }^{1}$ Strikingly similar in many passages to the Erwang benmo and suggesting that either one copied from the other is another loyalist work, the Qiantang yishi (Remnant events of Hangzhou). ${ }^{2}$ The anonymous Zhaozhong lu (Record of loyalists) contains biographies of 130 loyalists (including those who fought against the Mongols in the 1230s); it seems to have utilized independent sources as well as Wen Tianxiang's work. ${ }^{3}$ The Zhongyi ji (Collection of loyalist writings) is a fourteenth-century anthology of poems accompanied by biographies written by contemporaries extolling the virtues of the individual loyalists. ${ }^{4}$ These biographies appear verbatim in the Zhaozhong lu.

The liberal use other loyalists made of Wen Tianxiang's writings on the loyalist resistance points to their extensive circulation and considerable influence on their own works. In contrast, none of Wen's loyalist rivals left any extant writings. As a result, Wen's personal biases and interpretations of the last events of the Southern Song and the loyalist resistance have been transmitted to modern scholarship.

However, divergent interpretations and appraisals based on personal connections are responsible for discrepancies and conflicting material among loyalist sources, in spite of Wen's writings serving as a common source. One example is Deng Guangjian's biography of Wen Tianxiang. While contemporary and traditional versions are hostile to Zhang Hongfan, the Yuan general of Chinese ethnicity who inflicted defeat on the loyalists at Yaishan, Deng

1. Verbatim passages occur in the Ji Dushi (Wen Tianxiang, 16.11b-12a) and the Erwang benmo (located at the end of Songji sanchao, 6.67). See also Rao Zongyi, Jiulong yu Songji, 3.

2. Liu Yiqing's Qiantang yishi is a more valuable work and covers more events; it has a rough chronological order and is topically organized. Zhou Mi's Qidong yeyu seems to have been one of its sources. The Songji sanchao is a chronological account.

3. The authorship of the Zhaozhong $l u$ is unknown; however, the work must have been finished after 1289, as its biography of Xie Fangde records his death in 1289.

4. Zhao Jingliang's Zhongyi ji is an anthology of poems by Liu Xuan (1240-1319), his son, and other contemporaries. 


\section{Hagiography and Historiography}

sees Zhang as a human-hearted person who treated Wen with courtesy and who even on his death-bed pleaded with Qubilai to spare Wen's life. ${ }^{1}$ Deng had apparently developed a warm relationship with Zhang while in his service as family tutor; he later wrote the preface to Zhang's collected writings. ${ }^{2}$ In another example, the author of Qiantang yishi appears to have personally known Lü Wenhuan, the Song general who surrendered Xiangyang and entered the service of the Mongol Yuan. Lü is seen in sympathetic circumstances: exhausted after fighting for six years he had no choice but to surrender in order to spare the city and his family from a Mongol massacre. ${ }^{3}$ Zheng Sixiao's writings are friendly to both Chen Yizhong and Zhang Shijie, but his Xinshi has often been rejected by modern scholars as spurious on the basis of much conflicting and inaccurate material about the Song resistance. Such inaccuracies ranged from the whereabouts of Zhang Shijie and Chen Yizhong to the Mongols devouring Wen Tianxiang's heart. Zheng's work is an example of how the lack of information in the years immediately after the resistance (ca. 1283) could result in pure speculation and groundless rumors circulating in the city markets. In his biography of Wen Tianxiang, Zheng admits that he had not consulted Wen's entire writings and that his sources amounted to about one or two parts out of ten on the whole account. ${ }^{4}$ Zheng actually had a personal relationship with a member of the Song royalty in Sanjiang (in Fujian), but because the two friends lost contact after the resistance, Zheng was not able to draw on him as an informant about the events he described in the Xinshi. ${ }^{5}$ Zhou Mi, the versatile talent in art connoisseur-

1. Wen Tianxiang, 17.37a-b, 17.39a.

2. This preface is in Zhang Hongfan, 2a-3a.

3. Lü's surrender is portrayed as a difficult decision dictated by famine and the threat of massacres which had just occurred in Fancheng. See Liu Yiqing, 6.7, 8.4-5.

4. Zheng Sixiao, Xinshi, 92.

5. Zheng wrote a preface to the genealogy of the Zhao imperial clansmen in Sanjiang, Fujian, in which he recounted his close friendship with a certain imperial relative who joined the loyalist resistance and died some years later. This preface is in Zhao Xinian, 2.12-13. 


\section{Chapter Three}

ship, poetry, and random jottings, also wrote a great deal about the loyalist resistance and the loyalists. His personal informants included relatives of the imperial family, Yuan officials formerly in Song service, and northerners sojourning in Hangzhou. ${ }^{1}$ Because of his personal loyalty to friends, he did not criticize those among them who surrendered to the Yuan or later served, but satirized cruelly other defectors whom he did not count as belonging to his personal circle.

In sum, although the loyalists drew upon Wen Tianxiang's work and took over its basic contents and biases, each writer's individual point of view was largely responsible for discrepancies and divergent judgments. There are also many cases of conflicting information that are difficult to prove one way or the other. One example is relatively easy to determine: the unreliable $\mathrm{Er}$ wang benmo is surely wrong in showing Su Liuyi to have died of malaria in 1277 , contradicting more reliable sources which indicate that $\mathrm{Su}$ had in fact survived the defeat at Yaishan and died later in 1279 while attempting to revive the resistance. ${ }^{2}$ Another case is more difficult to assess: whether Xie Fangde fled to Fujian province before or after the collapse of Hangzhou (and thus to confirm or deny his participation in the resistance movement after the collapse of the capital). A Qing work, the $X u$ Zizhi tongjian, could not decide and thus made two separate entries of Xie's departure to Fujian. ${ }^{3}$ In the next chapter, I will use Xie's writings to show that he participated in the loyalist resistance for a few months after the surrender of Hangzhou.

\section{The Songshi Coverage of the Song Loyalists}

The writings of the loyalists as described above do not, however, provide a clear chronological and broad perspective of the events of the last years of the Southern Song and the resistance movement. The official histo-

1. Rao Zongyi, Jiulong yu Songji, 84-89. Zhou Mi's informants for his random jottings are either given in the text or listed at the end of the entries.

2. Songji sanchao 6.67 .

3. Bi Yuan, 182.4974 (for the first month of 1275) and 183.4986 (for the fifth month of 1276). 


\section{Hagiography and Historiography}

ries of the period, the Songshi and the Yuanshi (History of the Yuan), are helpful in filling this gap. ${ }^{1}$ The veritable records for Lizong's reign did not survive, and those for Duzong and Gongdi were not written; thus, the historical archives collected upon the surrender of Hangzhou in 1276 had little bearing on the subject. ${ }^{2}$ In the absence of these Song official sources, the Songshi compilers had to rely mostly on a Yuan official work, the Ping Song lu (Pacifying the Song), and biographies of illustrious Yuan generals who took part in the Song campaigns in order to draw up a logical chronology in the annals of Lizong, Duzong, and the Duke of Yingguo (Gongdi). An account of the two Song princes enthroned by the loyalists is appended to the Songshi annals of the Duke of Yingguo; in addition, the loyalists are given biographies. Fourteen separate biographies of the loyalists appear in the general biography section, seventy-seven in the zhongyi zhuan (group biographies of the loyal and righteous men), and two others are put with the rulin (Confucian scholars). ${ }^{3}$ In these biographies there is strong evidence that the Songshi used, among other sources, Wen Tianxiang's collected writings and Deng Guangjian's biographies of Wen and his followers, together with the

1. The $S S$ (41.783-47.948) and the $Y S$ (5.81-10.219) annals provide parallel coverage of the last years of the Southern Song and the loyalist resistance. The $Y S$ sometimes gives more details than the SS, e.g. the exact date of Li Tingzhi's death, in YS 9.185.

2. See Jin Yufu, Zhongguo shixue shi, 97, and Hok-lam Chan, "Chinese official historiography," 84.

3. The fourteen separate biographies, in SS 405-425, are those of Liu Fu, Gao Side, Ma Tingluan, Wang Lixin, Jiang Wanli, Wang Yue, Zhang Jian, Chen Yizhong, Wen Tianxiang, Jia Xuanweng, Li Tingzhi, Chen Zhongwei, Xu Zongren, and Xie Fangde. Wang Yinglin and Huang Zhen are in the rulin group biography (438). In the zhongyi biographies, the seventy-seven loyalists at the end of the Song appear in random order among loyal men of other periods in the Song (SS 446-55). See Appendix A. 


\section{Chapter Three}

Zhaozhong $l u .^{1}$ The fourteen separate biographies of the loyalists are in random order, and not all the leaders of the loyalist resistance are among them. All except four loyalists appearing in the zhongyi zhuan are martyrs who died for or because of the Song cause in 1273-79 (See Appendix A). These seventy-seven biographies are interspersed among the remaining 201 zhongyi personalities covering various periods in Song history. They represent $28 \%$ of all those eulogized for loyalty to the dynasty. The two men appearing in the rulin (Confucian scholars) section were not treated as loyalists by the Songshi compilers.

Due to the haste with which the Songshi was compiled, the general shortcomings of the project have direct relevance to the coverage of the Song loyalists. $^{2}$ Apart from the random appearance of the biographies of loyalists, conflicting material and inaccuracies also occur in the biographies. Another serious problem is the absence of biographies of important loyalists such as Deng Guangjian.

A conspicuous feature of the accounts of the loyalists is the reinforcement of Yuan official views. In the preface of the collective biographies of the zhongyi, the Songshi compilers state that their instructions were to record without fear of censorship the loyal acts and personalities of the former Song dynasty. The biographies were primarily based on private Song loyalist writings, but evidently some editing was done to make explicit the official Yuan perspective and to tone down the loyalists' anti-Mongol statements. The scholar-official in charge of the project was Ouyang Xuan (1283-1357) of

1. The biographies of Wen's personal followers are essentially identical in Deng Guangjian's Wen Chengxiang dufu zhongyi zhuan and the SS. See, e.g. the biography of Chen Zijing in SS 454.13356 and in Wen Tianxiang 19.47a. The Siku quanshu editors are mistaken in saying that the SS did not use the Zhaozhong lu. See Ji Yun, 57.1274-75. There are verbatim statements in the Zhaozhong $l u$ and the SS; moreover, the order in which biographies appear in SS 450 follows that of Zhaozhong lu, 12-14.

2. Deficiencies of the $S S$ are enumerated in Zhao Yi, 24.464-67. In one example of erroneous information in the SS, Hong Fu, a servant of Xia Gui who had surrendered to the Yuan army and later revolted, is seen only as a loyalist martyr (SS 451.13269). For details of this incident, see Li Zefen, vol. 3, 177-80. For an account of Ming and Qing criticism of the SS, Liaoshi, and Jinshi, see Hok-lam Chan, "Chinese official historiography, " 88-95. 


\section{Hagiography and Historiography}

Luling, Wen Tianxiang's place of birth. Ouyang Xuan was sympathetic to the Song loyalists, as shown by his preface to the collected writings of Wang Yanwu (1252-1324), loyalist and personal follower of Wen Tianxiang and fellow graduate of Ouyang's father. ${ }^{1}$ But although Ouyang Xuan admired Song loyalism, a pro-Yuan bias is noticeable throughout the accounts of loyalist activities. In the annals, the Mongols are already referred to as "Da Yuan" in 1232, even though the Yuan was not proclaimed as the title of the Mongol dynasty until $1271 .^{2}$ Accounts of the conquest of the Song repeatedly emphasize Qubilai's enlightened policies. The loyalists are commended for adherence to moral commitment to the Song, but the generous sympathy of the Mongol generals is also put into the official record. For example, in the biographies of Bian Juyi (d. 1275) and Zhao Maofa, Bayan is depicted performing sacrificial rites for the martyrs; Aju, too, is shown admiring Jiang Cai's loyal spirit and courage. ${ }^{3}$ The loyalists are praised for their efforts to save the Song, but these acts are interpreted as being against the will of Heaven and totally in vain. Abusive language used against the Mongols and Song defectors has been edited out of the original biographies. As for the loyalists who did not cooperate with the Mongols and died horrible deaths such as being minced and mutilated, the biographies merely record "unwilling to compromise they died." The portrayal of the Song loyalists in the Songshi is not the full picture, but it nevertheless casts some doubt on the official Yuan myth of easy conquest, mild resistance, and bloodless victories.

\section{Song Loyalist Writings and Censorship}

In discussing the writing and transmission of loyalist writings it is appropriate to consider the political climate in which they were written and circulated. The ubiquitous presence of the Yuan official view in the coverage of

1. Ouyang Xuan's biography is in YS 182.4196-99; for this preface, see Wang Yanwu, preface. $2 a-3 b$.

2. SS 41.797 .

3. For the sympathy shown by Bayan to Bian Juyi and Zhao Maofa, see SS 451.1325 and 450.13260; for Aju's admiration of Jiang Cai, see SS 451.13269. 


\section{Chapter Three}

the loyalists indicates that as late as the 1340 s when the Songshi was compiled, the Yuan was still sensitive on the issue of Song resistance. There are at present two divergent views about freedom of expression in the Yuan. Traditional and some modern Chinese historians stress that because of the repressive political situation under the Mongols, the loyalists used veiled language and ambiguous phraseology to convey their thoughts. In the West, Franke and Mote feel that because eccentric loyalists such as Zheng Sixiao did not constitute a political threat, the Mongol authorities simply paid no attention to what they wrote. ${ }^{1}$

To be sure, the situation under the Yuan compares favorably with the Ming and Qing literary inquisitions, in which authors of condemned works frequently suffered the death penalty or posthumous disgrace. ${ }^{2}$ The closest equivalent in the Yuan was the burning of Daoist books and woodblocks in 1258 and $1281,{ }^{3}$ but there are no known cases of literary inquisitions in which an individual was arrested and executed for reviling Yuan rulers and officials. The three years of Song resistance are even included in the Songshi annals of the last Song emperor, whereas the Southern Ming movement during the early Qing period is never mentioned in the Mingshi annals. Furthermore, the Mongols have often been considered generous in their treatment of the Song imperial family, compared to the savage attitude of the Jurchen Jin. Loyalty was a virtue admired in Mongol tradition since the time of Chinggis Qan, and when the Song was conquered, the Yuan government sought to employ especially diehard loyalists like Wen Tianxiang and Xie Fangde. The motive for this policy was to bring the newly conquered empire more readily into submission by persuasive example. Thus, the Mongols had no intention to be hostile to those who still felt a lingering loyalty to the for-

1. On the repressive atmosphere of the early Yuan, see Fu Lo-shu, "Teng Mu, " 44, 48, 53. For references to the Yuan being free from censorship, see Franke, "Some aspects of Chinese private historiography," 117-18; Mote, "Confucian eremitism," 285; Li Zefen, vol. 4, 778-90.

2. For accounts of Ming and Qing literary persecutions, see Ku Chieh-kang, and L. Carrington Goodrich, The Literary Inquisition of Ch'ien-lung.

3. Goodrich, Literary Inquisition, 3-4. 


\title{
Hagiography and Historiography
}

mer Song dynasty.

However, judging by their writings, the loyalists felt that the climate was not entirely conducive to free expression. A literatus in 1369 noted that "at the time when the Yuan was first established, those expressing opinions often used concealed and obscure phraseology." ${ }^{1}$ Two works discussed earlier in this connection are the Songshi and Chen Zhongwei's Erwang benmo. In regard to Wen Tianxiang's work, Zheng Sixiao writes that he saw both the original and later editions, in which derogatory references to the Mongols had been revised:

\begin{abstract}
The references to the [Mongol] bandits as "Great Yuan" and "Chief Minister," and to himself as "Tianxiang" in Wen's prefaces were not the original words of the venerable [Wen]. The earlier editions railed blatantly at the caitiffs and did not record their chieftains' names. Readers should detect these concealed and falsified words. It must have happened that those misguided by the bandits anticipated catastrophe and thus changed [the offensive language] to innocuous words. The fierce berating of the bandits in the poems [of the Zhinan lu] have also not been transmitted [to the new edition]. ${ }^{2}$
\end{abstract}

Some loyalists used historical analogies to express their thoughts about foreign conquest. Hu Sanxing (1230-1302) was a loyalist in Qingyuan who revealed his outrage by means of his annotations on the Zizhi tongjian

1. See Hu Han's (1307-81) commentary on Xie Ao's "Record of weeping at the western terrace, " in Cheng Minzheng, 3.7b.

2. Zheng Sixiao, Xinshi, 92. It seems that in the Qing there still existed a 1276-78 edition of the Zhinan $l u$ in five juan, in which some characters were missing and some passages deleted with black ink. See Mo Youzhi, 71-72. 


\section{Chapter Three}

(Comprehensive mirror as a guide to government). ${ }^{1}$ When his work was published in the late Yuan, it appears to have been subjected to some editing. However, the revisions were only randomly done, as many pejorative phrases have survived. Xie Fangde also annotated Confucian classics and Tang poems to convey his distress about foreign rule, ${ }^{2}$ but here too it would appear that if tampering had in fact occurred, it was not thoroughly carried out.

There are other indications that loyalists used obscure and allusive language in their writings because they did not feel the political atmosphere to be entirely free of restraint and danger. An incident described by Song loyalists in such a manner is the rescue of the Song imperial relics in Kuaiji (Shaoxing). ${ }^{3}$ In order to pay last respects to the Song dynasty while at the same time protecting their identity, poets gathered there and wrote highly allusive poetry. In 1284, Xie Ao (1249-95), a follower of Wen Tianxiang, wrote an essay which was later hailed as a masterpiece of loyalist literature. ${ }^{4}$ In the essay, Xie identifies neither the persons nor events mentioned, presumably in order to avoid being accused of seditious acts. Several years later, Xie served as a judge in a poetry competition held in Wuzhou, in which the theme assigned, rustic pleasures in the spring, was allusive rather than straightforward. The entries were couched in obscure language and submitted under pen names.

Of relevance to a discussion of Yuan censorship is the Xinshi of Zheng Sixiao, a collection of vitriolic essays enclosed in an iron case and

1. Hu's death is usually given as 1287 , but it should be 1302 , as shown in Zhou Zumo, "Sanxing shengzu xingli kao," 113-16. Chen Yuan noted concealed meanings and references to the former Song in Hu Sanxing's work. See his Tongjian Huzhu biaowei, 18-19, et passim.

2. See the Bibliography for titles of Xie's annotations.

3. On the response of the loyalists in Kuaiji to the desecration of the Song imperial tombs, see Chapter 5. On the poetry gatherings which took place at the same location in 1279, see Kang-i Sun Chang.

4. This essay is in Cheng Minzheng, 3.7b. 


\section{Hagiography and Historiography}

suspended in a dry well, at the monastery in Pingjiang where Zheng had lived. The preface indicates that the work was completed by 1283 , but the iron case was not retrieved until 1638, a time coinciding with the impending conquest of the Ming dynasty by the Manchu Qing. The Xinshi is in essence a work laced with strong abusive language hurled against the Mongols and foreign rule; it advocated a Song restoration. On the basis of its inaccuracies in describing Mongol customs and the Song resistance, the relatively wellpreserved state of the work, and the timing of its discovery, the Xinshi has been dismissed as a Ming forgery intended by its author to arouse nationalistic and ethnic emotions and instigate animosities against the Manchus. This was certainly the view of some Qing scholars and the Siku quanshu compilers. ${ }^{1}$ However, Ming loyalists such as Gu Yanwu (1613-82) and Wang Fuzhi (1619-92), and modern Chinese nationalists contended that the Xinshi had truly been authored by Zheng Sixiao. ${ }^{2}$ In more recent times, the work has been accepted as authentic by Mote and Kuwabara, but the last word has not yet been spoken. ${ }^{3}$ The Qing historian Quan Zuwang (1705-55) wavered: he first regarded the work as a forgery, but later treated it as authentic. ${ }^{4}$ An alternative view that the work was written by a group of patriots who were

1. See Ji Yun, 174.3761; Zhang Xincheng, 1159. Qing scholars who considered the Xinshi a forgery included Tan Rumu, Xu Qianxue, Yan Baishi, Zheng Xiaoxu, and Yuan Mei. For a summary of arguments for and against the proposition that the work as spurious, see Yang Ligui, 85-101.

2. Those believing in the work's authenticity included Gu Yanwu, Zhang Hong, Yao Jiheng, Yu Jiaxi, Peng Guodong, and Zhou Guanhua. See Yang Ligui, 84-85.

3. See Mote, "Confucian eremitism," 28; Kuwabara, 2, 9-13. A recent study reaffirms Liu Zhaoyou's earlier opinions about the Xinshi's spurious nature; see his "Xinshi zuozhe kaobian. " Luo Xianglin treats the work as a Ming forgery in his Pu Shougeng zhuan, 12, 31-32, but accepts it as authentic in his "Song wangtai yu Songji zhi haishang xingchao," 140-41.

4. Quan Zuwang is generally believed to have dismissed the Xinshi as a forgery; however, I find that he was in favor of its authenticity in some references (see his Jiqiting ji, waibian 44.1337, shiji 4.1507) and against elsewhere (waibian 25.1000, 34.1143-44; shiji 5.1525). 


\section{Chapter Three}

Zheng Sixiao's contemporaries has also been put forward. ${ }^{1}$

After considering the arguments on both sides and reading the Xinshi, I have concluded that neither its authenticity nor its spuriousness can be proved beyond doubt. The Xinshi should, however, be included as a source on Song loyalism, albeit with reservation for the following reasons. To use the factual inaccuracies of the work as an argument against its authenticity is weak. Zheng's contemporary, Zhou Mi, in depicting Mongol and other foreign customs, also quoted fantastic tales that he had heard at second or third hand, but the authenticity of his notebook miscellanies has never been questioned. The language and repetitive style used in the Xinshi can be found in Zheng's other extant writings. Furthermore, the individual that emerges from the Xinshi is consistent with the eccentricity of Zheng as conveyed by his paintings and by contemporary accounts. ${ }^{2}$

Zheng explains in the Xinshi that his main objective for writing it was "to respect legitimate and orthodox succession, repel the barbarians, praise the loyal subjects, execute the treacherous bandits, and to encourage the world and posterity to become loyal subjects. " 3 His instructions were to destroy the work should it be retrieved before the Song was revived. Zheng may have concealed the Xinshi because he feared that the Mongols might discover his writings and learn about a Song restoration movement.

Although Zheng Sixiao and traditional historians have exaggerated the repressive political climate under which the loyalists lived, there is evidence that the Mongol emperor distrusted Song loyalty in spite of his admiration for it. In this connection, one should mention a written statute forbidding the

1. See Yao Congwu, "Tiehan Xinshi zhong de nanren yu beiren de wenti," 109.

2. Zheng Sixiao painted orchids without soil to indicate his distress at the Mongol occupation of Song territory. In his collected works there are many poems and essays reproaching himself for being unfilial and disloyal to the Song, together with references to his peculiar habits and eccentric nature. See his Zheng Suonan xiansheng shiji wenji. Among Yuan literati who wrote about Zheng were Wang Feng (1319-88), "On the Song national university student Zheng Sixiao's ink orchid painting," in his Wuxi ji, 1.45b-46b; Zheng Yuanyou (1292-1364), 1.14-15; Tao Zongyi (ca. 1316-ca. 1402), Nancun zhuogeng lu, 20.246-47.

3. See his "Self-postscript," in Zheng Sixiao, Xinshi, 139. 


\section{Hagiography and Historiography}

Chinese to congregate in public. ${ }^{1}$ Moreover, among other specified groups, they were not allowed to carry arms, and the penalties for such an offense far outweighed banditry and thievery. ${ }^{2}$ The Yuan authorities certainly suspected subversive activities, and in 1283 Qubilai responded to rumors that the last pretender to the Song throne, Di Bing, was still alive. ${ }^{3} \mathrm{He}$ thus executed Wen Tianxiang after a plot to rescue the latter was discovered. ${ }^{4}$ In 1290 there were petitions to transfer Song imperial relatives to the capital, presumably out of fear that they might participate in a rebellion, possibly as figureheads. ${ }^{5}$ I suggest that in view of this political climate, even though there were neither censorship laws nor cases of literary inquisitions, there existed fear of the consequences of defamatory language used against the Mongols. Thus, the loyalists, friends, colleagues, sons and disciples exercised caution and self-censorship. The editors and publishers also saw the need to tone down certain passages and revise a few offensive words. Then there were $\mathrm{Lu}$ Xiufu's diary which Deng Guangjian never released to his fellow loyalists, and Deng's Tianhai $l u$ which Deng's family did not make available to the Songshi compilers. One could speculate that these writings contained unflattering material about the Mongols which Deng dared not reveal and thereby court disaster. For, even if the Mongols did not seem to care what eccentrics like Zheng Sixiao wrote, the loyalists and their associates guarded against giving collaborators opportunities to implicate them on the basis of seditious literature.

A question to be asked is how extensive this voluntary editing was.

1. YS 7.141.

2. Bandits who robbed and killed suffered only the cane, but those found in possession of weapons received the death penalty. See Cheng Jufu, 10.395-96.

3. YS 13.276 .

4. SS 418.12539-40.

5. YS 16.336. The provincial government of Jiang-Huai advised against moving the Song imperial relatives en masse to Dadu, citing the people's possible "restlessness" (i.e. rebelliousness) as the reason. 


\section{Chapter Three}

Absent in most literary collections of the loyalists is a fierce condemnation of the Mongols, who are referred to as "Dabing" (Great army), "Da Yuan" (Great Yuan) and "Tianbing" (Heavenly army). The Mongol conquest is euphemistically talked about as "flames of war, submission, and the change of dynasties." The epithets used against the Mongols are "barbarians, northern people, northern visitors, caitiffs, and barbarian chieftains." It is sometimes difficult to determine whether the loyalists later reconciled themselves to foreign rule before using the Yuan reign titles, or their editors changed their wording. One thing is certain though, such mild language was not used at the beginning of the Mongol conquest in Song official writings. In imperial rescripts for the period 1273-75, drafted by the erudite scholar and loyalist Wang Yinglin and preserved in his collected writings, we can easily find insulting terms for the Mongols, who are compared to ugly beings, swine, and snakes preying on other people's blood. ${ }^{1}$ As these rescripts survived through the Yuan, we can say that although there is evidence of editing, it was only randomly done.

While we might reasonably assume that the editing of loyalist writings in the Yuan was mostly done voluntarily and cautiously, the censorship of later periods was not. The Qianlong rescript of 1776 emphatically proclaimed that books by Ming authors which opposed the Qing dynasty must be burned; in the case of books dating from the Southern Song which criticized the Jin, or from the early Ming which criticized the Yuan, the offensive passages must be erased or revised, though not necessarily destroyed. ${ }^{2}$ Song loyalist writings would surely have fallen into the second category. As the Qing rulers were descended from the Jurchens, material detrimental to the Jin would have to be revised. Indeed there exist examples of such revisions in Zhou Mi's notebook miscellanies where Jurchen Jin emperors are referred to by their temple names, and the Jin dynasty is called "Da Jin" (Great Jin). ${ }^{3}$ Given Zhou Mi's antipathy to the Jin, as was typical of Southern Song officials

1. See, e.g. Wang Yinglin, Siming wenxian ji, 5.26b and 5.28b.

2. Goodrich, Literary Inquisition, 144, 147.

3. Zhou Mi, Guixin zazhi, xu b.49a, bie a.37b. 


\section{Hagiography and Historiography}

as well as northern Chinese in Yuan service, he would not have used that expression for the Jin, and Yuan editions would not have made the change. In addition to criticism of the Jin, the Manchus were sensitive to derogatory language used against the Khitan Liao and the Mongol Yuan.

\section{The Local Perspective on the Song Loyalists}

It was in view of the deficiencies of the Songshi, interest in local contributions to national history, and admiration of loyalism that alternative sources on the Song loyalists blossomed into a genre of loyalist literature. The Song yimin lu (Record of Song loyalists) is a Ming compilation of the writings and later eulogies of eleven yimin loyalists who were not included in the official histories. ${ }^{1}$ Its compiler explains that he was upset at this omission and thus published their writings to preserve them for posterity.

Efforts to extol native loyalists resulted in works with a distinctly local perspective. Gazetteers and family genealogies collected biographical information on native personalities who had played a role in the attempted restoration of the Song. The early Qing historian Wan Sitong (1638-1702) used such gazetteers and unofficial sources to supplement the list of loyalists in his Songji zhongyi lu (Records of loyal and righteous men at the end of the Song). ${ }^{2}$ The 544 men dealt with in the compilation include all the loyal men who fought against the Mongols, from the 1230s to the collapse of loyalist resistance in 1279. In this work Wan appended additional material to the Songshi biographies and also altered the text of the annals to make legitimate the reign of the two Song princes enthroned by the loyalists. The editors of the Qing imperial encyclopedia, Gujin tushu jicheng (Encyclopedia of past

1. Cheng Minzheng's Song yimin lu compiled the writings and relevant material on the following loyalists: Wang Yanwu, Xie Ao, Tang Jue, Zhang Yifu, Fang Feng, Wu Siqi, Gong Kai, Wang Yuanliang, Liang Longji, Zheng Sixiao, and Lin Jingxi. Quan Zuwang's comments on the imperial bones incident were inserted later.

2. Wan Sitong, Songji zhongyi lu. This compilation is very liberal and includes many former Song officials who served the Yuan without any hesitation or regrets. Wan also compiled material on the imperial bones incident (Nan Song liuling yishi); the various arguments about the ethnic background of the last Yuan emperor, Toghon Temür, are collected in the Gengshen jun yishi. Both volumes appear together under the title Nan Song liuling yishi. 


\section{Chapter Three}

and present books), also combed through official and alternative sources to compile records of 684 zhongyi subjects of the Song; out of this figure about one-third are loyalists who fought the Mongols. ${ }^{1}$ These records of Song loyalists take up six chapters and constitute only a small section in its general coverage of loyal subjects since antiquity (See Appendix B). The Late Qing historian, Lu Xinyuan (1834-94), in his Songshi yi (Appendage to the Songshi) added many biographies of Song loyalists under the categories of zhongyi and yixian (surviving literati). ${ }^{2}$ In his work Lu used gazetteers, funerary inscriptions, and other private sources. In more recent times, Chen Botao (1855-1930), feeling forlorn about the Republican Revolution of 1911, found consolation in the recollection of Song loyalists in Dongguan and in Kowloon. The Dongguan yimin lu (Record of remnant survivors in Dongguan) records the activities of the local loyalists during and after the collapse of Yaishan. ${ }^{3}$

By compiling and adding biographies of local loyalists and anthologies of their writings to previous collections, the above works primarily sought to record local contributions to Song loyalism. Quan Zuwang is generally recognized as a major historian of the Zhedong school, inheriting the legacy of Huang Zongxi (1610-95) and Wan Sitong. Better known for his scholarship on Ming loyalism, Quan's work on the Song loyalists consists of a number of separate essays discussing certain aspects, events, and personalities of the Southern Song. ${ }^{4}$

In several essays Quan excitedly traces his ancestors to the eminent

1. Chen Menglei. Loyal men from antiquity to the Ming appear in juan 705-764. The coverage begins with prefaces and essays on loyalty, followed by biographies of loyal men in each dynasty. Loyal men of the Song take up six juan while those of the Ming take up twentynine. See Appendix B.

\section{Lu Xinyuan.}

3. Chen Botao.

4. Quan's work on the Song loyalists consists of about thirty references to the affairs and personalities of the late Southern Song. They appear in random order in his collected writings, the Jiqiting $j i$. 


\section{Hagiography and Historiography}

Quan lineage of Kuaiji. From family registers and Song literature he documents his clan relationship to Empress Dowager Quan, mother of Gongdi. When the Song capital fell, Empress Dowager Quan's family (excluding her aged father) had accompanied the imperial entourage to Dadu and later died there. ${ }^{1}$ The mothers of Duzong and Lizong were also related to the Quan family. ${ }^{2}$ Furthermore, Lizong and his brother had been brought up by the Quan clan. Quan Zuwang emphatically states that although his ancestors had been prominent in the late Southern Song, they did not take advantage of their position to advance the family. In fact, after the fall of the Song, many relatives of the Quan family who had never served the Song decided to withdraw from political service because of their connections with Song royalty. ${ }^{3}$

In another essay, Quan claims descent from another clan member, Quan Quanweng (fl. 1260-1300), a poet who came in ninth in a poetry competition held in 1286-87. ${ }^{4}$ Quanweng's loyalty to the Song through withdrawal from public life is readily praised by Quan, who also credits Quanweng with playing a crucial role in the recovery of the Song imperial remains, a role hitherto never recognized. Dai Biaoyuan (1244-1310), a native of Qingyuan, was an affectionate friend of Quanweng; using Dai's writings together with the family registers, Quan informs his readers that because the new site for the imperial bones had then been in his family's possession, and because Quanweng was a close companion of Wang Yingsun (fl. 1260-1300, the mastermind behind the reburial of the imperial remains), Quanweng must have been involved in the planning and should accordingly be commemorated with the other participants of the incident. ${ }^{5}$ Quan goes so far as to say that without the participation of his family, the Song imperial relics would not have been recovered.

1. See Quan Zuwang, ji 36.4620-63; waibian 14.849-51.

2. Ibid. , ji 36.462-67.

3. Ibid., waibian 21.939 .

4. On Quan Quanweng as a poet, see ibid., ji 36.468; waibian 14.850, 33.1132.

5. Ibid., ji 33.417-18. 


\section{Chapter Three}

In addition to his ancestors' direct participation in the events of the Southern Song, Quan was interested in loyalist personalities and sites that were connected with his own native place, Qingyuan. In this respect, he reveals new information about the loyalists Wang Yinglin, $\mathrm{Hu}$ Sanxing, and others during the first generation of Yuan rule. ${ }^{1}$ In addition, Quan's work is valuable in supplementing the historical records relating to the local region. In one instance, he notes that the existing gazetteers did not record the historical significance of Jinzi mountain, where Zhang Shijie had camped with his forces and sought loyalist support in Qingyuan. Quan explains that the omission had resulted from deliberate suppression by the author of the gazetteer, Yuan Jue (1266-1327), in order to conceal his father's surrender to the Mongols. ${ }^{2}$ Quan also provides additional information about the descendants of the loyalists, with whom he was acquainted. ${ }^{3}$

In his work Quan expresses general views about the traditional historiography of Song loyalism. According to him, individuals who survived the change of dynasty but did not serve the new rulers should be considered loyalists; their biographies should therefore be placed next to the zhongyi biographies. $^{4}$ He argues that Liu Yin (1249-93) and Xu Heng (1209-81), who were born under the Yuan, would not have damaged their integrity if both had served. However, he criticizes Yuan Haowen (1190-1257), who lived under the Jin but still recommended over forty former Jin subjects to office in

1. For essays on Hu Sanxing, Wang Yinglin, and others, see ibid., waibian 18.906-07, 25.1008-09.

2. Ibid., waibian 14.842-43; shiji 2.1482 .

3. For example, Quan was acquainted with the descendants of Fang Feng and Wang Yingsun. See ibid., waibian 25.1000, shiji 7.1573-74. Quan's daughter became the grand-daughter-in-law of Fang Feng's descendant. See Chen Yuan, Chen Yuan shiyuan xue zawen, 56.

4. Quan Zuwang, waibian 42.1299-1300. 


\section{Hagiography and Historiography}

the Yuan. ${ }^{1}$ Sometimes this appraisal is not very logical and shows his partiality, as when he chides Dai Biaoyuan for serving the Yuan as an instructor in a prefecture and defends Wang Yinglin for serving as a local school director, his reasoning being that the latter office was at the local level and received no orders from the Yuan throne. ${ }^{2}$ And, as mentioned earlier, Quan has not been consistent in his views about the authenticity of the Xinshi. In arguing for the prominent role his ancestors had played in Southern Song, he points out that although his family had the potential to do so, it did not interfere with court politics; he later contradicts himself by saying that Duzong's accession to the throne was largely due to the efforts of his family (Jia Sidao is traditionally credited with Duzong's enthronement), but it was Jia Sidao who was solely responsible for ruining the empire. ${ }^{3}$ Quan also draws flawed conclusions: on the strength of two short extant poems which had placed ninth in an amateur poetry competition, he considered Quan Quanweng a giant among poets. In sum, Quan's concern with his family and local history, together with his personal prejudices, definitely undermined his objectivity as a historian.

A more recent interest in local contributions to Southern Song history is reflected in the debates in the 1950s involving several prominent scholars in Hong Kong: Jian Youwen, Luo Xianglin, and Rao Zongyi. In connection with the role Hong Kong and Kowloon played in the events of the loyalist resistance, the key issues raised are the route taken by the refugee loyalist court, the identification of local relics with real or imaginary historical per-

1. On Quan's attitude toward Liu Yin and Xu Heng, see Quan Zuwang, waibian 33.1128; on Yuan Haowen, see waibian 31.1101. For their biographies, see respectively, YS 171.4007-10 and YS 158.3716-30; Toghto, Jinshi, 126.2742-43. On Liu Yin's political withdrawal, see, inter alia, Tu Wei-ming. On Yuan Haowen's contributions to the Jinshi, see Hok-lam Chan, Histcriography, 5-8, 67-119.

2. On Dai Biaoyuan, see Quan Zuwang, ji 5.61; on Wang Yinglin, see waibian 19.915-20.

3. Ibid., waibian 14.850-51. 


\section{Chapter Three}

sonalities or events, and the reliability of various sources including folklore. ${ }^{1}$ It is generally agreed that in February 1276, Gongdi's brothers, Shi and Bing, left Hangzhou and passed through Wuzhou; in May and June they arrived at Wenzhou and Foochow respectively. In December 1276, pursued by the Mongol fleet, the loyalist court sailed by Quanzhou and Xiamen (Amoy), Chaozhou, Haifeng, Guangzhou, reaching Guanfu (Kowloon and Hong Kong) in April 1277. For six months in 1277 the loyalist court sojourned in Guanfu chang (now identified as Jiulong cheng), Guta (Fotang men, also in Jiulong cheng), and Qianwan (Quanwan), all within the present Kowloon territory. ${ }^{2}$

For centuries relics have reminded Hong Kong inhabitants of this episode in Song history: the rock used as a dressing table by Imperial Concubine Yang, the Erwang dian (Palace of the two princes), and the Song wangtai (a large rock identified as the remains of a lookout tower located on Sacred Hill). There are also relics traditionally associated with the refugee court which the scholars proved to be imaginative folklore; for instance, the Houwang miao (Temple of Prince Hou) had nothing to do with the brother of Imperial Concubine Yang, and the Jin furen mu (Tomb of Lady Jin) could not be the alleged grave of the sister of $\mathrm{Di} \mathrm{Shi.}{ }^{3}$ As early as 1899 the site itself was recognized by local inhabitants to have historical significance and successful appeals were made to the British authorities to have it thus declared to prevent commercial development on the premises. ${ }^{4}$ The original Song wangtai platform no longer exists, having been destroyed by the Japanese in World War II in order to extend Kai Tak airport. But the rock itself with the

1. On the debate, see in particular Jian Youwen, Songmo erdi nanqian nianlu kao and his Song huangtai jinian ji; Luo Xianglin, "Song wangtai," 99-146; Rao Zongyi, Jiulong yu Songji, preface and 221-22.

2. Rao Zongyi, Jiulong yu Songji, 24-31; Jian Youwen, Songmo erdi, 21-60; Luo Xianglin, "Song wangtai," 108-21.

3. Rao Zongyi, Jiulong yu Songji, 90-91; Jian Youwen, "The travelling palace of Southern Sung in Kowloon," 29-30.

4. Luo Xianglin, "Song wangtai," 112. 


\section{Hagiography and Historiography}

inscription "Song wangtai" remains largely intact, and has been moved to a different site to commemorate the Song princes. In 1958, after the completion of gardens surrounding the rock, Jian Youwen was requested by the Zhao family clan in Hong Kong (which claims descent from the Song imperial family) to write a commemorative volume identifying the relics and places of historical interest relating to the Song imperial princes in Kowloon and Hong Kong. ${ }^{1}$ Sparked by this interest, Luo Xianglin's main concern was to add details to many points raised. The primary purpose of Rao Zongyi's book was to question doubtful analyses and erroneous sources used by both Jian and Luo.

The three authors disagree on a number of issues, but the main bone of contention is the identification of Gangzhou, where the loyalist court had fled from the Kowloon sites in December 1277 and where Di Shi subsequently died. While traditional historians together with Jian Youwen and Luo Xianglin point to the Dayu shan on Lantao Island (on Kowloon territory), Rao Zongyi places it much farther to the west near Huazhou and Leizhou in western Guangdong province. ${ }^{2}$ In support of their argument, both Jian and Luo draw from Chen Zhongwei's Erwang benmo, a work that Rao shows to have been drastically edited and therefore unreliable. Rao instead follows Deng Guangjian's biography of Wen Tianxiang together with Zhou Mi's Guixin zazhi and the Yuanshi to argue his point, but Jian and Luo have not been convinced. Their determination to locate Gangzhou within the present crown colony of Hong Kong is related to an attempt to enhance the cultural history of this region. Although the debate has ended, interest in the Song dynasty has not waned, as indicated by the opening of a commercial amusement park named Songcheng ten years ago.

After several months in Gangzhou, where Di Shi died and Di Bing succeeded to the throne, the loyalist court sailed back to eastern Guangdong, and at Yaishan (located in Xinhui district), it anchored and stayed for nine months. Temporary lodgings were built and preparations made for the final

1. Jian Youwen, Song huangtai jinian ji.

2. Jian Youwen, "Gangzhou hezai," 75-88; Luo Xianglin, "Song wangtai, " 126-29; Rao Zongyi, Jiulong yu Songji, 51-83. 


\section{Chapter Three}

battle in March 1279. Since 1980 this site has again been recognized for its historical significance and therefore become a tourist attraction. ${ }^{1}$ Other sites of interest on the route of the refugee loyalist court continue to be pointed out by local inhabitants, but some claims are based on no more than unsubstantiated folklore. These include the cliff from which Lu Xiufu was thought to have jumped (in fact Lu leapt into the sea from the imperial boat) and a certain island where Wen Tianxiang's boat was to have been anchored and from where he witnessed the Yaishan battle.

Genealogies also reflect a local pride of participation in national history. I noted earlier that the compilers of gazetteers were interested in adding names of loyalists to already existing lists. Family registers also sought to put on record any relationship or contact with Song loyalists and the imperial family. In the case of the Huang family register of Taishan (Guangdong province), there is a record of a certain woman née Mi who cured Imperial Concubine Yang of an ailment. ${ }^{2}$ The Zhao family register claims a continuous descent from the Song emperors. A large number of Zhao imperial clansmen had accompanied the two Song princes to Guangdong, and most of these came from Foochow branches. At present there are branches in Hong Kong, Xinhui, Taishan, Dongguan, and in North America. ${ }^{3}$ Wen Tianxiang's descendants are traced through several registers; some branches have spread to

1. "Xinhui Yaimen jiyou, " Dagong bao, August 17, 1980.

2. Luo Xianglin, "Song wangtai," 139.

3. For example, the Zhaoshi zupu, compiled by Zhao Xinian, is the genealogy of the Xinhui branch of the Song imperial family, which originated in the Sanjiang branch in Fujian. In 1980 I interviewed in Seattle a seventy-year old gentleman, Willard Jue (Zhao), who had in his family collection a 1905 puban edition of Foushi Zhaoshi zupu, the genealogy of the Taishan branch of the Zhao family, claiming descent from the Song imperial family. It had been brought to Portland by his grandfather in 1907. He also had a 1966 reprint, a ballad narrative of the Zhao family history, an anthology of prose and poems of the Zhao family (Hong Kong, 1972), and a geographical treatise (1908 edition). In Hong Kong, the Zhao family clan (Chiu Clansmen's General Association) still publishes a quarterly newsletter and distributes it both locally and overseas. A branch association is active in Vancouver, Canada. The eminent linguist Y.R. Chao claimed to be the thirty-first generation descendant of the Song imperial family. See Y.R. Chao, 2. 


\section{Hagiography and Historiography}

Huizhou, Hong Kong, Taiwan, Malaysia, and the United States. ${ }^{1}$ The Xie family claims Xie Fangde and his wife in its registers. ${ }^{2}$ The fact that these genealogies have been vigorously kept up to date shows that connections with the Song loyalists and the imperial family continue to be regarded with pride. Although these genealogies have elements of truth in regard to participation in the events of the end of the Song dynasty, one can hardly doubt that both exaggeration and distortion have occurred, since some of these genealogies state at the outset that those who brought shame to the clan would not be recorded. This concern for home and family by historians has often constituted a conspicuous aspect of the historiography of the Song loyalists and has contributed to the myth-making process.

\section{Myth-making and Song Loyalism}

I have just discussed the nature of some sources which gave rise to a number of myths associated with the loyalists and their resistance to the Mongols. The accessibility of Wen Tianxiang's writings caused his points of view to be heard above all other loyalists, and thus he emerges from the beginning as the leader of the resistance while the shortcomings of his rival loyalists are highlighted. For ideological reasons, the Songshi compilers depicted the conquest of the Song to have been compassionate and gentle in spite of some known Mongol atrocities. Admiration for the loyalist spirit and local interest in history gave rise to the erroneous view that the loyalist resistance was popularly supported by all the soldiers and common people, when in fact many were but mercenaries attracted by profit or tenants compelled by their landlords to join the armies.

To take the end of the Song to be 1279 rather than 1276 is another distortion of historical fact. In February 1276, when Empress Dowager Xie surrendered Hangzhou, edicts were dispatched to order the entire empire to submit and to return the two princes who had fled to the southeast. The imperial family was then taken to the North, accompanied by thousands of offi-

1. See Li An, 251, on a Wen family descendant in New York. On the Malaysian branch, see Zheng Liangshu.

2. Xie Hongxuan, vol. 1, 128, 224-29. 


\section{Chapter Three}

cials and gift-bearers. Yuan authorities immediately took possession of imperial archives and treasures, and set up a provisional government to represent Yuan interests in Hangzhou. The Mongol emperor, by performing the Chinese sacrificial rites to the ancestors and to Heaven (if only by proxy), also formally brought the Song to an end. He soon proclaimed that the Song should henceforth be referred to as Wang Song (Vanquished Song). As far as the Yuan was concerned, the Song dynasty was thus terminated for all intents and purposes with the fall of Hangzhou. In the Songshi annals of the Duke of Yingguo, however, an account of Di Shi and Di Bing is attached. By this gesture the Yuan acknowledged the fact that resistance had occurred without according any legitimacy to the three years of its duration. In 1276 many civilian and military officials also felt that the Song had collapsed and accordingly surrendered or fled into sparsely inhabited areas to nurse their grief. Some considered themselves to be yimin loyalists and began writing about the collapse of the country and their personal bereavement. Only a few central government officials such as Lu Xiufu, Zhang Shijie and Wen Tianxiang later felt that the mandate of Heaven had not been withdrawn from the Song house during 1276-79, as indicated in the posthumous will of Di Shi drafted by Lu Xiufu: "I have no pleasure in being emperor. It is only that Heaven has not released the Song [from holding the mandate of Heaven]!" 1 These reasons thus justify regarding the Song dynasty to have ended with the occupation of the capital in 1276. Although the loyalists found support in the southeastern provinces in 1276-79, they were not powerful enough to actually begin administering the regions which they held or recovered from the Yuan forces.

The inclusion of the three years of resistance as part of the Song dynasty was a result of rewriting Song history during the Ming and Qing dynasties. What gave rise to this interest was general dissatisfaction with the composition of the Songshi and the legitimate status given to the Liao and Jin dynasties by writing their separate histories. ${ }^{2}$ Except for Wang Zhu who took an extremist position by denying legitimacy altogether to the Yuan dy-

1. Lu Xiufu, 2787.

2. See Hok-lam Chan, "Chinese official historiography," 96-104, and Jin Yufu, Zhongguo shixue shi, 139-44. 


\section{Hagiography and Historiography}

nasty, most Ming scholars wanted to combine the three histories into one, with the Song commanding legitimacy and the Liao and Jin incorporated into the history of the Song. Nostalgia and admiration for the loyalist spirit accounted for their wish to represent Gongdi, Di Shi and Di Bing as legitimate Song emperors, and be respectively known as Gongzong, Duanzong and $\mathrm{Di}$ Bing. In the Qing, chronological histories such as Bi Yuan's Xu Zizhi tongjian adhered to the Songshi convention of ending the Song in 1276, but private writings such as Wan Sitong's Songji zhongyi lu revised the Songshi annals and loyalist biographies to accord legitimacy to the two princes and the three years of loyalist resistance. Most Chinese and Western works now take 1279 to be the end of the Song, attesting to the success of Ming and Qing revisions of Song history. ${ }^{1}$ This is a curious and unjustified interpretation, especially in view of the fact that we regard the Ming dynasty to have ended in 1644 when the Ming capital was occupied by the Manchus, even though loyalist forces continued to threaten the new dynasty for several decades.

Another myth present in historical sources is the fantastic tale of Gongdi fathering the last Yuan emperor, Toghon Temür (Shundi, r. 13331368). ${ }^{2}$ In March 1276, the six-year old Gongdi journeyed to Dadu and was formally dethroned and demoted to the rank of Duke of Yingguo. In 1288 he left for Tibet to practice Lamaist Buddhism. An early Ming unofficial history, the Gengshen waishi (Unofficial history of the gengshen year), states that many years later he was given a Muslim wife, who in 1320 gave birth to a son. ${ }^{3}$ It happened that Qoshila (the future Mingzong, r. 1329) was passing through Tibet, and considering the birth to be auspicious, took with him back to Dadu both mother and child (Toghon Temür, the future Shundi). Another

1. For examples of 1279 being used as the end of the Song, see Jin Yufu, Song Liao Jin shi, 109; Langlois, China Under Mongol Rule, 467; Hervouet, viii; Conrad Schirokauer, 185.

2. There are two other similar cases of fantasy: the Jin emperor Zhangzong (r. 1190-1208) was believed to have been the grandson of the abducted Song emperor Huizong, and Emperor Yongle of the Ming was said to have descended from a Mongol. On the Yongle legend, see Shao Hsun-cheng; cf. Henry Serruys, "A manuscript version. " For the Jin Zhangzong rumor, see Zhou Mi, Guixin zazhi, xu b.47a.

3. Quan Heng, Gengshen waishi, a.10a-b. 


\section{Chapter Three}

Ming source corroborates the story, but with some minor variation of detail. ${ }^{1}$

Proponents of this story saw confirmation in Qoshila's admission that Toghon Temür was indeed not his own son. ${ }^{2}$ They further sought to verify it with a remark made by the Yongle Emperor (r. 1403-1424) of the Ming, that the portrait of Shundi bore an uncanny resemblance to the founding Song emperor. ${ }^{3}$ Many Qing scholars such as Quan Zuwang and Zhao Yi accepted the notion that Gongdi had indeed fathered Shundi, ${ }^{4}$ but others believed the rumor to be a myth created by Song loyalists and their sympathizers to compensate for their loss of empire and ruler. ${ }^{5}$ It was further argued that Qoshila would not have considered adopting a child, not to mention the Yuan aristocracy permitting a non-Mongol to be enthroned. The renowned scholar Wang Guowei (1877-1927) also regarded the story as true on the basis of the Fozu lidai tongzai (Comprehensive account of Buddhist monks in history) recording the forced suicide of Gongdi in 1323. ${ }^{6}$ His contention is that Qoshila had felt threatened by Gongdi (who knew about the circumstances of the son's adoption) and therefore put him to death. ${ }^{7}$ This argument, however, is not convincing enough to confirm the story as historical fact, and the whole story is largely speculative.

Both the depiction of the Song loyalists as faultless exemplars and the idealization of their loyalism as a paradigm of virtues unchanged through the ages have been affected by the myth-making process. Wen Tianxiang, the paragon of loyalist integrity, is praised to the utmost, while his faults--arro-

1. This was Yu Ying's "Song of the flying dragon of imperial Song." See Wei Qingmang, 552.

2. Quan Zuwang, waibian 42.1287.

3. Ibid., waibian 42.1289 .

4. Ibid., waibian 42.1289; Zhao Yi, 30.649-50.

5. Wei Qingmang, 574.

6. Nianchang, 22.734 .

7. Wang Guowei, 21.1060-61. 


\section{Hagiography and Historiography}

gance, extravagance and exaggeration of his own role--are not mentioned. On the other hand, as indicated in Chapter Two, Jia Sidao's crime as the "last chief minister" has been exaggerated. Not only are Wen and Jia portrayed as positive and negative counterparts of each other, but the entire group of loyalists emerges diametrically opposed to the collaborators and defectors. A deliberate attempt to stereotype and categorize has resulted in the widening and contrasting of the qualities of the two groups, and in the process our view of the large number of Song officials between these two extremes has been blurred.

Biographies of the Song loyalists in the Songshi include mainly those who died for or because of the Song cause, and thus they were martyrs whose integrity could not be questioned due to death. Although the Songshi preface to the biographies explains that those who survived the disasters but withdrew from society and concealed themselves should also be regarded as loyal men, only four such loyalists have been included. Unofficial historical sources outlined in the previous pages intended to supplement this gap by including biographies and accounts of the yimin loyalists who lived after the collapse of the Song but who did not eventually serve in the Yuan government. Thus two traditions of Song loyalists have been recognized so far, the martyrs and the survivors.

Such a classification scheme does not adequately consider those who later served the Yuan in minor educational offices and others who found themselves in compromising positions beyond their control. Some of these individuals have been included in the tradition of yimin, whereas others in exactly the same situation have been censured and lumped together with the defectors and collaborators. The prejudices and standards set by the individual writer determined who should or should not be criticized. Grouping these men with the collaborators in effect ignores the circumstances of their reemergence into public service and the particular type of loyalism they felt. In fact, not a few collaborators and defectors felt loyalty and some changed sides only under difficult situations. Placing loyalists and collaborators into polar opposites overlooks the common background and similar sentiments of the two groups. In order to further explore the close connection between the two extremes, a third group--the marginal loyalists--should be examined. Their loyalty was somewhat tarnished by their socializing with Yuan offi- 


\section{Chapter Three}

cials, or by taking up office in the new government after a period of withdrawal, or by withdrawing from public service only after a period of Yuan employment. These three traditions of Song loyalism are scrutinized separately in the following chapters. 


\section{FOUR / THE ZHONGYI TRADITION OF LOYAL- ISTS: WEN TIANXIANG AND THE MARTYRS, 1273-79}

Song loyalists of the zhongyi tradition (loyal martyrs) shared one common feature: they died during or shortly after the collapse of Song (127379) because of their personal loyalty to that dynasty. The yimin (remnant survivors) are those who survived the dynastic collapse and lived through the early years of Mongol rule, generally in seclusion and without participation in the new government. This chapter is concerned with the first group, and below will first outline the ideological and historical background to the zhongyi loyalists and then present a composite discussion of the group. Next, the careers of Wen Tianxiang, Li Tingzhi, Lu Xiufu, Zhang Shijie, and Xie Fangde are examined separately. The relationships of Wen Tianxiang and $\mathrm{Li}$ Tingzhi with the lesser known followers and subordinates are dealt with next, followed by a brief look at the "virtuous women" associated with the zhongyi tradition. Finally, this chapter offers a perspective on some former Song officials and generals who defected to the Mongols.

\section{Ideological and Historical Background}

The notion of zhongyi (literally, the loyal and righteous) embraces two fundamental Confucian concepts: loyalty and righteousness (duty or obligation). Zhong (loyalty) normally describes a subject's allegiance to the ruler and country, but before the Han dynasty (206 B.C.-A. D. 220) it was more often used in a general sense with other shades of meaning: trustworthiness and sincerity, faithfulness to oneself, and reciprocity with superiors and other men. ${ }^{1}$ The reciprocal relationship as hinted in the notion of $y i$ (righteous-

1. Julia Ching, "Neo-Confucian," 37-38. 


\section{Chapter Four}

ness, duty, or obligation) between subject and ruler was a key concern to classical Confucian philosophy: while the people and subjects owed loyalty to the ruler, the latter had the implicit responsibility to nourish the former. ${ }^{1}$ An absolute form of loyalty involving allegiance to one ruler and one country was not part of the teachings of the early Confucian philosophers, like Confucius (551-479 B.C.) and Mencius (372-289? B. C.) who wandered from state to state offering moral instructions to any ruler who would listen. ${ }^{2}$ But by the time of the Northern Song, leaders like Ouyang Xiu (1007-72) and Sima Guang (1019-86) expounded the more restricted view of loyalty--unilateral and absolute duty towards only one emperor regardless of his merits. Both men categorically condemned the disloyalty of Feng Dao (882-954) who had served five dynasties and ten rulers in succession. ${ }^{3}$ Feng Dao's service to successive dynasties and rulers was by no means unprecedented: apart from Confucius and Mencius, Yiyin (fl. 1700 B.C.), Taigong Wang (fl. 1050 B.C.), and many others served more than one ruler and dynasty without tarnishing their historical image. ${ }^{4}$

The Northern Song denounced Feng Dao's disloyalty but praised the Zhongjing (Classic of loyalty), attributed to the Han scholar Ma Rong (79166) but long regarded by modern scholars as a forgery of the Northern Song

1. Wang Gungwu, "Power," 7.

2. Ching, "Neo-Confucian," 41.

3. See Wang Gungwu, "Feng Tao."

4. Feng Dao was singled out for heavy condemnation because he had been repeatedly disloyal. See Wang Gungwu, "Feng Tao," 205. Yiyin and Taigong Wang were recluses who despite having lived under former regimes became founding ministers of the Shang and Zhou dynasties, respectively. See Sarah Allan, 91-101, 108-17. On Yiyin and Taigong Wang, see also Herbert A. Giles, nos. 913 and 1862. 


\section{The Zhongyi Tradition}

period. ${ }^{1}$ Like the Xiaojing (Classic of filial piety), the Zhongjing is divided into eighteen short chapters; each chapter relates loyalty to the hierarchical subject-ruler relationship and exalts unilateral and death-defying allegiance of subjects to the ruler in the face of national calamities, like rebellions and invasions. This narrow notion of absolute loyalty in fact grew in tandem with an absolutist monarchy during the Song; the concept became more exalted and revered to meet the need to counteract the vulnerability of the Song state to border incursions. At the same time, more emphasis was placed on integrity and morality. Zhu Xi (1130-1200) quoted the Neo-Confucian philosopher Cheng Yi (1033-1107) in a statement that applied to a widow's chastity in a specific sense but incorporated general concerns of integrity and loyalty: "To starve to death is a very small matter. To lose integrity, however, is a very serious matter." 2

It was within this political and intellectual context that the absolute loyalty of Yue Fei can be understood. Yue, the Southern Song general of humble peasant stock, was instrumental in regaining some lost territory from the Jurchen Jin. ${ }^{3} \mathrm{He}$ could have won more victories, but instead, obeying his sovereign Gaozong, Yue halted his advance and then meekly allowed himself to be stripped of his rank and be executed. Although Yue might have been convinced that Gaozong was wrong and unjust, his loyalty did not falter. James Liu discusses Yue's loyalty as personal in nature entailing complete

1. The Zhongjing can be found in, inter alia, Tao Zongyi's Shuofu, 70. On its spurious origins, see Mote, "Confucian eremitism," 279-82; Xiao Gongquan, vol. 4, 506-07; Zhang Xincheng, 762-63. A summary of the Zhongjing can be found in Ching, "Neo-Confucian," 3841. The work was translated into Mongolian, along with the Xiaojing, during the Yuan period. See Yang Shiqi, 720-21.

2. Wing-tsit Chan, xxiv-xxv, 177.

3. Yue Fei's biography is in SS 365.11375-95. Gaozong has been blamed for being the principal engineer of Yue Fei's death. His critics hinted that contrary to his sworn ambition to recover north China, Gaozong did not want Qinzong and Huizong to return lest they jeopardize his own legitimacy as emperor. See Zheng Yuanyou, 1.23-24; Wen Zhengming's (Wen Tianxiang's descendant, 1470-1559) poem "On Gaozong's edict to Yue Fei," in Wang Rongchu, 438-40; Jin Yufu, "Yue Fei," 415-18. On his military campaigns, see Kaplan. See also Hellmut Wilhelm, and James T.C. Liu, "Yüeh Fei." 


\section{Chapter Four}

submission to his sovereign; as such it departed from the "conscientious loyalty" that reflected broader concerns of ethnicity and state. ${ }^{1}$ Yue may have been a victim of the powerful minister Qin Kui (1090-1155), or of Gaozong's sense of unease over his position as emperor; but he was first and foremost a victim of his simple and passionate loyalty. ${ }^{2}$

The concept of absolute loyalty did not originate in the Northern Song, but may be seen as a revival of political values prevalent in early historical sources. If classical philosophers did not define loyalty as absolute and unilateral, early pragmatic and moralistic historians did. They praised the actions of loyal men as mirrors for posterity. For example, in the Xia dynasty, Wuguang killed himself rather than serve the Shang (1700-1050 B. C). Later, Boyi and Shuqi, princes of the Shang state of Guzhu, fled to the Shouyang mountains and subsisted on moss before dying of starvation rather than living under the newly established Zhou dynasty $(1050-221$ B. C. $) .^{3}$ The basic features of martyrdom were willingness to die in order to retain the virtue of baoguo (to repay or "requite" the country), refusal to serve two surnames (i.e., two dynasties) in succession, and aspiration for a place in history. The following passage prescribes a subject's duty: "Since a subject receives orders from the ruler, he should face death only and no other alternative." 4 The Shiji (Historical memoirs) refers to the concern for one's image in posterity: "If a loyal subject abandons his country, his name will not be clean." The same work offers a more explicit example of the loyal subject risking death for the sake of loyalty to only one ruler: "The loyal subject does not

1. James T.C. Liu, "Yüeh Fei," 294.

2. Yue Fei's narrow and limited vision of loyalty has recently drawn much debate and criticism from Chinese scholars, such as Gong Yanming. Yue Fei's myopic vision of loyalty can be compared to the ideal of the new socialist man in China's hero, Lei Feng, who equated his unswerving loyalty to the Communist Party as a $\operatorname{cog}$ in a wheel or a reliable screw.

3. Wuguang, Boyi, and Shuqi's biographies are in Sima Qian, 61.2121-29. See also Allan, 89-91, 111-17; Giles, no. 1657.

4. See Lüshi commentary to Liji, in Wang Meng'ou, 31; it is also quoted in Chen Menglei, juan 706 , vol. 311.36 . 


\section{The Zhongyi Tradition}

serve two rulers; the chaste woman does not marry two husbands . . . . Given the alternative of life without righteousness, I definitely prefer to be cooked to death." 1

In a later historical source, the Liangshu, Mencius is quoted out of context to lend ideological support to the loyal subject preferring death to a blemished reputation: "Life is what I desire; righteousness is also what I desire. If the two cannot be obtained together, I will let go of life and take righteousness. "2 Here, "righteousness" specifically refers to the loyalty and integrity of the loyal subject, even though Mencius' intention had been more general. The Shiji and later standard histories contained biographies of loyal subjects, but it was the Tsinshu (History of the Tsin) which first set aside a separate category of group biographies for loyal subjects who died for their country and who were held up as models for future generations. The preface to the biographies states:

The ancients have these sayings: "The moral man kills himself to fulfill his moral sense and does not seek to live and [thereby] harm it." They also say: "Dying is not difficult; it is how to live [properly] that is difficult. " How true were such words! This was because they knew a tarnished virtue is within easy reach; how could a righteous man begrudge his death! In sacrificing his body and obtaining a proper abode, the brave man does not begrudge his existence . . . . This is the reason why the former histories praised them highly and the later generations admired their valor. ${ }^{3}$

1. For these two passages, see the biographies of Yue Yi and Tian Dan, in Sima Qian, $80.2433,82.2457$.

2. Yao Silian, 43.611; Mencius, Gaozi chapter, in Legge, vol. 2, 411.

3. Fang Xuanling, 89.2297. Other similar categories of moral people in the standard histories are the xunli (upright clearks), xiaoyi (filial sons), and lienü (virtuous women). 


\section{Chapter Four}

This overwhelming concern with posthumous fame became the motivating force for loyal men to lay down their lives for the ruler and country. After the Tsinshu, most standard histories followed the precedent of giving loyal martyrs group biographies, albeit with some variations in the titles: jieyi (integrity and righteousness) in the Weishu, chengjie (sincerity and integrity) in the Suishu, and sijie (integrity to the point of death) in the Xin Wudai shi. ${ }^{1}$ To the traditional historiographers, loyalty and martyrdom for the state were long-ingrained traditions, abandoned temporarily during the turbulent Five Dynasties period when only three such loyal men were given biographies. An additional fifteen men were commended in another group biography for proving to be loyal at the end without being thus inclined at first. In the preface to the biographies of loyal men, the Songshi historiographers stress that the Song loyal men were outstanding enough to expunge the decadent morals of the Five Dynasties. ${ }^{2}$ Song loyalist behavior was thus observed as a continuation of a long tradition of loyalty as well as a unique response to the threat of alien conquest. ${ }^{3}$ Deciding whether to surrender or die was the paramount concern of many of the loyal martyrs in 1273-79.

\section{Composite Biography of the Martyr Loyalists}

The official history of the Song, Songshi, provides the primary source for a composite study of the zhongyi (martyrs) loyalists. All except four of the group loyalist biographies in this work are of the zhongyi tradition, and they supply sufficient information on the composition and activities of the

1. See Wei Shou, 87.1889; Wei Zheng, 71.1639; Ouyang Xiu, 32.347. The sishi (loyalty until death) biographies are in ibid., 33.356.

2. SS 446.13149 .

3. For a survey of loyal men across the dynasties, see Appendix B and Chen Menglei, juan 706-763, vols. 311-316. Chen and his associates gleaned biographies of loyal men from various official and local sources and grouped them according to the dynasties to which these men directed their loyalties. 


\section{The Zhongyi Tradition}

group. ${ }^{1}$

The eighty biographies of loyal martyrs in $1273-79$, found in the Songshi, do not represent a homogeneous group. They range from high-ranking central officials to an obscure tailor, a Buddhist monk, and a Daoist priest. Many were gentry members who responded to the qinwang edict and recruited armies and local militia to defend the Song. Of these men, $62.5 \%$ $(50 / 80)$ were civil officials up to 1275 ; most were degree holders. Upon joining the defense against the Mongols, they temporarily adopted military roles. The other $37.5 \%(30 / 80)$ had purely military careers and included not a few who had earlier committed crimes, or were town ruffians who took the opportunity to redeem past misdeeds. Key personalities, like Wen Tianxiang, Li Tingzhi, Wang Lixin, and Xie Fangde successfully combined civilian careers with military experience. A sizable number were local men who defended their native districts before attaching both themselves and their units to centrally appointed officials like Li Tingzhi and Wen Tianxiang. One also notices a considerable role played by the relatives of the Song imperial family. The zhongyi came from many parts of the country, from several northern Chinese defectors to natives of Jiangxi, Zhejiang, Anhui, Fujian, Sichuan, Hunan, and Hubei. The presence of Jiangxi men is particularly conspicuous, attesting to the importance of this region in the resistance movement and the attention given to the home province of Wen Tianxiang and Xie Fangde. No loyalists from Guangdong and Guangxi are recorded, probably because local gazetteers of these provinces were unavailable to the editors of the Songshi. Later compilations such as the Songji zhongyi lu do have many entries from these two provinces. Age is often missing in the biographies of lesser known loyalists, but there is enough information to observe three adult genera-

1. The list of eighty includes seven separate biographies in the section for outstanding officials (Liu Fu, SS 405; Wang Lixin, SS 416; Jiang Wanli, SS 418; Wen Tianxiang, SS 418; Li Tingzhi, SS 421; Xu Zongren, SS 425; Xie Fangde, SS 425) and seventy-three in group biographies (sixteen in SS 450; eleven in SS 451; seven in SS 452; thirty-seven in SS 454; and two in SS 455). I have left out from SS 454 the four loyalists (Zhang Shanweng, Huang Shen, He Shi, and Chen $\mathrm{Zijing}$ ) who survived the resistance and became recluses and taught or told fortunes for a living. The composite account is based on the above SS biographies, supplemented by unofficial sources, including the writings of Deng Guangjian, Zhao Jingliang, and Xu Dazhuo. 


\section{Chapter Four}

tions--the old, the middle-aged, and the young--ranging from the seventies to the twenties. Families, friends, servants, and others were deeply involved with the individual's loyalist activities and martyrdom. In many cases, brothers, wives, sons, and other relatives chose to perish with the martyred victim.

These zhongyi loyalists shared certain behavioral patterns not unlike those found among loyal men of previous dynasties. The centrally appointed officials and local commanders fought to the bitter end, even after all supplies had been exhausted and others around them had surrendered to the Mongols. They instantly executed the messengers who tried to persuade them to defect; then they displayed publicly the corpses in order to boost morale and to deter others from capitulating. Many of these loyalists had recruited units from among their tenants, town ruffians, bandit gangs, as well as among the Yao and She peoples to unite with centrally appointed officials. They willingly exhausted family fortunes to pay mercenaries and supply food and clothing to the soldiers. Wealthy local magnates also donated large quantities of food and provided lodging for the loyalist forces. While some zhong$y i$ served only as clerical assistants, the majority actually fought in hand-tohand combat against the Mongol army.

With few exceptions, all were active participants in Song defense and loyalist resistance, but both active and nonactive participants met a similar fate--death--as the consequence of their loyalty and support for the Song. Most were captured and killed by the Mongols because of their unwillingness to surrender; the rest committed suicide in various ways (by drowning, burning, strangling, poisoning, starving or hanging) rather than suffer what they perceived to be the indignity of capture and the dishonor of clinging to life after the collapse of the dynasty. A few also died of distress and illness caused by the defeat of loyalist resistance. At the moment of death, most made a point of facing south to symbolize their resolute loyalty to the Song. Just before dying, almost all berated the Mongol conquerors and Song defectors; some did not stop until their tongues were cut off. They also left written and eloquent statements testifying to their loyal spirit at the moment of death. Most of the utterances were traditional phrases about the duty and obligation of the subject to fulfill his loyalty. One Lin Kongzhai (d. 1276) bit his finger and wrote on the wall with his own blood: "Alive, I am a loyal and righteous 


\section{The Zhongyi Tradition}

subject; dead, I shall remain a loyal and righteous ghost. Though I can survive in the wilderness, I cannot bear to do just that. ${ }^{1}$ Before leaping into the river, one Xie Xu (d. 1276) expressed his antipathy toward foreign conquest as follows:

My ambitions to pacify the barbarians not yet realized--

Do not say let my thoughts flow east in the river.

Who can rescue the innocent submerged in the world?

A thousand years will not erase the regret of one death.

The Xiang River will not sink the loyal and righteous spirit,

The Huai and Fei Rivers felt ashamed and smashed the Qin

conspiracy.

The Tiao River flows north, passes through the Gusai Mountain,

My loyal heart will be preserved to eradicate the barbarian

caitiffs and chieftains. ${ }^{2}$

In prison and awaiting execution, one Confucian scholar regretted being ill and not able to rail at the enemy. His last words were:

In this crisis I will certainly not wish to return alive

And preserve an empty name in the world.

Everywhere has been defiled by barbarian blood,

Be sure to collect my bones at the Shouyang mountain

[where Boyi and Shuqi starved to death]. ${ }^{3}$

To get a clearer profile of the zhongyi loyalists, we now examine in more detail the lives and careers of five key loyalist personalities--Wen Tian-

1. SS 452.13309 .

2. Xu Dazhuo, a.13b.

3. I use Deng Guangjian's Wen chengxiang dufu zhongyi zhuan, in Wen Tianxiang, 19.1a, rather than the $S S$ version (454.13356), which has a milder tone and was based on the former. 


\section{Chapter Four}

xiang, Li Tingzhi, Lu Xiufu, Zhang Shijie, and Xie Fangde--together with their followers and subordinates.

\section{Wen Tianxiang and His Military Headquarters}

As a historical figure, Wen Tianxiang stands out as the greatest loyalist exemplar both in his and all subsequent times of Chinese national calamity until the present century. ${ }^{1}$ With virtually no exception, primary and secondary scholarship on Wen has been unstinting in praise and glorification, but the following account presents a more objective view.

Wen, the eldest of four sons, was born into a well-to-do gentry family originally based in Sichuan but which had relocated in Luling (Jizhou, Jiangxi province) for several generations before Wen's time. There had been no distinguished officials in the family, but as a child Wen had aspired to emulate prominent political figures from his place of birth, such as Ouyang Xiu. At twenty, he gained first place in the 1256 jinshi examination, an event which marked his first entry in the Songshi annals. ${ }^{2}$ The eminent Confucian scholar and examiner Wang Yinglin congratulated Emperor Lizong for having acquired such a promising subject. Lizong was much impressed and bestowed on Wen the names by which he was later known--Tianxiang (Auspicious omen from heaven) and Songrui (Lucky sign of Song). From this famous examination year also emerged some other men who later distinguished themselves as loyalists--Xie Fangde, Lu Xiufu, Hu Sanxing, Huang Zhen (1213-80), Shu Yuexiang (1217-98), and Chen Zhu (1213-97). ${ }^{3}$ Wen did not

1. SS 418.12533-40. The biographical details in this account have largely been drawn from Wen's $S S$ biography and his autobiographical poems.

\section{SS 44.857 .}

3. The anonymous Song work Dengke lu lists altogether the names, birthdates, lineage and descent, and places of origin of 601 graduates in descending ranks under five categories. Wen Tianxiang, Lu Xiufu, and Xie Fangde were the most outstanding of the group, which also included two defectors to the Mongols, Wen Bi and Qian Zhensun (d. after 1290). A large number of imperial relatives also graduated in this examination year. For a comparative study of this list with the only other extant Song list, the one for 1148 when Zhu Xi graduated, see E.A. Kracke Jr., "Family versus merit." 
maintain close contact with these graduates of the same examination year, except for his younger brother $\mathrm{Bi}$ (1238-95) and several obscure individuals who also passed the examination.

Wen's confidence in his political future was greatly strengthened by obtaining first place in the examination and by the personal recognition of the emperor. But his political career was interrupted almost before it started. His father, who had accompanied Wen and his brother to the capital, fell ill and died; the two brothers subsequently brought the body back to Luling and withdrew into mourning. When Wen returned to the capital after this family matter, his career never seemed to get off the ground. He had few powerful friends in Hangzhou, most likely because of his presumptuous airs and lack of influential family ties. In 1259 he memorialized that the eunuch Dong Songchen (fl. 1250-60) be executed for suggesting the transfer of the Song capital, but he received neither support from other officials nor any response from the throne. The offices he held in the 1260s were mostly regional, undistinguished and frequently in his home province of Jiangxi. In the Songshi annals he is not mentioned again until January 1275, when he responded to the qinwang edict. Appendix $\mathrm{C}$ shows his phenomenal rise in prestige and responsibilities, from the ranks of $8 \mathrm{~b}$ to $5 \mathrm{~B}$ by 1270 , to 3B in October 1275 and 1B in January $1276 .{ }^{1}$

In the years before 1275 Wen served as a regional official and acquired a wide range of experience dealing with local bandits in Jiangxi. However, he wanted to play a role in the central bureaucracy, and it was perhaps with this goal in mind that he wrote congratulatory and flattering addresses to political figures of the time, including the chief ministers Jiang Wanli, Zhang Jian, and Ma Tingluan. ${ }^{2}$ Jiang Wanli was the only prominent statesman with whom he had a relationship, who in 1273 reassured Wen of a potential role in the central government: "I am already old. Looking at the current climate and human affairs, there is certain to be an upheaval. I have observed many men in my time. As to the responsibilities [to ensure] human morals--much

1. The offices that Wen assumed in his career are compiled from SS 418 .

2. Wen also wrote to Wen Jiweng, Li Tingzhi, Chen Yizhong, among others. These letters are found in Wen Tianxiang, 5-8. 


\section{Chapter Four}

will depend on you. May you be encouraged."1

Unlike many of his contemporaries, there is little evidence that Wen directly opposed Jia Sidao and consequently suffered a setback in his official life. In 1271-73, much frustrated and disillusioned with his undistinguished political career, Wen retired to his native Luling and indulged himself and his many guests extravagantly in his newly constructed residence on Mount Wen. They organized poetry recitals and literary discussions, and drinking bouts attended by singing girls became daily routines. Wen was affluent enough to pursue such a life-style, and during this period of retirement his wife and at least two concubines gave birth to several children. Such a life in spite of the Mongol threat was typical of wealthy officials including Jia Sidao. Like other officials, only when news about the collapse of Xiangyang in 1273 became known did Wen reemerge from retirement. He was appointed judicial intendant of Hunan, and a year later he was put in charge of the administration of Ganzhou.

But it was with the promulgation of the qinwang edict after the fall of Ezhou in December 1274 that Wen's extravagant life-style abruptly ended. Overnight his essentially civilian career took on a military turn. He gave instructions to subordinates, friends, and relatives to recruit soldiers from Jizhou and Ganzhou (Jiangxi province). Included in this 10,000 strong force were Yao and She aboriginal peoples and Huai mercenaries. Just when he was about to set forth for the capital his grandmother died, but Wen obeyed the court's command to forego the mourning and resumed his public duties. Upon arrival in Hangzhou, he was put in charge of the capital. During 1275, Wen was appointed to secretary, then president, of the Ministry of War, as well as to other offices. This marked his first and only entry into central government politics before the Hangzhou collapse. He was offered, but did not accept, the post of commissioner of Military Affairs (1B) to negotiate with Bayan.

Throughout that year and into January 1276, Wen was again overly confident of his abilities and morals, envisioning himself as the savior of the Song imperial house. His speeches were self-assured, proud and intolerant of

1. SS 418.12534. 


\section{The Zhongyi Tradition}

those with whom he disagreed. Colleagues and veteran officials saw him as an upstart and a newcomer to be distrusted. Wen, in turn, antagonized them further by pointing out their faults. Wen's lack of political experience is seen in the naiveté with which he approached Bayan, the Mongol general responsible for Song's final subjugation. Bayan was about to occupy the Song capital with relative ease, but Wen insisted that the Mongol army retreat to the other side of the Yangzi River before negotiations for a peace settlement could commence! At this time Wen's view of loyalty was an all-consuming passion overriding family obligations and all other commitments. He was convinced that "since antiquity the primary concern [ought to be] fulfilling loyalty and not filial piety. ${ }^{1} \mathrm{He}$ did not hesitate to cut short the mourning period for his grandmother in order to devote himself to saving the Song state. In February 1275, he could not or would not attempt to understand Lü Wenhuan's anguish over surrendering to the Yuan forces; instead, he selfrighteously lashed out at Lü for protecting his wife and children instead of taking his own life. ${ }^{2}$

In the next three years of loyalist resistance, Wen did not emulate Yue Fei's limited loyalty, that is, render absolute loyalty to Gongdi and Empress Dowager Xie, the last sovereigns of the Song. His primary loyalty was to restore the Song dynasty and not to demonstrate simple allegiance to the present emperor alone. Therefore he did not see it as his sacred duty to accompany the imperial family to the Yuan capital; instead he escaped and repeatedly struggled to survive against great odds in the next few years. Apart from taking precedence over filial piety, Wen's loyalty was inspired and sustained by an ethnic consciousness. He saw the Mongols as alien intruders and "barbarian caitiffs" who violated his country: "The western barbarians [i.e., Mongols] have taken the Middle Kingdom / Humankind has been extin-

1. Wen Tianxiang, 15.4a-5a. The poem is entitled "Mourning Mother on the second anniversary of her death."

2. "Record of events, " in Wen Tianxiang, 13.9a. 


\section{Chapter Four}

guished." ${ }^{1}$ Wen was indeed commended by the Song court for "swearing an oath that he would not coexist with the barbarian caitiffs. "2

From the beginning of his active commitment to the Song defense in 1274 , Wen was aware that the mission was doomed to failure; however, he loudly declared to his Mongol captors that he had to make the efforts in the same way that a filial son would have wished to continue medication for ailing parents in the hope that they would recover. ${ }^{3} \mathrm{He}$ also knew that his course could only lead to death, but he intended to choose its time and place. Only when the slightest hope for a Song recovery was quashed would he resign himself to death to "requite the country." Though pursued by the Yuan forces, bandits, his loyalist colleague Li Tingzhi, and other hostile forces, he miraculously survived. Even when he attempted to take his own life, his decision sometimes faltered at the slightest glimmer of hope for escape and another chance for a more noble death. In January 1279, after capture by Zhang Hongfan he swallowed poison but did not die. He later regretted not taking the opportunity to kill himself in Guangzhou en route to Dadu because he thought he could escape. ${ }^{4} \mathrm{He}$ also planned to starve to death at his native place of Luling, but after passing through it and still not dying, he decided to postpone his death and resumed eating. ${ }^{5}$

For three years Wen was incarcerated in Dadu and subjected to much pressure to serve in the Yuan government; even his former sovereign Gongdi tried to persuade him to take up a post in the new dynasty. The Songshi records an episode which puts Wen in an accommodating light. After refusing another tempting offer to switch his loyalty to the Yuan, Wen made it known

1. Wen Tianxiang, 15.9b-10a. The poem is called "To the rhyme of Boyi and Shuqi's Song of the Western mountains." Another poem which expressed his antipathy toward the foreign nature of the Mongols is "On the road to Gaosha," in Wen Tianxiang, 15.2a-b.

2. Ibid., 17.14a.

3. Ibid., 17.35b.

4. Ibid., 17.39a-b, in a letter to his brother Bi.

5. "At Liujiang jun," in ibid., 14.8a. 


\section{The Zhongyi Tradition}

that if he were released from prison as a Daoist priest, he would be willing to serve as a consultant at a later time. ${ }^{1}$ Defendants of Wen's integrity vehemently denounce this account as a fabrication by the Songshi, meant to cast doubt on Wen's resolute spirit. However, I think the episode should not be so airily dismissed. It would have only been human for Wen to have experienced some misgivings during his long ordeal, when he felt guilty about neglecting his filial duties in the course of his single-minded devotion to the Song cause. He might well have made such a request in order to escape and revive loyalist resistance or to find a more noble way of death. At the same time, a defector from the loyalist camp, Wang Jiweng, and nine former Song officials who had entered Yuan service petitioned the throne to release Wen as a Daoist priest. ${ }^{2}$ The plan was supposedly foiled by the former Song chief minister Liu Mengyan, who feared that Wen would surely rekindle the resistance and thereby place them in an awkward and risky position with the Mongol court. ${ }^{3}$

If Wen had wished to delay his martyrdom in hopes for a later Song revival, his followers did not. At least two close friends and loyalists exhorted Wen to die as soon as possible to preserve an untarnished spirit for posterity. Wang Yanwu was Wen's landsman who had joined his qinwang campaigns in 1274 while a student of the National University. Having donated his family fortune to the Song cause, Wang had urged Wen to do the same in order to build up the army with Huai mercenaries. ${ }^{4}$ Shortly thereafter, Wang obtained permission to quit the resistance because his father had just died and his mother fallen ill. During Wen's captivity after January 1279, Wang wrote an essay to urge Wen to accept the finality of the loyalist defeat and to im-

\section{SS 418.12539 .}

2. For this account, see ibid.; Wen Tianxiang, 17.41a-b. For Wang Jiweng's biography, see YS 184.4229.

3. Deng Guangjian's account has Qingyang Mengyan rather than Liu Mengyan objecting to the petition. See Wen Tianxiang, 17.41b.

4. "Funerary address to Chief Minister Wen (before his actual death)," in Wang Yanwu, 4.1a-b. 


\section{Chapter Four}

mediately commit suicide to stop speculation and questioning about his loyalty. Wang then made numerous copies of the essay and with a friend posted them in conspicuous places between Ganzhou and Yanzhou, hoping that Wen on his journey to Dadu would see at least one copy and thereby hasten his decision to die. ${ }^{1}$

This essay, written in the form of an elegy to mourn Wen before his actual death, lists the reasons why Wen must as soon as possible take his own life. First, Wen's literary accomplishments had helped to maintain the status of Confucian scholars. Second, he had amply fulfilled filial piety towards both parents. Third, by ranking first in the jinshi examination at twenty years of age and by advancing to general and chief minister by the age of forty, Wen had put into practice what he studied. Fourth, he himself had stated that he was repeatedly close to death and expressed anxiety that if indeed he had died during any of those times, his virtue as a subject would not be glorious and untarnished. Wang argues that since Wen had already proven his loyalty in defending Fujian and Guangdong provinces, even if the attempted restoration failed in the end, his integrity was without doubt. What Wen now owed to the Song should be his own death:

Surely the chief minister [Wen] does not still wish to escape, or is your mind set at not yielding and your goal aimed at not dying? Or is it because the former ruler [Gongdi] is still alive and you cannot bear to let go of life? . . . . Men of distinction and mark know what to do at the right moment. If even with the strength of the entire southeast [the Song] could not prevent the fall of Xiangyang, now as one man in a defeated country [how could you] hope to resist the [Yuan] empire? Furthermore, the orphan of Zhao has leapt into the sea . . . Now the situation cannot be helped, and the country and ruler have both been seized. Regarding the duty of subject and son towards ruler and father, in approaching great virtue

1. Ibid., 4.2a-3a. 


\section{The Zhongyi Tradition}

and making a decision on a [national] calamity, if nothing can be done, then they should bend their purpose and endure a righteous death . . . Li Ling [d. 74 B. C.] capitulated but said: "If there is an opportunity I will then cut my own throat to show my [loyal] intentions." . . . Even if the chief minister is now not a Li Ling [i. e., defector or turncoat] . . . but as the days and months accumulate, your ambitions will dissipate and your spirit will rot, and then even if you had not been a [Li] Ling, you might turn out to be [like] him. Would that not be regretful? ${ }^{1}$

It is not known whether Wen actually read Wang's essay. But in Dadu while Wen awaited his fate in prison, Wang Yuanliang, the former Song court musician and poet who had accompanied the imperial family to the North, also advised Wen to die quickly and become a martyr to the cause:

\footnotetext{
From Yaishan you were captured and taken to Yan [Dadu];

Here the decision to embrace virtue and attain

righteousness is difficult.

Live, you will be shamed next to Boyi and Shuqi

for partaking of Zhou grain;

Die, you will emulate Zhang Xun [709-57] and Xu

Yuan [d. 757], the Tang officials.

The snow is leveled, the garrison blocked--where

will be the abode of your soul?

The full moon passing through the Heng mountain-the bones are not yet cold.

One strike of the sword is what you, sir, owe [to the Song];
}

1. Ibid., 4.3a-4a. On Li Ling, see Giles, no. 1171. After reading Wang's essay, the Yuan official and literary figure Jie Xisi (1274-1344) was convinced that Wen was of the same heart as Wang, and even if Wen's mind had not been set on dying, the essay would surely have moved him. See Cheng Minzheng, 1.2a-3a. 


\section{Chapter Four}

A pure page of history you must retain for posterity. ${ }^{1}$

More important than whether Wang Yanwu and Wang Yuanliang influenced Wen's determination to die is their motive for writing the elegies. They were concerned that Wen, the hero and justification for their loyalism, should not be blemished, but be a shining example to the movement they identified with. His martyrdom would thus lend dignity to the Song cause that they believed in. It was imperative that Wen become a martyr immediately because they were now resigned to the fate of total conquest and felt not the slightest hope for a Song restoration. Furthermore, in view of the defection of Wen's brother, genuine doubts may have been circulating at the time about whether Wen could maintain his loyalty to the end.

Wen in his conversations with Yuan authorities insisted on his desire not to serve two dynasties and not to waver from his determination to die. But from 1276 until his first two years of imprisonment in Dadu, Wen vacillated between hopes of escape and a wish for an early death; only by 1281 was he finally reconciled to the hopelessness of a Song revival. Incarcerated in a small, dark, damp room, he sustained his faith by writing about the personalities and events of the loyalist resistance. What in particular kept his spirit intact was a keen awareness of his historical role among the ranks of praiseworthy predecessors. In his immortal poem, "Zhengqi ge" (Song of the upright spirit), he avers that the upright spirit manifests itself in the cosmos as well as in human affairs. ${ }^{2}$ He lists twelve historical figures who had been his inspiration and guiding lights. Among them were the Grand Historian Qi and his three brothers who were executed because they had insisted on an accurate portrayal of a regicide; Su Wu (d. 60 B. C.) who did not capitulate after nineteen years of imprisonment even though his erstwhile friend, Li Ling,

1. Wang Yuanliang, Shuiyun ji, 35b-36a. This poem is entitled "Mourning Chief Minister Wen (before his actual death)." On Zhang Xun, see Giles, no. 63.

2. Wen Tianxiang, 14.39a-40a. For a translation of this poem and a brief description of these historical personages, see Carsun Chang, 348-53. Chang is mistaken on some points; e.g. on p. 35 he translates jian as a surname rather than "bamboo slips" and on p. 353 he transcribes Tsin as Qin. 


\section{The Zhongyi Tradition}

had defected; Yan Gaoqing (692-756) who berated the rebels to the Tang throne until his tongue was cut off; $\mathrm{Zu} \mathrm{Ti} \mathrm{(266-321),} \mathrm{who,} \mathrm{vowing} \mathrm{to} \mathrm{return}$ home, i.e. North China, launched a successful battle against the northern invaders; and Zhuge Liang (181-234), whose military campaigns symbolized the reunification of the country. ${ }^{1}$ Interestingly, Wen did not mention Song exemplars, not even Yue Fei, among his heroes.

In prison Wen also pondered his losses and sacrifices for the Song cause. He had used up his personal wealth and involved his entire family in his convictions and loyalist activities. During the war years he had lost his wife and two concubines, sons and daughters to either death, disappearance, or capture by the Yuan forces. His two brothers-in-law perished in battle after joining his armies, and he especially felt guilty towards his widowed sisters, who together with his wife and daughters were enslaved by the Yuan authorities. Left without a living son, Wen in 1280 adopted as his heir the son of his younger brother $\mathrm{Bi}$; like $\mathrm{Bi}$, this adopted son and his descendants later took office under the Yuan. Wen's guilt towards his family was poignant, and he wrote poems to express his distress and helplessness about their fate. ${ }^{2}$ Through such personal experience of guilt, Wen now understood the dilemma some of his friends and relatives had encountered and why they had capitulated and later served the Yuan. Certainly by 1280 his criticism of the defectors had toned down. While in prison he received several visitors, all of whom then had some direct contact with the Yuan administration. For instance, Deng Guangjian was in the service of Zhang Hongfan, Wen's captor and the general responsible for inflicting defeat on the loyalist forces at Yaishan. Jia Xuanweng was detained in Hejian and employed as an instructor. Wang Yuanliang was an official at Qubilai's court. Towards such men who found themselves in these compromising positions, Wen's affections did not change. He acknowledged that $\mathrm{Bi}$, for instance, had to look after family affairs and ensure a proper burial and mourning for their mother, who had died in 1278. In a poem about the meeting, Wen regrets that the two brothers

1. On Su Wu, Yan Gaoqing, Zu Ti, and Zhuge Liang, see Giles, nos. 1792, 2467, 2033, and 459.

2. Wen Tianxiang, 14.23a-24a. 


\section{Chapter Four}

were about to part forever but admits that alternatives existed for individuals, as in the case of the three virtuous ministers of the Shang who criticized King Zhou (r. 1050 B. C.) for his excesses. Later, Weizi served the conquerors and lived, Jizi pretended to be insane and survived, but Bigan resisted and was killed. The poem reads:

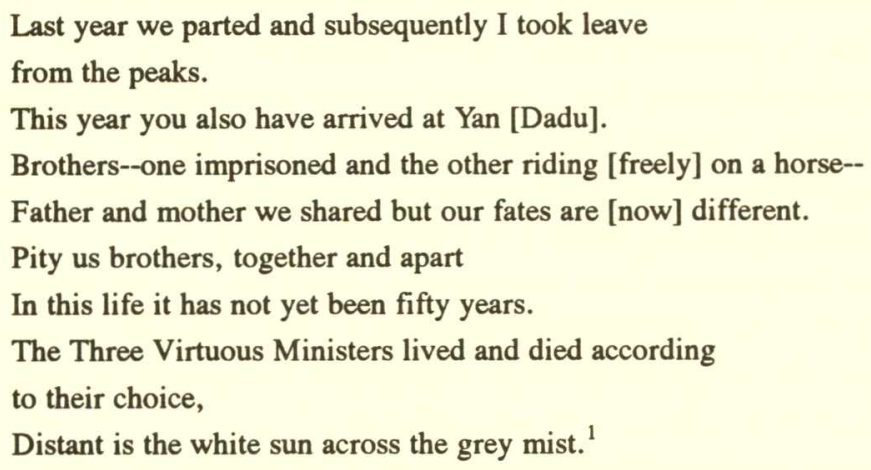

In sum, in the last three years of his life Wen's loyalism had become less self-righteous than before, harsh experience making him more realistic and pragmatic than disillusioned and frustrated. To former followers and subordinates who had deserted him, Wen's words were not bitter. But to those with whom he had no personal relationship and men he judged to be without morals such as Liu Mengyan, Wen remained critical.

Although he experienced some poignant doubts and could tolerate a less pure form of loyalty among his friends and acquaintances, Wen himself could not avoid death. In addition to his political loyalty to the Song dynasty, Wen felt other personal loyalties which would not permit him to have doubts cast on his integrity. Having always been convinced of the great impact his conduct would have on both the present and the future, death had to come sooner or later for the sake of maintaining glory for his family, his place of birth, and even for his fellow graduates from the civil service examinations. Two events finally alarmed Qubilai about keeping Wen alive. One was of an

1. "Upon hearing the arrival of $\mathrm{Bi}, "$ in ibid., 15.15a-b. 


\section{The Zhongyi Tradition}

astronomical nature: the conjunction of Saturn with the constellation of Hercules, interpreted by the Yuan court to be an inauspicious omen. The second was the revelation of a clandestine uprising that implicated Wen. ${ }^{1}$ Suspicious of subversion, Qubilai immediately transferred Gongdi to Shangdu and ordered Wen to be executed. Facing death in the market quarter of Dadu, Wen showed tranquility and relief that his long ordeal was about to end. In a selfevaluation, Wen expressed his satisfaction that he had fulfilled his life's purpose and attained the morality of the Confucian sages. ${ }^{2}$

When Wen died in early 1283, most of his subordinates and followers had predeceased him. While Wen was unpopular among the veteran court officials and other leaders of the resistance, paradoxically he had no trouble mobilizing support at the lower levels each time his forces were destroyed in battle. The first recruitment campaign took place in January 1273 in Ji and Gan prefectures where he was officially based; in the next few years he launched operations in Pingjiang, Nanjian, Tingzhou, and Chaozhou, all of which received local popular support.

Appendix D contains the names of forty-four personal supporters of Wen who died during their loyalist activities. ${ }^{3}$ Most of these men were from Wen's native province of Jiangxi, but others came from Anhui, Fujian, Zhejiang, Jiangxi, Hunan, and Guangdong. In most cases they were locally based people who, in 1275-79, responded to Wen's appeal to restore to Song loyalist control regions which had been captured by the Yuan forces. Almost twothirds had civilian careers or backgrounds before taking up arms, i.e., they had either passed their jinshi or district examinations or were Confucian scholars. Only one-third had purely military training or experience either as military officials or town ruffians who had earlier been engaged in physical combat. This proportion of civilian to military backgrounds is strikingly similar to the zhongyi loyalists with biographies in the Songshi, $63.6 \%$ as com-

1. SS 418.12539-40.

2. SS 418.12540. For a translation of this self-evaluation, see Carsun Chang, 347.

3. The source for this appendix is Deng Guangjian's Wen Chengxiang dufu zhongyi zhuan, in Wen Tianxiang, 19.41b-52b. 


\section{Chapter Four}

pared to $62.5 \%$. All had personal relationships with Wen and willingly acknowledged his leadership. One-half were "followers," or local men who recruited troops and voluntarily attached themselves to Wen's military headquarters, while another quarter were landsmen with whom he had been acquainted earlier. There were also poet friends and acquaintances from the 1250 s to the early 1270 s, fellow graduates of 1256 , a teacher, relatives and colleagues in the resistance efforts. Finally, as to the cause of death, twothirds were killed in battle, and the rest died by suicide or from illness and distress caused by the defeat. The fate of several men was unknown to Wen and the Songshi compilers, but they are presumed to have also perished soon after the defeat at Yaishan.

The structure of this network of relationships closely suggests the traditional mufu system (tent or military administration). ${ }^{1}$ The forty-four loyal martyrs were part of Wen's personal retinue, which consisted of his guests, friends, colleagues, classmates, fellow graduates, landsmen, and relatives-relationships which had a social or familial basis. It also consisted of a large number of local officials, scholars, and town ruffians who found it convenient and opportune to join his campaigns. Wen used some military experts as consultants in operations and sent others to various prefectures to recruit aboriginals, mercenaries, town ruffians, as well as tenants and slaves. Because Wen had an official appointment, first as military supervisor of Jiangxi and later as commissioner of Military Affairs, he also appointed his personal advisers and stalwarts to various offices. In his writings they are referred to by the titles which he had given them. ${ }^{2}$

All of these men were personally connected with Wen in one way or another; their loyalty was thus not merely directed to the Song state and emperor, but especially to Wen himself. The relationship was to an extent reciprocal: while Wen's followers remained loyal to him, he was fair, generous, and protective towards them. He did not criticize severely those who deserted him, but merely noted that such and such a person had fled and taken

1. For a broad historical outline of the traditional mufu system, see Kenneth E. Folsom, 139.

2. Wen Tianxiang, 16, et passim. 
some gold. ${ }^{1}$ Such an attitude might have been responsible for the personal devotion that Wen received from his supporters who obviously felt that they owed him something that they must repay. While in prison he paid final tribute to them by commemorating their loyalist deeds in his writings. ${ }^{2} \mathrm{Al}-$ though both Wen and his followers prescribed death as the ultimate end for Wen himself, he permitted other alternatives for his followers, such as resignation if they had certain obligations to meet. ${ }^{3}$ But Wen was a strict commander and demanded unyielding discipline from his men. In 1277, in order to restore order and set an example, he did not hesitate to court-martial two corrupt generals. ${ }^{4}$ His strictness with the unruly bandit Chen Yi may have caused the latter to turn against him and become informer to the Yuan general Zhang Hongfan who captured Wen. The sources indicate that Wen's men did not molest the local population but offered payment for food and supplies. It was partly due to such discipline that the local population supported Wen's resistance efforts.

\section{Li Tingzhi and His "Little Court"}

I have earlier argued that Li Tingzhi's role in Song defense and loyalist resistance was much more significant and crucial than previously acknowledged. Among the loyalist leaders Li actually had the most distinguished career and the longest experience in his dual roles as civilian and military official as well as central and local administrator. Li's family was

1. See, e.g., "Arrival at Yangzhou," in Wen Tianxiang, 13.37b-38a.

2. They appear mostly in the Ji Dushi (Wen Tianxiang, 16), which forms the basis for Deng Guangjian's Wen chengxiang dufu zhongyi zhuan.

3. For instance, Wang Yanwu was readily released of his political duties to look after his mother. See Wang Yanwu, 4.1a.

4. "At Meizhou," in Wen Tianxiang, 16.20b-21a. 


\section{Chapter Four}

based in Bianliang (Kaifeng) but had moved to Suizhou (Hubei). ${ }^{1}$ Both his literary talents and military skills were demonstrated early. In 1240 when the Yangzi fortifications were threatened, Li approached the much admired Song general Meng Gong (1195-1246) with his military proposals. ${ }^{2}$ Meng was immensely impressed and sent him to Sichuan, where in a subprefecture $\mathrm{Li}$ excelled in supervising agriculture and recruiting militia units. Several years later he sat for and passed the jinshi examination, whereupon he returned to Meng's service as an archivist and clerk. Meng was appreciative of Li's talents and just before he died, he made a special request to Jia Sidao to appoint $\mathrm{Li}$ as his successor. $\mathrm{Li}$, in turn, was devoted to Meng and spent the next three years mourning him.

Li subsequently became a close associate of Jia, who was then garrisoning the Jing-Hu region. After $\mathrm{Li}$ had completed his mourning period, Jia hired him as a consultant in the regulator's office. ${ }^{3} \mathrm{Li}$ was later transferred to the Huai region, where he had the opportunity to plan its defense and administration with Jia. Ten years later when Jia was promoted to pacifying commissioner of Jing- $\mathrm{Hu}, \mathrm{Li}$ was left to take charge of the Huai region including Yangzhou. After the Mongols retreated from Ezhou in 1259, Li resigned to mourn his mother who had just died but was summoned to return to office to assume Jia Sidao's former position, regulator of the Huai region where in 1260-61 he repelled Li Tan's incursions. He also brought about quick economic recovery in Yangzhou after a catastrophic fire and drought.

Li's administration of the Huai throughout the 1260s was considered benevolent and he therefore gained the confidence of scholars and talented people who flocked to his mufu. Himself a product of the mufu of Meng Gong, he now gathered around him a retinue of individuals whose skills he

1. Li Tingzhi's biography is in SS 421.12599-603. Unofficial biographies of $\mathrm{Li}$, such as that in Zhaozhong $l u$, are few and do not add to the SS account. The only modern study of $\mathrm{Li}$ is Li Qingyai's "Shu Li Tingzhi." It is highly laudatory in nature, solely based on traditional accounts, and does not provide additional information about $\mathrm{Li}$.

2. Meng Gong's biography is in SS 412.12369-80.

3. SS 421.12600 . 


\section{The Zhongyi Tradition}

fostered. Among his men with a background of civil service were Lu Xiufu, Hu Sanxing, Gong Kai, Yin Gu (d. 1274), and Zhong Jiyu (d. 1274); those with military training were Bian Juyi, Jiang Cai, Su Liuyi, and Ruan Kesi. ${ }^{1}$ Zhang Shijie had begun his career in the Huai, thus he most likely also had a personal relationship with Li Tingzhi. ${ }^{2}$ Lu, Gong, Bian, and Juan were Li's landsmen; Jiang Cai and Zhang Shijie were defectors from the North who had started their careers as obscure soldiers in the Huai army that Li controlled. All these individuals later distinguished themselves as loyalists; all except for Gong Kai and Hu Sanxing died as zhongyi martyrs to the loyalist cause. ${ }^{3}$ After Li's death in 1276, Lu Xiufu, Su Liuyi, and Zhang Shijie continued to play prominent roles in the loyalist resistance. With this large talented group, it was no wonder that Li's mufu was called a "little court." ${ }^{4}$ Apart from developing their special talents, $\mathrm{Li}$ recommended them to the Hangzhou court, as he did with Lu Xiufu, Su Liuyi, and most certainly Zhang Shijie. ${ }^{5}$ There can be little doubt that $\mathrm{Li}$ influenced his protégés and reinforced their commitment to the Song; his distrust of Wen Tianxiang in March 1276 must have also affected their attitude to Wen and accounted for Wen's sharp criticism of Li.

In $1269 \mathrm{Li}$ was ordered to relieve the siege of Xiangyang, but his efforts were gravely undermined by Fan Wenhu. Li thus shared the blame with Lü Wenhuan for its collapse and was demoted while his subordinates, includ-

1. For the connection with Li Tingzhi, see the biographies of Bian Juyi, Jiang Cai, Yin Gu, Lu Xiufu, and Zhong Jiyu (SS 450.13250, 450.13257, 451.13268, 451.13275, 454.13344). For the relationship to Gong Kai and Hu Sanxing, see Wan Sitong, Songji zhongyi lu, 15.1; Chen Yuan, Tongjian, 409-10.

2. Zhang Shijie and Su Liuyi could well have been acquainted through a mutual connection with Lü Wende in the 1260s.

3. Hu Sanxing and Gong Kai survived as yimin loyalists.

4. SS 451.13275. See also Gong Kai, 13b.

5. SS 451.13275 . 


\section{Chapter Four}

ing Su Liuyi, were banished. ${ }^{1}$ When Li was restored to his rank shortly thereafter, he persuaded the court to let Xia Gui, a veteran general, take charge of Huaixi while he concentrated on the defense of Huaidong. In 1275, after the fall of Ezhou, Li and his subordinates constantly mobilized men to strengthen Yangzhou's fortifications; even several months after the occupation of Hangzhou, they continued to resist the Mongol forces. By then the many years of warfare had taken their toll in Yangzhou: food supplies dwindled and many inhabitants drowned themselves in the river or starved on the roads. In spite of several edicts by the Song imperial family to surrender, $\mathrm{Li}$ did not relent but continued to resist the conquest with support from his dauntless and faithful generals, Miao Zaicheng (d. 1276) in Zhenzhou and Jiang Cai in Yangzhou. Unlike Yue Fei, who would have immediately laid down arms when requested by his sovereign, Li's loyalty was directed at the survival of the Song dynasty and thus he persisted in that goal to the end. Only in June 1276, after Li and Jiang Cai set out to join the loyalist court in Wenzhou, did Yangzhou surrender under its local administrator. Li's wife was taken hostage to persuade him to surrender. Unflinchingly, he tried unsuccessfully to drown himself; he was later captured at Taizhou and taken to Yangzhou when both he and Jiang were executed. ${ }^{2}$

The sources dealing with Li's relationship with the population of Yangzhou are contradictory. On the one hand, we are told that the people were grateful to him for restoring Yangzhou's economy in the 1260s and that after his death they wept profusely for him. ${ }^{3}$ On the other hand, the local administration which surrendered to the Mongols condemned Li for having put the city through many years of hardship. The surrendering official asked that $\mathrm{Li}$ be executed in revenge for having inflicted this calamity on the people. Thus the two groups responded differently to loyalist resistance, but both perceived $\mathrm{Li}$ as a central official who put state interests above local concerns. $\mathrm{Li}$ had an irascible temper, shown often when he killed emissaries who came

1. SS 421.12601 .

2. SS 421.12602 .

3. SS $421.12600,421.12602$. 
to persuade him to surrender. His general attitude towards his subordinates, however, was generous and apparently fair. To feed his soldiers adequately he exhausted the grain reserves of civilians, local officials, and officers, and perhaps thereby incurring their resentment. The soldiers, in return, fought bravely and stood by him. ${ }^{1}$

\section{Lu Xiufu and Zhang Shijie in the Refugee Court}

Of the talented men patronized by Li Tingzhi, Lu Xiufu achieved the greatest stature as a loyalist leader. ${ }^{2}$ A native of Zhenjiang, Lu was a fellow graduate of Wen Tianxiang in the 1256 jinshi examination, but the two did not meet again until 1275 in Hangzhou or 1276 in Foochow at Di Shi's enthronement. ${ }^{3}$ After attaining his jinshi degree Lu did not quickly become a distinguished civilian official, but later found himself in the personal retinue of Li Tingzhi. In about $1274 \mathrm{Lu}$ was recommended to and accepted by the central bureaucracy in Hangzhou. He soon advanced to a high position, and in 1275, as vice-president of the Ministry of Rites, his initial mission was to negotiate peace with the Mongols. ${ }^{4}$ A year later he escorted the two Song princes to the southeast and together with Zhang Shijie joined Chen Yizhong in Wenzhou. Lu was a placid man and got along with most loyalist leaders, even Wen Tianxiang. At first he had a working relationship with Chen Yizhong because the latter relied heavily on his military experience gained from his close contact with Li Tingzhi. ${ }^{5}$ However, in late 1276 the two quarreled and $\mathrm{Lu}$ was exiled to Chaozhou. As a result of Zhang Shijie's mediation, Lu was soon summoned back to the loyalist court.

\section{SS 421.12602 .}

2. Lu Xiufu's biography is in $S S 451.13275-77$. There are indications that it was based on a fuller biography by Lu's friend, Gong Kai; see Cheng Minzheng, 10.8b-12a.

3. The SS is mistaken in stating that Lu gained the jinshi degree in 1260. Lu's name appears in the Dengke $l u$ which contains the 1256 graduate list.

4. SS 451.13275 .

5. SS $451.13275-76$. 


\section{Chapter Four}

In spite of his military experience, Lu served only as a civilian official during the loyalist resistance. Throughout the three years he taught the two princes the Confucian classics and kept the court records and diaries. After Chen Yizhong's departure from the loyalist court, Lu was the key person in both financial and personnel administration, drafting edicts and official documents, while Zhang Shijie was in charge of military decisions and operations. After Di Shi died in April 1278, the entire loyalist court was about to disperse, but Lu rallied sufficient support to enthrone yet another successor, Di Bing. ${ }^{1}$ At the battle of Yaishan, when defeat was imminent, rather than subject the prince to capture and undignified incarceration, he first forced his own wife and children to jump into the ocean before himself leaping in with Di Bing. ${ }^{2}$ This was a bold move, as it could have been construed by future generations as an act of regicide. Lu's loyalty to the Song dynasty has not, however, been questioned because he made himself and his family martyrs to the Song cause. ${ }^{3}$

Of all the loyalist leaders, only Zhang Shijie had a purely military career; biographical details about him are also the sparsest. ${ }^{4} \mathrm{He}$ was a native of Fanyang, a clansman of the eminent general Zhang Rou who defected from the Jurchens to the Mongols. After committing a crime in North China, Zhang Shijie had defected to the Southern Song. Like Jiang Cai, another defector to the Song, Zhang was attached to the Huai army, then under the con-

\section{SS 451.13276 .}

2. Luo Xianglin doubts whether Di Bing had perished with Lu Xiufu. See his "Song wangtai," 140-41. Luo draws upon Zheng Sixiao's Xinshi for supporting evidence, yet in his $P u$ Shougeng zhuan he emphatically declares the Xinshi to be a Ming forgery (pp. 12, 3132). I think Gong Kai's information is accurate, because he obtained it through an eyewitness, albeit by way of several other informants. See also Huang Jin, 3.6a.

3. Lu's descendants survived through a son left behind in Chaozhou, where Lu was exiled for a brief period in 1276. See Jiang Yixue, 6-7.

4. Zhang's biography is in SS 451.13272; the fullest account of Zhang is in connection with the Yaishan defeat in Zhaozhong lu, 34-36. 
trol of Li Tingzhi. ${ }^{1}$ Zhang was already active in the late 1250 s, when his military prowess attracted the attention of the veteran general Lü Wende (d. 1269). Another loyalist figure, Su Liuyi, was then in Lü's service and likely made Zhang's acquaintance. Zhang also fought in Ezhou with Jia Sidao, and from 1268 to 1275 distinguished himself defending Song fortifications against Mongol advances. ${ }^{2}$

During the period of Song defense and loyalist resistance, Zhang felt that as a northerner he was discriminated against and suspected by Chen Yizhong. Chen was then commander-in-chief who took Zhang's personal troops from his command and assigned him to other units; in addition, Zhang, who was an expert in land warfare, was put in charge of the naval forces while Liu Shiyong, the naval expert, was given control of the army. ${ }^{3}$ It turned out, however, that the Huai soldiers who were dispatched to Foochow and Quanzhou continued to be loyal to Zhang. ${ }^{4}$

Just before Empress Dowager Xie surrendered Hangzhou, Zhang took some troops to join the two princes, passing Qingyuan on the way, where he failed to rally support for the loyalist resistance. Zhang's crucial role in recovering Fujian and Guangdong was commended by Wen Tianxiang. ${ }^{5}$ However, Zhang took the entire blame for conceiving and executing the strategy of Yaishan, which resulted in a colossal defeat for the loyalist fleet. Zhang escaped with a remnant force but was soon killed in a typhoon on his way to Champa where he had hoped to continue the resistance. ${ }^{6}$ Because of his val-

1. SS $451.13267-68,451.13272$.

2. SS 451.13272-73.

3. Songji sanchao 5.59; Bi Yuan, 181.4944.

4. SS 47.943 .

5. Wen Tianxiang, 16.11a-b.

6. SS 451.13274. However, Zhou Mi indicates that Zhang Shijie was killed by a subordinate, Zhou Wenying (fl. 1270-1290) who then surrendered to the Mongols. See Zhou Mi, Guixin $z a z h i, x u$ b.18b-20a. 


\section{Chapter Four}

iant military record and his death in pursuit of his goal, Zhang's martyrdom has also taken on heroic dimensions.

\section{Xie Fangde: A "Latent" Zhongyi Martyr}

Xie Fangde was a native of Xinzhou and a jinshi graduate of $1256 .{ }^{1}$ Considered together with Lu Xiufu and Wen Tianxiang as one of the most brilliant graduates, he did not develop a relationship with either Lu or Wen after gaining the degree. A short and ugly man, Xie's outstanding literary talents and his eloquent if blunt discourses on politics were well known to his contemporaries. ${ }^{2}$ He also acquired military skills from an early age. After several obscure and brief appointments, Xie returned to his native Xinzhou and nearby Fuzhou to persuade powerful gentry members to strengthen the local militia. In this endeavor he was later implicated in Jia Sidao's auditing regulations in the early 1260 s; he fell into disgrace and ended up repaying the expenses rejected by the auditing teams. Xie also criticized Jia Sidao's land reform scheme, an act for which he was further demoted.

Xie's next appearance on the political scene was in 1274 when, because of his close friendship with Lü Shikui (nephew of Lü Wenhuan, a defector to the Mongols), he convinced the Hangzhou court of Lü Shikui's loyalty to the Song. Xie also volunteered to persuade Lü Wenhuan to return to the Song, the court having agreed to absolve the latter of the crime of surrendering Xiangyang. To carry out his mission as an official of the Song court, Xie was appointed supervisor of Jiangzhou and later pacifying commissioner of Jiangxi, in charge of Xinzhou. ${ }^{3}$ When Lü Shikui defected to the Mongols and Xie did not even meet with Lü Wenhuan, Xie was embarrassed but not penalized by the Song court. He continued to supervise military defenses in Anren and Xinzhou against Lü Shikui and the Yuan army. The defenses of

1. Xie's biography (SS 525.12687-90) seems to have been based on the earliest (ca. 1289) account of him in the Zhaozhong lu, 36-39. In 1318 Xie's son also obtained a biography of Xie by Li Daoyuan.

2. Zhaozhong lu, 36 .

3. SS 425.12688. 
Xinzhou collapsed shortly before the capitulation of Hangzhou, whereupon Xie went into hiding. ${ }^{1}$ When he heard about the enthronement of Di Shi, he reemerged and was appointed regulator of Jiangdong, relying on the militia units he had earlier built up in his native subprefecture, Yiyang. ${ }^{2}$ By August 1276 most of his units had disbanded; after handing over the remnants to another loyalist general, Xie fled to the Jiangxi and Fujian border with his aged mother. There, he changed his name and lived in dilapidated hostels; wearing hempen clothes and straw sandals, he wailed uncontrollably in public --so strange a sight that passersby regarded him as mad. ${ }^{3}$ His wife, two sons, a daughter, a nephew, an uncle, and maids were soon captured and all except for his sons were killed or committed suicide because of their uncompromising attitudes towards their captors. ${ }^{4}$ The sons were compelled to serve as family tutors to Yuan officials and were released after six years. After having located their father, the elder son looked after the grandmother while the younger son stayed with Xie and sold shoes for a living.

From 1276 to 1289 Xie spent his life in Jianyang (Fujian province) as a fortuneteller, scholar, and teacher. In fact, it was not a drastic change in his life from scholar-official to recluse, for despite a political career lasting twenty-one years, he was actually in office for less than eight months. ${ }^{5}$ During

\section{Ibid.}

2. There is some confusion as to whether Xie fled from the Song battles, either just before Hangzhou surrendered or in mid-1276 after he had joined the loyalist resistance. I think the latter is correct: Xie later wrote that he did not obey Empress Dowager Xie and surrender in February 1276 after the capitulation of the Song imperial family because he saw it as his duty to continue to defend the country whereas Empress Dowager Xie saw it as her obligation to save lives by requesting her subjects to surrender. See Xie Fangde, Dieshan ji, 4.10b (letter to Liu Mengyan). Only sixteen out of sixty-four original juan of Xie's collected writings survive. There has also been doubt as to whether all of the surviving sixteen juan were in fact Xie's own writings. See Zhang Xincheng, 1161.

3. SS 425.12688 .

4. Zhaozhong lu, 37; SS 425.12690.

5. Xie Fangde, Dieshan ji, $4.1 \mathrm{~b}$, in a letter to Cheng Jufu declining appointment to office. 


\section{Chapter Four}

this period, his primary concern was to look after his mother, and because he made only a meager living by telling fortunes he gratefully accepted gifts of food, clothing, brushes, and paper. ${ }^{1}$ He maintained close contact with loyalist friends in Jianyang, such as Xiong He (1253-1312), a former Song official who repeatedly refused Yuan employment. ${ }^{2}$ Xie, however, associated himself mostly with other fortunetellers, medical healers, and Daoist priests; he later taught many students. In order to console himself over the demise of the Song and to develop his talents, Xie became a literary critic, educator, poet, and annotator of the Confucian classics and other literary writings. ${ }^{3}$ His grief over the dynasty's collapse is poignantly recorded in his annotations on the Shijing (Book of poetry), in which he described the fall of the Eastern Zhou (771-221 B.C.) as the enormous shame of the Middle Kingdom and likened it to the present plight. In this work he also commented on the concepts and practice of loyalty, filial piety, and antiforeign sentiment. ${ }^{4}$

After living for ten years under the new dynasty, Xie became increasingly sensitive to the abuses of officials and administrators, many of whom were northerners, and personally championed the plight of the former Song scholar-officials whose economic and social status had sharply declined. He wrote that nine out of ten Confucian scholars had escaped into occupations such as Buddhist monks, Daoist priests, medical healers, and carpenters because the salary of a scholar-official was not adequate to keep him from hun-

1. Xie's collected writings, Dieshan ji, contain many poems and essays thanking his benefactors for their generous donations. See especially juan 3.

2. Xiong He's "Reply to a suggestion to quit drinking," in his Xiong Wuxuan xiansheng wenji, 5.63-64, compares his refusal of Yuan employment to someone who would not give up drinking to serve an enlightened ruler.

3. Other extant writings by Xie are mostly annotations and commentaries: on Tang and Song prose, see his Wenzhang guifan; on Tang regulated poetry, see his Xie Dieshan Tangshi jueju zhujie; on miscellaneous notes about poets, see Bihu zaji.

4. See, in particular, his comments on the "Shuli" and "Yuanyou tao" poems in Shijing, in his Shi Zhuan zhushu, a.8a-9a and a.18a-19a. 
ger and cold. ${ }^{1}$ He sighed that scholars were ridiculed for their lowly socioeconomic status, being in the ninth category, one rank above beggars and one below prostitutes. ${ }^{2}$ Although this has been proven by several modern scholars to be an unsubstantiated statement, the decline in the scholarly profession's prestige and privilege was there for all to see. Xie wholeheartedly supported his friend's decision to become a recluse in order to "transcend the ten [social] classes. ${ }^{3}$ Xie associated himself with a wider circle of acquaintances that also included Yuan officials. In 1286 he bade farewell to the local subprefect, a northerner from a military family, and commended him for his three years of benevolent administration. He strongly approved his plan to go to Dadu to seek a better post and asked him to convey his regards to his former friends Liu Mengyan, Lü Shikui, Jia Xuanweng, and Qingyang Mengyan (fl. 1270-90) who were then serving in the Yuan government. ${ }^{4} \mathrm{Xie}$ also wrote to Yuan officials to recommend a great-grandson of $\mathrm{Zhu} \mathrm{Xi}$ for an appointment as director of a local school. ${ }^{5}$ Xie already knew the official, for whose father he had written a funerary inscription. ${ }^{6}$ These contacts with the Yuan government indicate that, contrary to popular tradition, Xie Fangde's loyalism was not absolute to the point of total isolation from the new government.

Such a life was typical of a yimin loyalist living under the Mongols but still feeling loyal to the former Song dynasty. Although Xie dealt with Yuan officials and approved of his sons and friends serving the new govern-

1. "Preface to bidding farewell to Fang Bozai who is returning to Sanshan," in Xie Fangde, Dieshan ji, 6.4a.

2. Ibid., 6.3b. Cf. Zheng Sixiao, Xinshi, 129.

3. Xie Fangde, Dieshan ji, 6.4b-5a.

4. "Preface to sending off Subprefect Shi to the capital," in ibid., 6.2b.

5. "Letter to Administrator Mu of Jianning recommending School Director Zhu, " in ibid., 5.3a-4a.

6. "Funerary inscription for Mr. Mu," in ibid., 8.1a-4b. 


\section{Chapter Four}

ment, his loyalty to the Song did not permit him to take up an appointment. $\mathrm{He}$ felt strongly about the Mongols being foreigners, and often expressed in his writings his resentment that since the "Middle Kingdom was established by the Five Emperors and Three Kings," there had never been a case of total subjugation of the dynasty under alien rule until the Mongol conquest. ${ }^{1}$ As a subject of the former dynasty, he believed it was improper to serve the new conquerors. He considered that his duty should have been to die or commit suicide in order to requite the Song, but filial obligations to his aged mother took precedence over loyalty. His sense of filial commitment was so extreme that he felt he was not released from it until the mourning period for his mother was over and some means were found to bury her properly. She died in 1286. Immediately after that came the first of at least five attempts to recruit him for service in the Yuan government, most probably because of his reputation as a scholar and fortuneteller.

Cheng Jufu (1249-1318) was the Yuan official involved with the 1286-87 mission to recruit southern Chinese. ${ }^{2}$ Cheng was himself a southern scholar who had been taken as a hostage to the Yuan capital when his uncle surrendered to the Mongols. Xie did not reproach him for serving the new government but begged him to understand his own reasons for refusing employment. ${ }^{3} \mathrm{He}$ would be opposing Heaven and Earth to accept an appointment while in mourning; moreover, as a subject who had lost his country, he should not even continue to live. Xie further asserted that the Song had collapsed because filial piety was not fostered by the state after 1274. Ministers such as Jia Sidao, Wen Tianxiang, Chen Yizhong, and Liu Fu were not permitted to complete their mourning periods but were recalled to service. In Xie's view, this moral decay had hastened the Song demise and therefore the Yuan should take this neglect of filial obligations as a lesson to avoid its own

1. "Preface to sending off Huang Liuyou who is returning to Sanshan," in ibid., 6.6a-b.

2. Cheng Jufu's biography is in YS 171.4015-18. On the 1286-87 mission to recruit talented men from south China, see Yao Congwu, "Cheng Jufu yu Hubilie;" Sun Kekuan, "Jiangnan fangxian yu Yanyou ruzhi," in his Menggu hanjun, 345-63; Yuan Ji, 41-57.

3. Xie Fangde, Dieshan ji, 4.2a-3b. 


\section{The Zhongyi Tradition}

collapse.

Later, after his former teacher Liu Mengyan recommended him to office, Xie was incensed and sarcastic. In the letter rejecting Liu's offer, Xie launched a caustic attack on Liu's service to the Yuan despite the high offices he had attained under the Song:

The fact that there are no talented men in Jiangnan [South China] has never been as shameful as today . . . . You, sir, were a top graduate in your youth; in late life you became chief minister. In merits, titles, wealth, and prestige--it can be said that your ambitions have been fulfilled. You then galloped four thousand li to Dadu to pay respects to the Great Yuan--could it be because you wanted to inquire about the [Song] emperor and empress dowagers, and let the world and posterity know that the righteousness between ruler and minister could not be deserted ... Recently . . . the provincial government of Jiang-Huai brought down an imperial order to the South to seek good men . . . . Once this order was proclaimed, everyone laughed. Why? It is because there have not been good men, proper men, in Jiangnan for a long time. Those who say that [i.e., you] are all deceiving [the Yuan] ... The reasons why I absolutely cannot serve are threefold. First, my old mother died at ninety-three and is still buried in shallow soil . . . My wife, daughter, and maids died in prison because of their relationship to me . . . and five [other] persons, my nephews and younger brothers, who died for the country--their spirits cannot be found and their wandering souls cannot be summoned. . . The second reason is . . . in 1276 after I was relieved of military command, abandoned my office and fled afar, I did not surrender . . . . Even if Boyi and Shuqi did not serve the Zhou dynasty and ate moss at the Western mountains, they must have also known about the grace of King Wu [of the Zhou who conquered the 


\section{Chapter Four}

Shang]. ... [The third reason why I reject your recommendation is] because the grace I have received from the late [Song] empress dowager had indeed been great . . . 1

In 1288 the local administrator, Wei Tianyou (fl. 1280-1300), wanted to collect a reward for recruiting Xie and thus escorted the latter under heavy guard to the Yuan capital. Xie escaped once but after recapture, realized that he could not in the end avoid forced employment with the Yuan and thus made his final decision to die and leave his loyalty intact. ${ }^{2}$ The historical precedent he used to justify his delayed martyrdom was Gong Sheng (68-11 B.C.), who starved to death fourteen years after Wang Mang's (45 B.C.A.D. 23) usurpation. ${ }^{3}$ Boyi and Shuqi also died some years after the Shang had collapsed; thus they too became his models for not immediately committing suicide. On his journey to the Yuan capital, Xie's students urged him to take the final step to ensure an untainted reputation in history. One such poem reads:

Thirty years of persistence to perfect your conduct,

Now comes the test to truly show a Confucian immortal.

All others have bent their knees and compromised themselves,

Only you sir, loudly reviled [the captors] directly [to their face].

In this journey, be sure to use your three-inch tongue,

If you return [alive] you will not be worth one cash.

To the end your purity is left intact

And a fragrant name is retained for transmission to posterity. ${ }^{4}$

1. Ibid., 4.5b, 4.6a, 4.9a-11a.

2. Ibid., 4.11b-14a. Xie also wrote to Wei Tianyou stating his case for refusing an appointment to office.

3. Account of conduct written by his student Hu Yigui, in ibid., 16.7a.

4. Ibid., 2.7b. This was written by his student Zhang Zihui. 
By that time Xie too saw no alternative to death. He eloquently declared his reason for dying: "I only wish to die quickly and leave a name . . . in history, so that I can shame the disloyal subjects of the empire in ten thousand generations." ${ }^{1}$ Upon arrival in Dadu, Xie prostrated and mourned Empress Dowager Xie; soon after he refused all food and died from starvation. ${ }^{2}$ For Xie, death occurred thirteen years after the capitulation of Hangzhou, and thus he could be called a "latent" zhongyi loyalist. Because of this delay in martyrdom, Xie was able to feel no guilt about abandoning filial obligations. He angrily lambasted those who would not leave him alone and who insisted on recommending him to office:

\begin{abstract}
Let me query you several sirs--to allow one Xie to be a lazy man of the Great Yuan--what harm will it do to the government and the way of the Great Yuan? To kill one Xie to fulfil his martyrdom to the Great Song--what benefit will it reap for the government and the way of the Great Yuan? ${ }^{3}$
\end{abstract}

The Women Zhongyi Loyalists

Throughout the accounts and biographies of the Song loyal martyrs, we find numerous cases of whole families dying together for the Song cause. While the male relatives of the family often have separate or attached biographies, the women are mentioned only in passing. ${ }^{4}$ In the Songshi six of these women are given biographies in the lienü zhuan (group biographies of virtu-

1. Ibid., 4.13a.

2. SS 425.12690; Zhaozhong lu, 39 .

3. Xie Fangde, Dieshan ji, 4.12b.

4. On hagiographies of virtuous women in Chinese history, see Jennifer Holmgren and Xu Bingyu. 


\section{Chapter Four}

ous women) to commend them for their virtuous conduct in regard to chastity, filial piety to the in-laws and loyalty to the state. ${ }^{1}$ All but one were wives (the exception being a concubine) who refused to cooperate with the Yuan administration and died as a result. Their behavior included being filial to inlaws and faithful to husbands, sacrificing their lives to help their husbands escape death, refusing to have sexual relations with their captors, scolding them, and dying or committing suicide. In other sources, daughters followed their fathers to death, as in the case of the university student Xu Yingbiao; mothers also chose to die with their sons, as in the case of the loyalist leader Chen Wenlong. ${ }^{2}$ There were also former palace women who did not submit to the Mongol captors, the reason being that they had already been favored by the former Song emperors or princes. These women were loyal not because of some commitment to the Song cause but because of chastity and filial piety. Loyalists such as Wen Tianxiang and Zhao Maofa were the first to praise their wives for accompanying them in their loyalist mission and for not hesitating to die. ${ }^{3}$ The foremost concern of these women was not loyalty to the state, but fulfilling their roles as expected by their husbands and fathers. Their death or suicide can thus be observed as complementary acts to the loyalty of their husbands, as conveyed in the traditional dictum: "The loyal subject does not serve two rulers; the virtuous woman does not marry two husbands. "4

Other sources, however, portray some women as being directly and independently loyal to the Song. In one case a She woman, Xu Furen (Lady

1. These biographies are in SS 460.13489-93.

2. On Xu Yingbiao, see Chapter 2; on Chen Wenlong's mother, see SS 451.13280-81.

3. "Mourning my wife," in Wen Tianxiang, 15.5a; SS 450.13259.

4. Sima Qian, 82.2457. Tao Zongyi's Nancun zhuogeng lu, 3.38-40, praises the chaste and heroic women active at the end of the Song. 
$\mathrm{Xu}$, fl. 1270-85), led a force to fight against the Mongols. ${ }^{1}$ One imperial concubine hanged herself rather than consent to have sexual relations with her Mongol captors, after declaring her personal commitment to the Song dynasty: "If the country cannot escape from contamination / I can fortunately still avoid tainting my body / Having received the benefits of the Song / I will be ashamed to be a subject of the northern [barbarians]." ${ }^{2}$ In the writings of contemporary literati, singing girls and prostitutes angrily repelled the advances of the Mongol generals and soldiers because they did not wish to be "defiled by barbarian blood." After affirming their loyalty to the Song they committed suicide. ${ }^{3}$

Loyal martyrs of both sexes expressed their ultimate loyalty by death after berating the enemy and leaving self-righteous testimonies to their loyalty. For the men in general, loyal conduct was defined as direct commitment to the dynasty, but for the women, involvement in the loyalist resistance was mostly indirect but also voluntary. Except for a few like Xie Fangde, they lived and conducted themselves as if they were still under the Song and had no contact with the new order. But in all cases death was the final proof of their virtue and the vindication of any doubts about their behavior. Compared with the zhongyi men, a larger proportion of the women committed suicide. Involuntary death and suicide were both salient aspects of the zhongyi tradition of loyalists, and both manners of death were considered equally lofty and noble. Suicide certainly had no stigma of cowardice and mental illness. The long tradition of suicide as protest against current politics and wrongful judgment, as well as of a statement of one's noble intentions may be traced to the pre-Shang period, and certainly the Zhou. Qu Yuan's (343-277 B.C.) suicide drew the most attention and myth from history as a dignified form of

1. Lady Xu is mentioned with Chen Diaoyan in Zhang Shijie's biography in SS 451.13272. See also YS 10.206. She appears to have married Zhou Wenying, whom Zhou Mi believed to have killed Zhang Shijie. See Zhou Mi, Guixin zazhi, xu b.20a-b.

2. Zhao Jingliang, 5.17a; Wang Feng, 1.21a-22a.

3. For example, see Xu Dazhuo, b.20a-b. 


\section{Chapter Four}

political and personal protest. ${ }^{1}$ However, throughout various periods, his plunge into the river, while greatly praised, has been considered excessive. Even Southern Song moralists such as Zhu Xi believed that a better alternative for Qu Yuan might have been passive protest or withdrawal from society and politics. ${ }^{2}$ During the Song resistance, there were some to whom the idea of suicide was not acceptable due to other commitments. Xie Fangde's latent martyrdom has been discussed in this connection; the alternative, the yimin tradition of loyalists, is the focus of the next chapter.

\section{The Reluctant Defectors and Collaborators: Antithesis of Loyalism?}

Traditional and secondary sources share a strong tendency to treat loyalists and defectors as polar opposites. A crucial point that has long been ignored is that both groups had similar experiences in defending the Song during its last years and in loyalist resistance. Some defectors, like loyalists, lost personal fortunes, families and friends in the course of their initial loyalty to the Song. It was accepting neither involuntary death nor suicide as the ultimate solution that divided the defectors and collaborators from the loyalists. What sustained most loyalists was their personal attachment to their leaders, while the latter looked forward to posthumous fame. Defectors and collaborators, by way of contrast, have been seen as pure opportunists without morals, who went over to the winning side to reap the most benefits. Thus in traditional accounts of the final years of Song, they are depicted as defecting as easily as "the wind sways trees." A list appended to the Songji zhongyi lu shows that 124 men defected in 1234-79; a modern study indicates 141 men defected in 1238-79. ${ }^{3}$ Both lists have been compiled from official

1. On Qu Yuan, see Giles, no. 503. His biography is in Sima Qian, 84.2481-91. A translation and commentary can be found in David Hawkes, 11-19. Lawrence A. Schneider's study of $\mathrm{Qu}$ Yuan focuses on the mythical lore surrounding him.

2. Sima Qian and Jia Yi (201-169 B.C.) felt that Qu Yuan could have served another state or withdrawn temporarily until the times were more ideal. See Schneider, 21-24. On Zhu Xi's views, see ibid., 76.

3. These two lists are found in Wan Sitong, Songji zhongyi lu, appendix.12-19; Li Zefen, vol. 3, 150-59. Li includes even the Song sovereign, Gongdi, as a defector. 
sources, among them the Songshi and the Yuanshi. It seems that even these are not comprehensive lists. The defectors listed include military and civilian officials, although the former group far outnumbered the latter.

One reason for the large number of defections and surrenders was the Yuan policy of conciliation, which reinstated to high positions those who capitulated, but wiped out entire cities if they put up prolonged resistance. Faced with these clear-cut alternatives, the opportunists easily made their choice, and many even welcomed the arrival of the Mongols with offers of capitulation many miles from their defense posts. These men, pursuing selfish goals and personal gains, subsequently applied their military skills on the Mongol side in order to gain trust and further promotions in the Yuan government. A conversation Qubilai had with these collaborators indicates that many of them were indeed pure opportunists. When queried as to why they had gone over so readily, they replied that it was because Jia Sidao had discriminated against them and favored bureaucrats. Qubilai retorted: "Supposing that if [Jia] Sidao had really discriminated against you, that was only the fault of Sidao; furthermore, wherein did your ruler let you down? If it was really as you said, then Sidao's discrimination was most appropriate." ${ }^{1}$

However, sources on these defectors and collaborators are inadequate to show the individual circumstances of each defection and the dilemma faced by the defector. None has been accorded a biography in the Songshi, not even in the sections reserved for treacherous officials and renegades. In the Yuanshi only several defectors who rose to high ranks in the Yuan have been given biographies. ${ }^{2}$ However, in some cases, there is ample evidence that pure opportunism was not the primary motive for surrender. The circumstances of the surrender indicate that the differences between the loyal and the disloyal were not as distinct as previously believed. Take Lü Wenhuan as an example. His family had been involved in defending the Song against the Yuan for over twenty years. He was personally responsible for the defense of Xiangyang for six years and had no intention of capitulating until the very

1. YS 9.180 .

2. For example, these were Liu Zheng, Gao Xing (d. 1313), Zhou Quan (d. 1305), and Luo Bi (d. 1299). 


\section{Chapter Four}

bitter end. By 1273, his campaigns had exhausted food and military supplies, many people were dying on the roads, and the remaining population resorted to cannibalism to order to survive. Lü was well aware that by then there was not the slightest hope for victory, and it was clear that everybody would suffer the consequences of continued fighting. For him, surrender was not a private affair, but a decision that had an enormous impact on the people. Not only would his wife and children be spared atrocious deaths, the entire population of Xiangyang would survive. Having made the agonizing decision to surrender, Lü went into the city and wailed, not satisfied with his decision but faced with no other alternative. His heart remained heavy even when engaged in Mongol campaigns to conquer the Song. In 1276 when the "mercybegging" officials on their journey to the Yuan capital attempted to curry favor with the Mongols by undignified conduct and criticism of contemporary Song officials, Lü reviled their fickleness and immorality. ${ }^{1}$ After defecting, Lü's participation in the Song conquest was possibly affected by his son being held hostage in Dadu, a common Mongol practice to ensure the loyalty of their generals. It was perhaps partly this pressure that caused him to attract other members of his family to defect, including his nephew Lü Shikui, cousin Wenfu, and son-in-law Fan Wenhu. Yet, despite Lü Wenhuan's important role in the conquest of the Song, he does not have a biography in the Yuanshi.

In other cases, many military and civilian officials surrendered only after Empress Dowager Xie had capitulated in Hangzhou. She had issued edicts ordering the Song territories to submit to the Mongol army, thus it could be said that Xia Gui and Fang Hui surrendered in compliance with her orders. Xia had been a loyal general with decades of military service to the Song; he was then already seventy-nine and his son had perished while defending the Song in $1275 .^{2}$ As for Fang Hui, what was unforgivable in the minds of his contemporaries was the fact that he wrote flattering prefaces to official Yuan works praising the conquerors. Fang, however, never re-

1. "The Liuyuan pavilion," in Wen Tianxiang, 13.16a.

2. On Xia Gui's son who was awarded posthumous honors for bravery, see Wang Yinglin, Siming wenxian ji, 5.36a-b. 
nounced his loyalty to the Song; he justified his surrender by arguing that as the Song had already perished, it would have been futile to hold onto a small command. He insisted that his surrender had saved thousands of civilian lives. ${ }^{1}$ Some of Fang Hui's poems expressed feelings so closely akin to those of loyalists that one was included in an anthology of loyalist writings in the Yuan. $^{2}$

Wen Tianxiang's younger brother, Bi, was another reluctant defector. He had followed Wen to resist the Mongol forces, but while Wen had been completely preoccupied with the resistance movement, Bi had been left in charge of the family which included their mother, Wen's wife, concubines, and children. ${ }^{3}$ In 1275 when the grandmother died, it was Bi who transported the coffin back to Luling, their native county. Later, Bi was appointed administrator of Huizhou and again took the whole family with him. When their mother died in 1278, Bi arranged for a temporary burial before returning to his political duties. Only after Wen was captured and Yaishan fell did Bi finally surrender to the Yuan administration, his primary motive for staying alive being to carry out his responsibilities to the surviving family members and to attend to ancestral rites. ${ }^{4}$ Like Lü Wenhuan, he surrendered for reasons other than sheer opportunism.

After surrendering and holding office in Dadu, many defectors did not forget their former compatriots. Thus Wang Jiweng petitioned to have Wen Tianxiang released from prison as a Daoist priest, and Lü Shikui sought to care for Xie Fangde's daily needs, which Xie rejected. ${ }^{5}$ Others, like Liu

1. For an example of Fang Hui's flattering address to the Yuan, see Liu Minzhong, preface.2a-3a. For Fang's justification for his defection, see "Bidding farewell to my son Cunxin to Yan, " in Fang Hui, Tongjiang xuji, 25.21a.

2. See Zhao Jingliang, 6.4a. This is a mourning poem to Lü Wenhuan ridiculing the latter's surrender to the Mongols.

3. From Wen Bi's funerary account of their mother, in Wen Tianxiang, 18.2b.

4. Ibid., 18.3a.

5. On Lü Shikui's attitude toward Xie Fangde, see Zhaozhong lu, 39. 


\section{Chapter Four}

Mengyan recommended some loyalists, their children and pupils to office, no doubt thinking that they were doing a favor for their former friends, whose friendship they still valued and whose understanding they desperately sought. ${ }^{1}$

1. There exist studies of defectors in other historical periods. On defections to the Mongols during the Jin collapse, Igor de Rachewiltz shows that, besides pure opportunism, defectors were motivated by a desire to save as many lives as possible. See his "Personnel, " 106-07. On the circumstances under which a loyal general turned traitor in the Tang, see Charles A. Peterson, "P'u-ku Huai-en." The sometimes subtle differences and narrow borderline between a loyal and disloyal subject in the modern context are discussed by Morton Grodzins. 


\section{FIVE / REGIONAL LOYALIST CENTERS AND PERSONALITIES, CA. 1276-1300}

The Song loyalists of the zhongyi tradition were killed or committed suicide, and generally had little experience with foreign rule because death occurred immediately or shortly after the collapse of the dynasty. This tradition of loyalists is regarded as the more praiseworthy type by the Songshi preface to the zhongyi biographies. ${ }^{1}$ The loyalists who survived and withdrew from society under Mongol rule are mentioned, but a few of them were given biographies in the Songshi. In fact, there were large numbers of survivors, some of whom were active loyalists and others were passive sympathizers of the loyalist cause. Because these men were largely ignored in the standard historical sources, subsequent nonofficial writings and anthologies on the loyalists were primarily interested in amending this omission. The Qing historian Quan Zuwang argued at length for standard histories to include loyalist survivors in the zhongyi biographies. ${ }^{2}$

These loyal survivors are referred to as yimin, literally, surviving or remnant people. The term first occurred in the Zuozhuan and in Mencius' allusion to a poem in the Shijing and had originally been applied in a general sense to people surviving a dynasty after a national catastrophe. ${ }^{3}$ Only much later did yimin specifically refer to those individuals, mostly former officials, who refused a political career under the succeeding dynasty. In their writings

1. SS 446.13150 .

2. Quan Zuwang, waibian 42.1299-1301.

3. Mencius, Wanzhang chapter, in Legge, vol. 2, 353. 


\section{Chapter Five}

the Song loyalists used both connotations of the term. ${ }^{1}$ It was in the Ming and Qing that the more specific meaning took precedence over the original and more general one. The yimin have not been treated as a group in standard histories. Many of them withdrew from public office into mountain or forest retreats, and were included with the yimin as yinyi (recluses), while others were accomplished scholars and were given biographies in the rulin (eminent Confucian scholars) or wenyuan (literati) biographies. In cases where a certain individual was a recluse, Confucian scholar, and loyalist, his inclusion in any one of these biographies was arbitrary.

That loyalty need not be manifested by immediate death was justified in the minds of the yimin loyalists by numerous historical precedents. Boyi and Shuqi were both yimin (remnant subjects) and yinyi (recluses) because they lived in virtual seclusion to protest against the Zhou conquest in $1050 \mathrm{~B}$. C. An example closer in time was Tao Qian (372-427), who survived the Eastern Tsin (317-420) as a rustic and loyalist until he died a natural death. ${ }^{2}$ Tao's sentiments and creative genius served as a model for the Song loyalists. Apart from not taking office, Tao's protest against the new political order was symbolized by his refusal to use the new dynasty's reign titles. The yimin loyalists regarded Tao's poverty, transcendence, and utopian ideals as a source of spiritual consolation and a guide for survival under the new government. Thus active defense and death for the sake of the country were not the only ways to demonstrate loyalty to the dynasty; for scholar-officials and literati of the former order, who were essentially Confucian in orientation, passive protest and withdrawal would suffice.

The yimin loyalists of the Song continued to exist under the new dynasty after the collapse of the capital and the final defeat of loyalist resistance. Among them were a few active participants in the resistance, but most

1. See especially the writings of Wen Tianxiang, Xie Fangde, Wang Yuanliang. Their contemporaries, Liu Yin and Fang Hui, also used both connotations of the term.

2. Tao Qian's biography is in Fang Xuanling, 94.2460-63. Xie Fangde shows that Tao already used the ganzhi cyclical reckoning to record the years in 401 (not 405 as conventionally taken in Xie's time) because at that time Tao already predicted the fall of the Tsin. See Xie Fangde, Bihu zaji, 1a-2a. See also James Robert Hightower. 


\section{Regional Loyalist Centers}

had not participated but still grieved over Song's demise. Many were former officials, students in the capital or successful candidates in subprefectual and prefectual examinations. Most returned home just before or during the collapse of the capital city. For individuals who had received a salary or degree from the Song, withdrawal from public office was "compulsory." ${ }^{1}$ However, among those who withdrew were many who did not take office under the Song; therefore, their act can be considered "voluntary." The yimin group, in fact, included many former officials who were criticized in official histories as having fled from their responsibilities, an act denounced by the Song court in 1274 as cowardice. ${ }^{2}$ For a few, retirement had been approved by the court, as in the case of Ma Tingluan who was gravely ill, but others like Wang Yinglin simply left the court. For most of these men, active resistance was not in their minds. For some the life of an yimin began immediately after the collapse of the capital in February 1276; for others it began after March 1279, when the resistance was wiped out in the Yaishan debacle.

A few of these men isolated themselves and so became real recluses as well as surviving Song subjects, but most gathered in regional or cross-regional groups to mourn the demise of the country and to soothe their spirits while living under the new political system. Loose networks of relationships were formed in the first generation of Yuan rule in South China. In each regional group or network key personalities emerged while other individuals from both local centers and from outside the prefectures gathered around them for leadership and guidance. Regional centers of yimin activities developed in Annam, Dadu, Kuaiji, Wuzhou and Jiande, Luling, Qingyuan, Raozhou and Wuyuan, Pingjiang, Dongguan, as well as in Huzhou and Hangzhou. Map 3 shows the location of these eleven loyalist centers. ${ }^{3}$ While

1. For the distinction between "voluntary" and "compulsory" varieties of Confucian withdrawal, see Mote, "Confucian eremitism," 258.

2. SS 47.928; Liu Yiqing, 7.8; Bi Yuan, 181.4950.

3. This list of eleven loyalist centers does not claim to be comprehensive. Some of the major loyalists centers in each group are discussed in order to outline the main features of Song loyalism in $1276-1300$. 


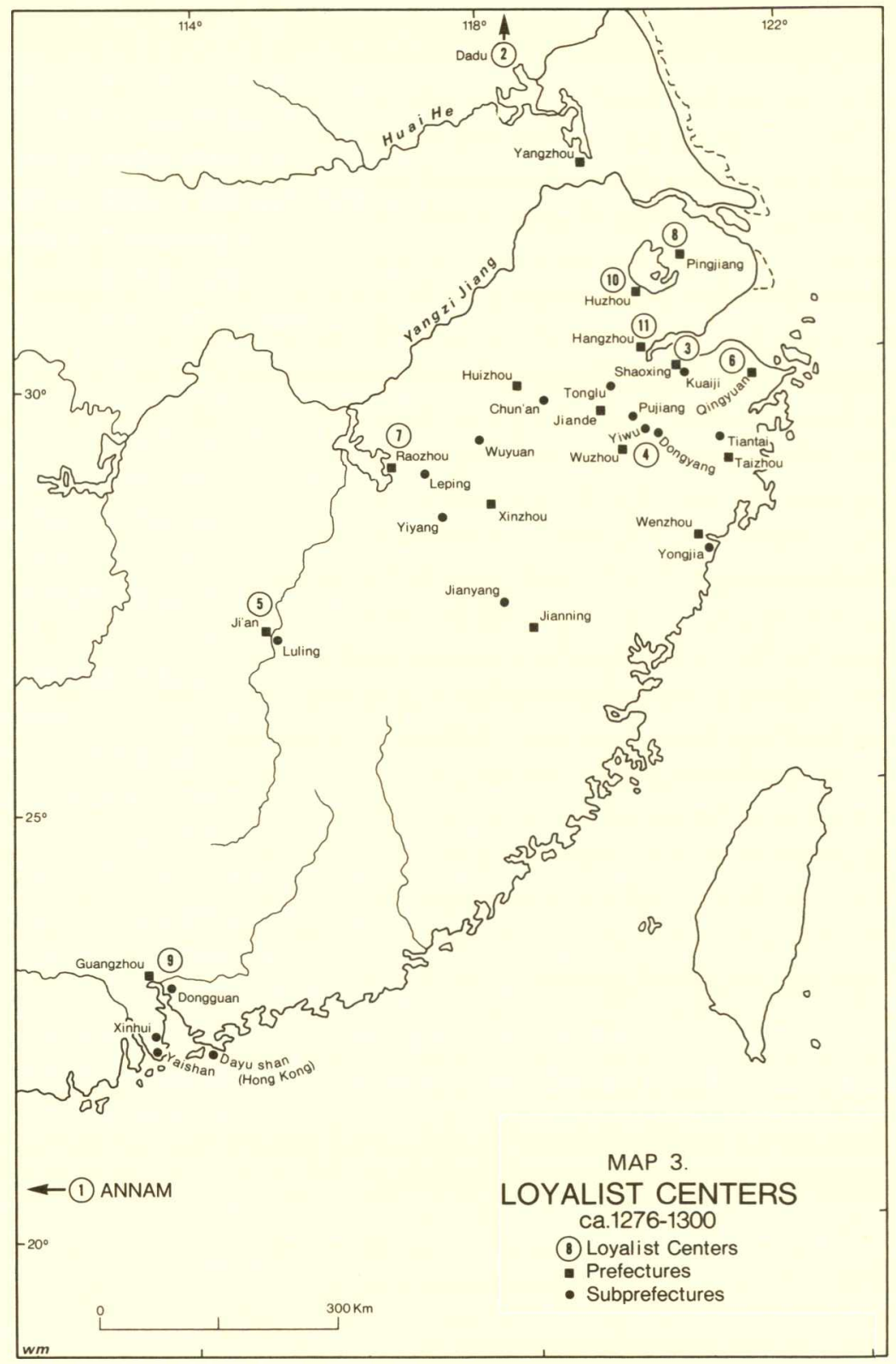




\section{Regional Loyalist Centers}

the latter two centers will be dealt with in the next chapter in connection with Zhou Mi and his circle of friends, we will now turn to the other nine regional groups and their leaders.

\section{Center 1: Chen Yizhong and the Loyalists Abroad}

Chen Yizhong was a key personality in the Song court before its collapse and in the loyalist court up to his flight to Champa in January 1278. Born to a poor family in Wenzhou, he was among the six National University students who audaciously impeached Ding Daquan in the mid-1250s and subsequently suffered banishment. ${ }^{1}$ Pardoned by Jia Sidao when the latter became chief minister, he gained his jinshi degree two years later and quickly advanced in his political career. By 1274 he was promoted to ministerial rank and became the most powerful political figure after Jia's downfall. I have earlier reconstructed Chen's crucial role in the evacuation of the two Song princes. Like Wen Tianxiang and the other loyalists, Chen also involved his family, including his younger brother, in the resistance. ${ }^{2}$

Chen left the loyalist court in 1278 in order to investigate Champa and Annam as possible future bases for loyalist operations. Thus after the defeat at Yaishan, Zhang Shijie and Su Liuyi attempted to join Chen, but died before reaching their destination. Upon arrival in Champa, Chen was well received by the local authorities but did not have time to amass support before the loyalist fleet was annihilated. Chen stayed in Champa until 1282 when his host kingdom was attacked by the Mongols; he then fled to Siam with supporters and died there, a refugee in exile. ${ }^{3}$ Other followers traveled north to

1. The following account of Chen Yizhong is based on his biography in SS 418.12529-33. Liu Fu, another key participant in the resistance movement who died shortly after Di Shi's enthronement, was one of the other students involved in this political incident (SS 405. 12242-49). Liu Fu's collected writings, the Mengchuan shiji, are in Liang Song mingxian xiaoji 362.

2. This was Chen Zizhong. See Wan Sitong, Songji zhongyi lu, 8.16.

3. Hok-lam Chan, "Chinese refugees," 2. Chan says that alternative accounts show Chen to have gone to Java, Cambodia or Japan. I follow the $S S$ account. 


\section{Chapter Five}

the neighboring kingdom of Annam and some returned to China. ${ }^{1}$

Survivors of the Yaishan crisis also went to Annam: they included two civilian officials of the loyalist court, Chen Zhongwei and Zeng Yuanzi, together with their families and that of the captured Su Liuyi. ${ }^{2}$ The Annamese king welcomed the loyalists and admired the poetic talents of Chen Zhongwei and Zeng Yuanzi, who both held the jinshi degree. ${ }^{3}$ In Annam Chen Zhongwei wrote the Erwang benmo, an account of the two Song princes enthroned by the loyalists. In 1282, a diplomatic mission returned this work to China where it was edited several times during the Yuan. ${ }^{4}$

These loyalists evidently worsened Annamese relations with the Mongols by participating in Annam's resistance in 1285. That year the Mongol army captured the Jiaozhi leader and Chen Zhongwei's son-in-law, together with over four hundred men, most of whom were presumably Song loyalist refugees. ${ }^{5}$ Zeng Yuanzi and the sons of Chen Zhongwei and Su Liuyi also surrendered their forces to the Mongols and thereby incurred Annamese resentment. ${ }^{6}$ On the whole, however, the Song loyalists' arrival in Southeast Asia has been considered an important event in the history of Chinese colonization in the region. The loyalists were actually preceded by earlier migrations of people from Fujian, who were attracted both by lucrative trade and the desire to escape political harassment. ${ }^{7}$ Although they originally sought

1. Hok-lam Chan, "Chinese refugees," 3; Chen Zhutong, 124-25.

2. For Chen Zhongwei's biography, see SS 422.12618-20. Zeng Yuanzi does not have a biography in SS.

3. Hok-lam Chan, "Chinese refugees," 4-5.

4. See the preface to Erwang benmo, in Songji sanchao, 6.65; Rao Zongyi, Jiulong yu Songji, 3-6.

5. YS 209.4644.

6. SS 422.12620; YS 209.4645. The YS shows Dingsun instead of Wensun as Chen Zhongwei's son.

7. Chen Zhutong, 125-49. 


\section{Regional Loyalist Centers}

temporary refuge, the loyalists and their descendants stayed permanently. ${ }^{1}$

Apart from Southeast Asia, there are indications of Song loyalists dispersing elsewhere after all resistance against the Mongols had ceased. There is an account of a Qiu Kui (fl. 1270-90) from Quanzhou who sailed to an island off the Fujian coast rather than live on conquered land. ${ }^{2}$ Qiu Kui continued to be on friendly terms with Pu Shougeng's brother Shoucheng who was blamed for persuading the former to surrender to the Mongols in $1277 .^{3}$ Farther south in Dongguan, Li Yong (fl. 1250-90) departed for Japan after the Song demise; he later went to Annam and never returned to China. ${ }^{4}$

\section{Center 2: Wang Yuanliang and the Dadu Group}

On its journey to the Yuan capital in 1276, the Song imperial family was accompanied by thousands of voluntary and involuntary followers. Some of those who felt loyal to the Song and who did not die or commit suicide on the way were appointed to positions in the Yuan government, and others were allowed to return to South China by the late 1290s. In Dadu former Song officials and palace women gathered to mourn the collapse of the Song. The main participants were Wang Yuanliang, Wang Qinghui (fl. 1270-90), Jia Xuanweng, and Deng Guangjian. While in prison until his execution in early 1283 , Wen Tianxiang could also be considered a member of this loyalist group because of his correspondence with Wang Yuanliang and Deng Guangjian.

Wang Qinghui was a concubine of Emperor Duzong, who, together

1. Hok-lam Chan, "Chinese refugees, " 9-10.

2. Wan Sitong, Songji zhonyi lu, 15.20. Qiu Kui's collected writings, the Diaoji shiji, are extant.

3. Qiu Kui was a student of the loyalist martyr Lü Dagui (d. 1277), a Confucian scholar who was killed by Pu Shougeng for refusing to draft the surrender statement to the Mongols. Qiu Kui's collected writings do not support the traditional view that Shoucheng had taken part in the surrender of his brother Shougeng. See Chen Yuan, Western and Central Asians, 16-17; Luo Xianglin, Pu Shougeng zhuan, 57-58.

4. Li Yong's biography is in Chen Botao, b.1a-2b. 


\section{Chapter Five}

with Wang Yuanliang, taught Gongdi the Confucian classics and poetry during the journey to Dadu and thereafter. ${ }^{1}$ Endowed with poetic talent and in despair over the demise of the Song and the unknown consequences of captivity in Dadu, she wrote in 1276 a much-acclaimed poem on the wall of a postal station in Bianliang (Kaifeng), the former Northern Song capital, en route to the Yuan capital. Responding to this poem which expressed a desire to remain pure and aloof like the moon, Wang Yuanliang composed another one in the same tune and rhyme. ${ }^{2}$ Three years later when Wen Tianxiang and Deng Guangjian read the poem on the wall on their way to Dadu, they responded with poetry to commiserate with her grief. ${ }^{3}$ After some years in Dadu, Wang Qinghui became a Daoist nun.

Wang Yuanliang was a court musician primarily in the service of Empress Dowager Xie. A native of Hangzhou, he had volunteered to accompany the imperial family to the North. ${ }^{4}$ Until his arrival in Dadu he wrote poetry to describe the surrender of the Song capital, the chaos in the palace quarters, the ravages of war where the imperial retinue passed through, and the reception of the imperial family given by Qubilai's court. ${ }^{5}$ In the Yuan capital, apart from contact with Wen Tianxiang, Deng Guangjian, and Wang Qinghui, Wang Yuanliang communicated with Jia Xuanweng in Hejian

1. Wang Guowei, 21.1061; the "Song of Huzhou" is found in Wang Yuanliang, Shuiyun ji, $9 b$.

2. "Manjiang hong, to the rhyme of Wang Qinghui," in Wang Yuanliang, Hushan leigao, 5.5a-b. There are many poems exchanged with Wang Qinghui in his poetry collections. See, e.g., Hushan leigao, 2.7b, 2.8b, 2.10b-11a, 2.14b-15a.

3. Wang Qinghui's original $c i$, along with the two composed by Wen Tianxiang and one by Deng Guangjian to the same theme, song title, and rhyme perhaps appeared at first in Zhou $\mathrm{Mi}$, Haoran zhai yatan, c.9b-10b.

4. Wen Tianxiang, Liu Chenweng, Ma Tingluan, Zhao Wen, and Xie Ao wrote biographies of Wang Yuanliang; these appear together in Cheng Minzheng, 11.1a-10a; Wang Yuanliang, Shuiyun ji, appendix.a-c; Hushan leigao, 5.9-11b.

5. See, in particular, the long ballads, "Song of Huzhou" and "Drunken song," in his Shuiyun ji, 1a-10a, 13a-14a. 


\section{Regional Loyalist Centers}

through poems and letters. ${ }^{1}$ He also maintained relations with former Song officials and members of the imperial family including Gongdi, the empress dowagers, imperial son-in-law Yang Zhen (fl. 1270-90), and the grandfather of Gongdi, Prince Fu (fl. 1270-90). Like the other accompanying officials in the Song imperial entourage, Wang was given a position in the Yuan court which he occupied for over ten years. His duties were perhaps in the capacity of a court musician and poet, and were not much different from his former service in the Song court. ${ }^{2}$ In Dadu, he witnessed the deaths of Empress Dowager Xie and Prince Fu, whom he mourned in funerary poems. Several years later Empress Dowager Quan entered a nunnery, and in 1288 Gongdi went to Tibet to become a Lamaist monk. ${ }^{3}$ Immediately thereafter, Wang felt that his duties to the Song imperial family had been fulfilled and obtained permission to return to the South to become a Daoist priest. Former Song officials and palace ladies bade him farewell and presented him with parting poems. ${ }^{4}$ On his return to South China, Wang passed through the same sites he had visited with the imperial retinue more than ten years earlier. He did

1. For poems to Jia Xuanweng, see Hushan leigao, 2.6b-7a; to Wen Tianxiang, see 2.9b10a, 2.16b; Shuiyun ji, 35b-37b; for poems to Wu Qian, see Hushan leigao, 2.6a.

2. He also wrote a poem mourning Qubilai's empress Cåbi (d. 1281); see Wang Yuanliang, Hushan leigao, 3.7b-8a. Her biography (YS 114.2871-72) is translated in Francis W. Cleaves, "The biography of the Empress Cảbi." Cảbi is praised in history as being sympathetic to the Song imperial family. See also Rossabi, "Khubilai and the women in his family," 169-70.

3. For poems mourning Empress Dowager Xie and Prince Fu, see Wang Yuanliang, Hushan leigao, 3.8-9a; on Empress Dowager Quan entering a nunnery and Gongdi departing for Tibet, see ibid., 3.9a-b.

4. On the farewell by eminent men of Dadu, see ibid., 3.9b-11a. The farewell poems by the palace women of the Southern Song, including Wang Qinghui, are collected in the Wang Song jiu gongren shici, appended to the Hushan leigao. It contains eighteen poems written by seventeen palace women. The volume includes a poem by Wang Yuanliang, which mourns the death of Wang Qinghui, one of the contributors to the volume. On the basis of this slim evidence, the modern scholar Wang Guowei concludes that the volume was a forgery by loyalists. See Wang Guowei, 21.1061. However, the mourning poem is undated and could have been written years after Wang Yuanliang's return to south China. 


\section{Chapter Five}

not hasten to his home in Hangzhou but made side trips to visit his former friends and colleagues as well as loyalists in various regions. He showed them his poetry collections and spoke in detail of the surrender of Hangzhou and the fate of the imperial family. His friends sympathized deeply with his grief and wrote prefaces to his work. ${ }^{1}$

With one notable exception, primary and secondary sources do not mention that Wang Yuanliang had served the Yuan. ${ }^{2}$ Nor has it been noted that his poetry reflects two different moods and personalities. On the one hand, his poetry reveals the profound grief of a Song loyalist over the demise of the dynasty and the humiliation of the imperial family subjected to captivity. The social critic in Wang Yuanliang deplores the oppression of the local people by corrupt officials and clerks who exacted heavy taxes and forced them to flee and abandon their children. ${ }^{3}$ On the other hand, not a few poems express gratitude to Qubilai for welcoming the Song imperial retinue in ten grand feasts upon arrival, and for granting tax-exempt property to the Song imperial family. Wang praises Qubilai for marrying off Song imperial concubines to carpenters and artisans instead of taking them into his harem. In the same laudatory tone, the Mongol general Bayan is commended for his restraint in combat. During his entire sojourn in Dadu Wang remained friendly to Song defectors and collaborators such as Lü Wenhuan, Myriarch Huang (fl. 1280), Liu Mengyan, and Qingyang Mengyan. ${ }^{4}$

Wang Yuanliang could not explain to his friends the equivocation with which he wrote the poems praising the Yuan, nor could he justify his service

1. The prefaces by Liu Chenweng and Ma Tingluan are extant in Cheng Minzheng, 11.2a4a; those by Xie Fangde, Deng Guangjian, and Zhang Jian have not survived.

2. The one exception is Wang Guowei, 21.1061. Wang postulates that it must have been a high position if he had been released from service as a Daoist priest.

3. See, in particular, the poems "Journey to the north" and "Drunken song of Yishan" in Shuiyun ji, 18b-19a, 22a-23b, 32a-b.

4. On poems referring to Qubilai and Bayan, see Wang Yuanliang, Shuiyun ji, 19a, 13b. On Song defectors and collaborators, Myriarch Huang, Liu Mengyan, and Zan Wanshou, see Hushan leigao, 2.7a, 2.9b, and Shuiyun ji, 28b-29a, respectively. 


\section{Regional Loyalist Centers}

to the Mongols--a fact which cast doubt on his loyalty to the Song. He repeatedly told his friends that he could only look at the present state of the world in a drunken stupor. Realizing that they would never completely appreciate the poignancy of his experiences in the North, he wrote the following poem to a friend, Xu Xuejiang (fl. 1270-90):

\footnotetext{
After ten years of high living in the White-Jade Hall, I submitted my reasons for permission to return home. Under the solitary clouds and setting sun I crossed the Liao River, On horseback against the western winds I climbed the Taiheng mountains, The salary from my office still remains in the knapsack, The imperially bestowed clothes still emit the fragrance of the imperial presence.

Only now it is difficult to answer my guest's query, From antiquity the affairs of the Central Plain have long been subjects for ridicule. ${ }^{1}$
}

The poem essentially conveys his gratitude to the Mongol emperor whom he served. Perhaps he was initially forced to take up the position because of his musical talents, or he may have felt that since his sovereigns, Gongdi and Empress Dowager Xie, as well as other members of the imperial family, had taken Yuan titles and positions, he would be disloyal if he did not follow them into submission. Although he was grateful to Qubilai, there is little doubt that his greater loyalty was to the Song imperial family. For as soon as Empress Dowager Xie had died and Gongdi had left for Tibet in 1288, he returned to South China. Perhaps because he felt guilty about his compromise with the Mongol court during his sojourn in Dadu and because his friends did not approve of him in this regard, he subsequently wandered about aimlessly, his long beard and tall, thin figure making him appear more like an immortal than a human being.

1. Wang Yuanliang, Shuiyun ji, 21a. 


\section{Chapter Five}

While in Dadu, Wang Yuanliang most probably met Jia Xuanweng, a former high-ranking official who stood out as the only minister who did not endorse the Song surrender statement and who unwillingly joined the ministerial retinue to the Yuan capital in $1276 .{ }^{1} \mathrm{He}$ is said to have wept and refused food and drink for several months in protest against the Mongol invasion. $\mathrm{He}$ stayed in Dadu for two years, where he declined an office, and then was sent to Hejian (south of Dadu), and later took up a position lecturing on the Yijing (Book of change) and the Chunqiu (Spring and autumn annals). When Wen Tianxiang and Deng Guangjian passed through Hejian in 1279 on their way to Dadu, the three met again and shared their grief and experiences.

Jia, however, was the sole southerner and loyalist in Hejian; he subsequently communicated with the others only through correspondence. He expressed homsickness for his native Sichuan and Hangzhou, which was a veiled reference to his longing for the collapsed Song dynasty as well. He regarded his sojourn in Hejian as a forced detention in the North, rarely used Yuan reign titles, and referred to the Yuan capital only by its ancient name of Yan. Jia's misgivings about foreign rule in general was, however, gradually dispelled by his admiration for the high standard of Confucian learning among northern scholars and recluses, whom he received warmly and considered his "like-minded" friends. He was relieved that "Confucianism was capable of following its own path and not be transformed [adversely] by the change of dynasties," and thus believed that scholarship and learning knew no boundaries between the North and the South. His grief for the Song dissolved in the course of time, as he observed that reunification of the country now made possible even the reintegration of Buddhist and Daoist schools. ${ }^{2}$ Jia was already sixty-three when he went to the North; after living there for

1. For Jia Xuanweng's biography, see SS 421.12598-99. This discussion is mostly based on his collected writings, Zetang ji. Almost the entire collection was written during his sojourn in Hejian; it consists of many "descriptive essays" of studios and halls written upon request, describing his experience with northern scholars. For his homesickness and unhappiness about being detained in the north, see the poem "To former friends in the south" and "Descriptive essay on the Jing room, " in Jia Xuanweng, 6.11a, 2.4b.

2. See ibid., 2.38a, 4.27b, 2.28a for "Preface to bidding farewell to Yang shanzhang," "Funerary essay to mourn Liu Wenwei," and "Descriptive essay on the Ruiyun monastery." 


\section{Regional Loyalist Centers}

almost two decades, his attitude towards foreigners also became more liberal. In a preface to Yuan Haowen's Zhongzhou ji (Collected writings of Yuan Haowen), he commended the compiler for regarding foreigners as civilized and equal to Chinese. ${ }^{1}$ In 1294 Jia was allowed to return to South China, where loyalists such as Lin Jingxi welcomed him with poems. After his departure, loyalist activities in the North came to an end, as Deng Guangjian and Wu Jian (one of the chief ministers who signed the surrender statement and went to Dadu with Jia), had already left long before him. ${ }^{2}$

\section{Center 3: The Loyalists in Kuaiji and the Recovery of the Song Imperial Relics}

After 1127, the tombs of the Song emperors were located near Kuaiji (Shaoxing) and were referred to as cuangong (temporary burial palaces) rather than ling (mausolea), because hopes for repossession of the Central Plain were not abandoned in the Southern Song. During and after the defeat of loyalist resistance, these tombs were excavated and looted while loyalists in Kuaiji attempted to recover the imperial relics. The clandestine nature of the mission to retrieve the imperial relics resulted in conflicting eyewitness and other contemporary accounts of the incident. Traditional scholarship on the incident does not agree on four main contentious issues: the actual dates of the excavation and the recovery and reburial of the relics; the identity of the persons involved in the incident; the location of the reburial site; and the number of tombs excavated. The account below attempts to synthesize the information available on the subject. ${ }^{3}$

1. Su Tianjue, 38.509-10. A partial translation is found in Chen Yuan, Western and Central Asians, 294-95.

2. Jia Xuanweng was permitted to return home in 1294 (YS 18.385). Wu Jian, on account of his old age, had already begged to return upon arrival in Shangdu in 1276. See Liu Yiqing, 9.15.

3. The earliest record of the looting of the imperial tombs is perhaps by Zhou Mi, Guixin zazhi, $x u$ a.38a-b, bie a.44a-50b. Part of this material, in addition to other traditional sources on the incident, is collected in Wan Sitong, Nan Song liuling yishi. See also Yan Jianbi; Paul Demiéville; Franke, "Tibetans in Yüan China." 


\section{Chapter Five}

From 1278 until about 1285, the Lamaist monk Byan-sprin 1Can-skya (Yanglian zhenjia, d. 1292) in collaboration with the notorious Sangge (d. 1291), engaged in a large project to excavate the Song imperial tombs and the graves of eminent officials. It is said that Byan-sprin 1Can-skya increased his personal wealth by looting these graves, although many of the treasures thus acquired were turned over to the central government which then allocated funds for the construction of Buddhist monasteries. ${ }^{1}$ To his critics the most heinous act committed by him was his impiety to the former Song rulers by exposing the relics to the open air. He also allegedly ordered some relics to be transferred to a site on the former Song palace grounds in Hangzhou, on which a pagoda named "Pagoda to suppress the south" would be built. ${ }^{2}$ Byan-sprin 1Can-skya and his acolytes also drained the mercury from Emperor Lizong's corpse in order to dislodge a precious pearl in his mouth; the skull was subsequently lost and later retrieved and used as a drinking utensil by them. ${ }^{3}$ The Yuanshi estimated the total number of tombs violated to be over a hundred. ${ }^{4}$

Byan-sprin 1Can-skya's critics over the centuries have unreservedly condemned the desecration of the Song emperors' graves and the violation of traditional Chinese burial practices. A more objective look shows that he might not have deliberately meant to humiliate the Song imperial family and its subjects, but his religious zeal led him to reclaim the original sites of Buddhist monasteries which had been demolished to construct the imperial tombs. ${ }^{5}$ It is generally believed that the excavations had been undertaken

1. On Yang's ethnic origins, see Franke, "Tibetans in Yüan China, " 321. On the submission of the tomb treasures to the Yuan, see YS 13.269, 13.271-72.

2. See Luo Youkai's biography of Tang Jue, in Wan Sitong, Nan Song liuling yishi, 7b.

3. Zhou Mi, Guixin zazhi, bie a.47a-b.

4. YS 202.4521 .

5. Franke, "Tibetans in Yüan China," 325. 


\section{Regional Loyalist Centers}

without Qubilai's knowledge. ${ }^{1}$ Traditional Chinese scholars in particular blame former Song officials then in Mongol service for not raising objections to the excavations. They insist that had there been some protest in the Yuan court, the sinicized Lian Xixian (1234-80), the sympathetic Bayan, and the enlightened Qubilai would not have condoned Byan-sprin lCan-skya's misdeeds. ${ }^{2}$ Indeed in 1291 , the Lamaist monk was severely penalized when Sangge, his protector, was disgraced at the Yuan court. ${ }^{3}$ The downfall of these two men served to totally dissociate Qubilai from the excavations, but it is incredible that he had not been aware of the incident, since the funds received from the excavations were submitted to the Mongol court for the construction of the Buddhist monasteries. ${ }^{4}$

As soon as the plundering of the imperial tombs was known, it appears that a group of dedicated loyal men, mostly natives of Kuaiji, embarked upon a daring scheme to recover the imperial relics and rebury them at the Lanting site in Kuaiji. At least half a dozen persons were involved in this affair: Wang Yingsun, Tang Jue (b. 1247), Lin Jingxi (1242-1310) and his companion Zheng Buweng (fl. 1270-90), Luo Xian (fl. 1270-90), and perhaps Quan Quanweng. ${ }^{5}$

Tang Jue is recorded to have been a filial son who used up his inheritance entertaining a handful of young men in order to enlist their help to

1. Demiéville, 461.

2. See, e.g. Wen Ruilin's preface to Wan Sitong, Nan Song liuling, 1b-2a, and Yanai, 76. On Lian Xixian's adoption of Confucian mourning, see Chen Yuan, Western and Central Asians, 45-47.

3. Sangge's biography is located in the section for traitorous officials, YS 205.4570-76. See also L. Petech, and Franke, "Tibetans in Yüan China," 323-24.

4. YS 13.269.

5. Luo Xian was a eunuch, and Wan Sitong suggests that it was for this reason that he was not normally included as one of the participants. See Wan Sitong, Nan Song liuling yishi, $47 \mathrm{a}$. 


\section{Chapter Five}

smuggle out the imperial relics and replace them with animal bones. ${ }^{1}$ In a separate incident, Lin Jingxi and his landsman Zheng Buweng disguised themselves as beggars; after bribing the junior Lamaist monks to let them through, they obtained the relics of Gaozong and Xiaozong (r. 1162-89). ${ }^{2}$ In both cases the recovered bones were then reburied and wintergreen trees planted to mark the new location. In the traditional accounts of Tang Jue and Lin Jingxi, both appear to have worked on their own without previous knowledge of each other. Qing commentators have, however, supplied evidence to show that the two were house guests of the local magnate Wang Yingsun, who was in fact the mastermind and financier of the mission. ${ }^{3}$ Wang Yingsun was the son of a high-ranking Song official and related to the Song imperial family. For these reasons he did not want to focus suspicion on himself, but he may have paid for the assistants and for the bribes needed to ensure a successful venture. The Qing historian Quan Zuwang insisted that his ancestor, Quan Quanweng, had been a participant in the event and should be commemorated together with these daring, loyal subjects of the Song. $\mathrm{He}$ argued that the reburial site was situated in the Quan family estate, which had earlier been granted by the Song court. ${ }^{4}$

A mass of literature has been produced over the centuries praising the personalities involved in the recovery of the imperial relics. The key protagonists, Lin Jingxi and Tang Jue, were the first to refer to the incident in their poems. ${ }^{5}$ Their symbol for the entire event was the wintergreen tree, which in turn became the oblique reference for subsequent writings on the

1. Luo Youkai's biography of Tang Jue, in ibid., 7b.

2. Zheng Yuanyou's biography of Lin Jingxi, in ibid., 10b-11b.

3. See, e.g., Huang Zongxi's annotation to Xie Ao's poem, "Preface to the wintergreen tree, " in Wan Sitong, Nan Song liuling yishi, 39b-40a.

4. Quan Zuwang, ji 33.417-18.

5. These were the "Written while dreaming" poems in Lin Jingxi, 3.103-04. In Luo Youkai's biography of Tang Jue, several lines of Tang's poem are identical to Lin's. It has been suggested that they were originally Lin's, later mistakenly attributed to Tang. 


\section{Regional Loyalist Centers}

subject. Traditional sources suggest that in an attempt to keep a low profile about the mission and their participation, both they and their friends deliberately falsified facts and dates, thus causing the still unsolved controversy about the incident. In the earliest account of the incident written by their friend Zhou Mi, nothing is said relating to the participation of either Tang Jue or Lin Jingxi. ${ }^{1}$ Another friend, Xie Ao, a survivor of the loyalist resistance and personal follower of Wen Tianxiang, composed a commemorative poem, the "Dongqingshu yin" (Preface to the wintergreen tree), on which the Ming loyalist Huang Zongxi wrote a commentary. ${ }^{2}$ In this piece, Xie's information about the dates of the reburial also conflicts with that of Zhou Mi and other accounts. Because of the popularity of this poem and his reputation as a Song loyalist, Xie has traditionally been regarded as an active participant in the incident. ${ }^{3}$ That, however, has been disproved because at the time it occurred Xie was traveling in Fujian and could not have been physically present in Kuaiji.

In any case, after the incident the individuals involved continued to see each other at social and literary gatherings in which other acquaintances and visitors participated. The best-known meeting occurred in 1279, during which fourteen poets met on five occasions at five different locations in the Kuaiji mountains in order to compose poetry in five tunes in the yongwu genre (celebration of the object). Altogether thirty-seven of these poems survive in a volume edited by one of the youngest participants, Chen Shuke (12581339). ${ }^{4}$ At least half the members in the group were natives of Kuaiji, in-

1. Zhou Mi, Guixin zazhi, bie a.47a-b.

2. This poem, with annotations by Zhang Mengqian and Huang Zongxi, is in Xie Ao, Xifa $j i, 247-49$, and Wan Sitong, Nan Song liuling yishi, 36b-40a. A Qing dramatization of the Song loyalists also uses the wintergreen tree as the symbol of Song loyalism. See Jiang Shiquan.

3. Yang Weizhen (1296-1370) was the first to include Xie Ao among the participants in the recovery and reburial of the imperial relics, which Quan Zuwang showed to have been unlikely. See Quan Zuwang, ji 33.416-17.

4. See Chen Shuke. 


\section{Chapter Five}

cluding Chen Shuke, Wang Yingsun, Tang Jue, Wang Yisun (1232-91), Wang Yijian and Tang Yisun (both fl. 1270-90). Five of them apparently owned property in the Kuaiji mountains and took turns hosting the meetings. The other participants were Hangzhou natives either seeking a sanctuary from the chaos of war, or were traveling through Kuaiji; they included Zhou Mi, Qiu Yuan (1247-1327), Zhang Yan (1248-1320), Lü Tonglao and Li Penglao (both fl. 1260-1300). The poems are full of obscure allusions and oblique references, and recent studies of them have shown that the major themes were the tragedy of the Song imperial family and the collapse of loyalist resistance in Yaishan. ${ }^{1}$ It has also been suggested that the participants witnessed the looting of the tombs and that their meetings were conceived as ceremonial rituals to pay final homage to the former ruler and dynasty. ${ }^{2}$ One notable detail is the absence of Lin Jingxi: this can be explained by his departure for his home in Wenzhou on a brief trip. Actually, Lin Jingxi may have been a participant, as the poetry volume did not include all participants nor all poems produced in the meetings.

Shortly after these gatherings, Zhou Mi and the other visitors left Kuaiji and returned to their respective homes. Of the poets whose works are represented in the volume, several later took up office under Yuan rule. They included at least Wang Yisun, Qiu Yuan, and Chen Shuke, who may have reluctantly taken this decision under difficult circumstances. ${ }^{3}$ There is, however, little doubt that in the 1270s, 1280s and even during their service to the Yuan they remained spiritually loyal to the Song and expressed genuine sadness and pessimism about the demise of the dynasty.

Of the key personalities in the Kuaiji loyalist group, Tang Jue is the

1. On this poetry collection see Xia Chengtao, "Yuefu buti kao," in his Tang Song ciren nianpu, 377-82; Chia-ying Yeh Chao, "On Wang I-sun"; Shuen-fu Lin, 191-93; Kang-i Sun Chang, 353-85.

2. Xia Chengtao, 379, 382.

3. Wang Yisun apparently served as director of a local school in the 1280 s. See Chia-ying Yeh Chao, 62-66. 


\section{Regional Loyalist Centers}

least known. ${ }^{1}$ His poems have been confused with those in Lin Jingxi's collection, and even his biography has been laced with myth, presumably to fill the gaps and the sparse details on him. Much more information is available on Wang Yingsun and Lin Jingxi. Wang was by far the most influential in social, economic, and political standing. A former Song official and one of the most affluent art connoisseurs of the time, he hosted many house guests and patronized not a few destitute scholars such as Lin Jingxi. ${ }^{2}$ After the fall of the Song he wrote and painted, living the typical life of a political recluse. In 1289 he bought some property on Mount Tao where he built a house and a local academy. ${ }^{3}$ Although Wang did not serve the new government, he regarded the Yuan with ambivalence and associated himself with Yuan officials in order to keep his social and economic status. His son also socialized with loyalists such as Lin Jingxi and may have later joined the Mongol service.

Lin Jingxi is probably the best-known essayist and poet among the loyalist group in Kuaiji. ${ }^{4}$ A native of Wenzhou and former Song official, after the Song demise he lived in Kuaiji with some landsmen, including Zheng Buweng, who assisted him with the reburial of the imperial relics. After the demise of the dynasty, he remained for the next twenty years a guest of Wang Yingsun and traveled frequently between Hangzhou and his native county. He also taught students and associated with Daoist priests and Bud-

1. The writings on Tang Jue, including the biographies by Zhang Mengqian and Luo Youkai, are collected in Cheng Minzheng, 6.1a-15b.

2. Wang Yingsun's collections are frequently mentioned by Zhou Mi. See, in particular, Zhou Mi, Yunyan guoyan lu, 2.3a-4b. Wang Yingsun was also a painter; see Xia Wenyan, 5.5a.

3. "Descriptive essay of Wang Yingsun's school on the Taoshan, " in Lin Jingxi, 4.111-13; "Descriptive essay of travel to Taoshan," in Deng Mu, Boya qin, buyi.1a-2a.

4. In Lin Jingxi's collected writings, Zheng Buweng and Chen Zhengguang are particularly mentioned as his friends from the same district and with the same frame of mind and ambitions as himself. See his Jishan ji, 1.3-4, 4.111-13. 


\section{Chapter Five}

dhist monks. ${ }^{1}$ In his poetry, loyalism is manifested in repeated references to the symbols and traditions of loyalty: for instance, the sunflower naturally faces the sun, the bird starves rather than go to another owner, and the virtuous woman rejects remarriage. Also present are frequent praises of historical loyal figures such as Boyi and Shuqi in the early Zhou, Su Wu and Cai Yan in the Han, as well as the Song loyalist martyrs Lu Xiufu, Wen Tianxiang, and Xu Yingbiao. ${ }^{2}$ Lin's loyalism had ethnic and racial overtones. He interpreted unusual occurrences of natural phenomena as supernatural reactions to the unnatural state of alien rule: "Thus when human beings lose the constants of human beings, ghosts and spirits practice their strange [ways]; when the Middle Kingdom loses its constants, barbarians conduct their bizarre [practices]. Strange occurrences are already unspeakable, how much more so when they have been beckoned to come close?" ${ }^{3}$ Lin's distress over the imposition of foreign rule was not assuaged by the reunification of the country. He cynically commented on Lu You's poem instructing his heirs to inform him about the recovery of the North: "Now that the nine provinces have been reunified, how will you convey that information to your father during the family sacrifices?" ${ }^{4}$ In later years, Lin's uncompromising loyalism also succumbed to the passage of time: he associated with northerners and did not condemn his younger brother for his Yuan employment. ${ }^{5}$ He himself, however, did not resume a public career.

1. The Jishan ji has frequent references to poetry exchanges and travels with Buddhists and Daoists.

2. Lin Jingxi, 1.2, 1.12-13, 1.23, 1.23-25, 2.67-68, 3.104-05. Cai Yan (Cai Wenji) is noted for a poem in eighteen stanzas expressing her distress during her forced sojourn among the Xiongnu people. See also Giles, no. 1983.

3. "Discourse on the flitting light," in Lin Jingxi, 4.128.

4. "Postscript on the poetry volume of Lu You," in Lin Jingxi, 3.100-01.

5. On his friend from Dadu, see Lin Jingxi, 4.120-21; on his younger brother, see his preface to bidding him farewell to a new assignment, in ibid., 5.136-37. 


\section{Regional Loyalist Centers}

\section{Center 4: Xie Ao and the Loyalists in Wuzhou and Jiande}

Xie Ao, a native of Fujian and unsuccessful jinshi candidate, was a personal follower of Wen Tianxiang and a survivor of the loyalist resistance. ${ }^{1}$ He had recruited a thousand men from his hometown and turned over his wealth to the loyalist cause. After Wen's capture in 1278, he escaped and thereafter spent his life traveling throughout Fujian and Zhejiang. In the course of his travels he established close contacts with loyalist groups in Hangzhou and Kuaiji, but he is most often identified with the loyalists in Wuzhou, where the two Song princes first stopped during their flight to the southeast in early $1276 .^{2}$

In Wuzhou, Xie became an intimate friend of Fang Feng (1240-1321) and Wu Siqi (1238-1301), and associated with frequent visitors from Jiande. Fang Feng did not take office under the Song, but although a commoner he was regarded highly by the chief minister Chen Yizhong. ${ }^{3}$ In 1275 , Fang was keenly aware of the urgency of the political situation and wrote to Chen, requesting that he continue to resist the "conniving caitiffs": "Even a caged animal will struggle, how much more so should a country about to collapse?"4 After the defeat of loyalist resistance, Fang adopted the sobriquet "Loyal survivor of Dongyang" to show his loyalty to the former dynasty. Fang's loyalism is basically cultural rather than racial in nature, as indicated by his relatively mild tone towards foreign customs. In his preface, Fang declared:

1. Xie Ao was on the staff of Wen's military headquarters. Sources on Xie are in Cheng Minzheng, 2.1a-5.13b. Xie's extant writings are in his Xifa ji; he also edited a volume of poems by former Song subjects, entitled Tiandi jian ji, appended to the Xifa ji, 243-45.

2. In Hangzhou, Xie associated himself with Zhou Mi's circle of friends who included Deng $\mathrm{Mu}$, Dai Biaoyuan, and Deng Wenyuan. References to the two Dengs are in Deng Mu's biography of Xie Ao, in Deng Mu, Boya qin, 13a-b. In Kuaiji, he associated himself closely with Lin Jingxi, Tang Jue, and Wang Yingsun.

3. On Fang Feng, see Cheng Minzheng, 8.1a-11b. The first to write his biography were his students Song Lian and Huang Jin.

4. Fang Feng, Cunya tang yigao, 3.1a-2b. For reference to Fang Feng's calling himself Dongyang jun yimin, see Fang's preface to Qiu Yuan's poetry, in Cheng Minzheng, 8.11a. 


\title{
Chapter Five
}

\begin{abstract}
The customs of the foreigners are really not worth mentioning, but one should nevertheless consider them as human beings. Those born in alien lands were [merely] ruined by their customs and practices, and although controlled by law, they cannot be transformed [by Chinese culture]. Yet among them there are some who like poetry and books and adhere to virtue and righteousness. They undertake three years of mourning [for their parents] and there are no promiscuous and jealous women. Such cases lend support to the fact that the goodness of human nature does not differ between foreigners and Chinese. $^{1}$
\end{abstract}

Of foreigners, Fang was most impressed with the Japanese and the Koreans because they adopted the Chinese written language and the Confucian classics.

Wu Siqi was a former Song official who retired from political life after the demise of the dynasty. ${ }^{2}$ Thereafter he called himself "Master of total return," an indication of his determination to keep his virtue and loyalty intact. He was a direct descendant of the controversial philosopher-scholar Chen Liang (1143-94) who spoke out bitterly against foreign rule on Chinese territory and who has been regarded by modern scholars as a proto-nationalist. ${ }^{3}$ It is likely that Chen's antipathy towards foreigners greatly influenced Wu's loyalism to the Song.

With these new friends Xie shared his grief over the collapse of the Song, and they eagerly listened to his accounts of the loyalist resistance in

1. Fang Feng, Yisu kao, 1a.

2. On Wu Siqi, see Cheng Minzheng, 9.1a-12a. See especially the biographies by Song Lian and Ren Shilin, in ibid.

3. Chen Liang's biography is in SS 436.12929-43; see also Xiao Gongquan, vol. 4, 461-64, and Hoyt Cleveland Tillman. 


\section{Regional Loyalist Centers}

which they did not participate. Xie's loyalty first and foremost focused on his devotion to Wen Tianxiang. Xie is usually portrayed as an eccentric and solitary figure who wept alone for his former patron, but in Wuzhou, Xie was accompanied by his new friends. Xie is best known for engaging in a ritual mourning in order to bring back Wen's soul from the North. The incident took place at the tomb of Yan Guang (37 B.C.-A.D. 43) in Tonglu. ${ }^{1}$ After the event, Xie wrote the Xitai tongku ji (Record of weeping at the western terrace), in which he referred to Wen Tianxiang and his own companions in oblique terms. In a commentary to the work, Huang Zongxi rectified previous annotations and identified Xie's companions as Wu Siqi (who often traveled to Tonglu), Yan Lü (fl. 1270-1300), a native of Tonglu and descendant of Yan Guang, and Feng Guifang (fl. 1270-1300), possibly a native of Wuzhou. $^{2}$ Because this essay has often been praised as attesting to Xie's loyal spirit and as a gem among loyalist literature, it is translated below in full:

At the beginning when [the chief minister Wen Tianxiang] set up his military headquarters [at Nanjian], I first followed him to battle as a commoner. The next year [1277] I took leave of him at Meizhou. In the following year the chief minister passed through [the place] that Zhang Xun and Yan Gaoqing used to visit. Grief-stricken words and heroic spirits were never lacking in his compositions, and the poems on Zhang Xun survive and provide material for study. To my death I will regret not seeing the chief minister for a last time, and now I can only recall the parting words. Each time I think about them, I would search in my dreams, or in the mountains, rivers, ponds and pavilions, clouds and forests. Where we parted I have paced back and forth looking forlorn but dared not

1. On the ritual of zhaohun (summoning the soul), see Hawkes, 101-14. On Yan Guang, see Giles, no. 2468.

2. The original annotations were done by Zhang Mengqian. As Huang Zongxi has shown, they are not convincing in identifying Xie's companions. My translation and dates rely on Huang Zongxi's corrections in Wan Sitong, Songji zhongyi lu, 11.8-15. 


\section{Chapter Five}

weep aloud. Three years later [1282] I passed through Pingjiang where the chief minister had first set up his military headquarters [in 1275]. There I looked over from the Fuchai terrace and cried for him. Four years later [1286] I wailed for him on the Yue terrace, and now five years later [1291] I weep on the Ziling terrace.

At first on a certain day my three friends [Wu Siqi, Yan Lü, and Feng Guifang] and I had arranged to meet at Yuezhou and stay overnight. The afternoon rain did not cease. We rented a boat at the river [bank] and from it came ashore to visit the Ziling temple and to rest beside it. The monk's quarters were run down and dilapidated, and going inside was like entering a tomb. Upon returning [to the boat], with the boatmen we prepared some sacrificial vessels. Soon the rain stopped and we climbed the western terrace. In a deserted pavilion corner we set up an altar and bowed, prostrated, and wept three times before rising and prostrating again. I then remembered the time in my youth when each time we passed through here I would always pay my respects at this temple. That was when I first came here while accompanying my late father. Now I am old, and the country and people have all been transformed. As if I had regained what I lost I looked to the east and repeatedly bowed and wailed. Clouds floated from the southwest and created an air of mystery in the forest, as if they too wished to join in the grief. I then used a bamboo scepter to beat on a rock, reciting a tune modeled on the songs of Chu: "At dawn the soul ascended, how extremely remote! At dusk it returned, the water in the pass is black! Transforming into a red bird . . ! " When I finished singing, both the bamboo and rock were smashed to pieces.

We sighed at each other, and then climbed the eastern terrace. After stroking an old rock we returned to rest in the boat. The boatmen were at first startled by my 


\section{Regional Loyalist Centers}

weeping, and said a patrol boat had just passed by. We then moved everything back into the boat, and took turns drinking wine and composing poems to express our feelings. In the early dusk, snow fell and the wind was cold, such that we could not stay out [on the river]. Thus we anchored and went ashore, staying overnight at [Yan Lü's] house. At night we again wrote poems to reminisce about the past. The next day the wind and snow were even fiercer. I took leave of Wu Siqi at the river [bank] and with [Feng Guifang] set off for home. We walked thirty $l i$ and again stayed overnight at Yuezhou before arriving home.

Later [Wu Siqi] sent me a letter saying that on the day we left, the wind and sails were hostile for a long while before settling down. When all was calm he suspected that spirits must have been protecting our return trip back. I sighed: Alas! Since the infantry soldiers of the state of Ruan died over a thousand years ago, there had been no weeping in [those] lonely mountains. Whether it had truly been spirits assisting us cannot be known, but this journey has certainly been worthwhile and great. The fact that [Wu Siqi] put his thoughts down to show his feelings is certainly grievous. I wanted to emulate the Grand Historian who wrote the events of the end of Han, such as the contending Chu and Qin states. Then if my contemporaries do not now know my mind, people of subsequent times will be sure to read about it from this record. Thus I have written the [Xitai tongku ji] and appended it to my writings on the end of the Han. ${ }^{1}$ Since my late father first climbed the terrace until now, it has been twenty-six years. My late father was named so and

1. Xie Ao had aspired to write a history of the last years of the Han dynasty. See Fang Feng's biography of Xie, in Cheng Minzheng, 2.7a-b. 


\section{Chapter Five}

so, and his courtesy name was so and so. The year when

I first climbed the terrace was $1265 .^{1}$

Xie Ao, Fang Feng, and Wu Siqi also traveled to Hangzhou and Kuaiji, always writing travel diaries to remind them of the pleasures they had experienced. ${ }^{2}$ Fang's student Song Lian (1310-81) wrote that hardly a month went by without these three friends embarking on some journey. ${ }^{3}$ To finance their travels, they evidently relied on Zhou Mi's patronage while in Hangzhou and Wang Yingsun's finances while in Kuaiji. In Wuzhou they were guests of Wu Wei (fl. 1270-1300), an affluent former Song official. To supplement their income, they accepted students. Fang Feng in particular was known for his outstanding students such as the Jinhua scholars Huang Jin (1277-1357), Liu Guan (1270-1342), and Song Lian. ${ }^{4}$ Occasionally Xie fell on hard times when he had to transport firewood to Hangzhou in order to subsist. $^{5}$

Apart from the basic demands of making a living, Xie, Fang, and Wu formed poetry clubs such as the Xishe and the Yuequan yinshe, gathering in the company of other "like-minded" poets. In 1286-87, as members of the Yuequan poetry club, they sponsored a competition to encourage young ama-

1. Wan Sitong, Songji zhongyi lu, 11.8-15.

2. Fang Feng and Xie Ao also co-authored travel diaries, e.g. "Travels in Jinhua" in 1289, of which only one juan out of nine has survived. See Xie Ao, Xifa ji, 233-39; Fang Feng, Cunya tang yigao, $4.1 \mathrm{a}-5.4 \mathrm{~b}$. The titles vary slightly in the two works.

3. Song Lian's biography of Wu Siqi, in Cheng Minzheng, 9.5a.

4. On Liu Guan and Huang Jin, see their biographies in YS 181.4189, 181.4187-88. On Song Lian, see Mote's biography of him in Goodrich and Fang, Dictionary of Ming Biography, 1225-31. On the scholarship and political thought of these Jinhua scholars, see also Langlois, "Political thought," 178-82, and Sun Kekuan, Yuandai Jinhua xueshu.

5. Deng Mu's biography of Xie Ao, in Deng, Boya qin, $12 \mathrm{~b}$. 


\section{Regional Loyalist Centers}

teur poets in Zhejiang and nearby districts. ${ }^{1}$ Their patron, Wu Wei, provided the funds while Xie, Fang, and Wu Siqi served as judges. ${ }^{2}$ The contest was declared open in the tenth month of 1286; three months later it closed and in a month and a half the winners were ranked. Altogether there were 2,735 entries, out of which 280 obtained honorable mention. The competitors were required to write a poem on the theme of Tao Qian's series of poems entitled "Pleasures of farming in the spring." Wu Wei greatly admired Tao Qian's imperturbable demeanor and his transcendent poetry, and chose the contest title to make an oblique comparison of the present withdrawal of himself and the participants to the political seclusion of Tao. It has also been suggested that the purpose of the competition was to compensate the young scholars and poets for the suspension of the civil service examination since the Song collapse. ${ }^{3}$ The competitors, mostly representatives of various poetry clubs in Hangzhou and Wuzhou, submitted entries anonymously or under pseudonyms, perhaps because they feared political complications, since both the patron and the judges of the competition did not conceal their loyalty to the Song. ${ }^{4}$

The first sixty winning entries appearing with the judges' comments survive in a volume edited by Wu Wei. Distributed to them as prizes were

1. The results of the poetry competition with the sixty winning entries are given in the poetry volume edited by Wu Wei. See also Yokota Terutoshi.

2. See Wu Wei, 1a; Wan Sitong, Songji zhongyi lu, 14.16-18. Such poetry competitions in which wealthy patrons hired established poets as judges were common in south China during the Yuan. The Yuequan yinshe competition is the best known of such events. See Yokota, 99-100.

3. As noted by Liu Chenweng in 1286, in "Preface to the poetry collection of Cheng Chuweng" (in Liu Chenweng, 6.9b): "After the examinations were suspended [in 1274] there was not one scholar who did not turn to poetry. "See also Yoshikawa, Genminshi gaisetsu, 81.

4. Quan Zuwang believed that the multiple entries of the same person and the use of pseudonyms were either due to deliberate concealment through fear of censorship, or to confusion resulting from the transmission of the volume over such a long period. See Quan Zuwang, waibian 34.1143, and Yokota, 112-19. 


\section{Chapter Five}

the volume of poetry, silk, brushes and ink, as well as poems written to them by the judges. Of the winners who later became known were Lian Wenfeng (f1. 1280-1300), Quan Quanweng (Quan Zuwang's ancestor), Bai Ting (1248-1328), and Qiu Yuan, who were respectively ranked first, ninth, eighteenth, and forty-fourth. At the time of the contest the competitors appeared to be Song loyalist survivors who responded in that capacity. But although they at first had no intention of compromising their ideals and loyalty to the former dynasty, by the 1300s not a few including Bai Ting and Qiu Yuan had taken up Yuan appointments as education officials. ${ }^{1}$ Fang Feng's son became a jinshi under the Yuan when examinations were restored; he most likely also took office.

Apart from being compatriots, poetry associates, and traveling companions, Xie Ao and the Wuzhou loyalists practically became sworn brothers. They taught each other's children, arranged marriages among them, and pledged to continue their friendship after death. ${ }^{2}$ In the 1280 s Xie Ao and his friends bought a plot of land near the terrace where they mourned Wen Tianxiang. The site, named Xujian ting, recalled the incident of Jizha (ca. 500 B.C.) fulfilling his promise of a sword to Prince Xu even when the latter had died. Apart from serving as spiritual affirmation of loyalty towards the Song dynasty, the site also sealed the friendship between Xie Ao and his friends. ${ }^{3}$ In addition, the site was intended to be a cemetery plot for the group, and when Xie Ao died of tuberculosis in Hangzhou in 1295, he left instructions for his body and writings to be looked after by Fang Feng of Wuzhou. Xie's body was indeed transferred to the site and buried there. Xie's friends and students came from as far as Hangzhou and Dongguan to

1. On Bai Ting and Qiu Yuan entering Yuan service, see Chapter 6.

2. For example, Xie Ao taught Fang Feng's sons (see Fang Feng's biography of Xie, in Cheng Minzheng, 2.9a), and Wu Siqi's daughter married Fang Feng's son.

3. Fang Feng's biography of Xie Ao, in Cheng Minzheng, 2.8b. On the allusion to the "promised sword" by Jizha (ca. 500 B.C.) to Prince Xu, see Giles, no. 287. 


\section{Regional Loyalist Centers}

attend his funeral. ${ }^{1}$ They included Deng Wenyuan (1258-1328), a native of Sichuan who had moved to Hangzhou and later served as a high official in the Yuan, as well as Fang Youxue (f1. 1270-1300), a member of the loyalist group in Dongguan.

In Jiangshan county of Wuzhou resided the four recluses of the Chai family, Chai Wang (1211-80) and his three cousins, who returned home, barricaded their gates and refused to serve another dynasty after the Song demise. ${ }^{2}$ None of the Chai recluses appear to have been associated with other loyalists, not even Fang Feng's group in Wuzhou. However, Chai Wang was a former friend of Zheng Sixiao's father and may have continued a friendship with Sixiao. Chai Wang was better known as a poet; out of several thousands of poems written, he selected about two hundred that he deemed worthy of transmission and humbly signed his name as the "Refugee subject of the Song" to the work. A year after Chai Wang's death, his son Xijun (fl. 12701290), a former student of the National University, also disdained to serve the Yuan.

A notable Confucian scholar, Jin Lüxiang (1232-1303), also retired to Wuzhou and did not enter public office under the Yuan. ${ }^{3}$ When the Song was about to collapse, he had submitted a plan to save the country from invasion but was ignored ${ }^{4}$ Living under Mongol rule, he regarded himself as a "Scholar employed by the former dynasty" and did not use the contemporary reign titles in order to register his protest against the new order. Although he

1. On Deng Wenyuan and Fang Youxue who attended Xie Ao's funeral, see Cheng Minzheng, 2.8a.

2. Chai Wang's collected writings exist as the Qiutang ji. The following account is based on the funerary inscription written by his landsman Su You'an (fl. 1270-90) in 1281, and Chai's own preface to his collected poetry: "Funerary inscription of the historian-official of the Song, Chai Wang" and "Preface to the poetry collection of Daozhou Taiyi, " in Chai Wang, appendix 1.1a-5b, 2.1a-b.

3. On Jin Lüxiang, see YS 189.4316-18. His extant collected works are known as the Renshan ji. On Jin's writings before and after the Song collapse, and his response to the Mongol conquest, see Langlois, "Political thought in Chin-hua," 151-55.

4. YS 189.4316 . 


\section{Chapter Five}

shared some students with Fang Feng, there is little evidence that he socialized with him or with the other loyalists in Wuzhou.

In Chun'an county of Jiande, west of Tonglu, lived another group of loyalists in retirement who apparently had no contact with the Xie Ao/ Fang Feng group. Fang Fengchen (1221-91), his younger brothers Fengzhen (jinshi 1262) and Fengjia (fl. 1270-1300), He Menggui (jinshi 1265), and Fang Yikui (fl. 1270-1300) were the leading figures in the group who refused to serve in the Yuan government and taught students for a living. Fang Fengchen was a top jinshi graduate in 1250 and had attained senior status in the Song bureaucracy when he withdrew for more than ten years to protest against Jia Sidao's rise to power. ${ }^{1}$ After Jia fell into disgrace, he was appointed president of the Ministry of Rites (2B) but declined because of the objection raised by his ill father. Fengchen and Fengjia had also been Song officials who firmly declined recommendations to office. Fengchen called himself "Loyalist survivor of the mountain hut." He Menggui was also a high-ranking official who had deserted the Song court during its collapse. ${ }^{2}$ In 1286-87 he was recommended for office by Cheng Jufu, but declined pleading illness. Both he and his landsman Fang Yikui were closely associated with the Fang brothers.

This group of former Song officials also socialized with northerners and foreigners who held office in the Yuan, such as the accomplished calligrapher Xianyu Shu (1248-1301) and the sinicized Jurchen scholar Jiagu Zhiqi

1. Despite his high rank in the Song dynasty, Fang Fengchen does not have a biography in the $S S$ because the compilers could not obtain an account of conduct on him. See the SKQS preface to Fang's collected writings, Jiaofeng wenji, 1a-b. The writings of Fang's younger brother, Fengchen, are appended to the Jiaofeng wenji.

2. His biography in his family records shows that he left the court after realizing that the conquest of the Song was inevitable. See "Family biography," in He Menggui, 11. Fang Yikui's poetry, including poems to He Menggui and Fang Fengchen, is extant and known as Fushan yigao. 


\section{Regional Loyalist Centers}

(d. 1283). ${ }^{1}$ Jiagu was a friend of Zhang Hongfan; both had directly been involved in suppressing the loyalist resistance. Jiagu and Xianyu may well have recommended the Fang brothers and He Menggui to office, an offer repeatedly declined. The next generation, however, did not reject appointments to office. Having never served under the Song, all three sons of Fengchen, one of Fengzhen, and He Menggui's two sons later took up positions as education officials. $^{2}$

\section{Center 5: The Luling Loyalists at Wen Tianxiang's Place of Birth}

Wen Tianxiang's personal retinue during the resistance was characterized by a large number of landsmen and personal contacts. Not all of Wen's followers died as martyrs just before or after Wen's own martyrdom. Xie Ao, a native of Fujian, had escaped during the Yaishan battle and subsequently mourned Wen with loyalist groups in Kuaiji, Hangzhou, and Wuzhou. Among Luling natives who survived and returned home were Wang Yanwu, Zhang Yifu (fl. 1270-90), and Deng Guangjian. In Luling they shared their experiences in the North with Liu Chenweng, a former official, eminent scholar and poet.

Wang Yanwu had initially followed Wen Tianxiang in 1275, but he resigned in the next year to mourn his deceased father and look after his sick mother. In addition to the already mentioned essay urging Wen to commit suicide in 1279 , Wang wrote an elegy praising Wen's indomitable loyalty and upright spirit after the latter died in $1283 .{ }^{3}$ On the strength of these two

1. On Xianyu Shu, see Marilyn Wong Fu. Jiagu Zhiqi's biography is in YS 174.4061-62. For contacts between Jiagu and Fang, see Fang Fengchen, 6.8b, waiji 3.33a; for examples of poetry exchanges between Jiagu and He Menggui, see 10.13a.

2. On Fang's three sons, see his biography by Xu Youren (1287-1364), in Fang Fengchen, waiji 3.29a-b; on He's two sons, see He Menggui, 11.22a.

3. Writings by and on Wang Yanwu are compiled in Cheng Minzheng, 1.1a-12b. The two elegies mourning Wen, "Essay mourning the chief minister (when he was still alive)" and "Essay mourning the chief minister from afar" are also in Wang's own collected writings, in Wang Yanwu, 4.1a-7b. Wang Yousun (b. 1223), also a native of Luling, has also been credited with writing an essay to mourn Wen before the actual death. 


\section{Chapter Five}

pieces he is traditionally commended for his loyal commitment. Wang, however, felt his filial obligation to be more compelling: the many funerary addresses to his parents attest to it. ${ }^{1}$ After Wen's death, Wang lived another thirty years during which his loyalty to the Song underwent a definite transformation. Like his friend who helped him distribute the essay urging Wen to die, he did not take up public employment under the Yuan but consorted with Yuan officials and even wrote literary pieces for them. He congratulated his son's brother-in-law on obtaining a position in a prefecture. ${ }^{2}$ Zhao Wen (1239-1315), a native of Luling, had also followed Wen in the loyalist resistance but later served the Yuan. ${ }^{3}$ Wang's relationship with this landsman, however, remained very close.

Zhang Yifu, a native of Luling, had voluntarily accompanied Wen Tianxiang to the Yuan capital in 1279. For the next three years until Wen's execution, Zhang looked after him and prepared his food, a service for which Wen was extremely grateful. ${ }^{4}$ After Wen's death, it is said that Zhang hid Wen's head, collected his nails and hair, and returned them to Luling for burial. He also took with him Wen's writings and no doubt described Wen's last days to the mourning loyalists in Luling. ${ }^{5}$

1. Wang Yanwu, 4.5a-8b, 9.7a-15b.

2. See "Descriptive essay on the Zhujing hall" (for Myriarch Liu) and "Congratulating the elder brother of my son's wife who obtained a position as instructor, " in Wang Yanwu, 3.7a$9 \mathrm{a}$ and $7.8 \mathrm{~b}$.

3. For Zhao Wen's collected writings, see his Qingshan ji. He served the Yuan first as director of a school and later as instructor in a prefecture. For Wang Yanwu's letter thanking for Zhao's condolences to his mother's death, see Wang Yanwu, 7.7a-11a.

4. Wen Tianxiang was the first to refer to Zhang Yifu caring for himself (Wen Tianxiang, 16.1b). Sources on Zhang, including Tao Zongyi's biography of him, are in Cheng Minzheng, 7.1a-3b.

5. Zhang is believed to have searched and found Wen's wife, née Ouyang, in Dadu; he then accompanied her to cremate Wen's body. See Cheng Minzheng, 7.1a-b. However, from poems written by Wen and Wang Yuanliang, it would appear that Ouyang had actually predeceased Wen. 


\section{Regional Loyalist Centers}

Deng Guangiian was also a central loyalist figure in Luling. He had been rescued from the sea in 1279 and subsequently forced to go to Dadu with Wen. Wen was immensely impressed with Deng and on the journey wrote many poems to him as well as a preface to his poetry collections. ${ }^{1}$ Upon arrival in Dadu Deng seems to have communicated with Wang Yuanliang, sharing lamentations about the collapse of the Song. While in the North, Deng made lasting friendships with former Song officials and northerners in Mongol service. At that time he may have befriended Cheng Jufu, whom he saw again in 1289 when the latter was recruiting talented men for the central Yuan administration. ${ }^{2}$ While in the North Deng's primary student was Zhang Hongfan's son, Gui (1264-1327), who was already a prominent Yuan general at the age of sixteen and who later rose to high ranks in the Yuan bureaucracy. ${ }^{3}$ In subsequent years Zhang Gui memorialized to allow the Song imperial family to retain its tax-exempt status; undoubtedly this concern had been influenced by Deng. After several years of service in Zhang Hongfan's home, Deng was released in 1281 and returned to Luling, where he wrote Wen's biography, the biographies of Wen's followers who were killed or committed suicide, and the record of the loyalist court based on the diary that Lu Xiufu had entrusted to him. Altogether Deng was away from his native prefecture for two decades, but after he returned home he soon renewed relationships with old friends such as Liu Chenweng and Zhao Wen.

It was Liu Chenweng who appears to have been the friendliest with

1. For Wen's poems to and in reference to Deng, see especially Wen Tianxiang, 14.11a-12b and 14.14a-15b; for Wen's preface to Deng's Donghai ji, see ibid., 14.14a-15a. Neither the Donghai ji nor the Tianhai lu has survived.

2. On Cheng Jufu's relationship with Deng Guangiian, see Yuan Ji, 92. For Cheng's reference to Deng's death and his mourning poem to him, see Cheng Jufu, 24.12b-13b, 28.3a.

3. For Zhang Gui's biography, see YS 175.4071-83. On Zhang Gui's memorial, see Zhao Yi, 30.636. Zhang is listed as belonging to Ouyang Shoudao's school of studies (Sunzhao xue'an) through his relationship with Deng Guangjian. See Huang Zongxi, Song Yuan xuean, 88.101. Deng had already returned to Luling in late 1281. See Liu Chenweng, 10.28b29a. 


\section{Chapter Five}

Deng Guangjian upon his return to Luling. Liu and Deng, together with Wen Tianxiang, had been former students of Jiang Wanli and Ouyang Shoudao (b. 1209). Liu was a child prodigy and gained first place in the jinshi examination. ${ }^{1}$ After fifteen years of service including only one month at the central court, Liu's career ended as professor of the Court of Imperial Sacrifices (4A). He did not participate in loyalist resistance, but after the fall of the dynasty did not serve in the Yuan government. At the time of the surrender of Hangzhou and the captivity of the imperial family in February 1276, Liu had already returned to Luling. In a $c i$ entitled "Bingzi songchun" (Farewell, spring, 1276), he expressed his grief over the demise of the Song and equated the passing of spring to the involuntary departure of the imperial family for the Yuan capital:

Farewell, spring!

Spring gone--no road left in the world.

Beyond the swings, the fragrance of the grass reaches up to the sky.

Who will dispatch the sand in the wind over to the southern banks?

Reluctantly, with deep melancholy,

It randomly reminisces about the catkins at the ocean gates.

The wild crows flew past.

The dipper has changed position and the town is deserted.

No longer can be seen the source from which it arrived at the beginning of the new year.

Spring gone--who is the most piteous?

The messenger geese are silent; the pigeons have

1. On Ouyang Shoudao, see his biography in SS 411.12364-66. His collected writings are known as Sunzhai wenji. On Liu Chenweng's early literary success, see "Descriptive essay on the Lixin Hall of the subprefectural school in Luling," in Liu Chenweng, 3.53b. 


\section{Regional Loyalist Centers}

no master.

The cuckoo sounds echo at the Long Gate in the dusk.

Recalling the jade trees in the fallow soil,

Tears fall as dew.

In Xianyang the guest is sent off but several times

looked back--

The horizon cannot be crossed.

Spring gone--will it return?

...

I sigh at the spirits visiting the former country,

Even flowers remember the former age.

Life wanders and falls aimlessly,

Turning to the children, we talk through the night. ${ }^{1}$

Despite the sad and desolate sentiments expressed in the poem, there is a glimmer of hope as Liu reminds himself that spring always returns; moreover, he comforts himself with the thought that his family is still intact. At that time and in subsequent years, he considered himself the "Fleeing refugee" of Luling. ${ }^{2}$ Although he was not an active loyalist, he greatly admired loyalist acts and wrote encomia for loyalist figures such as Jiang Wanli, Wen Tianxiang and lesser known personages. ${ }^{3}$ During these years Liu's eldest son, Jiangsun (b. 1257), shared with him the grief over the collapse of the

1. This poem, in the song title lanling wang, is in Liu Chenweng, 9.5a-b.

2. Huang Xiaoguang, 11.

3. For the encomia for Jiang Wanli and Wen Tianxiang, see Liu Chenweng, 7.34a-35a. For other loyalist personages, see "Funerary inscription for Huang Chunfu" and "Funerary inscription for Chen Libu," in Liu Chenweng, 7.1a-7b, 7.15a-19a. 


\section{Chapter Five}

country and socialized with his loyalist friends. ${ }^{1}$

As Liu Chenweng realized that the Mongol Yuan was due to stay for a long time, his loyalty changed in intensity and form in the following years. His sorrow for the former Song was assuaged by the reunification of China effected by the Mongol conquest: "Under the empire carts and books [once again] travel between the North and South. The pedestrians in big crowds pass through the palaces of Bianliang [Kaifeng, Northern Song capital]. "2 In the 1290s Liu wrote funerary inscriptions for both Chinese and foreign Yuan officials. ${ }^{3} \mathrm{He}$ also conveyed best wishes to his many friends departing for the Yuan capital, presumably in order to seek positions in the government. Liu accepted students of all ethnicities, among whom Xue Angfu (fl. 1280-1300), an Uighur, acquired a solid reputation as a poet. ${ }^{4} \mathrm{Liu}$ 's son, Jiangsun, showed even stronger ambivalence about the former Song. In the 1290s he obtained a temporary post as instructor in a prefecture, but a decade later at the age of fifty he was still writing to Yuan officials, hoping to acquire a po-

1. Liu Jiangsun was a prolific writer: thirty-two juan of his collected writings survive under the title of Yangwu zhai wenji. His father's colleagues, acquaintances, and companions became his own friends. Liu wrote the funerary inscription for Zhao Wen, in Liu Jiangsun, 29.12a-16a. Wang Yanwu's collected writings also contain correspondence with Liu Jiangsun. See "Reply to Liu Jiangsun who wrote the funerary inscription for my eldest son, " in Wang Yanwu, 3.

2. These are the first two lines of the poem "Sending off Li Hetian on his travels to Hangzhou, " in Liu Chenweng, 7.50b.

3. For example, Liu Chenweng wrote the funerary inscription for a high-ranking Yuan official who administered Luling for only forty days before his death. Liu undoubtedly exaggerates when he states that not one scholar-official refrained from mourning the deceased man. See "Funerary inscription for the chief minister Mangha dai meitang," in Liu Chenweng, $7.24 b-28 a$.

4. Xue Angfu's poetry, which has not survived, was highly praised by Zhao Mengfu. See "Preface to the poetry collection of Xue Angfu, " in Zhao's Songxue zhai wenji, 6.64. For a partial translation of Zhao's preface, see Chen Yuan, Western and Central Asians, 132-34. 


\section{Regional Loyalist Centers}

sition in the bureaucracy. ${ }^{1}$ Thoroughly frustrated, he blamed the lack of political opportunities for scholars on the suspension of the examination system after the fall of the Song: "For twenty years there have been no jinshi examinations . . . . If the [Song] had not collapsed, it would not have been thus!"2

In 1288 the loyalists in Luling were joined by a visitor from Dadu. This was Wang Yuanliang, who was probably introduced to them by Deng Guangiian. After reading Wang's poetry relating to the fate of the imperial family and other issues, they wrote prefaces to it. $^{3}$

\section{Center 6: Wang Yinglin and the Loyalists in Qingyuan (Ningbo)}

Only days before the collapse of Hangzhou in February 1276, the loyalist general Zhang Shijie took his remaining forces to Qingyuan, where he hoped to find support for his continued resistance against the Mongols. On his arrival, the local administrators Yuan Hong (1248-98), Xie Changyuan (fl. 1260-1300), and Zhao Mengchuan (fl. 1260-1300) betrayed the loyalist Yuan Yong (d. 1276) and surrendered to the Yuan generals. In the next year there was another loyalist uprising, but it was quickly quelled by the Mongol occupation forces. Wang Yinglin, a native of Qingyuan and former highranking Song official and erudite scholar, praised the loyalty of Yuan Yong, who perished along with seventeen members of his family. ${ }^{4}$ The tradition of active resistance was, however, not characteristic of the loyal survivors who gathered in Qingyuan after the collapse of the Song. Their loyalty to the former dynasty was a lingering nostaglia for the past, and its essence and inten-

1. "Descriptive essay on Shuangfeng school, Nanjian," in Liu Chenweng, 2.7a; "Letter to the administrator Yao Sui," in Liu Jiangsun, 8.5a-b.

2. "Returning from a visit to Yanping," in Liu Jiangsun, 7.11a-12b.

3. Prefaces to Wang Yuanliang's poetry were written by Liu Chenweng, Deng Guangjian, and Zhao Wen. Wang Yanwu and Liu Jiangsun's collected writings also refer to Wang Yuanliang's poetry. See Cheng Minzheng, 11.1a-5a.

4. On loyalist resistance in Qingyuan, see the biographies of Yuan Yong (Wan Sitong, Songji zhongyi lu, 8.9) and Zhao Menglei (d. 1277)(SS 454.13356). Wang Yinglin's poem praising Yuan Yong is in Wang Yinglin, Siming wenxian ji, 5.47b-48a. 


\section{Chapter Five}

sity varied from passive protest to some degree of accommodation. In addition to Wang Yinglin, the other figures were his son Changshi (1267-1327), Hu Sanxing, Shu Yuexiang, Liu Zhuangsun (1234-1302), Chen Yunping (fl. 1260-1300), Huang Zhen (1213-80), Chen Zhu (1214-97), and others.

This group, natives of Qingyuan or of nearby Taizhou, appears to have first met in 1276-79 at the residence of Yuan Hong, who had surrendered to the Mongols. ${ }^{1}$ Qingyuan was then plagued by loyalist uprisings as well as by local bandits from which these scholars and former Song officials sought refuge. During this period they mourned the demise of the Song and at the same time shared their scholarly interests in the Confucian classics, history, and geography. Upon return to their respective homes, these friends continued their relationship and participated in regular gatherings where they composed poems and held serious discussions. As late as 1294 Wang Yinglin was still hosting a poetry society, the guests being Chen Yunping, Shu Yuexiang, and Liu Zhuangsun. ${ }^{2}$

Wang Yinglin came from a family of distinguished political and scholarly men. ${ }^{3}$ His political career had spanned over thirty years by the fall of the Song, but it suffered several setbacks due to his criticism of Jia Sidao. In 1275 Wang was the chief drafter of imperial decrees, appointment notices, and posthumous awards to officials, some of whom turned out to be ardent loyalists and others defectors. Derogatory terms such as "pigs, swine, snakes, ugly caitiffs" in reference to the Mongols were used in these official writings, reflecting the attitudes of both Wang and the Song government to-

1. See Quan Zuwang, waibian 18.906.

2. Ibid., waibian 25.1008-09. The poetry of this group was later collected in a volume, and the gathering itself was compared by Yuan Jue to the Luoyang Poetry Society of Wen Yanbo (1005-69) and eleven veteran officials. "Preface to the poetry volume Shilun tang yaji, " in Yuan Jue, 50.5b.

3. See Wang Yinglin's biography in SS 438.12987-91, in the section for eminent Confucian scholars. There are three chronobiographies of Wang by the Qing scholars Qian Daxin, Zhang Dachang, and Chen Jin. They are appended to Wang Yinglin's collected literary writings, Siming wenxian ji. See also Langley. 


\section{Regional Loyalist Centers}

wards the Mongol threat. ${ }^{1}$ Apart from drafting these documents, Wang criticized Liu Mengyan and Jia Sidao for their incompetent policies; however, he did not offer any constructive proposals to solve the external and internal problems. At the end of the year, only months before the surrender of Hangzhou, Wang fled to his native home and did not return even when summoned by the Song court. ${ }^{2}$ For this irresponsible behavior he was faulted by Ming scholars. His defense came from Quan Zuwang of the Qing, who argued that Wang was not a military official, and since his counsel was not heeded by the court, his departure should be regarded simply as a resignation. ${ }^{3}$ Wang left the court for a reason other than anticipating chaos in the event of the capital's collapse: his younger brother, Yingfeng (1230-75), had just died and he was obligated to return home to look after family affairs. ${ }^{4}$

Upon his return to Qingyuan, Wang devoted the last two decades of his life to scholarship and teaching. He added dozens of titles to his previous writings on the Confucian classics, geography, history, education, and poetry. ${ }^{5}$ Among his students were his son Changshi, Hu Sanxing, Shi Mengqing (1247-1306), Dai Biaoyuan, and Yuan Jue (son of Yuan Hong). In the 1290s Wang taught a Mongol, Bai Xing (1251-1311), whose surname was Yuluboli (Urlugbayli?). ${ }^{6}$ By that time Wang was writing inscriptions and essays on behalf of Yuan officials. It thus appears that as a former high-ranking official of the Song, Wang had compromised his loyalty. Indeed, it was alleged

1. Wang Yinglin, Siming wenxian ji, juan 5, passim.

2. $S S$ 47.935-36.

3. Quan Zuwang, waibian 19.916.

4. See the chronobiography by Qian Daxin, 9a-b. Wang Yingfeng had passed the jinshi examination in 1256 with Wen Tianxiang and Lu Xiufu. Yingfeng wrote the preface to the first family genealogy of Quan Zuwang. See Quan Zuwang, waibian 25.1009.

5. Wang's writings amount to twenty-nine titles (fourteen mentioned in his self-obituary, nine others in SS and six others in bibliographies). See Langley, 476-89; Lü Meique.

6. On Bai Xing's student-teacher relationship to Wang Yinglin, see Yuan Jue's spirit-way stele of Bai Xing in Yuan Jue, 26.452; see also Langley, 472-73. 


\section{Chapter Five}

by Ming scholars that he took a position under the Yuan as a school director. Quan Zuwang, however, claimed that Wang did not actually serve and even if he did, the position of school director would not be appointed from the throne and thus should not be regarded as a sacrifice of Wang's integrity. ${ }^{1}$ In 1295 Wang's student Yuan Jue reluctantly accepted an appointment in the government, and in 1302 Dai Biaoyuan also served. Wang's son Changshi did not hold office, but his grandson Housun (1301-67) did.

Wang's sudden departure from the Song court at a critical time, his indiscriminate choice of associates and students, and his possible acceptance of a Yuan government appointment may have made Wang himself unsure whether he had been disloyal to the Song. Some doubt about fulfilling his political obligations indeed shows in the humble and uncertain tone of his funerary inscription, his final self-appraisal entitled "Self-obituary of the yimin of Junyi":

\footnotetext{
Wang is my surname; Yinglin my name; and Bohou my courtesy name. My ancestors were men of Junyi [in Kaifeng], and had lived in Yin county [in Qingyuan] since the time of my great-grandfather. Yimin refers to my not forgetting the past .... In my studies my late father was my teacher; my younger brother [Yingfeng] was my friend . . . A At nineteen [sui] I became a jinshi graduate of the second class--that was in [1241]. At thirty-four I passed the boxue hongci examination--that was in [1256]. My first appointments were . . [ [over twenty positions ending at] . . . president of the Ministry of Rites ... and president of the Ministry of Personnel . . . I then begged to resign and dwell among the fields--that was in [1275] . . . My nature was diligent and I ha.' few desires; I was direct and not sociable. I was not used to conforming with current practices. At court I was reserved and assiduous; at home I was simple and thrifty. When
}

1. Quan Zuwang, waibian 19.916. 


\section{Regional Loyalist Centers}

administering local districts, I was honest and benevolent to the people. Such conduct was in accordance with my family's instructions. I drafted altogether forty-five juan of imperial documents. My talents are limited and my compositions do not reach [the standards of] the ancients. $I$ indulged in learning and even when old did not get weary of it. I have written [fourteen titles] . . . . but they are not worthy of transmission. I am writing my own funerary inscription . . . . In my life I call myself a recluse, and dead, I address my burial place as the "Grave of the former jinshi Mr. Wang." . . . . The epitaph reads:

In studying antiquity I may have been impractical, My ambitions consistent but foolish.

In office or in retirement, It was as if [all] was restrained or planned.

If I am not worthy of being called a veteran surviving official [of the Song],

Perhaps I have succeeded in guarding my moral character.

When I return to my ancestors, Can I [face them] without trepidation? ${ }^{1}$

Despite this doubt in Wang's mind, he regarded himself a man of Song to the end of his life. His loyalism was not characterized by active resistance, and his distress at the Song demise was alleviated by his conviction that civilization and culture would in the end transcend alien rule. He thus compared the Yuan dynasty with the short-lived Qin (221-09 B.C.): "Scholars were not debased by the Qin dynasty . . . . the classics were not destroyed by the Qin dynasty .... [Chinese] customs and practices were not corrupted by the Qin

1. "Self-obituary of the loyal survivor of Junyi," in the chronobiography of Wang Yinglin by Chen Jin, 33b-35b, appended to Wang Yinglin, Siming wenxian ji. My translation of the epitaph differs from Langley, 459. 


\section{Chapter Five}

dynasty." 1

Among Wang's students, Hu Sanxing, a native of Tiantai, shared with him a great passion for studies in historical geography. Hu was a successful jinshi graduate in the 1256 examination along with Wen Tianxiang and Lu Xiufu. ${ }^{2}$ Wang Yinglin presided at the examination, where all four most likely first met. Shortly thereafter, Hu entered the service of the Huai general $\mathrm{Li}$ Tingzhi with his fellow graduate Lu Xiufu. While in the Huai region, Hu undertook an ambitious project to annotate place names and events in Sima Guang's Zizhi tongjian. In $1270 \mathrm{Hu}$ left the Huai region for Hangzhou where he was hired as family tutor by Jia Sidao's publisher friend, Liao Yingzhong, who promised to obtain Jia's support to print Hu's work. ${ }^{3}$ In $1275 \mathrm{Hu}$ seems to have joined Jia's military campaigns; after Jia's defeat he returned home to Tiantai, where he lost the entire manuscript during the chaos caused by war and banditry. He then bought another copy of the Zizhi tongjian and recommenced the annotations, completing the entire project by 1285 . Part of the work was done when he was a guest in Yuan Hong's house in 1276-79, where Wang Yinglin and other former Song officials were also seeking refuge from the war. He concealed the finished manuscript in Yuan Hong's home, where it survived the disturbances caused by local bandits in $1289 .{ }^{4}$ Although Yuan Hong was a defector and Yuan official, Hu accepted his patronage and taught his son Jue. His loyalty to the Song was nevertheless intense, as evident in his annotations on events of Chinese history. He referred to the Song as "Our dynasty" and "Present dynasty" rather than "Former Song"; while praising the loyal acts of historical figures he condemned for-

1. Wang Yinglin, Wengzhu Kunxue jiwen, 1.6a-b; Quan Zuwang, waibian 19.916. Cf. the translation in Langley, 461.

2. Chen Yuan, Tongjian Huzhu biaowei, 409-10.

3. "Preface to the newly annotated Zizhi tongjian" by Hu Sanxing, in Su Tianjue, 32.423-26.

4. On the work's storage, see Quan Zuwang, waibian 18.906. On Yuan Jue as Hu's student, see "Mourning my teacher Hu Sanxing," in Yuan Jue, 43.731-32. 


\section{Regional Loyalist Centers}

eign rule and disloyal men in no uncertain terms. ${ }^{1}$ When discussing the fall of an earlier dynasty, he equated the distress with his own experience during the collapse of the Song: "Regarding the country's demise, those speaking about it are already deeply grieved. How much more so is [the grief] for those witnessing [the demise]?"2

Hu's loyal feelings towards the Song did not permit him to serve in the new government, although he compromised and continued his relationship with Yuan Hong and other Yuan officials. His son Youwen (fl. 1270-1300) rejected the Yuan, but his grandson could not resist the allure of office. For the rest of his life Hu did not socialize much; among his few friends were Chen Zhu, a fellow graduate of 1256 and native of Qingyuan, who became Youwen's father-in-law. ${ }^{3}$ Chen Zhu seems to have maintained close relations with other fellow graduates including Shu Yuexiang and Huang Zhen, whose grandson married his daughter. ${ }^{4}$ Among his last compositions was a funerary address to mourn his friend and examiner Wang Yinglin, which he completed in 1296. He died the following year. ${ }^{5}$ Like Wang, Chen avoided taking office under the new government despite his extreme poverty. This decision was more easily reached and adhered to because he was already in his sixties when the Song collapsed and he did not expect to live much longer. His unwillingness to serve was related to his having been a Song official; in addition, it seems that his wife was a descendant of the Song imperial fam-

1. During the Sino-Japanese war of 1937-45, Chen Yuan identified his distress about foreign invasions with Hu Sanxing's loyalty to the Song. He categorized Hu's annotations on the Zizhi tongjian according to topics, and commented on Hu's references. See Chen Yuan, Tongjian Huzhu biaowei, passim.

2. Sima Guang, 285.9323.

3. "Preface presented to son-in-law Hu Youwen, " "To Hu Sanxing," and "To son-in-law Youwen," in Chen Zhu, 38.3b-4b, 79.2a-3b.

4. "Preface to son-in-law Huang Zhengsun on his departure for Yue," in ibid., 38.1a.

5. "Essay mourning Wang Yinglin," in ibid., 89.9b-10b. 


\section{Chapter Five}

ily. ${ }^{1}$ After the collapse of the Song he mingled freely with Buddhist and Daoist monks, from whom he accepted gifts of medicine and tea. He called himself "Former veteran official of Siming," and did not use Yuan reign titles until the 1290 s. His loyalty to the Song did not destroy his relationship with his former friends, Yuan Hong and Zhao Mengchuan, who had surrendered to the Mongols and subsequently served under them. ${ }^{2} \mathrm{He}$ became more accommodating towards the Yuan administration and its officials, occasionally writing commemorative essays on their behalf. His sons later took up positions as education officials with his approval, perhaps through recommendations from these politically influential friends. ${ }^{3}$

A fellow graduate and companion of Chen Zhu was Shu Yuexiang, a native of Taizhou, who died a year after Chen Zhu. Shu was an official in Hangzhou; after its collapse, he returned home where he witnessed the atrocities and carnage of war, such as scholars and women being taken captive and herded north along with goats and cattle. ${ }^{4}$ Apart from the Mongol armies, he also blamed local bandits for extensive destruction and unrest in the late 1280 s. He looked beyond his own impoverishment as a result of the change of dynasties and he felt compassion for the genuinely poverty-stricken people. Although he had to sell family possessions and pawn clothes in exchange for food, he considered himself fortunate in view of others worse off

1. This assumption is based on the fact that the ming of his wife and her siblings start with $\mathrm{Bi}$ and that of their father starts with Chong, the same as the corresponding generations of the Song imperial family. For the names of his wife and father-in-law, see ibid., 35.5a, 65.5a$6 \mathrm{~b}$.

2. On writings to Yuan Hong and Zhao Mengchuan, see, e.g., ibid., 80.9b-10a, 89.5a-6b. For a letter to a Mongol, see "To the district's high official Menggu Qizhuan," in ibid., $73.2 b-3 b$.

3. For writings sending off his sons to their employment as education officials, see ibid. 33.1a-2b, 33.4b-6a, 33.9b-10b.

4. Shu Yuexiang's writings, mostly poems, exist under the title Langfeng $j i$. On the suffering of the common people as personally witnessed by Shu, see "Ravages of war in 1276," "Receiving a report about the northern army," and "Last year the Yuan army entered Taizhou," in Shu Yuexiang, 1.23a-b, 1.14b, 3.6b-7a. 


\section{Regional Loyalist Centers}

than himself who had to sell their sons and daughters. ${ }^{1}$ After the collapse of the Song, Shu's constant companion was a landsman, Liu Zhuangsun, who sought refuge with him and accompanied him to poetry gatherings with Wang Yinglin. Neither he nor Shu served in the Yuan government despite their poverty, but their friends included many Yuan officials and former Song officials who joined the Yuan government. ${ }^{2}$ Shu and Liu both accepted students in order to eke out a meager living, but Shu also accepted financial support from Xie Changyuan, a defector mentioned earlier. ${ }^{3}$ Perhaps Shu could thus afford to travel occasionally to Hangzhou to renew old friendships and meet new acquaintances.

Shu's loyalty to the Song thus reflected a certain degree of accommodation, although he did not in the end take up office under the new government. His fellow graduate and close friend, Huang Zhen, a native of Qingyuan, was less compromising in his attitude towards the Yuan. ${ }^{4}$ Considered an eminent Confucian scholar together with Wang Yinglin, Huang was a Song official for seventeen years, during which he was often an advocate acting on behalf of the lower strata of society. In 1275 he became ill and obtained permission to resign his post and return home. After the collapse of the Song, he felt that as a former Song official he was obliged to seclude himself from the world. His friends, Shu Yuexiang and Chen Zhu, did not get any news of him for several years and worried about him. ${ }^{5}$ It is said that he swore never to enter the city; a year after the defeat of loyalist resistance,

1. "Parting with the silver vase," in ibid., 5.14a.

2. On Liu Zhuangsun, see Wan Sitong, Songji zhongyi lu, 13.21. Quan Zuwang believed that both Liu and Shu ought to be commemorated for their refusal to reemerge in public office; however, he did not know that Shu received financial support from defectors. See Quan $\mathrm{Zu}$ wang, ji 5.61.

3. "Remembering the Bamboo cane poem," in Shu Yuexiang, 2.14a-b.

4. Huang Zhen's biography is in SS 438.12991-94.

5. "My fellow graduate Huang Zhen," in Shu Yuexiang, 1.28b-29a; for Chen Zhu's poems to Huang, see Chen Zhu, 90.1a-b. 


\section{Chapter Five}

he died in dire poverty.

Chen Yunping was the most outstanding poet in Wang Yinglin's loyalist group. In the 1260 s he had already gained a reputation in poetry circles in Hangzhou. But unlike his poet friends, Chen played an active role in the loyalist resistance through his connection with the loyalist martyr Su Liuyi. Later, he was suspected of participating in anti-Mongol activities and arrested by Yuan authorities, but he was released through the influence of Yuan Hong. ${ }^{1}$ In the 1290s he was recommended to office but declined the appointment upon arrival in Dadu.

\section{Center 7: Ma Tingluan and Loyalists in Raozhou and Wuyuan}

The Qingyuan loyalist survivors were at least in their fifties by the end of the Song, and they died before 1300 without serving in the Yuan. Likewise, Ma Tingluan and veteran officials were already old when the dynasty collapsed. Most of them spent the last ten years or so of their lives occupying themselves with assiduous scholarship, "writing ten thousand characters a day. "2 After the demise of the Song, Ma and his family returned to their home in Raozhou, which was also the native prefecture of the great loyalist martyr, Xie Fangde. ${ }^{3}$ Ma Tingluan came from a distinguished but impoverished scholar-official family. After gaining his jinshi degree in 1246, Ma steadily advanced to chief minister by 1269 . On account of illness he was granted a pension and a sinecure in his home prefecture in 1273. The demise of the Song affected his illness adversely, but he still wrote extensively on the

1. Chen Yunping's poetry collection is the Rihu yuchang. On Chen's arrest, see Quan Zuwang, waibian 47.1386; "Account of my late father, " in Yuan Jue, 33.568-69.

2. Zhou Mi, Zhiya tang zachao, b.21b.

3. On Ma Tingluan, see his biography in SS 414.12436-39. Ma's retirement is not attributed to illness in this official biography; furthermore, it states that Ma was ordered in 1274 to return to the Song court but did not comply. 


\section{Regional Loyalist Centers}

Confucian classics and on institutional history. ${ }^{1}$ Among his closest friends during this period were Zhou Mi, with whom he exchanged correspondence and poems, and Fei Jietang (d. 1287), a native of Sichuan who seems to have settled in Raozhou. ${ }^{2}$

As a veteran official, Ma felt some guilt for not being with the Song court in its last years; he wrote of his longing for his sovereign and agonized over his "unpaid debt"--death--as was expected of loyal subjects. ${ }^{3}$ Thus when Ma was summoned to the Yuan capital in 1278, presumably to be granted a post, he did not accept. ${ }^{4}$ While reading the poetry collection of Wang Yuanliang twelve years after the events Ma was still painfully reminded of his grief over the demise of the lost kingdom and the fate of the imperial family:

Since I parted with [Wang] Yuanliang in [Hangzhou], it has already been over ten years. One day he came to Leping [in Raozhou] to see me. I was bedridden with illness and although I forced myself to get up to receive him, I could not. My family led Yuanliang to the bed. Seeing each other and talking, it was as if we had been separated for a lifetime. Restless, I had profound thoughts. Yuanliang showed me a manuscript of his [Hushan poetry] and requested me to write a preface to it. Browsing through the volume and reading about [1275] I started to perspire; coming to [the events of 1276] my tears poured out. Then reading the ten stanzas of the "Drunken song" I held on to the mat and wept uncontrol-

1. Most of Ma Tingluan's writings have not survived. His Biwu wanfang $j i$ was compiled by his son Duanlin, but only a small portion of the original is now extant. For a study of Ma Tingluan and his lost writings, see Huang Xiaomin.

2. On poems and essays to and about Fei Jietang, see Ma Tingluan, 18.11a-14b, 24.1a-2b; for prefaces for and poems to Zhou Mi, see Ma Tingluan, 15.2a-4a, 22.2b-3a.

3. See especially Ma's poem to Zhou Mi, in Ma Tingluan, 22.2b-3a.

4. Ma was summoned together with Zhang Jian. See YS 10.206. 


\title{
Chapter Five
}

\begin{abstract}
lably, and lost sense of what they said. My family led Yuanliang out. I had a relapse and could not utter one word for Yuanliang. I thus describe his [poetry] collection as "poetry of history. ${ }^{11}$
\end{abstract}

To the end of his life Ma refused to use Yuan reign titles. In prefaces and funerary inscriptions, he marked the dates by references to the cyclical year, his own age, and historical events. ${ }^{2}$

Ma Tingluan's collected writings were compiled by his son, Duanlin, who is better known as a historiographer and institutional historian. ${ }^{3} \mathrm{Ma}$ Duanlin had passed the subprefectural examinations and taken office, but in 1273 he resigned to look after his sick father. The next year he was dissuaded by his mother from sitting for the jinshi examination due to family responsibilities. ${ }^{4}$ Back in Raozhou after the Mongol conquest he did not socialize much with either his own or his father's friends. For the next twenty or thirty years he examined Tingluan's vast historical documents and used his intimate knowledge and experience of government and court affairs to write an institutional history from the remote past to the beginning of the Southern Song. ${ }^{5}$ His Wenxian tongkao (Comprehensive study of documents and sources) was published in 1319; it was intended to be used as a guide to future government with its concealed criticism of both the Song and Yuan dynastic systems. Ma quotes his father's works and opinions so frequently that the final product re-

1. Ma Tingluan's "Preface to Wang Yuanliang's poetry, " in Cheng Minzheng, 11.3b-4a.

2. For example, "On Fang Jingyun's manuscript" and "Descriptive essay on Laoxuedao court, " in Ma Tingluan, 15.4a-5a, 18.4a-6b.

3. See Bai Shouyi, and Hok-lam Chan, "'Comprehensiveness'."

4. Ma Tingluan's "Funerary inscription for my wife," in Ma Tingluan, 19.15b-16a.

5. Ma Duanlin's own preface to the Wenxian tongkao, in Su Tianjue, 32.437. 


\section{Regional Loyalist Centers}

flects to a great extent Tingluan's own views. ${ }^{1}$ While his father was alive, Duanlin felt obliged to follow his example of not serving another dynasty. Towards 1300 , however, after the completion of his work, the passage of time made it less objectionable for him to accept an appointment with the Yuan first as a school director, then as an instructor in a prefecture. His teacher, Cao Jing (1234-1315), also served as an education official to supplement an inadequate income.

Both Cao Jing and Ma Duanlin's mother were natives of the nearby subprefecture of Wuyuan (in Huizhou). Cao's close friend and landsman was Hu Ciyan (1229-1306), who passed the jinshi examination in 1268, the same year as the loyalist martyr Chen Wenlong who graduated at the top of the list. ${ }^{2} \mathrm{Hu}$ had been a prefect of Guichi in 1275 ; when the general defending the district surrendered he fled home with his mother. For the rest of his life he taught private students for a living and repeatedly declined appointments to public office, but he maintained close relations with his former friends Cao Jing and Chen Li (1252-1334), as well as with Fang Hui. ${ }^{3}$ Cao and Fang took up employment in the Yuan, but $\mathrm{Hu}$ explained his own rejection of service to another ruler in two long poems, in which a middle-aged widow declined remarriage. Hu's position is obvious in the widow's reply, in which gratitude is expressed for the matchmaker's good intentions, but since the widow had married in middle age despite her lack of looks and talent $\mathrm{CHu}$ first served the Song in his middle years), she could not forsake her deceased husband after his death. ${ }^{4}$ In adhering to this stand, Hu was looking at the example of Xie Fangde, whom he admired greatly but did not know personally.

1. Ma Duanlin acknowledges his father's influence; see Hok-lam Chan, "'Comprehensiveness'," 37; Bai Shouyi, 211.

2. Hu Ciyan's writings survive as the Meiyan wenji. Cao Jing's poems and letters to Hu are appended to this work (9.1a-3b, 10.1a-14b).

3. Hu's other close friend was Chen Li, whose writings survive under the title Dingyu ji. Chen $\mathrm{Li}$ also wrote a local genealogy of his native prefecture. See Harriet T. Zurndorfer.

4. "To the widow by the matchmaker" and "To the matchmaker by the widow, " in Hu Ciyan, 2.3a-6b. 


\section{Chapter Five}

Cheng Chuweng (d. 1289) was a poet and Hu Ciyan's landsman. After surviving the loyalist resistance, he traveled through South China, visiting Ma Tingluan, Liu Chenweng, and Xie Fangde, who wrote prefaces to his poetry. ${ }^{1}$ When Xie was taken captive and sent to the North in 1289 , Cheng voluntarily followed him and died on the journey. Another Wuyuan native and former friend of Xie Fangde was Xu Yueqing (1216-85), who had been a Song official. ${ }^{2}$ After the collapse of the dynasty, Xu cut himself off from the world and did not speak for three years. When he recovered his speech, he was so grief-stricken that he became deranged and died several years later.

\section{Center 8: Zheng Sixiao and Gong Kai in Pingjiang}

Pingjiang (Suzhou) was one of the last prefectures to collapse before Hangzhou surrendered. It did not play a role during the ensuing loyalist resistance, nor was it the center of loyalist gatherings during the first generation of Yuan rule. However, in Pingjiang lived two eminent loyalist artists who apparently did not socialize with each other. Zheng Sixiao was a native of Lianjiang (Fujian province) who had accompanied his father, Zhen (d. 1262), to Pingjiang on an official appointment. ${ }^{3}$ Although the family subsequently settled there, Zheng continued to correspond with his old friends in Fujian, among whom were some imperial relatives. In 1275 Zheng was a National University student who petitioned the throne to increase defense measures, but he soon returned to Pingjiang to look after his ailing mother, who died the next year. As the only son, he felt compelled to go into mourning

1. On Cheng Chuweng, see Wan Sitong, Songji zhongyi lu, 15.10. On prefaces to Cheng Chuweng's poetry, see Liu Chenweng, 6.9-19b; Ma Tingluan, 22.8a; Xie Fangde, Dieshan $j i, 6.8 \mathrm{a}-9 \mathrm{a}$ (this preface has Hanweng instead of Chuweng, but it seems to be the same person.

2. Most of Xu Yueqing's writings which survive were written before the collapse of the Song. They exist as the Xiantian ji which contains few, if any, loyalist sentiments.

3. Zheng Zhen's writings, Qingjun ji, were edited by Qiu Yuan and prefaced by Chai Wang's brother in 1301. Appended to the work are Zheng Sixiao's poetry and prose collections, Zheng Suonan xiansheng shiji wenji. Zheng Sixiao also wrote a preface to the genealogy of a branch of the Song imperial family located in Foochow. See Zhao Xinian, 26. 


\section{Regional Loyalist Centers}

for the full period and, therefore, to his agonizing regret abandoned plans of joining the loyalist resistance. He never married nor produced an heir, a situation which compounded his guilt and regret.

As a result of his profound sense of guilt, Zheng completely withdrew from political and social life; even when walking and talking with others, his solitude was evident. ${ }^{1}$ His eccentric character, reflecting his extreme attachment to the Song, was known to his younger contemporaries in the Yuan. $\mathrm{He}$ did not face north, covered his ears at the sound of foreign speech and wailed in the wilderness on special occasions to express his grief over the dynasty's demise. Friends and acquaintances forgot his original name because he adopted sobriquets and styles that conveyed his longing for the Song; for example, "Sixiao" refers to "Pining for the Song. "2 Zheng was a Confucian scholar, geomancer, poet, and essayist, but after the Song collapse, he rejected appointments even as a private tutor. ${ }^{3}$ Contemporary accounts quote his phrases featuring a singular devotion to the former dynasty: "Not knowing today's date or month / I dream only of the mountains and rivers of the Song" and "In this life apart from ruler and father / I have not received benefit from another source. ${ }^{4}$

Zheng's paintings best convey his attitude towards the Song: his fa-

1. "Declining Wu Pan's appointment as Confucian tutor" and "Descriptive essay about the Buddhist hall of Shifang chansa," in Zheng Sixiao, Zheng Suonan, 48b, 56b.

2. Cahill is mistaken in saying that his name was Zheng Mo; he apparently misread and took mou (so-and-so) as Zheng's name. See Cahill, Hills, 16. The earliest accounts of Zheng Sixiao (excluding his own writings and the controversial Xinshi) were by Yuan literati such as Zheng Yuanyou, 1.14-15; Wang Feng, 1.45b-46b; Tao Zongyi, Nancun zhuogeng lu, 20.246-47. See also Mote, "Confucian eremitism," 284-86. Li Chu-tsing's biography of Zheng is more detailed but contains several mistakes, such as Zheng wishing himself to be called "loyal and filial" when in fact he wanted the exact opposite (Franke, Sung Biographies: Painters, 15-23).

3. For the long treatises on geomancy and related matters, see "Reply to Recluse Wu asking about travels and geography, " in Zheng Sixiao, Zheng Suonan, 11b-47b. For his refusal to be employed, see "Declining Wu Pan's appointment as Confucian tutor," in ibid., 47b-49a.

4. Wang Feng, 1.46a-b. 


\section{Chapter Five}

vorite subjects were bamboo and orchid, both symbols of purity and integrity. Later accounts of Zheng describe his ink paintings of orchids as symbolic of his hatred of alien rule. Orchids appeared stemless and rootless in his work, and when questioned about this peculiarity, Zheng impatiently explained that he wished to stress the point that China no longer belonged to the Chinese. ${ }^{1} \mathrm{He}$ was a generous man who donated property and paintings to others but adamantly refused requests by prominent men for his work.

It is in the Xinshi that Zheng's loyalism is most outspoken and characterized by racial and ethnic prejudices. The Mongols are likened to swine, dogs, and other animals. References to Mongol customs and history are vastly inaccurate, attesting to the fact that Zheng had no personal contact with foreigners and wrote down only the general misconceptions circulating at the time. In an essay on legitimate succession in Chinese history, he declared foreign rule to be incompatible with both civilization and natural evolution: "The rule of legitimate succession came from the sages . . . If a subject conducts himself as ruler, and the barbarians conduct the affairs of the Middle Kingdom--of all the inauspicious occurrences from the past to the present, none is worse than that! For barbarians to rule the Middle Kingdom--that is not the fortune of the barbarians. [The situation] can be compared to cattle and horses, which once they understood human language, clothed their fur and tails, and dressed their four hoofs. If a three-foot child saw them, he would only regard them as evil manifestations of cattle and horses, and would not dare call them human beings. "2 Zheng further argued that mere possession of the Middle Kingdom through military victories did not prove the legitimate status of the conquest dynasty.

In sum, Zheng's response to the Mongol conquest and the essence of

1. Zheng's biography in the Suzhou fuzhi preface (undated), in Zheng Sixiao, Zheng Suonan, appendix.2a. The ink-orchid painting is reproduced in Lee and Ho, painting no. 236. On sources relating to Zheng's art, see Chen Gaohua. For extant paintings by Zheng, see Cahill, An Index of Early Chinese Painters and Paintings, 263.

2. The quotation is taken from "Discourses on legitimate successions in the past and present," in Zheng Sixiao, Xinshi, 94. On Zheng's opinions on legitimate rule based on territory, see ibid., 96. 


\section{Regional Loyalist Centers}

his loyalism to the Song was total seclusion. As indicated in his autobiographical essay, the only way he could look at the present state of the world was in isolation and forgetfulness. ${ }^{1}$ He sought consolation in Buddhism and Daoism, but at the end of his life he was equally disillusioned with both as well as with Confucianism, to which he had devoted his early years. He thus called himself "Outsider of the three teachings." For the rest of his life he did not stop blaming himself for neglecting his filial and loyal obligations; at his death, he left instructions that his epitaph should read "Zheng so-and-so, the disloyal and unfilial person of the Great Song." ${ }^{2}$

Despite the mutual interest in painting, Zheng does not appear to have known Gong Kai, a writer, calligrapher, and painter of some renown. ${ }^{3}$ Gong was personally acquainted with the loyalist personalities of the resistance such as Lu Xiufu, with whom he had served on Li Tingzhi's staff. When the Song collapsed, Gong was in Sichuan but soon returned to Hangzhou where he spent some years in the loyalist circles of $\mathrm{Zhou} \mathrm{Mi}$ and Deng Mu; he also searched for eyewitness accounts and records of the loyalist resistance. ${ }^{4} \mathrm{By}$ 1292 he settled in Pingjiang, where he wrote the biographies of Lu Xiufu and Wen Tianxiang, and painted landscape and horses. Like his other friends, Gong was destitute and sold paintings and essays to support his family. His loyalism is best expressed in his horse paintings: the portrayal of the emaciated horse glancing ahead in a dignified posture symbolizes well his own spirit

1. "Biography of Yishi jushi," in Zheng Sixiao, Xinshi, 97-98.

2. Zheng Sixiao, Zheng Suonan, appendix.2b.

3. Gong Kai's writings have been collected in his Guicheng sou ji. Some pieces also appear in Cheng Minzheng, 10.1a-21b. See also his biography in Franke, Sung Biographies: Painters, 64-69; Lee and Ho, 93-95.

4. In 1287 Gong joined one of Zhou's art connoisseurship parties and contributed a long colophon to Zhou's new acquisition. See Ye Shaoweng, Sichao wenjian lu, postscript.18384. Gong also presented Zhou with at least one painting, named "Jiangji tu." Deng Mu was a close friend of Zhou and could have been introduced to Gong in the 1280 s. 


\section{Chapter Five}

of protest and resistance to the new dynasty despite his poverty. ${ }^{1}$ Gong Kai is also noted for writing the encomia with a preface on Song Jiang and the thirty-five bandits of the Water Margin, who were active in the early Southern Song. ${ }^{2}$ By focusing attention on these bandits Gong Kai recognized their potential power, which, in his opinion, might have been harnessed by the Song government to strengthen its defense against usurpers and foreign invaders. Gong Kai avoided official employment under the Yuan, but continued friendships with people who surrendered and subsequently served in the government, such as Fang Hui, to whom he gave one of his paintings. ${ }^{3}$

\section{Center 9: Zhao Bixiang and the "Mediating" Loyalists in Dongguan}

During the loyalist resistance in the southeastern provinces, at least two branches of the imperial Song family migrated to the South. In Dongguan, one family of imperial relatives and at least three locally based lineages formed a loyalist circle of about thirty to fifty survivors in the first generation of Yuan rule. The key personality was Zhao Bixiang (1241-91), who met in poetry gatherings and excursions with a core group of eight others. ${ }^{4}$

Zhao's family, descendants of the son of the first Song emperor, had originally been transferred to Fujian; after three generations there, the clan had moved to Dongguan where it became established local gentry. In 1265 Zhao Bixiang and his father both passed the jinshi examination, and after

1. On the "Emaciated horse," see Lee and Ho, 94-95; Chen Gaohua, 287-99; Cahill, An Index, 295-96.

2. Zhou Mi, Guixin zazhi, xu a.30a-37a. In the late Yuan novel by Shi Nai'an and Luo Guanzhong, Shuihu quanzhuan, these bandits appear as heroes rather than bandits.

3. "Poem to Fang Hui," in Gong Kai, 1a-b.

4. Zhao Bixiang's writings are known as Fupou ji. The following account of the Dongguan loyalists is based on Chen Botao's Dongguan yimin lu, compiled while Chen was seeking refuge in Kowloon after the republican revolution in 1911. Chen assembled a group of friends who, like himself, felt deeply distressed about the change of political order and sought consolation in the momory of the Song loyalists. The poems and essays composed during these gatherings have been compiled in a volume by Su Zedong, entitled Songtai qiuchang. 


\section{Regional Loyalist Centers}

serving in the Song government for some time, returned to Dongguan. ${ }^{1}$ When the loyalist court moved south, Zhao Bixiang offered Wen Tianxiang's brother $\mathrm{Bi}$ his support but soon left to take care of family responsibilities. Before resigning, Zhao persuaded the local ruffian leader Xiong Fei to raise an army for the Song cause. After his father died in 1278, Zhao went to see Wen Tianxiang in Huizhou, and the two became instant friends and composed poetry to each other's rhymes. Upon final defeat of the loyalists forces, Zhao, as an imperial relative, was offered an appointment in the Yuan government but he declined and returned home. He lamented the demise of the Song at the sites of the resistance battles and prostrated and wailed in the direction of Yaishan. He also drew a portrait of Wen Tianxiang, to which he bowed morning and night. It is said that for the rest of his life he met only in the company of other loyalists and imperial relatives; relationships within the group were strengthened by marriage and teacher-disciple arrangements.

Of the imperial relatives who became part of Zhao Bixiang's circle, Zhao Dongshan (fl. 1270-1300) and Zhao Shiqing (fl. 1270-1300) were the closest. ${ }^{2}$ After the Song collapsed, Dongshan covered his ears when others talked about the Yuan dynasty and Shiqing became a virtual recluse. Bixiang's sons were also part of the loyalist circle, and in spite of their poverty, they did not take up employment under the Yuan.

One of the families with which Zhao had relations was that of $\mathrm{Li}$ Yong and his two sons, Chunsou and Deming (both fl. 1270-1300). ${ }^{3} \mathrm{Li}$ Yong was a recluse who sent his son-in-law, the local loyalist Xiong Fei, to support the Song. Li Yong himself eventually went to Japan to teach the Confucian classics, never to return to China after the Mongol conquest. Complying with his last wishes, he was buried in Annam rather than in occupied Song territory. While Li Yong never took public office, his sons had been Song officials. When Mongol troops entered Dongguan, Chunsou implored them not to destroy the town and massacre the people; when offered the administration of

1. "Biography of Zhao Bixiang," in Chen Botao, a.1a-3a.

2. For the biographies of these two loyalists, see ibid., 1.34a-35b.

3. On Li Yong and Li Chunsou, see ibid., b.1a-2b, b.3a-5b. 


\section{Chapter Five}

the district as his reward (presumably for successfully persuading the local defendants to surrender), he firmly declined. Thereafter the two brothers did not take up employment, but taught students to make a living.

One of Li Chunsou's students was Chen Geng (fl. 1270-90), who with his father, Yixin (d. 1289), and brother was closely associated with Zhao Bixiang's loyalist circle. ${ }^{1}$ His son, in fact, married Zhao Bixiang's daughter. Zhang Heng (fl. 1270-1300) was also a member of the loyalist gatherings. ${ }^{2}$ His elder brother, Yuanji (fl. 1270-90), played a compromising role with the Mongols. In 1278 Yuanji went with Li Chunsou to dissuade the Mongol army from destroying the town, but whereas Chunsou refused an office, the former accepted the administration of Dongguan as his reward. ${ }^{3}$ Neither Heng nor another brother served the Yuan, and their children intermarried with Zhao Bixiang's family.

Apart from these families, there were others in the group who expressed some protest against the Mongol conquest. One local magnate advised the loyalists in his district not to overburden the common people, and donated money to help the loyalist cause. ${ }^{4}$ Another cried until he fell ill and died soon after the Song demise, having forbidden his children and grandsons to serve the Yuan. ${ }^{5}$ During the resistance, one of Wen Tianxiang's relatives advised Wen Bi to rebuild walls and recruit garrisons to prepare for the Mongol advance, and when $\mathrm{Bi}$ surrendered, upbraided $\mathrm{Bi}$ for shaming the Wen family. ${ }^{6} \mathrm{He}$ then took his sons to settle in the eastern part of the district and vowed never to go into the city. He grew vegetables to make a living. There was also one Fang Youxue, a former Song official whose wife was a

1. On Chen Yixin and Chen Geng, see ibid., b.14a-16b.

2. "Biography of Zhang Heng," in ibid., b.36b-37a.

3. Ibid., b.4b.

4. "Biography of Di He, " in ibid., b.25b-26a.

5. "Biography of He Wenji, " in ibid., b.27a-28a.

6. "Biography of Wen Yinglin," in ibid., b.41b-42a. 


\section{Regional Loyalist Centers}

descendant of the Song imperial family. Fang and his three brothers did not accept appointments under the Yuan, and apart from being active in Dongguan, maintained friendships with loyalist personalities in other regions such as Xie Ao and Fang Feng in Wuzhou. ${ }^{1}$

Like other loyalist circles discussed earlier, the loyalism of the Dongguan men varied in intensity and character with each individual, entailing both accommodation and resistance. They did not criticize Zhang Yuanji and Li Chunsou for negotiating with the Mongols, nor did they break off ties with Yuanji who took office under the Yuan. In fact, Li Chunsou is included as a member of the loyalist group. His "negotiation for peace" with the Yuan forces to avoid a massacre of the district was actually a euphemism for "surrender" and even Zhao Bixiang, the leading loyalist personality in the group, appears to have taken part in the deliberations. ${ }^{2}$ This compromising role, however, has been suppressed by the genealogies and gazetteers which constitute our major source for these local figures. ${ }^{3}$

In this chapter I have reconstructed and discussed the major themes and personalities of nine loyalist groups which formed after the fall of Song. Except for Annam, Wuzhou, and Qingyuan, these centers have not received much attention from modern scholars. ${ }^{4}$ While dealing with Chen Yizhong and the loyalists who sought refuge in Southeast Asia, I touched on overseas colonization as one consequence of loyalist resistance. With Wang Yuanliang and the loyalists in North China, we looked at their ambivalence towards the Mongol emperor and government despite their loyalist leanings. The major

1. "Biography of Fang Youxie, " in ibid., b.38b-39b.

2. Ibid., b.25b.

3. These were the sources Chen Botao used in his compilation. See ibid., postscript to the index.

4. On the loyalists in Annam, see Hok-lam Chan, "Sung refugees." Xie Ao, Fang Feng, and Wu Siqi of the Wuzhou group are discussed in connection with the second generation of scholars under Mongol rule in Langlois, "Chin-hua Confucianism, " 45-73. The loyalists in Qingyuan are mentioned in Langley's account of Wang Yinglin's students after the collapse of the Song. See Langley, 463-73. 


\section{Chapter Five}

activities of the Kuaiji loyalists focused on recovering the imperial relics, as well as on allusive poetry mourning the Song collapse. While examining the Wuzhou loyalists, I probed the nature of Xie Ao's grief and devotion to Wen Tianxiang, as well as his friendship with Fang Feng and Wu Siqi. Through teaching, these three compatriots made a positive impact on the next generation who played an active role in the Yuan government. They also supported young scholars and poets, as shown in the poetry competition which they sponsored and judged in 1286-87.

Liu Chenweng, the noted poet, is generally associated with the Luling loyalist group. Both he and Deng Guangjian, a survivor of the resistance and landsman, became less distressed with the Song demise over time and through contacts with northerners. The key feature of the Qingyuan group was scholarship combined with teaching. As they gradually realized the positive effects of reunification, loyalists like Wang Yinglin also became more optimistic about the future. In Raozhou and nearby Wuyuan, loyalism to the Song centered around Ma Tingluan and his son Duanlin. In Pingjiang, the talented artists Zheng Sixiao and Gong Kai expressed their loyalism through their paintings, some of which are extant. Lastly, with the loyalists in Dongguan, we observed more clearly the mediating role they played between the established gentry and the Yuan government.

Some loyalist personages discussed in this chapter are well-known figures while others are obscure. Some formed social circles in their native counties, but many left their homes and lived the life of exiles or sojourners in other prefectures. The large number of these self-exiled former scholars and officials reflects the instability of literati families after the Song demise. This examination of their lives and activities under the new political order has revealed a sharp economic decline and downward social mobility of the educated elite. Individuals adopted a practical and pragmatic response to alien rule, in spite of their lingering loyalty towards the former dynasty. In most cases, their loyalty to the Song can be observed to undergo a change over time, and ranged from passive resistance to some degree of accommodation, a process that has been ignored by their contemporaries and later biographers. Each individual, opting out of voluntary death as the ultimate solution, worked out a satisfactory alternative that was not absolute in nature nor drew extraordinary criticism from their contemporaries and later critics. 


\section{SIX / ZHOU MI AND MARGINAL LOYALISM IN HANGZHOU AND HUZHOU}

Absolute loyalism to the Song ruled out any kind of contact with the Yuan government or its officials. The martyr loyalists who died during or shortly after the Song demise were absolute in their loyalty because they did not live under the new regime, nor did their loyalty need to be tested over the passage of time and changed circumstances. As for the yimin loyalists discussed in the previous chapter, the cases of Zheng Sixiao and Xu Yueqing were exceptional: the former kept his loyalty unblemished by total withdrawal and the latter by insanity. As a result of their behavior, both were considered irrational and eccentric even in their own times. The others could not avoid some contact with the Yuan dynasty in their social, economic, political, and personal lives. With them, loyalism could not exist in a vacuum, but had to take into account social and family responsibilities. For these men who lived ten, twenty, or even thirty years after the fall of the Song to adhere to the narrow and absolute dimensions of loyalty from 1276 to 1300 was virtually impossible and rarely accomplished.

For a detailed study of the connection between absolute and marginal manifestations of loyalty, Zhou Mi and his circle of friends in Huzhou (Center 10) and Hangzhou (Center 11) provide a rich source. ${ }^{1}$ Among the zhongyi

1. The primary sources for a biography of Zhou Mi consist of his biji collections and poetry and prefaces on these writings by his contemporaries. Among art historians, Zhou is known for his art connoisseurship and special relationship to Zhao Mengfu, the eminent Yuan artist and official. See van Gulik, 200-15; Li Chu-tsing, Autumn Colors, 21-22; Li Chu-tsing's biography of Zhou Mi in Franke, Sung Biographies, 261-68. Zhou is considered a poet of the yongwu genre and associated with Zhang Yan and Chen Yunping. See Wang Yinghua. Xia Chengtao's chronobiography of Zhou Mi, "Zhou Caochuang nianpu" (pp. 315-22), was first written in 1935 and based on the Qing scholar Gu Wenbin's earlier work. Zhou is perhaps best known for his biji, of which there are six major extant collections, all written after the fall of the Song. 


\section{Chapter Six}

and yimin loyalists, Zhou was the most sociable, versatile, and intriguing personality. He is traditionally regarded as the key loyalist figure in Hangzhou in the same ardent manner as Zheng Sixiao in Pingjiang. ${ }^{1} \mathrm{He}$ was a prolific writer of biji (random jottings), poet, artist, connoisseur, historian, and official whose personal experiences included the loyalist centers in Hangzhou and Huzhou. In addition, he was the only loyalist who had contact with almost all other loyalist groups discussed in the previous chapter. Many of these "like-minded friends" and "traveling companions" reemerged into public office after a period of withdrawal, but Zhou Mi resisted taking this crucial step and preserved his integrity as an unblemished loyalist in the eyes of traditional historians. Apart from former loyalists who became Yuan officials, Zhou socialized openly with northerners and foreigners, often bringing together loyalists and nonloyalists. Excited by the positive impact of political reunification on culture and the arts, Zhou's antipathy to alien rule gradually dissipated. This chapter examines the life of Zhou Mi before and after the dynastic collapse in order to observe the transformation of his loyalism and that of his many friends and associates. A reconstruction of his activities and personal relationships, followed by a study of the predicament of accepting employment faced by individual members of his circle, provides a new perspective on the marginal loyalists--the middle-ground of Song loyalism between the exemplars and collaborators.

\section{Before and During the Song Demise}

Zhou Mi's life before the Mongol conquest was carefree and extravagant, typical of well-to-do scholar-officials of his time. He was born to an eminent clan originally based in Qizhou (Shandong province) which had dis-

1. "On the portrait of Zhou Mi" (dated 1366?) in which Wang Xing (1331-95) states that neither Zhou Mi nor Zheng Sixiao compromised their integrity in any way. See Zheng Sixiao, Zheng Suonan, appendix.5a-b. 
tinguished members during the preceding six generations. ${ }^{1}$ When the Song transferred its capital to Hangzhou, Zhou's great-grandfather, who held office as executive censor, moved the family base to Huzhou. Zhou's grandfather and father were both officials, but by the latter's time, the family wealth was already in decline. ${ }^{2}$ No doubt much of it was spent on the some 42,000 books and 1,500 rubbings and other art objects acquired over three generations. In Zhou's time, the family still owned the former Huzhou residence of the disgraced chief minister Han Tuozhou (1152-1207); its grandeur ranked alongside the magnificent mansions of imperial clansmen and high officials. ${ }^{3}$ One such home had previously belonged to Zhou's maternal grandfather Zhang Liangneng (d. 1214), a distinguished official. ${ }^{4}$

Zhou Mi grew up in Huzhou but spent a great deal of his childhood, youth and early adulthood traveling through Zhejiang and Fujian while accompanying his father on official duties. ${ }^{5}$ Zhou Jin (d. 1265?), himself a cal-

1. The sixth-generation ancestor Fang was a hermit on Mount $\mathrm{Li}$ who refused a summons to the court in ca. 1070. The fifth-generation ancestor Xiaogong was a second-degree graduate and senior secretary in the Ministry of Personnel. Zhou's great-great-grandfather Wei received posthumous honors. His great-grandfather Pi moved to Huzhou with sixteen family members during the transfer of the capital to Hangzhou. His grandfather $\mathrm{Bi}$ was senior secretary in the Ministry of Justice. See "Self-obituary of the old man of Bianyang," in Zhu Cunli, vol. 5, 428-32.

2. As evidence of declining family fortunes, Zhou Mi recalls that his father could not afford some rare books in Hangzhou, which later went into the collection of Chai Wang, a yimin loyalist. See Zhou Mi, Guixin zazhi, xu b.2b.

3. On Han Tuozhou, see his biography in SS 474.13771-78. Zhou Mi, Guixin zazhi, qian.5b$12 \mathrm{~b}$, is a description of the famous Huzhou gardens and residences whose magnificence declined by Zhou Mi's time.

4. Ibid., qian.7a. There are also many references to him in Zhou Mi's Qidong yeyu, 11.140, $16.211,18.239$. He was a third-rank official and one of the ten top officials in the 1210s. See also Peterson, "First Sung reactions," 217, note; Xia Chengtao, 317-18.

5. In Jianning, Fujian, Zhou Mi caught golden-backed turtles and in Hangzhou watched performances by snake and animal charmers. See Zhou Mi, Guixin zazhi, hou.17b and hou.27a28b. The latter reference is partially translated in Gernet, 224-25. 


\section{Chapter Six}

ligrapher, poet, and connoisseur, exerted a singular influence on his only son's life, especially on his feelings for family roots, passion for the arts, and choice of friends and acquaintances. ${ }^{1}$ Zhou Mi's mother was conversant with poetry and he inherited that talent along with her family's interest in antiques. $^{2}$

In his youth Zhou had already met through his travels some of his lifetime friends including Mou Yan (1227-1311), ${ }^{3}$ Zhao Yuyin (1213-65), father of the eminent Yuan artist and official, Zhao Mengfu (1254-1322), ${ }^{4}$ and his wealthy father-in-law Yang Boyan (d. 1254). ${ }^{5}$ Both the Mou and Zhao families also lived in Huzhou. Yang's family home was one of the most prominent and affluent in Hangzhou, where Zhou stayed in the 1250s. Zhou was then attending the National University and disapproved of the abuses committed by his fellow students who accepted bribes and impeached honest

1. Zhou Mi does not seem to have had any brothers; there were three half-sisters by his father's secondary wives (Zhu Cunli, 430). He also had a cousin or uncle who lived in Qingyuan, where Zhou might have owned some property (Xia Chengtao, 347).

2. Zhou also writes about himself and his mother being plágued by frequent illnesses. See his Qidong yeyu, 14.184-85.

3. Mou Yan was the son of Mou Zicai (jinshi 1221), a chief minister in Lizong' reign (biography in SS 411.12355-61). Mou Yan and Zhou Mi first met in 1246-47 in Quzhou, where their fathers were holding office and keeping company with Yang Boyan and Hong Shuzhai (fl. 1250-70). See Zhou Mi, Pinzhou yudi pu, 2.1a-b; "Postscript to Zhou Mi's self-obituary," in Mou Yan, 16.9b.

4. Zhao Yuyin, an imperial clansman, owned and lived in the prominent residences of $\mathrm{Hu}-$ zhou. In Zhou's Caochuang yunyu there is a mourning poem for him (5.190-91). His son, Zhao Mengfu, was probably introduced to Zhou later in the 1260s, when both Zhou and Zhao Yuyin found themselves involved with Jia Sidao's public-land reform. Yuyin was appointed the official in charge of the scheme in Huzhou. Liu Yiqing, 5.2; Xianchun yishi, $1.1 \mathrm{~b}-2 \mathrm{a}$.

5. Yang Boyan was a descendant of Yang Yizhong, a meritorious subject enfeofed by Emperor Gaozong. Yang Boyan was also an official and scholar of the Confucian classics: his extant writings are entitled Jiujing buyun. Zhou and Yang may have shared a mutual interest in poetry and art. 


\section{Zhou Mi and Marginal Loyalism}

officials. ${ }^{1}$ Soon Zhou passed and ranked thirteenth in an examination held at the Ministry of Personnel, whereupon Yang sent congratulations to Zhou's father. ${ }^{2}$ A short time later, he apparently married Yang's daughter, and in 1255-57 he accompanied his father to Tingzhou (Fujian) where the latter was appointed prefect. ${ }^{3}$ Zhou Jin may have died soon after the termination of his post, whereupon Zhou Mi went into mourning. ${ }^{4}$

Zhou Mi passed the jinshi examination in 1260, before he turned thirty. ${ }^{5}$ However, in about 1261 he launched his official career through the merits of his grandfather, who had been a third-rank official. His first appointment was in the treasury department in Jiankang (Nanjing), where his honesty and diligence impressed his superiors. ${ }^{6}$ In 1263 he was promoted to supervise Jia Sidao's land reform in Changzhou, where the problem of private hoarding of grain by large landowners was most acute. ${ }^{7}$ By acting upon the instructions of the central government, Zhou incurred the hostility of the

1. Xia Chengtao, 317. The abuses of the students were most rampant in 1253-60: they would raise the notorious example of the Qin burying the scholars alive if they did not get what they wanted. Neither the emperor nor the ministers dared reprimand them too severely; they intimidated also the city merchants. See Zhou Mi, Guixin zazhi, hou.11a-13b. Zhou admits that only Jia Sidao managed to curtail their power and abuses; he particularly upbraids them for flattering Jia while he was powerful and criticizing him when Jia fell into disgrace. In 1275-76, however, these students seem to have played a loyalist role: they mourned loyalist martyrs, requested the court to take an aggressive defense policy, and accompanied the imperial entourage to Dadu.

2. Zhou Mi, Guixin zazhi, hou.31b-32a. Yang Boyan had also ranked thirteenth in an earlier examination.

3. Ibid., qian.18b.

4. Zhou Jin's life after 1257 is not known. It is certain, however, that he predeceased Zhou Mi's mother, who died in 1264. Contrary to the occasion of his mother's death which he discusses at length, Zhou mentions neither the date or the mourning period for his father.

5. "Preface to bidding Peng Tinglan farewell," in Liu Jiangsun, 12.18-19b.

6. Zhu Cunli, 429.

7. Ibid. 


\section{Chapter Six}

powerful local magnates who suffered most seriously from the policy. Soon he resigned to look after his ailing mother, who died the following year. ${ }^{1}$ During and after the mourning period, Zhou for the first time felt the burden of family responsibilities.

In $1267 \mathrm{Zhou}$ resumed his political career, and until 1274 was based in Hangzhou, where he worked in the water transport department, the imperial pharmacy, the Fengqu granary, and other offices. Among his colleagues were Yuan Hong, Chen Guo (fl. 1270-90), Gao Side (jinshi 1229), Li Lailao and his brother Penglao (both fl. 1260-1300). ${ }^{2}$ In 1270 he befriended the chief minister Ma Tingluan. ${ }^{3}$ In spite Ma's patronage, distinguished family background, and influential marriage connections, Zhou's seventh and final post was subprefect of Yiwu (in Wuzhou) from 1275 to the prefecture's surrender just before Hangzhou collapsed. This means that with a public service of twenty-five years less the mourning periods, Zhou merely reached the sixth rank--certainly not an impressive record. ${ }^{4}$

Zhou later claimed to have done his utmost to advance his political career to bring glory to his family, and he attributed his lackluster performance to the dynasty's collapse..$^{5}$ That, however, is only partly true. During the entire time he held office, he displayed greater interest in creative activities than in administration. It was through his father that Zhou entered the literary world at a young age. In Huzhou and wherever Zhou Jin was posted,

1. Ibid., 429-30.

2. For the colleagues of Zhou and Yuan Hong, see "Former teachers and friends of my late father," in Yuan Jue, 33.570-74. The collected writings of the Li brothers, Guixi eryin ji, contain many poems to Zhou Mi. The Zhou and Li families may have been friends for generations.

3. Xia Chengtao, 341; Ma Tingluan, 15.3a. Zhou states that in 1274 he was often visiting Ma, who was plagued with illness. See Zhou Mi, Guixin zazhi, hou.15b.

4. It normally took a Tang official 23.6 years from his first assignment to chief minister ranked $3 \mathrm{~b}$ or higher. See Sun Guodong, 334. If this study is indicative of promotions in the Song bureaucracy, then Zhou Mi's record is certainly not impressive.

5. Zhu Cunli, 429. 


\section{Zhou M.fi and Marginal Loyalism}

father and son entertained excellent scholars and illustrious men of the day; in return, they were invited to similar social functions. In the company of singing girls and amidst a serene setting of "plum trees, bamboo, ponds, willows and lotus plants" they would in a state of drunken euphoria "write poetry and discuss prose, make music and sing songs." ${ }^{1}$ During these "pleasures of the brush, inkstone, lute and cup--not a day passed without them," Zhou poured wine and composed poetry with his seniors and peers.

But it was in Hangzhou, where the eminent poets gathered, that Zhou explored the literary scene on his own. There, in the late 1250 s he may have met Wu Wenying (1200-60), the leading $c i$ poet who was then patronized by the wealthy Zhang Shu (f1. 1250-80). ${ }^{2}$ Both Zhang Shu and his son Yan turned out to be Zhou's lifetime friends. ${ }^{3}$ In Hangzhou Zhou also studied $c i$ under Yang Zuan (d. 1268), founder of the Yinshe (Recital society) to which belonged the Li brothers as well as friends and colleagues of Zhou's father. ${ }^{4}$ Yang's daughter was in the imperial harem; she later became the consort of Duzong and mother of Prince Shi, who was the half brother of Gongdi and the first prince enthroned by the loyalist movement in 1276. Yang's son, Liangjie, also occupied a high position in the Song court; he later escorted the two Song princes to the southeastern provinces in anticipation of a loyalist restoration. Yang Zuan was probably also related to Zhou's father-in-law, who may have first brought Zhou and Yang Zuan together.

Yang Zuan's school of $c i$ concentrated on elegant and refined compo-

1. Zhou Mi, Pinzhou yudi pu, 2.1a-b.

2. Xia Chengtao, 331. Zhou Mi wrote a few poems relating to Wu Wenying. See, e.g., Zhou Mi, Pinzhou yudi pu, 1.24a-b.

3. Zhou Mi wrote many poems to Zhang shu. See Caochuang yunyu, 3.120-21; Pinzhou yudi $p u, 1.11 \mathrm{~b}, 1.21 \mathrm{~b}-23 \mathrm{a}, 2.4 \mathrm{a}-\mathrm{b}$. Zhang's "Jixian" studio was a popular meeting place among Zhou Mi and his friends at this time.

4. The teacher Zhou had as a youth was Yao Rong (fl. 1240-70) from Fujian. See Zhou Mi, Qidong yeyu, 14.182-84. Yang Zuan is credited with creating two hundred new meters of $c i$ form, now lost. On Yang's relationship with the Song imperial family through his daughter, see Rao Zongyi, Jiulong yu Songji, 84-90. 


\section{Chapter Six}

sition, achieved by rigid adherence to set musical patterns and painstaking choice of language. His poetry society, one of the many that gained popularity in the upper classes of Southern Song, had as its major activity poetry readings combined with pleasure outings, often on West Lake or in the Kanbi Garden owned by Zhou's in-laws. ${ }^{1}$ Poems were written to each other's rhymes, usually describing in minute details objects such as plums, daffodils, chrysanthemums, and scenery. With Yang's death in 1268, the poetry society dissolved but Zhou maintained close ties with the Li brothers who became his colleagues in the water transport department. The three went on excursions to scenic spots in Hangzhou and Huzhou, where Zhou frequently returned in spite of his official appointment in the capital. ${ }^{2}$

During the 1260s Zhou also exchanged poems with Yang Zuan's former students. Other close poet friends were Chen Yunping of Qingyuan and Wen Jiweng of Huzhou, and the Daoist priests Zhang Ruoxu (fl. 1270-90) and Liu Lan (d. 1276). In the early 1270s in Kuaiji he also met Wang Yisun, a poet usually ranked the best among Zhou Mi's circle. ${ }^{3}$ Even before the demise of the Song, Zhou Mi was recognized as a talented poet and his ci were considered among "the most marvelous in the world." 4 By 1276 his poetry volumes were compiled with prefaces contributed by some of the friends just

1. Wu Zimu, Mengliang $l u, 10.299$, says these Hangzhou societies were popular and unique in the empire.

2. Zhou Mi, Pinzhou yudi pu, records such excursions (1.10a-11b).

3. For poems to Li Ruoxu, see Caochuang yunyu, 4.156-59; to Liu Lan, see Pinzhou yudi $p u, 2.19 \mathrm{~b}-20 \mathrm{a}$. For poems to Chen Yunping, see Caochuang yunyu, 6.230-31; Pinzhou yudi $p u, 1.19 \mathrm{a}-21 \mathrm{~b}$. Wang Yusun wrote several poems to Zhou Mi. See Zhou Mi, Juemiao haoci jian, 7.14b-15b, 7.17a-b. On Wang Yisun's poetry, see Chia-ying Yeh Chao, "Wang I-sun."

4. Modern literary critics do not consider Zhou Mi and his circle of friends (Chen Yunping, Wang Yisun, Zhang Yan, Qiu Yuan) to be major poets, but anthologies of Song poetry normally include large selections from their works. Wang Guowei states that Zhou and his group were limited by their experience; in their search for exquisite forms and refined words, their poems fall short of expressing spontaneity and emotions. He opines that their poems could be written by the hundreds in a day. See Adele Rickett, 59-61, 79-81, 83, 89. 


\section{Zhou Mi and Marginal Loyalism}

mentioned. ${ }^{1}$

Apart from poetry, Zhou also nurtured a budding antiquarian interest. In the late 1250 s he inherited some antique objects from his maternal grandfather and father-in-law. ${ }^{2}$ These treasured acquisitions added substantially to the impressive family collection. At this time he was already known to the best artists and connoisseurs; in 1260 he invited the imperial clansman, calligrapher and painter Zhao Mengjian (1199-1267) to an outing on the West Lake where, in the company of other art lovers, they inspected and commented on objects from each other's collections. ${ }^{3}$

Thus until the dynasty's fall, Zhou Mi's life was filled with pleasure outings, poetry gatherings, and antiquarian exhibitions, combined comfortably with an official career. This life-style was typical of upper middle-class officials of the day--the essence of which was to enjoy life, generally unperturbed by political events. Although the Mongols had posed a threat for more than forty years, Zhou, like most officials from Wen Tianxiang to Jia Sidao, never really envisioned that the Song could be completely conquered. His poetry up to 1274 certainly did not reflect this concern, although some close friends in political circles, such as Ma Tingluan and Wen Jiweng, would surely have kept him informed on current developments. ${ }^{4}$ By late 1274 , however, Zhou found the Hangzhou bureaucracy apprehensive with rumors about the impending Mongol crisis, which happened to coincide with two unexpect-

1. The $c i$ and shi collections are known as Pinzhou yudi pu and Caochuang yunyu, respectively. Calligraphic prefaces by Li Lailao, Li Penglao, Chen Cun, and Wen Jiweng are found in the latter, preface, 1-14.

2. In 1259 Zhou obtained a rubbing of a tripod from his father-in-law's studio (Xia Chengtao, 330). The collection of his father-in-law's family was substantial and listed in Zhou Mi, Yunyan guoyan lu, 3.1a-3b.

3. Zhao Mengiian's collected writings survive as the Yizhai wenbian. His date of death was established to be 1267 , thus proving his alleged hostility against his distant cousin Zhao Mengfu who served the Yuan to have been groundless. See Jiang Tiange.

4. There are only several poems with political content in his poetry before 1275 (Caochuang $y u n y u, 6.228-29,6.231-32,6.235-36)$. Two are on the flood in Huzhou and one is on Emperor Duzong's death. 


\title{
Chapter Six
}

ed natural disasters--a devastating flood in Huzhou and a landslide in the capital. Returning to Hangzhou from Huzhou that fall, his colleague Chen Guo told him about his nightmares concerning the Song demise:

\begin{abstract}
"In the first month of spring I [i.e. Chen Guo] repeatedly dreamed about arriving at a large palace hall . . . Approaching close I saw a strange creature squatting on the imperial bed. Next to it was a child in mourning clothes. Just at that moment I woke up in fear. Now the successor is in fact an infant, occupying the throne because the late emperor has passed away. The child in mourning clothes [thus] turned out to be an accurate premonition--nothing could be more inauspicious than this!" I [i.e., Zhou Mi] at the time thought it unreliable, being merely a dream. And yet during that winter, the crossing [of the Yangzi by the Mongol army] in fact took place. ${ }^{1}$
\end{abstract}

It was only after the Song had collapsed that Zhou realized the full significance of the event. He was not an eyewitness of the last days of Hangzhou as the Song capital, since he was then briefly assigned as the subprefect of Yiwu. After hearing the news of the Song surrender, he went to Qingyuan to visit a cousin, and there met Dai Biaoyuan and his friends. The meeting might have been arranged by his friend and colleague in the water transport department, Yuan Hong, a native of Qingyuan who defected to the Yuan in 1276. In the first half of 1279 , shortly after the defeat of loyalist resistance, Zhou was in Kuaiji with thirteen other poets mourning the fall of the Song and expressing outrage at the violation of the Song mausolea. ${ }^{2}$ Out of thirtyseven poems in the anthology compiled on this occasion, Zhou contributed three. The other participants included local Kuaiji men and central figures involved in the mission to recover the imperial relics. Half of this circle had

1. Zhou Mi, Guixin zazhi, qian.5a.

2. Zhou Mi was a contributor to the series of Yuefu buti poems. 
been acquainted with Zhou and included his cousin Wang Yingsun, the two Li brothers, Zhang Yan, and Qiu Yuan.

Being with friends during this time helped Zhou alleviate the pain and sorrow caused by the Song demise. But when returning to his family home in Huzhou later that year Zhou was unprepared for the personal suffering that awaited him. Huzhou was the last Song stronghold before Hangzhou surrendered; prolonged resistance and subsequent plundering resulted in extensive destruction and waste. ${ }^{1}$ Gone were the residence, library, and gallery owned by his family for many generations, and so were his concubines and servants. Fortunately his primary wife, son and daughter were still alive. At fortyseven and destitute, he took his family to live permanently in Hangzhou, returning to Huzhou only for brief visits.

In Hangzhou, Yang Dashou (fl. 1270-1300), his wife's relative, provided the family with lodging in the Guixin quarter. ${ }^{2}$ Yang's residence and gardens were a familiar sight, where Zhou had spent much time during the previous three decades. Since fighting did not take place in Hangzhou during the Mongol invasion, and perhaps because Yang Dashou cooperated with the Mongols, the Yang family did not lose its wealth and status. Shortly thereafter, Zhou was given land and presumably money with which he built his own residence and several studios "among mulberry trees and bamboo, pavilions and pond." Having a generous and affluent relative spared Zhou the frustrations and hardships involved in making a meager living from private tutoring, selling essays, and attracting patrons--a fate from which many of his friends could not escape.

After the Collapse: Life in Huzhou and Hangzhou, 1280-98

For a brief period after settling in Hangzhou, Zhou withdrew from his large circle of friends and colleagues and pondered his personal suffering. His losses--an official career, wealth, and home--were made worse by prema-

1. Zhao Liangchun was the defending general in Huzhou. See his biography in $S S$ 451.13265-66.

2. "Preface to the poetry composed at the banquet by the Yang family pond," in Dai Biaoyuan, 10.91-92; Zhu Cunli, 431. 


\section{Chapter Six}

ture old age and ill health. The most poignant wound inflicted on him was the nagging feeling of being permanently relegated to a sojourner's status in Hangzhou. Writing poetry was no longer a frivolous and purely convivial pastime but became a private and compelling activity to which he turned for solace, reaching the point where "it was not that he could write poetry, but that he could not abstain from [it]." 1 The two volumes produced during the early 1280 s are no longer extant, but the profound emotional impact of dynastic change may be sensed through prefaces to these poems by his friends Ma Tingluan, Dai Biaoyuan, and Deng Mu. ${ }^{2}$ As if they themselves were experiencing the same emotions and turmoil, they observed that Zhou's poetry had become mature and skilled through personal tragedy, aging, and poverty. The poems of his youth were described as "talented," those of his adulthood as "erudite," but the work now produced as "deep-feeling and explosive, disquietingly pensive and sadly sublime." 3

Like his early poetic styles, his carefree and extravagant life also belonged to the past. Although earlier he had often complained about premature aging and frequent illness, now ill health (and probably a lack of sufficient funds) restricted his travels. His last concubine left him by 1281 . Zhou told himself that it would be healthier for him to have fewer desires of the flesh and better to relive pleasures and travels through fond and vivid reminiscence. $^{4}$ An anthology of travel notes by Tang and Song literati, the Cheng-

1. "Preface to the Laji ji," in Ma Tingluan, 15.2b.

2. The two poetry collections, Laji ji and Bianyang shiji, are no longer extant; the former was still listed in the Ming catalog, Yang Shiqi's Wenyuan ge shumu, 436, while the latter was listed in the Qing catalog, Zheng Yuanqing's Hulu jingji kao, 2.29a-b. For prefaces to these collections, see Ma Tingluan, 15.2a-4a; Dai Biaoyuan, 8.76-77; Deng Mu, Boya qin, 30 .

3. Dai Biaoyuan, 8.76-77.

4. Zhou Mi, Guixin zazhi, qian.30a-31b. 
huai $l u$, was probably edited in this quiet and pensive state of mind. ${ }^{1}$

The introspective period seems to have ended by 1282 , and on the whole helped Zhou to make and abide by the major decision of his life--not to seek appointment in the new government. This move was a "compulsory withdrawal" for him, as it was for former officials of the Song. The fact that his family had been in Song service for several generations put additional responsibility on him to preserve its honor and integrity as loyal subjects. Such sentiments, rather than a strong ethnic antipathy for alien rule, were the essence of his loyalism. Unlike Wen Tianxiang, he did not feel committed to take up militant resistance and, if that failed, to die in order to "requite the country." His friends and colleagues were of a similar mind. Unlike Zheng Sixiao, he did not interpret political withdrawal to mean total exclusion of social and cultural life. In fact, for the next two decades he was preoccupied with an extensive network of old friends and new acquaintances, whose companionship alleviated his suffering and developed his versatile talents.

In the 1280s, reemerging into society after a period of introspection, Zhou naturally found himself among old friends, their children and associates, many of whom had been Song officials. Having suffered similarly to Zhou during the dynasty's collapse, they initially could not bring themselves to work for the new government. Zhou kept up communications with his former colleagues and veteran officials, including Ma Tingluan and Chen Guo, who had gone home after the Song demise and were relieving their boredom by writing commentaries on the Confucian classics and copying Buddhist sutras. $^{2}$ Through Ma he was apparently introduced to Fei Jietang, a native of Sichuan who had gone to live in Raozhou and Hangzhou after the dynasty fell. Fei became his principal informant on Sichuan in his random jottings. With these old veterans of the Song court Zhou held discussions on the collapse of the Song and shared the remorseful feelings of being displaced

1. Zhou refers to this mood as chenghuai guandao which appears in the above reference as well as in the preface to the Chenghuai lu. It is an allusion to Zong Bing (fl. 420-79), who traveled throughout the country for thirty years; when he was old and sick he sketched the landscapes he had visited on his walls to invoke the pleasures of his earlier travels.

2. Zhou Mi, Zhiya tang zachao, b.21b. 


\section{Chapter Six}

persons.

Zhou Mi was the only loyalist who had some contact with almost all the loyalist centers described in the previous chapter. Among the refugees in Annam he apparently knew a Jiang Dacheng (fl. 1280-90), who gave him information about that group. ${ }^{1}$ Zhou Mi may have heard about the events of the loyalist resistance through returned members of the Yang family, who had accompanied the two princes to the southeastern provinces and with whom Zhou was acquainted through his former teacher Yang Zuan. In the Dadu group he shared a friend with Wang Yuanliang, namely Xu Xuejiang. ${ }^{2}$ It was perhaps through $\mathrm{Xu}$ that he learned of the exchanges of poems among Deng Guangjian, Wen Tianxiang, Wang Yuanliang, and the imperial concubine Wang Qinghui. Zhou had numerous contacts with the Kuaiji group through participating in poetry gatherings in 1279; in addition, he was Wang Yingsun's cousin and a close friend of Wang Yisun. With Fang Feng and Xie Ao in Wuzhou he shared several intimate friends, including Deng $\mathrm{Mu}$ and Dai Biaoyuan. Zhou was acquainted with the Luling group through Liu Chenwang and his son Jiangsun; furthermore, Zhou was a colleague of Zeng Feng (d. 1277), Wen Tianxiang's former teacher who died in the loyalist resistance. ${ }^{3}$ Zhou's connection with the Qingyuan group was his friendship with Chen Yunping, Dai Biaoyuan, and his former colleague Yuan Hong. He also had a cousin or uncle in the prefecture. As for the Raozhou group, Zhou maintained contact through his mentor Ma Tingluan and his new acquaintance, Fei Jietang. Gong Kai, a close friend living in Pingjiang, also participated in Zhou's gatherings, inscribed his art possessions, and gave him presents of paintings. ${ }^{4}$ Finally, Zhou kept in touch with the Dongguan group

1. Zhou Mi, Guixin zazhi, xu a.8a-9a.

2. Xu Xuejiang was a member of the Yinshe to which also belonged Zhou Mi in the 1260 s. For the reference to Zhang Yan's Ciyuan on this information, see Xia Chengtao, 334. Xu was a close friend of Wang Yuanliang when the latter returned from the north.

3. Liu Jiangsun, 12.18a-19b. On Liu Chenweng, see Guixin zazhi, bie a.37b-38a, 42a-b. On Zeng Feng, see Qidong yeyu, 14.184-85.

4. See Ye Shaoweng, postscript.183-84. 


\section{Zhou Mi and Marginal Loyalism}

most likely through Fang Youxue, a close friend of Fang Feng and Xie Ao.

Zhou was personally connected with another loyalist center in $\mathrm{Hu}-$ zhou, his native home before the collapse of the dynasty. Although he resettled in Hangzhou, he returned at least once a year to tend the family graves. There he renewed old friendships with his former colleagues and friends Gao Side, Chen Cun (jinshi 1247), Wen Jiweng, and Mou Yan; he also socialized with the imperial scion Zhao Mengfu and his circle.

Gao Side, a veteran official, was the son of a celebrated loyal martyr who sacrificed his life in the 1230s fighting the Mongols. Probably influenced by his father's patriotism, Gao went to Huzhou to live after the surrender of Hangzhou. Chen Cun, also a veteran official, returned to his native prefecture of Huzhou and mourned deeply its loyalist martyr, Zhao Liangchun. He refused Yuan employment seven times, and instead, taught students for a living. ${ }^{1}$ Both Chen Cun and Gao Side were preoccupied with copying Confucian classics and Buddhist sutras.

Wen Jiweng claimed Sichuan as his native home, but in fact lived in Huzhou and knew Zhou Mi before 1275, when he contributed a preface to Zhou's early poetry volume. ${ }^{2}$ A veteran high-ranking official (2B), he was criticized by the Song court for fleeing from his responsibilities during its collapse. Returning to Huzhou, Wen devoted his time to scholarship on the classics and repeatedly turned down recommendations to office. Wen apparently did not socialize much, but corresponded with his student He Menggui and his former colleague Fang Fengchen, both of whom had retired to Yan-

1. Gao Side's biography is in SS 409.12322-28; his collected writings, Chitang cungao, contain some exchanges with Huzhou personalities, including the Daoist monk and poet Liu Lan, also Zhou Mi's close friend. On Chen Cun, see Lu Xinyuan, 34.8a. Mou Yan's Lingyang $j i$ contains several essays and poems to him (4.12a, 6.15a-b).

2. Wen Jiweng has no biography in $S S$, in spite of his $2 \mathrm{~B}$ rank. These biographical details are based on Lu Xinyuan, 34.9b. 


\section{Chapter Six}

zhou. ${ }^{1}$ Like their sons, Wen's son served as an instructor in a prefecture under the Yuan.

Of the Huzhou personages, Mou Yan was closest to Zhou Mi. Mou's family was originally based in Sichuan, but he had lived in Huzhou as a child. A childhood friend of Zhou Mi, he was almost as gregarious as Zhou; furthermore, his family connections were even more influential. His father was a chief minister, and he himself was on intimate terms with Prince Fu, Duzong's father. ${ }^{2}$ In spite of its political prominence, his family was poor; after the collapse of the Song, Mou was often cold and hungry and depended on donations from his friends. ${ }^{3}$ A former official of the Song, after its demise he returned to Huzhou and for the next thirty-six years of his life did not leave the prefecture. He taught students and kept company with old and new friends, and gladly responded to their requests for essays and poems. He wrote at least four pieces for Zhou Mi, commenting on Zhou's changed lifestyle and devotion to his past. ${ }^{4}$

In the late 1280s, through Zhou Mi and his friends, Mou Yan was introduced to other acquaintances including Zhang Zhongshi (1260-1325), who subsequently became his son-in-law. Zhang Zhongshi and Mou's other friends, Deng Wenyuan and Dai Biaoyuan, later took up positions with the Yuan, as did Mou's three sons, Yinglong (1247-1324), Yingfu and Yinggui

1. He Menggui was in contact with Wen Jiweng and his sons after the Song demise. See "On Wen Jiweng's diet" and "Preface to Wen Benren's poetry, " in He Menggui, 5.9a-b and 5.21a-b. Wen Jiweng considered himself as close to Fang Fengchen as his own brother and wrote a lengthy funerary inscription for Fang, "Funerary inscription for the late president Fang Fengchen," in Fang Fengchen, 3.5a-20a.

2. Mou Yan's Lingyang ji contains some personal addresses, including birthday wishes, to and for Prince Fu (19.8a-b, 20.7b-8a, 21.6b-7b, 21.8b).

3. Zhou Mi, Guixin zazhi, xu b.21b.

4. "Encomium on Zhou Mi," "Descriptive essay on Zhou Mi's Fu hut," "Preface to Zhou Mi's Qidong yeyu," and "Postscript to Zhou Mi's self-obituary, "in Mou Yan, 7.2b, 10.1a$2 \mathrm{~b}, 12.5 \mathrm{a}-6 \mathrm{a}, 16.9 \mathrm{~b}-10 \mathrm{~b}$. 


\section{Zhou Mi and Marginal Loyalism}

(both fl. 1280-1335). ${ }^{1}$ Mou also stayed on friendly terms with Fang Hui, who was Zhou's enemy, and Liu Mengyan, the former Song chief minister who rose to high rank in the Yuan and recommended Mou's children to office. $^{2}$

In Huzhou, Zhou Mi and Mou Yan both related to a vibrant group of young scholars, poets, and painters, who in the first decade after the Song collapse had also withdrawn from politics. Known as the Eight Talents of Wuxing (Huzhou), they included Qian Xuan, Zhao Mengfu, Mou Yinglong (Mou Yan's eldest son), Xiao Zizhong, Chen Wuyi (Chen Cun's grandson), Chen Zhongxin, Yao Shi, and Zhang Fuheng (all fl. 1270-1300). ${ }^{3}$ Like their teacher Ao Junshan (fl. 1270-1300), they were natives of Huzhou and previously associated with Zhou Mi directly or through their fathers, teachers, or friends. For instance, Zhao Mengfu's father, Yuyin, an imperial relative and official of the Song, had been a close associate of Zhou. With this circle Zhou Mi shared a passionate interest in painting and calligraphy as well as in poetry. Returning to Huzhou once a year, Zhou joined them and pursued his artistic interests. Although none of Zhou's paintings and calligraphy has survived, he is known to have practiced calligraphy and excelled in painting plums, bamboos, orchids, and rocks. ${ }^{4}$ Zhou Mi, in turn, imparted his poetic skills to the other members of the group. Like Zhou, the Eight Talents did not participate in the military resistance, but they also lamented the fall of the dynasty. In the early 1280 s they did not entertain thoughts of reemerging into

1. Mou Yinglong has a biography in SS 190.4337-38. Yingfu was pacifying commissioner of Zhedong when he wrote the preface to his father's Lingyang ji (Mou Yan, preface.1a-b). On Yinggui, see Dong Sizhang, 12.39b.

2. Fang Hui wrote several poems to Mou Yan, who was born the same year as Fang. See Fang Hui, Tongjiang xuji, 21.4b-5b, 21.28a-b. In 1299 Mou wrote a poem to his former teacher, Liu Mengyan, when the latter was eighty years old. See Mou Yan, 4.7a.

3. On the names and biographical sketches of the Eight Talents, see Don Sizhang, 12.33b.

4. Zhou Mi states that his father was skilled in calligraphy, but he himself failed in attempts to emulate the styles of the masters. See Zhou Mi, Guixin zazhi, qian.44b-45a. On Zhou Mi's reputation as a painter, see Xia Wenyan, 5.2b. 


\section{Chapter Six}

public life under the new dynasty. In gathering with friends to talk of the past, compose poetry and pursue their artistic passions, they were not unlike the other loyalist groups discussed in Chapter 5. Beginning in 1286 with the recruitment of Zhao Mengfu by Cheng Jufu, all of the Eight Talents except for Qian Xuan eventually entered Yuan employment. Thus almost all members of this group have traditionally been classified as collaborators rather than Song loyalists, ignoring the fact that for an entire decade, from 1276 to 1286, their life-style was identical to that of Zhou Mi and the other loyalists.

Qian Xuan, considered by art historians as the most important of the loyalist artists, was a generation older than Zhao Mengfu and the other members of the group. ${ }^{1}$ After the collapse of the Song, as a jinshi and former official of the conquered dynasty, Qian felt deep sorrow and could not respond to the summons to office. Subsequently, Qian preferred to keep his own company; he painted only in solitude and when drunk. His protest against the new government manifested itself in his archaic styles, in which he showed a nostalgic longing for the past and a search for his cultural roots. In spite of the different road he took from Zhao Mengfu and the others, the rumor about a break with Zhao seems to have been groundless. On the contrary, Qian showed keen interest in Zhao's acquisitions of paintings and art objects in the course of the latter's official travels under the Yuan. ${ }^{2}$

Although Zhou Mi went often to Huzhou, it was in Hangzhou that he became the focus of a loyalist group that embraced his old friends: the $\mathrm{Li}$ brothers, Qiu Yuan, Zhang Yan, Bai Ting (Qiu Yuan's friend), and Zhang Zhongshi (Mou Yan's son-in law). ${ }^{3}$ With the exception of the Li brothers,

1. On Qian Xuan, see Cahill, "Ch'ien Hsüan;" Lee and Ho, 92-93; Chen Gaohua, 309-25; Xia Wenyan, 5.3a. On Qian Xuan's extant paintings, see Cahill, Index, 264-70.

2. For a comparison of the art of Qian Xuan and Zhao Mengfu, see Li Chu-tsing, "The role of Wu-hsing," 346-57.

3. Zhang Zhongshi's ming often appears as Ying, but is given as Mo by Dai Biaoyuan and Mou Yan (e.g., "Postscript on the genealogy of the Zhang family of Xiqin, " in Mou Yan, 16.9a). On Zhang Zhongshi, see, among many prefaces to his writings, "Descriptive essay of the Xuegu studio," in Dai Biaoyuan 2.33-34; and "Admonition to the Xuegu studio," in Mou Yan, 7.3a-b. 


\section{Zhou Mi and Marginal Loyalism}

most of his earlier friends from Hangzhou had died or gone home after the collapse of the Song. Zhou's companions at this time thus belonged to a younger generation. Zhang Yan was related to him through his father Zhang Shu; Zhang Zhongshi came from the same lineage as Zhang Yan and could well have been a cousin. Zhang Yan, Qiu Yuan (a native of Hangzhou), and Bai Ting (a native of Qingyuan whose original surname was Shu) were young, promising poets in Hangzhou. Zhang Yan and Qiu Yuan had accompanied Zhou to Kuaiji in 1279 and participated in the poetry gatherings deprecating the looting of the imperial tombs.

In the early 1280s Zhou wrote poetry and went on short excursions with these young friends, sharing with them the sorrowful sentiments about the Song collapse. Of these young companions, Zhang Yan was the only one who did not serve the Yuan. From an aristocratic family which in its heyday patronized excellent poets, after the collapse of the dynasty Zhang Yan suffered heaviest from the loss of material wealth. ${ }^{1}$ For the next four decades of his life he became a pathetic figure, wandering through various parts of the country in search of wealthy patrons, the only alternative to selling essays and teaching. In 1286-87 Bai Ting and Qiu Yuan participated in the Yuequan yinshe poetry competition held in Wuzhou, where they became acquainted with the loyalist circle of Xie Ao and Fang Feng, as well as Lian Wenfeng, the top winner of the competition. Upon returning to Hangzhou, Qiu and Bai most likely brought these new friends to Zhou Mi, Zhang Zhongshi, and Zhang Yan. A new friend that was made in Hangzhou at this time was the scholar-poet Tu Yue (fl. 1260-1300), a native of Hangzhou. ${ }^{2}$

At the end of the Song a few Buddhist monks and Daoist priests took up the loyalist cause; after the dynasty collapsed, some former Song officials

1. Zhang Yan's poetry collection is the Shanzhong baiyun ci. On Zhang Yan's travels to seek patrons, see "Preface to seeing off Zhang Yan on his travels to the west," in Dai Biaoyuan, 13.116-17. For its translation, see Shuen-fu Lin, 195-97.

2. On Tu Yue, see "Preface to seeing off Tu Yue to Wuzhou," in Dai Biaoyuan, 13.109-10; "Preface to seeing off Tu Yue to Linshui as an instructor, " in Mou Yan, 5.7a. 


\section{Chapter Six}

entered monasteries to demonstrate their loyalty to the former order. ${ }^{1}$ Wen Riguan (fl. 1270-1300) was a Buddhist monk, a skilled painter of grapes, who expressed indignation at Byan-sprin 1Can-skya for desecrating the Song mausolea. ${ }^{2}$ The Song loyalists were, by and large, eclectic in their religious views, but Zhou Mi and his circle tended to favor Daoism and consorted with a large number of Daoist priests.

In 1289 Zhou was accompanied by Qiu Yuan, Lian Wenfeng, and Zhang Zhongshi on an outing (his second) to the nearby Dadi Mountain retreat, where he met Deng $\mathrm{Mu}$, a native of Hangzhou, Daoist recluse and Confucian scholar. ${ }^{3}$ Having never served the Song, Deng's withdrawal to the mountains was a purely voluntary gesture prompted by loyalist feelings for the Song. In his allegorical autobiographical essay, he shows that he could tolerate life (presumably under Mongol rule) only if he had no knowledge of anything, including the names of Heaven, Earth, and man. ${ }^{4}$ Like Zhou, the change of dynasties convinced him of the ephemeral nature of material things and, taking the idea a level higher, he felt that the change itself was activated by the incessant transformation of all matter. Zhou was impressed with Deng's loyalist feelings as well as his intimate knowledge of Daoism; he felt close enough to request a preface to his poetry collection. But the two occasionally differed in opinion: while Zhou attributed the collapse of the Song to the so-called "spurious learning" and empty talk of Neo-Confucianists, ${ }^{5}$

1. SS 455.13382 contains the biographies of a Daoist priest and a Buddhist monk who perished in the loyalist resistance. On former officials withdrawing into monasteries, see Zheng Yuanyou, 1.2-4, 1.9.

2. Wen Riguan was befriended by Xianyu Shu. On Wen, see Zheng Yuanyou, 1.8-9; Chen Gaohua, 300-08.

3. Deng Mu's collected writings are entitled Boya qin. Zhou Mi and his companions composed poems at the Daoist retreat during both visits, the first being in 1265. See Deng Mu, Dongxiao shiji, 5.3a-b, 9.7b-8b, 10.8a-9b.

4. "Biography of no such man," in Deng Mu, Boya qin, 11a-12a.

5. For Zhou Mi's attack on Neo-Confucians, see Haeger, "Intellectual context, " 505-09, 512. 


\section{Zhou Mi and Marginal Loyalism}

Deng compared the Song demise to a foolish man who shared his killings with a dog whose greed was not appeased and later gobbled up its benefactor. ${ }^{1}$ Another parallel was drawn in which a ghost oppressed the common people until the god of Heaven destroyed it and reversed its evil doings. While Zhou Mi's loyalism was not racial in substance, Deng vehemently opposed foreign rule and argued against sharing territory with foreigners whose greed he considered to be insatiable.

Deng has been considered the only philosopher and political thinker among the Song loyalists on the basis of his two political essays, Jundao (Way of the ruler) and Lidao (Way of the magistrates). ${ }^{2}$ In the former, he set forth the premise that in the ideal era of the sage kings the throne was a coveted, prestigious position and nobody wished to be king. At that time the sage kings were only concerned with what they could do for the people, and not what the people could do for them. Since the Qin dynasty, which Song loyalists often compared with Mongol rule, the throne became coveted and the opposite became true. ${ }^{3}$ The latter essay states that because the virtuous disdained society and withdrew from it, it was no longer possible to employ only the virtuous and the talented in government. Thus incompetent and evil officials came to power and exploited the common people. It concludes by advocating the elimination of officials and prefects so that people could rule themselves, suggesting something akin to democracy and anarchy. ${ }^{4}$ In his criticism of despotic rulers and corrupt officials and in his advocacy of revo-

1. "A man of Yue meeting a dog" and "A ghost flattered in Chu," in Deng Mu, Boya qin, 10a-11a.

2. Deng Mu has also been credited with the theory of a plural galactic universe. See Joseph Needham and Wang Ling, 221. For discussions of Deng's political philosophy, see Fu Loshu, "Teng Mu;" and Qiu Shusen.

3. "The way of the ruler," in Deng Mu, Boya qin, 3b-5a. For its translation into English, see Fu Lo-shu, "Teng Mu," 67-71.

4. "The way of the magistrates," in Deng Mu, Boya qin, 5a-6b. For a summary, see Fu Loshu, "Teng Mu," 71-72. It has been pointed out that the Boya qin inspired the Mingyi daifang lu, written by the Ming loyalist Huang Zongxi. See Fu Lo-shu, "Teng Mu," 71-90; Qiu Shushen, 8. For an analysis of Huang Zongxi's work, see de Bary. 


\section{Chapter Six}

lutionary action to abolish these evils, Deng was voicing his protest against the Yuan bureaucracy as well as the late Song absolutist state and its magistrates. Since the ruler did not have "four eyes, two beaks, a scaly head, and wings," any ordinary person could potentially become a ruler. ${ }^{1}$ Deng, however, did not despair like his loyalist companions, but was optimistic and looked forward to playing an active role. This intention is clearly stated in his preface to his collection of poems and essays of which only one-third has survived:

These poems and essays I have collected are entitled Boya qin [The lute of Boya]. Although Boya [Chunqiu period, 771-477 B.C.] was a skillful lutist, after [his patron] Zhong Ziqi died, he did not play for the remainder of his life. This shows that it is difficult [to find someone] to appreciate the lute. Now the world has no one to appreciate it, and my ceaseless playing the lute is foolish indeed. Boya smashed his lute and broke the strings because Ziqi died. As I have not yet met [my] Ziqi, how can I know whether he has died or not? Thus I have kept these [poems and essays]. ${ }^{2}$

Deng Mu compared the former officials of the Song who withdrew permanently from official life to Zhong Ziqi's loyal lutist, Boya. As for himself who had never served the Song, he could morally cooperate either with the new government or a Song restoration if either proved to be benevolent.

Deng Mu's constant companion in the Dadi mountains was a fellow Daoist recluse, Ye Lin (d. 1306). It has been suggested that Deng and Ye both committed suicide to resist an attempt by the Yuan bureaucracy to re-

1. Deng Mu, Boya qin, 4b.

2. "Self-preface," in ibid., 1 a. 


\section{Zhou Mi and Marginal Loyalism}

cruit their services in $1305 .^{1}$ I believe, however, that there is insufficient evidence to support this assertion, particularly in view of the above preface which expressed Deng Mu's wish to await an opportunity to serve an enlightened ruler.

During the last two decades of his life, Deng met many of Zhou's friends in other loyalist circles, in particular Wang Yingsun, Lin Jingxi, Xie Ao, and Shu Yuexiang, most of whom visited the Dadi retreat; Deng Mu also went often to Kuaiji to see them. Zhou apparently introduced Deng to Wang Yingsun, through whom he might have met Xie Ao in 1294. Xie commuted to Hangzhou often to see his wife and through Deng Mu, Zhang Zhongshi or Zhou Mi, met Deng Wenyuan, a native of Sichuan and resident of Hangzhou after the Song demise. ${ }^{2}$ At that time Deng Wenyuan was sharing a house with Zhang Zhongshi and his brother.

Zhou Mi, together with Deng Mu and Xie Ao, have often been considered the key loyalist figures in Hangzhou. Although Zhou and Xie shared many friends, there is no direct evidence showing that the two knew each other. Zhou's role was not so much in being a key loyalist personality in Hangzhou as in supplying a link with the other loyalist groups and in providing a venue for loyalist visitors passing through Hangzhou. One of these occasions took place in 1288 , when Zhou Mi invited fourteen friends, including natives of Hangzhou and temporary residents, to celebrate the completion of his pond. On that day his guests were urged to compose poetry and forget about the sorrows of the day. Zhou Mi also displayed his art objects for his friends to admire and on which to write colophons. ${ }^{3}$

Dai Biaoyuan was the most important visitor to Hangzhou, and he be-

1. In 1305 Wu Quanjie (d. 1346) was commissioned to seek talented men in south China and he thus obtained the names of Deng Mu and Ye Lin, both of whom declined to serve. See Wu's preface to Deng Mu's Dongxiao tuzhi, 1a-b. On the basis of a statement that the two recluses died "without illness," Fu Lo-shu argues that Deng Mu and Ye Lin committed suicide by starvation ("Teng Mu," 40, 42).

2. On Deng Wenyuan, see his biography in $Y S 172.4023-25$, and his collected writings in Baxi ji.

3. Dai Biaoyuan, 10.91-92. 


\section{Chapter Six}

came a popular personality among Zhou Mi's coterie. ${ }^{1}$ A landsman of Bai Ting (whom he met in Hangzhou) and Zhou Mi's friend Chen Yunping, Dai came from a scholar-official family of modest means. When his official career ended with the collapse of the Song, he was left virtually destitute; during 1276-79 he sought refuge among the Qingyuan loyalists. A man of strong commitment to his family, he immediately hired himself out as a private tutor, selling essays to supplement a meager income. At times he actually tilled the land and begged for donations. His teaching duties took him frequently to Hangzhou where he resided for many years in the 1280s and 1290s next door to Zhang Zhongshi and Deng Wenyuan. Zhou might have initially introduced Dai to the latter two; in any case, Dai soon found himself most welcome in Zhou's circle and established many lifelong relationships. Among these were Zhao Mengfu, Zhang Yan, Qiu Yuan, Bai Ting, Tu Yue, Xianyu Shu, Wang Yingsun, Xie Ao, and Deng Mu. That Zhou was the first point of contact is documented: Dai recorded that it was from Zhou that he had first heard about Bai Ting, through whom he became acquainted with Qiu Yuan. ${ }^{2}$

Dai participated in many of the activities surrounding Zhou's circle, but he often stood outside the circle so he could observe objectively the effects of dynastic change on the Hangzhou literati. These comments are extant in the form of "descriptive essays" on studios and academies associated with these men, as well as in prefaces and postscripts on his contemporaries' travels and writings. He also wrote prefaces to most of Zhou's later poetry and biji collections, commenting on the impact of the Song conquest on Zhou

1. Dai Biaoyuan was almost as popular as Zhou Mi in intellectual circles in Hangzhou and other prefectures after the collapse of the Song. He also wrote many colophons on art objects, but does not seem to have been an art collector himself. His collected writings, Shanyuan ji, provide rich material on the life of the scholars, especially on the contrast before and after the collapse of the Song. For his biography, see YS 190.4336-37. To date, the only substantive work on this interesting personality is Sun Fuhou's chronobiography, Dai Shanyuan nianpu.

2. "Preface to the poetry of Bai Ting" and "Preface to the poetry of Qiu Yuan," in Dai Biaoyuan, 8.79-80, 8.75. 


\section{Zhou Mi and Marginal Loyalism}

Mi's work and life-style. ${ }^{1}$ Unlike Zhou and his helpless friends in the 1280 s who lamented the fall of the dynasty, Dai exhibited a pragmatic and rational acceptance of the change. He did not whine about his poverty, nor did he feel embarrassed about accepting donations of food and money. After witnessing the piteous decline of the social and economic status of the Hangzhou literati and the deterioration of their scholarship, it was this rational, calm and objective attitude that made him take upon himself the task of raising cultural standards and the status of the literati.

Southern scholars like Fang Hui and Zhou Mi often complained about ill-treatment and oppression by northern Chinese and foreigners serving in South China. ${ }^{2}$ However, in spite of this general resentment, several northerners counted conspicuously among Zhou Mi's circle. Beginning in the mid1280s, he expanded his network of friends while pursuing his interests in art, and came into contact with northern Chinese in the employ of the Yuan government who chose to settle in Hangzhou, or whose official duties took them nearby. One outstanding personality among them was Xianyu Shu, who as administrator witnessed the destruction of Yangzhou and showed sympathy for the Song loyalist movement. ${ }^{3}$ A notable calligrapher and art connoisseur, Xianyu Shu shared with Zhou a passion for the arts and became closely acquainted with many of Zhou's friends. Another close companion was Li Kan (1245-1320), a native of Jizhou (Hebei) and skillful ink painter of bamboo. ${ }^{4}$

1. For these prefaces, see Dai Biaoyuan, passim. For prefaces to Zhou Mi's writings, see Dai's "Preface to the Qidong yeyu," in Zhou Mi, Qidong yeyu, preface. 1; "Preface to Zhou Mi's Bianyang shi," in Dai Biaoyuan, 8.76-77.

2. For complaints about northern Chinese and foreigners oppressing southerners and being arbitary and arrogant in south China, see Zhou Mi, Guixin zazhi, xu a.5a-b; "Preface to bidding Jingwen farewell," in Fang Hui, Tongjiang xuji, 12.15b-16a; Yao Congwu, "Cheng Jufu yu Hubilie."

3. Xianyu Shu's collected writings, Kunxue zhai zalu, are extant. Xianyu is frequently mentioned in Zhou Mi's references to art collecting; his private collection is listed in Zhou Mi, Yunyan guoyan lu, 1.2a-b. See also Marilyn Wong Fu. On Xianyu's sentiments in regard to the invasion of the Song, see ibid., 402.

4. On Li Kan, see Chen Gaohua, 100-21; and Kao Mu-sen. 


\section{Chapter Six}

Li Kan was Zhou Mi's principal informant about northern art styles, foreign customs, and extraordinary occurrences. Apart from Li Kan and Xianyu Shu, there were other northerners and foreigners who became fellow connoisseurs and "traveling companions" of Zhou Mi, a circle drawn together by mutual interest in painting and art connoisseurship. They included the Central Asian Gao Kegong (1248-1310), the northern Chinese Guo Tianxi (fl. 1270-1320) and Qiao Kuicheng (fl. 1270-1320), and the Uighur Lian Xigong (12401300). ${ }^{1}$ The latter was the younger brother of Lian Xixian, known inter alia for his adherence to Confucian mourning for his mother. To these new acquaintances Zhou introduced his Hangzhou art collector friends, among them Wang Zhi (fl. 1270-1300). ${ }^{2}$

Among the loyalist groups scattered in regional centers Zhou $\mathrm{Mi}$ played an integrating role by bringing together his disparate friends. Now, within this enlarged circle, Zhou brought his new acquaintances into contact with his old companions and colleagues. For instance, Zhou knew Xianyu Shu and Li Kan first, who along with others, were introduced to Zhao Mengfu and his painter friends in Huzhou. Mou Yan and Dai Biaoyuan were similarly befriended by Xianyu Shu and the others. The setting for these introductions was in the form of social gatherings, during which all of Zhou's friends, Yuan officials and loyalists, were invited; Zhou Mi also accepted their invitations and thus met new arrivals to Hangzhou. The participants have recorded at least three such events.

In 1287 Zhou acquired a rubbing by Wang Xianzhi (344-88), Baomu $z h i$ (Epitaph to the governess), and invited his friends to view it and write

1. For sources on Gao Kegong, see Chen Gaohua, 1-29. On the private collections of Gao Kegong, Guo Tianxi, Qiao Kuicheng, and Lian Xigong, see Zhou Mi, Yunyan guoyan lu, 2.7a, 2.2a-3a, 1.1a-b, 2.5b-6a, and 4.1b-2a. Like Li Kan, they were on official duties in the provincial government of Jiang-Zhe and took the opportunity to mingle with Hangzhou connoisseurs. On Lian Xigong's relationship with Lian Xixian, see Zheng Yuanyou, 1.1.

2. Wang Zhi was a native of Hangzhou and owned a substantial private art collection. See Zhou Mi, Yunyan guoyan lu, 1.4a-6a. He was recommended for office by an eminent official about 1300. See "Preface to bid farewell to Wang Zhi," in Dai Biaoyuan, 13.114. 


\section{Zhou Mi and Marginal Loyalism}

colophons on the scroll. ${ }^{1}$ Among the guests were Xianyu Shu, Qiu Yuan, Bai Ting, and Deng Wenyuan. Other friends who were not present at the unveiling were later invited to view the new acquisition and contribute a colophon: they included Zhao Mengfu, Wang Yisun, Wang Yingsun, Wang Yijian, and Lü Tonglao. Another gathering occurred in 1293, at Xianyu Shu's residence, for a viewing of a "translucent" bronze mirror acquired by Xianyu. ${ }^{2}$ In 1298 , Xianyu Shu held another private exhibition to examine a piece of calligraphy by Wang Xizhi (321-79). ${ }^{3}$ Again during these occasions their common interests bound northerners and southerners, loyalists and nonloyalists in close companionship.

Beginning in the late 1280 s and increasingly more so in the 1290 s, Zhou's activities were chiefly in art connoisseurship rather than poetry gatherings. They took the form of visits to private collections and libraries, accompanied by Xianyu Shu and Wang Zhi in particular. Without some contact with high Yuan officials, Zhou and his friends could not have had the opportunity to view collections such as the former Song imperial library. The visits were thorough and systematic, so that Zhou was able to make notes in the Zhiya tang zachao (Miscellaneous notes from Zhiya Studio) and enter them as catalogs in the Yunyan guoyan lu (Record of things viewed through the eyes as cloud and smoke). ${ }^{4}$ With the generous patronage offered by his relative Yang Dashou, and the influence of Yuan officials, Zhou Mi was not destitute but he often regretted no longer owning a substantial private collection. During the visits to these private collections his objective was two-fold: to appreciate the art objects per se, and to describe them in detail so that he did not need to actually possess such articles to recapture their aesthetic beauty.

1. This scroll with the colophons by Zhou Mi's friends is now in a private collection and was seen by Xia Chengtao. See Xia Chengtao, 356. The colophons inscribed while the scroll was in Zhou Mi's possession are also given in Ye Shaoweng, postscript.177-86. See also Marilyn Wong Fu, 396-97.

2. See Marilyn Wong Fu, 395; Zhou Mi, Guixing zazhi, xu b.31a-b.

3. Marilyn Wong Fu, 407-08; Kao Mu-sen, 92-93.

4. These visits are recorded with dates in Zhou Mi, Zhiya tang zachao, juan a, et passim. 


\section{Chapter Six}

He consoled himself with the thought that in the final analysis it was better to own a catalog, and not to worry about coveting treasures and then fearing their theft or destruction. Through these outings, Zhou's network of relationships extended to other Yuan dignitaries like Myriarch Fei Gongchen (fl. 1270-1300), whose collections he was invited to view and perhaps catalog. ${ }^{1}$ He may also have been commissioned by them to acquire various art objects, acting in some respects as a dealer. ${ }^{2}$

\section{The Dilemma of Service to the Yuan}

While Zhou was freely mingling with both loyalists and those serving the Yuan bureaucracy, most loyalists gradually reemerged from their political withdrawal and broke away from the decision not to serve two dynasties. Like Zhou Mi, they had suffered loss of material wealth and of political and social status during the turbulent years of the Song collapse. Until then they had been relying on private teaching or family savings, patrons or donations to support themselves and their families. Drinking and composing poetry among friends were diversions rather than fulltime occupations for many in Zhou's circle. Zhao Mengfu was the first to reemerge into public office in 1287 during the well-known Cheng Jufu mission to recruit men of talent for the Yuan court. ${ }^{3}$ The fact that Zhao Mengfu had spent a decade in compulsory eremitism in Huzhou, in the company of the Eight Talents of Wuxing, is often forgotten in the light of this "unforgivable" service to the Yuan. The guilt of deserting his principles was considerably exacerbated by the fact that he was a Song clansman; he felt it intensely for the rest of his life and carried it into his paintings and poetry. But right from the time that he was recruited, he hesitated and felt uneasy about the position that he neither initially sought

1. For a visit to Myriarch Fei's collection, see Zhou Mi, Zhiya tang zachao, a.4b. On Fei, whose funerary inscription was written by Mou Yan, see "Postscript to the funerary inscription of Fei's ancestors, " in Huang Jin, 30.25b-26b.

2. Zhou Mi, Zhiya tang zachao, a.7a-b.

3. For Zhao Mengfu's biography, see YS 172.4018-23; see also Chen Gaohua, 30-99. Li Chu-tsing has written about Zhao's guilt in regard to his reemergence into public life. See Li's Autumn colors, 81-85; "The Freer," 314-22. 


\section{Zhou Mi and Marginal Loyalism}

nor happily accepted. In a preface to bid farewell to Wu Cheng (1249-1333), who was returning to South China instead of taking up a post in Dadu, ${ }^{1}$ Zhao expressed envy for Wu's return and asked him to explain his dilemma to his friends in Huzhou and Hangzhou, who might not understand why he had responded to the summons:

Scholars when young maintain their studies at home; many wish to come out and make practical use of their studies for the country. That would allow the wisdom of the sages and the virtuous to extend all over the empire. That was the original motive of scholars. And yet often they stay in seclusion and feel satisfied among the greenery and the cliffs, and even though dying in old age, they would still not regret it. Is that fearing the will of Heaven and grieving over one's poverty? If truly one withdraws and ponders over what one studies, what is useful and what is not useful at present? When can studies be put into practice and when not be put into practice? Thus the plans for our emergence are clearly determined by our wishes. It is not for the purpose of settling and finding an abode.

In recent years, the [Yuan] emperor sent envoys to inspect [the area] south of the Yangzi to seek the virtuous and talented in order to plan for and rule [the empire]. And so the censor Mr. Cheng [Jufu] was also dispatched. Mr. Cheng understood well the emperor's desire for talented minds, thus he got Mr. Wu Cheng of Linquan to return with him [to Dadu]. Mr. Wu is widely learned and knows many things: the classics are thoroughly understood [by him] and his conduct is impeccable. He is up to date and knows about current affairs--a truly excellent choice. Somehow I was also put on the list of the

1. On Wu Cheng's dilemma of public service, see David Gedalecia, 601-05. 


\section{Chapter Six}

recommended.

After arriving at the capital, Mr. Wu changed his mind and wished to return, saying: "My learning is of no practical use here; it cannot be put into practice. "I then composed a poem on Tao Qian and two on $\mathrm{Zhu} \mathrm{Xi,}$ and returned [to my quarters in Dadu]. Mr. Wu's heart is the same as mine. My talents cannot measure up to his by one hundredth. When he is gone, what will become of me?

In my native district there is my teacher, Mr. Ao Junshan, and Qian Xuan, Xiao Zizhong, Zhang Fuheng, Chen Zhongxin, Yao Shi, and Chen Wuyi [i.e., six of the Eight Talents of Wuxing] are my friends. With these several companions in my native home I traveled among the mountains and the waters and was happy indeed. Reading books and strumming the lute I now entertain myself. How could one have suspected that the creator would not spare me [from political involvement]? And how can I be of any use?

The day Mr. Wu left [for South China] he said to me: "I will soon leave and travel down the Yangzi and seek your friends. " I then presented him with my three poems as a parting gift and listed the names of my teacher and friends for him to visit and inform them of my situation. "Dai Biaoyuan, a native of Qingyuan, and Deng Wenyuan, a native of Sichuan, are also my friends. When you arrive in Hangzhou, convey my feelings to them as well. ${ }^{11}$

We observe from this preface that Zhao Mengfu would have been content to remain in Huzhou had he not been summoned. Apparently Zhao's

1. "Preface to bidding farewell to Wu Cheng who is returning to the south," in Zhao Mengfu, 6.62-63. 


\section{Zhou Mi and Marginal Loyalism}

acceptance did affect Zhou Mi's friendship with Zhao briefly, which may have been the reason why Zhou was not listed among the acquaintances Wu Cheng was asked to visit. The break in relationship did not last long; three years later Zhao was writing to Zhou expressing his weariness in office and his longing to resign and return to his friends in South China:

In the dusk the deserted streets emit a white mist, On the way home, the prized horse cannot gallop fast enough.

Disappointed again--my desire to doze in the shade of flowers at high noon.

Tomorrow morning--rise again at the cock's crow, Three years wearily have I served as secretary in the Ministry of State,

Even in dreams my heart is never away from my native place.

This longing I communicate to Master Zhou of Hangzhou Burning incense in his Soul-searching Studio. ${ }^{1}$

The relationship was likely restored by Zhou Mi's avid interest in the cultural and artistic opportunities opened up by the reunification of the country, and Zhao Mengfu, as Yuan official and artist, could help him. Zhao often visited Hangzhou, bringing with him samples of northern trends and styles of painting, calligraphy, and other art objects. Through Zhao, Zhou also heard about the customs and practices of northerners and foreigners. Deeply touched by Zhou's deep concern for his ancestral home in Qizhou, when Zhao Mengfu returned to Hangzhou in 1295 he painted from memory the landscape of Qizhou and presented the painting to Zhou to enable his friend to visualize the place he had never seen but always claimed as his. ${ }^{2}$ In a poem written to Zhou after a meeting in 1296 Zhao Mengfu indicated his

1. "On returning from the office, to be sent to Zhou Mi," in ibid., 5.54.

2. On this painting, see Li Chu-tsing's Autumn Colors. 


\section{Chapter Six}

relief that Zhou was among the few friends who really understood him. ${ }^{1}$ Through Zhao, Zhou Mi met other Mongol dignitaries and northern Chinese, including the above-mentioned Myriarch Fei (father-in-law of Zhao's daughter), who had defected to the Yuan in 1275.

After Zhao Mengfu, Zhou saw other friends leave to take up positions in the Yuan court. These included Wang Yisun (in 1288), Chen Yunping (1291), Yuan Jue (1295), Tu Yue (1296), and Deng Wenyuan (1298). ${ }^{2}$ Few responded to the summons without misgivings, but reassurances by northern friends already in Yuan employment such as Li Kan, Guo Tianxi, and Xianyu Shu assuaged their scruples about accepting office. These Yuan officials and artist friends had first recommended them to office. In about 1300 the talented poet Bai Ting finally accepted an office from $\mathrm{Li}$ Kan, after rejecting Bayan's offer in 1275 and that of Cheng Jufu in 1286-87. Among those recommended by Gao Kegong were Deng Wenyuan, Ao Junshan, Yao Shi, and Chen Wuyi. ${ }^{3}$ Those who finally entered the Yuan government reassured others on their visits home, arguing that the anticipated obstacles to adjusting to a new style of life turned out to be insignificant. ${ }^{4}$ In virtually all cases, the stated excuse for hesitating to serve was the fear of being incompetent, but the more pressing reason for former Song officials was uneasiness about

1. "To the rhyme of Zhou Mi's poem," in Zhao Mengfu, 3.28.

2. On Wang Yisun's service to the Yuan, see Chia-ying Yeh Chao, "Wang I-sun," 62-66. Zhou Mi wrote a poem to see off Chen Yunping on his journey to the north in response to a summons to office. See Zhou Mi, Juemiao haoci jian, 7.4b. On the appointments of Yuan Jue, Tu Yue, and Deng Wenyuan, see the prefaces to bid them farewells, in Dai Biaoyuan, 12.108-09, 13.109-10, 14.118-19.

3. On Bai Ting's recommendation to office by Li Kan, see Song Lian's epitaph of Bai, in Song Wenxian gong quanji, 19.9b. On Gao Kegong's recommendation of Deng Wenyuan and some of the Eight Talents, see Deng Wenyuan's account of Gao's conduct, in Deng Wenyuan, b.23b-24a; Chen Gaohua, 7-8.

4. For example, Deng Wenyuan advises his friend, a Yuan official, to accept a higher appointment. He argues that he himself had been through the same doubts ten years previously, when deciding whether to serve or not. See his "Preface to bid farewell to Guo Wenqing who is assuming the administration of Fuliang, " in Deng Wenyuan, a.16a. 


\section{Zhou Mi and Marginal Loyalism}

serving another dynasty. ${ }^{1}$ Nevertheless, Wang Yisun reluctantly took office but resigned a short while later, while Chen Yunping arrived in Dadu and returned without serving. Tu Yue and Yuan Jue declined office several times before accepting at Dai Biaoyuan's urgings. It is noteworthy that after Zhou Mi's death in 1298, many more in his circle, including Qiu Yuan, Bai Ting, and Dai Biaoyuan, became Yuan officials. Like many of his friends, Qiu Yuan was most unhappy in his service as an instructor in a prefecture. He explained that this decision to accept office was due to poverty and hunger, and not because he wished to become eminent and wealthy:

Before serving I always longed to serve;

When serving I wish to return home.

It then became clear that it is proper to return

And I realize that my seeking employment was wrong.

I took up employment basically due to poverty,

And not due to envy for great wealth.

....

The times are hard with scholars losing employment,

Out of ten families nine are cold and hungry.

How could I not think of the concerns of Yu and

[Hou]ji [i.e., plight of the empire]?

My strength limited--my will opposed. ${ }^{2}$

For the same reasons, Dai Biaoyuan wanted to take up a post and in 1302 was recommended to office. ${ }^{3}$ However, he served for only five years and returned home.

Most of these former Song officials and degree-holders served as edu-

1. For feelings of incompetence, see the above cited prefaces by Dai Biaoyuan.

2. This is from a stanza in a series of poems sent to Hangzhou friends. See Qiu Yuan, Jinyuan ji, 1.20a. Qiu Yuan's other collected writings are known as Shancun yiji. Bai Ting also accepted Li Kan's offer of employment due to poverty. See Song Lian, 19.9b.

3. "Self-preface," in Dai Biaoyuan, preface.5. 


\section{Chapter Six}

cation officials; their offices ranged from tiju (superintendent of schools, 5B) and jiaoshou (instructor of a prefecture, 8-9) to unranked positions such as xuezheng (supervisor of schools) and shanzhang (director of schools or academies). ${ }^{1}$ Ranked positions were appointments from the Yuan court, while unranked offices were appointed at the provincial or local level. Some loyalists finally accepted unranked offices but rejected appointments from the central bureaucracy. For those who felt guilty about serving, the price was indeed high, for even positions as instructorships fetched a meager remuneration of only thirty to forty ounces of silver; thus in spite of their service they did not end up much better off than before. ${ }^{2}$ In exceptional cases, however (e.g., Zhao Mengfu, Yuan Jue, Deng Wenyuan, Bai Ting), more distinguished and financially rewarding positions were reached.

The Loyalism of Zhou Mi, 1276-98

After the collapse of the Song, Zhou's loyalism was first characterized by his close association with loyalist personalities active in various regions in South China. As a former subject, his loyalism was not so much directed to the Song ruler as to Song culture and civilization. Zhou felt compelled to make use of his extensive cultural and political experience to record the customs, culture, and arts of the former age. The Wulin jiushi (Former events of Wulin county), Yunyan guoyan lu, and Juemiao haoci (Absolutely marvelous ci poetry) were written expressly for this purpose. The first was an attempt to update and supplement previous regional records of Hangzhou; it contains rich material on court protocol and imperial festivities since the transfer of the Song capital to the South, graduation ceremonies of jinshi graduates, popular festivals and entertainment centers, and even the names of

1. On these positions, see YS 91.2316. See also Zhou Zumo, "Songwang hou," 196-97.

2. See ibid., 204-08. In this study of Confucian scholars in south China who served the Yuan as instructors, Zhou Zumo indicates three reasons for their reemergence: to gain tax-exempt status, to avoid racial discrimination, and to alleviate poverty. 


\section{Zhou Mi and Marginal Loyalism}

dishes served in Hangzhou restaurants. ${ }^{1}$ Zhou's sources were unofficial and private. As stated in his preface, the work recorded material he had heard from retired officials when he was a child; the details were supplemented by practical experience gained when he was an official. Only after the change of dynasty did he feel the ephemeral nature of the pleasures and customs described in the work which, like the companionship of old friends, were subject to the vicissitudes of the times: "I thought life was always like this; earlier I did not realize that peace and pleasurable things are difficult to come by. "2 $\mathrm{He}$ often related these events to his children, who did not believe him, and thus in order to preserve at least the memory of the past age and its glories, he wrote them down for posterity. Following the same intention, the Yunyan guoyan lu is a description of forty-five private art collections (i.e., all private except for that of the former Song imperial library), ${ }^{3}$ and the Juemiao haoci is an anthology of almost four hundred $c i$ poems by over a hundred Southern Song poets. ${ }^{4}$ Without Zhou's writings, some of these sources on the Southern Song period would not otherwise have been preserved.

Zhou considered himself a serious historian and felt compelled to supplement certain historical events by the particular views of his family. After reading through the records and diaries of his maternal and paternal grandfathers who were both prominent statesmen, he believed (as his father did) that official versions were biased and not up to the standard of his family's records. Because the family library was completely destroyed and he was the last person to have read the books therein, he felt an obligation to draw

1. For a list of Zhou Mi's extant and lost writings, see Xia Chengtao, 371-76. Previous unofficial regional records which Zhou wanted to supplement included Meng Yuanlao's Dongjing menghua lu. See "Self-preface," in Zhou Mi, Wulin jiushi, preface.1a.

2. See ibid. for his motives in writing the Wulin jiushi and for this quotation.

3. Cf. Marilyn Wong Fu, 398, note 54, who says there are forty-one collectors listed. This work also includes the collection of zithers found in north and south China, as well as a list of skillful lutists.

4. Many of the entries by Zhou Mi's friends, like Wang Yisun and Zhang Yan, in the Juemiao haoci are personal poems written to him. 


\section{Chapter Six}

on his memory to reproduce the contents. This was his motivation for writing the Qidong yeyu (Unofficial words of the man from the east of Qi). ${ }^{1}$

Zhou was particularly annoyed at the historiographical tradition of evaluating a person's merits or demerits on the basis of his final victory or defeat. ${ }^{2}$ Thus he opposed the additional incrimination that contemporary historians heaped on the disgraced "treacherous officials" Jia Sidao and Han Tuozhou, because imperial objects had been found in their residences after their disgrace. ${ }^{3}$ He admitted that his wife's family also owned such objects through the spontaneous generosity of the emperor. Although Zhou, like his contemporaries, blamed Jia Sidao for the Song collapse, he was more objective. He argued that despite his other faults, Jia did manage to control the abuses of the Song relatives, eunuchs, and university students. ${ }^{4}$ To be fair to Jia, Zhou placed partial blame for the fall of the Song on the Neo-Confucian philosophers who, in Zhou's opinion, concentrated on "pure discussions" rather than practical methods to improve the precarious state of the country. ${ }^{5}$

Zhou's views on the legitimacy of the Yuan succession to the Song reflect his historical inclinations and his loyalist feelings. He agreed with his former colleague Chen Guo, who elucidated seven "breaks" and six "continuations" of orthodox succession from the disintegration of the Zhou dynasty up to the collapse of the Tang. ${ }^{6}$ It seems that both Zhou and Chen were hoping for a "continuation," i.e. a native dynasty, after the "break", i.e. the Mongol Yuan dynasty, suggesting an optimistic outlook.

1. "Self-preface," in Zhou Mi, Qidong yeyu, preface.1. Mou Yan's preface to the work comments on the unofficial nature of Zhou Mi's work, while that of Dai Biaoyuan discusses Zhou Mi's concern with his ancestral home. See Mou Yan, 12.5a-6b; Dai Biaoyuan's preface in Zhou Mi, Qidong yeyu, preface.1.

2. Zhu Cunli, 430.

3. Zhou Mi, Guixin zazhi, hou.13b-14b.

4. Ibid., hou.11a-13b.

5. Ibid., $x u$ b.4b-6a.

6. Ibid., hou.41a-45b. 


\section{Zhou Mi and Marginal Loyalism}

Zhou's loyalist feelings were also evident in his outrage at the excavation and desecration of the Song imperial tombs. Apart from condemning Byan-sprin 1Can-skya, he denounced the Chinese monks who curried favor with a Lamaist monk by first giving him the idea to loot the graves. In these accounts he used supernatural and retributive elements to prove his point that a bad end would befall those responsible for the infamous incident. ${ }^{1}$

Zhou stood as an ardent loyalist in his harsh criticism of defectors and collaborators. His accounts of their undignified defection all follow the same pattern of ridicule and censure. Before the Mongol army set foot in the district, each of these officials made a public declaration of their loyalty to the Song and determination to repel the enemy forces, and to die if that mission failed; later they could not be found and when the common people assumed that they had died for the Song cause and mourned them, it turned out that they had left their defense posts to welcome the Mongol army. ${ }^{2}$ The criticism of Fang Hui, who surrendered in early 1276, was severe and extended to Fang's disloyalty to Jia Sidao and to his allegedly debauched private life. ${ }^{3}$ Despite his attempts to be objective in portraying some individuals, like Jia Sidao, Zhou's depiction of Fang Hui was highly prejudiced and resulted from a feud between them. The two actually shared many friends in Hangzhou and in other prefectures, from the loyalists Ma Tingluan and Mou Yan to the northerner and Yuan official Li Kan.

If Zhou was excessive in his mockery of Fang Hui, he was silent about his friends who also surrendered to the Mongols. They included Yuan Hong and Fei Gongchen, with whom he continued to be friends in the next

1. Ibid., bie a.44a-50b; $x u$ a.37b-38b.

2. See the accounts of the defections of Fang Hui, Jian Caiwang, and Hong Qiwei, in Zhou Mi, Guixin zazhi, bie a.32a-37a, $x u$ a.24b-25a, $x u$ b.18a-b. Fang Hui's collected writings are Tongjiang $j i$ and Tongjiang xuji.

3. On Fang Hui, see Pan Bocheng; de Rachewiltz' biography of Fang in Franke, Sung Biographies, 349-55; Sun Kekuan, "Guixin zazhi ji Fang Hui shi shuzheng," in his Menggu hanjun, 107-32. 


\section{Chapter Six}

two decades. ${ }^{1}$ Later, when his friends departed for the Yuan capital to serve the new government, although he might have been displeased he did not criticize them in public or in his writings. The double standard he applied is evident in his record of the incident in which Zhao Mengfu composed a poem to mock the disloyalty and expediency of the former Song chief minister Liu Mengyan, at the time when Zhao and Liu were both serving at the Yuan court. ${ }^{2}$ Thus Zhou's historical objectivity was adversely affected by his personal relationships and sentiments.

The defectors were ridiculed for their disloyalty to the Song, but a more serious issue for Zhou was their general fickleness and hypocrisy. Zhou particularly upbraided the scholar-officials in Hangzhou whom he felt were friendly and approachable when one was of equal social and economic status; however, once the other party fell into dire straits, the turnabout was brutal and final. By contrast, Zhou applauded the obscure individuals such as a physician formerly in Empress Dowager Xie's employ who continued to show loyalty to the former sovereign many years after the collapse of the dynasty. ${ }^{3}$ Zhou's friend Dai Biaoyuan also expressed his indignation at prominent men in Hangzhou, who were arrogant and superficial. ${ }^{4}$ Such criticism of the lack of morality and integrity among Hangzhou men reveals the tensions present among the elite circles of the former Song capital. Perhaps, indeed, there were not a few collaborators who turned against former friends and colleagues who had suffered a drastic decline in social and economic status.

It would be a serious mistake to regard Zhou Mi's loyalism as unchanging and only concerned with the preservation of Song cultural and art history. Beginning in the late 1280 s, as his circle of friends expanded to include northerners and Yuan officials, the content and orientation of his writ-

1. Zhou might have also criticized Yuan Hong for defecting, although his writings do not give evidence of it. This criticism may have prompted Yuan Jue's uncomplimentary remarks.

2. Zhou Mi, Guixin zazhi, xu a.39b.

3. Ibid., $x u$ b.15a-16a.

4. See "Descriptive essay on the Qianyi studio," in Dai Biaoyuan, 2.35. 


\section{Zhou Mi and Marginal Loyalism}

ings took on new dimensions and showed a change in his loyalism and an unevenness in historical accuracy. This is particularly noticeable in his Guixin zazhi (Miscellaneous records from the Guixin quarter), a biji miscellany written from 1280 to 1298 . Through his connoisseurship activities undertaken with friends of diverse backgrounds, Zhou was exposed to the positive effects of the reunification of the country. From these new friends, he eagerly elicited information about Sichuan, North China, and even foreign territories, and their customs and habits. Apart from poetry gatherings and art exhibits, Zhou considered informal visits by friends of diverse backgrounds and political views the highlight of his later years. ${ }^{1}$ With them Zhou shared memories of the past era and the glories of the former dynasty, and exchanged the latest gossip about the literati and historical figures. The topics of these conversations ranged from the arts, poetry and poetics to culture in general, archeological excavations, fantastic tales, freakish occurrences, local customs, historical and political marginalia, autobiographical and biographical observations, and mere gossip. Because such conversations provided some introspective moments, brief laughter and enjoyment, Zhou Mi felt the urge to write them down so he could later recapture the pleasures of the visits. Unlike his earlier sole concern to preserve the memory of a past age, self-indulgence became his major motivation for writing the Guixin zazhi.

Zhou Mi, in fact, was often engaged in writing several miscellanies at the same time, which accounts for the duplication of information. Because some items were entered after conversations with friends, it follows that his visitors could also record the same item, as in the case of one appearing almost identical in Bai Ting's collected writings. ${ }^{2}$ In a preface to his writings, Bai Ting, like Zhou Mi, stated that he was merely recording what he and his guests were discussing earlier. ${ }^{3}$ Thus Zhou's influence on his younger contemporaries extended from poetry to their random jottings.

Zhou indicated in his preface that the entries were made at night when

1. "Self-preface," in Zhou Mi, Guixin zazhi, preface.1a-b.

2. This is the item on bianzhang (chief minister). See ibid., qian.45a-b. Cf. Bai Ting, 2.17b.

3. "Self-preface," in Bai Ting, preface.1a. 


\section{Chapter Six}

he was feeling sad and lonely. As they consisted of recollections and reminiscences of earlier talks, they contained many mistakes regarding dates and other details. To be sure, Zhou stated that he was often forgetful and could only recall a small part of the whole. ${ }^{1}$ The historical reliability of an item is also dependent on its nature and the informant. Xianyu Shu, Zhao Mengfu, and Li Kan were the major informants on the arts, culture and customs of North China and foreign areas. ${ }^{2}$ If the material was reported at second hand and dealt with something the informant was not familiar with, the item can be dismissed as hearsay and unreliable. An example of this is the fantastic tale about promiscuous Mongol women having sexual intercourse with the offspring of a wild horse and a dragon. ${ }^{3}$ Although often a credulous person, Zhou Mi used common sense in rejecting stories about Muslims killing albino children in order to obtain pearls from their brains. ${ }^{4}$ If, on the other hand, the material dealt with poetry and art collections, with which both Zhou Mi and his informants were familiar, it was undoubtedly highly accurate. Given Zhou's familiarity and personal experience, his portrayal of the customs and culture of Hangzhou in the late Southern Song can be regarded as reliable. As for historical and biographical information, each case must be determined separately. Regarding the additional information on historical events drawn from his family library, even accounting for his family's bias against the Neo-Confucian school of $\mathrm{Zhu} \mathrm{Xi}$, one can perhaps still assume a fairly high degree of reliability.

A crucial point to consider when evaluating Zhou Mi as a historian is the nature of biji miscellanies, which consisted of items entered casually as in a diary. Anything that came to mind was jotted down without thought to organization or relevance to the previous entry. Thus the content of these works

1. "Self-preface," in Zhou Mi, Guixin zazhi, preface.1a-b.

2. In the Guixin zazhi the informant's name is often given in the text or at the end of an entry.

3. Zhou Mi, Guixin zazhi, xu a.39b-40a.

4. Ibid., bie a.40a. 


\section{Zhou Mi and Marginal Loyalism}

was not the result of meticulous research, but merely an opinion of the moment. To draw on Zhou Mi's work for events of the Song and Yuan periods as reliable simply because he was a contemporary is thus not always advisable. Modern historians, however, have often indiscriminately quoted Zhou for elucidation and support of certain facts and records to supplement other historical sources. ${ }^{1}$ To account for some errors concerning persons, dates and facts in Zhou Mi's work, a modern scholar has simplistically suggested that Zhou deliberately blended history and gossip in order to avoid Mongol censorship. ${ }^{2}$ It is clear from the above discussion that these mistakes resulted from a combination of Zhou's forgetfulness and the circumstances under which he wrote.

Zhou Mi's writings have been interpreted as supporting evidence of his passive resistance to Mongol rule, uncompromising loyalty to the Song, and a desire to "requite" the former dynasty by preserving its relics and culture. $^{3}$ After an examination of his various sources and informants as well as his motives for writing, I feel that this view of Zhou's loyalism is exaggerated. As stated earlier, jotting down miscellaneous notes was often an activity that relieved his boredom and allowed him to recapture the earlier pleasures of conversations among friends. By the 1290s few of these friends remained staunch loyalists but were in fact about to enter, or were already in, Yuan employment. Perhaps in the years immediately after the Song collapse, Zhou genuinely intended to record the history of the Song as a passive protest to Mongol rule, but towards the mid-1280s and increasingly more so in later years that was no longer his sole motivation in his random jottings.

Zhou Mi's life after the Song demise was both typical and atypical of his scholar-official contemporaries. Like them, he lost his financial independence, but in his case he found a generous patron in his relative Yang Dashou who provided him with the material means for a comfortable life. He was

1. For example, in regard to the flight of the two Song princes, see Rao Zongyi, Jiulong yu Songji, 6; in regard to the imperial relics, see Yan Jianbi, 46-48.

2. Fu Lo-shu, "Teng Mu," 53.

3. For example, see Ji Yun, 165.3454-55; Xia Chengtao, 357. 


\section{Chapter Six}

thus spared the need to teach or to compose essays on commission, a situation that confronted many of his friends who had been Song officials. It has been suggested that because of his expertise in the arts, Zhou was commissioned by Yuan officials and local magnates in Mongol employ to catalog their private collections of paintings and art objects, and so in the course of his work he could not avoid socializing with these nonloyalists and thus undermined his reputation as a loyalist. ${ }^{1}$ Zhou was certainly not destitute, as he could afford to have several studios and acquire art objects. Some acquisitions may of course have been gifts from Yuan dignitaries to pay for services rendered. Zhou Mi's life was atypical in another area--the nature of his extant writings. His friends left collected prose and poetry, including numerous prefaces and essays written for contemporaries. Many of these writings on Zhou Mi's works survive, but there is no record that Zhou wrote any preface and essay in return. While many of his friends taught privately and entered lasting relationships with their pupils, Zhou had few or no students after the collapse of the Song.

Contrary to previous assumptions, it should be noted that, except for the brief period of introspection in 1280-81, Zhou's decrepitude did not set in until a decade after the Song collapse because, as noted earlier, he maintained a rather lively life-style with old and new friends. ${ }^{2}$ But as the years passed and more of his friends left Hangzhou to take up appointments as education officials, Zhou Mi became less active, his aging appearance and frequent mood changes contrasting sharply with his earlier youthful demeanor and carefree personality. Though he still participated in connoisseurship outings, he became increasingly concerned with the past and with his roots, a sentiment which took on a more personal and poignant significance. $\mathrm{He}$ thought incessantly about his ancestral home in Qizhou as well as his destroyed family home in Huzhou. The sobriquets adopted in this late phase of life reflected his mental anguish in feeling distant and detached from these

1. Xia Chengtao, 357, 369.

2. See, e.g., Shuen-fu Lin, 194-95. 


\section{Zhou Mi and Marginal Loyalism}

\section{two places. ${ }^{1}$}

In 1291 , in this nostalgic and sensitive frame of mind and contemplating his death, Zhou had a mountain hut constructed next to his ancestors' graves in Huzhou. He even composed his own funerary inscription and epitaph, instructing his cousin Wang Yingsun to fill in the dates of his death. In the epitaph he evaluated his life and justified parts of it that needed qualification:

The old man of Bianyang, Zhou Mi, was styled Gongin. My ancestors were natives of Qi . . . I was first hired in the treasury department in Jiankang through the merits of my grandfather. I was honest and diligent and regarded as talented. Thus six times there were appointment letters, and I was transferred to the transport and pharmacy offices in the capital, and the military governments. From the Fengqu granary I was promoted and soon the court dispatched me to administer Yiwu [Wuzhou]. My lifelong ambition to bring glory to the family can thus be said to have been fulfilled. And yet times were constantly changing, and my goals were not realized even at an old age. Was that not the doing of Heaven!

During [1261-64] when the limitation of land [i.e. Jia Sidao's land reform] was carried out, Changzhou was most seriously affected. The court ordered me to supervise it; upon arrival [in accordance with central government policy] I confiscated three-tenths of the excess

1. During his lifetime Zhou Mi adopted many styles and sobriquets. In his youth and adulthood he used Gongiin (Public and diligent), Caochuang (Grass window) and Pinzhou (Duckweed island). The names adopted after the Song collapse reflect his preoccupation with his place of origin, Qizhou, and his family home, Huzhou: to the former belong Qiren, Sanqi (Native of Qi), Huabuzhu shanren (Recluse of Hua Mountain) and Liren (Man of Li Mountain); to the latter belong Bianyang laoren (Old Man on the sunny side of Bian Mountain), Sishui qianfu (Hermit of the four rivers), Tiaoren and Zharen (Man of Huzhou). Zhou's contemporaries also referred to him as Zhou Yiwu, Yiwu being the location of his last public office. 


\section{Chapter Six}

land and thus greatly opposed the wishes of the powerful [local] officials.

Before trouble descended on me, it happened that my mother was taken ill and I immediately returned to look after her. For the next year I attended to her health diligently but she died the year after. During the experience of bereavement, I arranged the funeral to the best of my abilities and then edited Shenzhong bian (On bereavement) in five chapters. My three younger sisters were all born from my father's concubines, but I tried my best to marry them to prominent families. To distant relatives who were poor I gave assistance generously; to those who became ill I disregarded any inconvenience and sent them medicine and remedies. Even with small living creatures such as insects and worms, I wanted to sustain their lives.

I was unyielding and abhorred crimes. If I heard of anything unjust, my hair bristled and I knocked my fist, and would not condone it.

From a tender age I was bright and quick at learning, and I admired and respected the lofty. My family owned many books, many of which I copied by hand; even when old I did not abandon this . . . . As for the causes of orderly government and chaos, I would examine the truth and did not like to follow the [current opinions] and echo them ... My family collected many famous paintings and calligraphy books, all of which I have cataloged in a volume. Now not one-hundredth [of the collection] has survived, and yet my hobby in antiquities is still as strong. My nature is humorous . . . . I mingle easily in common circles, and yet defiled men cannot contaminate me. During the change of dynasty my old home collapsed . . . . and I thus became a man of Hangzhou ... I have written [eight books] . . . . I have roughly cultivated my virtues and refrained from shame .... With the 
Zhou Mi and Marginal Loyalism

veteran men whom I met, appreciated, and [who] helped me [and] with prominent men of the time, I moved up and down for over twenty years. But in my life I have not turned against my integrity and have not rebelled against the instructions of my family. In my office and associations, from beginning to end I have not deviated from the norm and can almost [without guilt] face my parents in the underworld. ${ }^{1}$

In this self-appraisal, Zhou was certainly much more confident than the erudite scholar Wang Yinglin towards his conduct after the collapse of the Song. The statement that he remained pure even among the contaminated was likely provoked by current criticism of him mingling with Yuan dignitaries, which cast doubt on his loyalism to the Song. He was certain that he had fulfilled his filial commitments by being in office for a long period, but blamed the change of dynasty for an undistinguished political career. Zhou felt no remorse for what he did and did not accomplish in his life, and ended the epitaph with a note of confidence, claiming that in a thousand years, his mind would be known and understood by posterity. ${ }^{2}$ He seems to have been ready for death and was certain that he would feel no shame or guilt when facing his ancestors.

After composing the inscription and epitaph, Zhou asked his lifelong friend Mou Yan to write prefaces for the inscription and for the mountain hut. Mou was moved by Zhou's feelings for his ancestral homes and for the past, and he marveled at his readiness to cope with death. ${ }^{3}$ Zhou also requested a preface from Yuan Jue, son of his former colleague and friend, Yuan Hong. In contrast to the affectionate tone of Mou Yan's prefaces,

1. Zhu Cunli, 428-31.

2. Ibid., 432.

3. Mou Yan, $16.9 \mathrm{a}-10 \mathrm{~b}, 10.1 \mathrm{a}-2 \mathrm{~b}$. 


\section{Chapter Six}

Yuan's piece is flat and impersonal, a large part of it quoting Zhou Mi. ${ }^{1}$ Yuan Jue was apparently not pleased about Zhou's indiscriminate circle of friends, for he later wrote about him: "In his late life [Zhou Mi] mixed with prominent men through connoisseur activities and slightly blemished his character." 2

Zhou died in 1298, just after another art connoisseurship gathering at Xianyu Shu's house. Ironically, none of his many friends commented on his death nor wrote any funerary inscriptions for him. The one exception was a mourning poem composed by Lian Wenfeng, not one of his closest friends. ${ }^{3}$ The silence on his death is responsible for the current controversy about the date of his death which has been placed in 1298, 1299, and $1308 .{ }^{4}$ I take 1298 as the most likely, on the basis of a colophon on the Baomu zhi scroll and Liu Guan's postscript to a painting by Gong Kai. ${ }^{5}$ Zhou was probably buried in Huzhou, in accordance with his wishes to be interred at his place of birth among his ancestors. He was survived by a son, Yong (fl. 1280-1300), and a daughter (who married in 1287). Zhou Yong inherited neither the versatile talents nor the popularity of his father. Soon Zhou Mi's prized art possessions were given away or sold, and the family passed into obscurity. ${ }^{6}$

4. "Inscription to the Fu hut, " in Yuan Jue, 17.312-13.

2. "Former teachers and friends of my late father," in ibid., 33.574.

3. "Poem to mourn Zhou Mi," in Lian Wenfeng, b.7b-8a.

4. See Xia Chengtao, 366.

5. The late Qing scholar Gu Wenbin argues that Zhou Mi died in 1298 on the basis of the colophon written on the Baomu zhi scroll in 1307, which states that Zhou Mi had died nine years previously. See Gu Wenbin, 18b-19b. There is additional evidence that Zhou Mi died some years before 1308. In a commentary on Gong Kai's painting formerly owned by Zhou Mi, Liu Guan writes that when Gong died in 1307, Zhou had predeceased him by several years. See "Postscript to the Jiangji printing," in Liu Guan, 18.16b-17a.

6. The Baomu zhi scroll and Gong Kai's painting, among other prized possessions, passed shortly from Zhou Mi's son and grandsons into other hands. See Xia Chengtao, 469; Liu Guan, 19.17a. 


\section{Zhou Mi and Marginal Loyalism}

In this chapter we have observed the loyalism of Zhou Mi and his "traveling companions"--the essence of which was not passive protest against Mongol rule but a subtle accommodation to the new government and its institutions. Zhou might have begun as an ardent loyalist in 1279 , refusing to accept the new rulers and writing about Song institutions to preserve the past and ignore the new order. Soon, however, through his interest in art and because of the reunification of the country, he came into contact with Song defectors, northerners, and foreigners, and he developed a keen interest in other regions of the Mongol world empire. While pursuing his passion for the arts and satisfying a curiosity about North China, Zhou unwittingly played the role of mediator between his loyalist friends and the Yuan dynasty.

As Zhou Mi's friends gradually returned to the political arena, their absolute loyalism (i.e., refusal to cooperate with the new government under any terms) dissolved and was transformed into accommodation. The exact dimensions of change varied with the personal circumstances of each individual and the length of time that had elasped since the Song demise. While many of his friends eventually took up employment under the Yuan with deep regret, Zhou Mi did not go as far as that. However, even Zhou's liberal associations with Yuan dignitaries drew criticism from a young contemporary. Zhou Mi's attitude towards those who served was dictated by personal relationships rather than by strictly objective views. His loyalty towards his friends enabled him to condone their resuming public office, but he ridiculed harshly those who surrendered and whom he did not like. As for himself, his withdrawal from politics was influenced by filial commitments, but he did not see any need to exclude Yuan officials from his network of friends. In time his feelings of loyalty to the former dynasty mellowed and by the late 1280 s and 1290 s it was no longer recognizable as resolute, passive protest against Mongol rule. By then, Zhou's loyalism was not as inflexible and unaccommodating as previously thought; had he lived after 1300 and been in more dire straits he might have himself accepted an appointment in the Yuan government. Of greater importance is the insight that Zhou Mi's loyalism and its transformation over time and circumstances gave to the second generation under the Yuan, i.e., men who had not yet been adults at the time of the Song collapse and who had never served the Song. In spite of their descent from loyalist fathers and their tutelage under loyalist teachers, they did not 


\section{Chapter Six}

see a contradiction in their admiration of Song loyalism and their attempt to play a more active role in the foreign government. In sum, Zhou Mi's loyalism was a workable compromise with Mongol rule without sacrificing his integrity; that of his many friends was an individual choice necessitated by various circumstances. 


\title{
SEVEN / THE TRANSFORMATION OF SONG LOYALISM
}

\author{
Song Loyalism: Its Nature, Intensity, and Duration
}

In a broad perspective, this study has been concerned with the historiography of the Song loyalists, particularly in exploring the distance between myth-making and reality with regard to loyalty, dynastic succession, resistance to foreign conquest, opportunistic collaboration, and the varying responses of the intellectuals and their followers. Conquest and resistance are common themes in history; yet official and unofficial sources of the time of Song collapse make Song loyalism and loyalists appear unique in Chinese history.

Traditional views of Song loyalism give a one-dimensional image of the loyalists as uncompromising individuals who struggled against Mongol rule in either militant or passive resistance. These loyal sentiments have been conceived as unchanging and absolute in nature, and this conception has been more emphatic in exemplary loyalist figures such as Wen Tianxiang and Xie Fangde. Traditional history-writing about the loyalists has been chiefly concerned with identifying, classifying, and rejecting individuals as loyalists. In this respect, the collaborators and defectors have been seen as the loyalists' polar opposites and censured for their lack of integrity.

The preceding chapters debunk the myth of absolute loyalty; in fact, the popular tradition of Song loyalism was largely the result of the loyalists' sentimental portrayals of themselves and their cause. Uncritical admiration by their contemporaries and later sympathizers reinforced and perpetuated the idealization. These writers searched for historical parallels and model conduct to bring relevance into their times and consolation for their own plight. Their writings are responsible for the myths of Song loyalism and present an incomplete picture of the loyalists. Until now, attention has been focused on 


\section{Chapter Seven}

heroic examples of loyalism and consequently many loyalist personalities have been neglected. The suppression of unflattering details and embellishment of favorable facts has resulted in the representation of Song loyalism as absolute and uncompromising. Very little is known about the more obscure individuals commended for their loyalist activities. Contrary to popular tradition, rather than loyalty to the Song being the primary motivation in loyalist behavior, participation in the loyalist resistance was more often due to personal loyalty to an individual leader like Wen Tianxiang. Relatives, friends, tenants and mercenaries took part in the resistance for reasons other than political loyalty to the Song.

Surprisingly, the centers of strong military resistance were rarely the centers of yimin gatherings after the collapse of the Song. For instance, Xiangyang, Changzhou, and Yangzhou resisted most resolutely the invading Mongol armies, but after 1276 these prefectures do not appear to have become regional centers where loyalist survivors were active. The obvious deduction might be that there were no loyalist personalities in these districts after the defeat of the resistance, but it could also be supposed that many accounts of local loyalism depended on the enthusiasm of local historians. To be sure, many traditional writings on the Song loyalists were inspired and influenced by local perspectives and interests. For example, our knowledge of the loyalists in Qingyuan has been enriched by Quan Zuwang, whose interest in his ancestors' role in loyalist resistance led him to carry out extensive research on this subject. More recently, the debate in the 1950s among Hong Kong scholars on Song loyalist activities in that region was much affected by their keen concern to establish Hong Kong's significance in Song history. The information thus collected often carries a strong provincial bias which reduces its value as source material.

Song loyalism has traditionally been conceived as a single body of values opposed to dynastic transition and alien rule. After having studied official histories and the loyalists' own collected works, I suggest that Song loyalism was not so simple. Three separate traditions have been identified: the zhongyi loyalists who died for or because of the Song cause, the yimin loyalists who survived the Song collapse and loyalist resistance and lived during the first generation of Yuan rule, and the marginal loyalists whose loyalty to the Song was doubted by traditional historians because of some compro- 
mising position. Song loyalism embraced a range of conduct from absolute intransigence to grudging accommodation. In the years immediately after the Song demise, loyalists engaged in active military resistance, participated in the recovery of the imperial relics, ignored Yuan reign titles, rejected friendships with Yuan officials and Song defectors, withdrew from political life and refused to serve the Yuan government. However, the intensity and duration of such loyalist behavior gradually eroded and became transformed over time. We find that even the loyalism of Wen Tianxiang and Xie Fangde--the paragons of loyalist virtue--was in the final analysis not absolute but later involved a degree of compromise. Wen Tianxiang associated himself with Wang Yuanliang and Deng Guangjian who were in Yuan service; moreover, he expressed some doubt about his determination to die and become a martyr. Xie Fangde would have reconciled a life as a loyal survivor and continued his friendship with northern scholar-officials in Yuan office had he not been forced to take up Yuan employment. With few exceptions, most loyalists socialized with Yuan officials and wrote commemorative essays for personal and financial obligations. They certainly regarded some as close friends; not a few fully approved of their children serving the Yuan.

After the Song demise, the local elite in some prefectures such as Fuzhou maintained their economic and social position; however, this stability was not apparent in other places. For example, in Davis' study of the Shi lineage in Qingyuan, while 240 members held office in the Southern Song, only ten occupied positions in the Yuan. ${ }^{1}$ The ravages of war and loss of positions in the Song government caused the loyalists to move with their families in search of employment and subsistence opportunities. Being suddenly forced to sell essays and accept food donations made it impossible for most loyalists to uphold absolute loyalism; thus Yuan rule seemed less objectionable. Traditional historians ignored this fact and praised only the exemplary loyalists while dismissing those who later served.

Traditional scholarship also overlooked the fact that for the loyalists who died shortly after the Song collapse and whose loyalty did not need to be tested through extreme poverty, it was much easier to retain a reputation as

1. See Hymes, 216; Davis, 181. 


\section{Chapter Seven}

ardent and intransigent loyalists. For others who lived ten, twenty or thirty years after the imposition of foreign rule it was more difficult to adhere to the same uncompromising standards without being seen as eccentrics or neglecting family and social commitments. For instance, whereas Lu Xiufu (who died in the resistance), Ma Tingluan (a retired veteran Song official), and Zhou Mi (who had a wealthy patron) did not have to worry about eking out a living, Qiu Yuan and Dai Biaoyuan endured poverty and served the new government only after 1300 . By gradually rationalizing Mongol rule, it was much more acceptable in the eyes of the loyalists themselves and society to take up service in 1300 than in 1280. As indicated in the profile of Zhou Mi and his extensive network of friends, accepting the new government became a salient feature of Song loyalism in the late 1280s and 1290s. By 1300, few Song loyalists still adhered to absolute loyalty. Indeed, loyalist activities had largely lost direct relevance and what remained was nostalgic reminiscing about loyalist conduct in the aftermath of the Mongol conquest.

The loyalists and their contemporaries recognized that loyalism was a relative concept, but they criticized what they considered to be questionable loyalist behavior. The followers of Wen Tianxiang and Xie Fangde prescribed for their leaders the utmost unblemished and absolute form of integrity and loyalty. In order to obtain that goal, they exhorted them to commit suicide and leave no doubt to posterity about their exemplary conduct. At the same time, they demanded of themselves less absolute manifestations of loyalty and continued to live decades after the collapse of the Song. Zhou Mi mocked the defectors' fickleness and disloyalty. He, in turn, was criticized by Yuan Jue for keeping company with eminent Yuan officials, but Yuan Jue himself took up employment with the Yuan government and became friendly with higher Mongol dignitaries. Fang Hui was treated with contempt by Zhou Mi for surrendering and prostrating in front of northern Chinese and foreigners; but a few years after resigning his Yuan post Fang chided Cheng Jufu for carrying out a commission by the Yuan throne. ${ }^{1}$ Zhao Mengfu, himself a Song clansman and in Mongol service, ostracized Liu Mengyan, a high-ranking chief minister, for deserting the Song government. Apparently, by up-

1. "Poem to bid farewell to Cheng Jufu," in Fang Hui, Tongjiang xuji, 12.5b. 
braiding others for dubious loyalty and lack of integrity, those who were themselves criticized on the same basis consoled themselves that their own conduct was more honorable than that of others. One former Song official who later served the Yuan was exceptionally honest in evaluating his flight from the Song court during its last days: even though he did not "flee a hundred paces," he admitted that the pertinent point was that he did after all flee from his responsibilities. ${ }^{1}$

Efforts to minimize their guilt about disloyal behavior caused some of these individuals, who still felt loyalty to the former Song, to leave their Yuan positions after a brief period of service. Deng Guangiian and Wang Yuanliang, who had been forced to serve, resigned and returned to South China in order not to further compromise their principles. During the first generation of Yuan rule not a few loyalists, because of poverty and a commitment to keep up the scholarly tradition, compromised their integrity and wrote essays for Mongol officials and taught foreign students; some worked in official schools and took up positions as directors of local schools. They served because they felt that teaching positions did not involve them directly with the Yuan government and thus did not compromise their loyalty to the Song. With this view some loyalists thus refused promotions to instructors in prefectures, as this position would weigh more heavily on their conscience. This type of rationalization was also used by Qiu Yuan, Dai Biaoyuan, and many others who served as instructors but still considered themselves subjects of the former Song by calling themselves "jinshi," "surviving subject," "fleeing," or "refugee subject" of the former dynasty. Simply to dismiss these men as nonloyalists and collaborators who could not maintain their integrity to the end is to ignore the whole range of loyalist behavior and its transformation over time and circumstances.

Among the loyalists, the meaning of loyalism also varied according to the traditional Confucian values of zhong (loyalty), xiao (filial piety), zhengtong (legitimate succession) and huayi (ethnic distinction between Chinese and foreigners). The notion of loyalty was the most important for zhongyi loyalists such as Wen Tianxiang, Lu Xiufu, Li Tingzhi, and Zhang Shijie. In

1. "Mourning poem for Xu Zongren," in Wang Yi, 1.9b-10a. 


\section{Chapter Seven}

general, they rejected the narrow and myopic vision of loyalty to one ruler and sovereign (as was the loyalty of Yue Fei) in preference for a broader definition of loyalty to the dynasty and its survival in the face of total conquest. Had their loyalty been directed solely towards their sovereigns, Gongdi and Empress Dowager Xie, they would have obeyed their last edicts to surrender immediately and accompany the imperial entourage to the Yuan capital. As Xie Fangde noted, Empress Dowager Xie wished to perform her duties as sovereign by preventing further bloodshed and harm to her people, but as a subject of the Song, his commitment and duty were to sustain the empire. In the same way Wen Tianxiang replied to criticism of his abandonment of the captured sovereigns to enthrone the two Song princes, declaring that his greater responsibility was to the survival of the Song empire. To some leaders loyalty meant that the Song state took priority over all other commitments and the consequence of their devotion to this principle was death. Many personal followers and family members died with them but the nature of their loyalty was different. Whereas Wen Tianxiang and Li Tingzhi saw it as their political duty to die for the country, those who voluntarily accompanied them to their death did so out of a personal loyalty and duty to their leaders, husbands, fathers, patrons, and masters.

Xie Ao, one of the yimin, directed his loyalty to Wen Tianxiang; his commitment to the Song state was of secondary importance. Thus Xie Ao's lavishly praised essay was actually a personal mourning tribute to his leader and patron to whom he was grateful for showing interest in him, a mere commoner. Most yimin felt that the Song collapse did not necessitate actual participation in military resistance, but simply a feeling of loyalty and nostalgia towards the former dynasty and quiet withdrawal from direct political cooperation with the new government. This type of loyalism was exhibited in the early years of Yuan rule by Wang Yinglin and the personalities and groups described earlier. Some of these had been Song officials who had been criticized by the Song court for deserting it just before or during its surrender. At the start of Yuan rule, they decided to stay loyal to the former dynasty by devoting themselves to its culture and civilization; thus they spent much of their lives in scholarship and teaching. Zhou Mi's efforts to preserve the memory of the customs and practices, arts and poetry of the former era, and Wang Yinglin's prolific writings on textual criticism and the Confucian 
classics are examples of this dedication and ideal of loyalty.

To account for some former officials who later served the Yuan or communicated with its officials and Song defectors in social, economic, and personal ways, it could be said that they showed their devotion to Chinese civilization by attempting to sinicize the foreigners in the hope of softening alien rule. As one such former Song official who took up a Yuan appointment quotes from the ancient Confucians: "When medicine is practiced, people live; when Confucianism is practiced, the empire and posterity survive. ${ }^{1}$

Also indicative of the various forms of loyalty are the different historical heroes adopted by the loyalists to justify their conduct or misconduct and raise their morale. For instance, Wen Tianxiang admired immensely the heroic generals and advisors who defied death and opposed the enemy to the end. To justify his "latent" martyrdom Xie Fangde drew a parallel between himself and Boyi, Shuqi and Gong Sheng, who died by starvation many years after the dynastic crisis. As for the yimin loyalists who survived into the first generation of Mongol rule, they followed Tao Qian, who did not disdain poverty and refused to use the reign titles of the alien dynasty.

Filial piety to one's parents and ancestors and loyalty to the ruler have traditionally been seen as complementary concepts and as harmonious with each other, as expressed in popular sayings like "to be loyal is to be filial" and "the loyal subject must first be a filial son." However, among the Song loyalists the demands of filial piety and loyalty conflicted and necessitated a painful choice of one over the other. Wen Tianxiang and the martyrs who participated in military resistance and died instead of surviving to look after their parents or enter a period of mourning considered their loyalty to the state their first priority. But for Xie Fangde and Wang Yanwu, filial piety took precedence; they quit the resistance to attend to their filial commitments. In fact, Xie Fangde did not approve of Wen Tianxiang, Li Tingzhi, Chen Yizhong, and the others who during their mourning periods responded to court summons to resume their political duties. The choice of filial piety over loyalty was also made by defectors such as Wen Tianxiang's brother Bi and Lü Wenhuan. For Zhou Mi and the yimin loyalists, filial piety meant at-

1. "Descriptive essay of Quansheng hall," in Wang Yi, 7.12b. 


\section{Chapter Seven}

taining high political office and ensuring that the family name and honor were not blemished through personal misconduct. To serve the succeeding dynasty would have amounted to a serious betrayal of Zhou's family which for many generations had included Song officials.

At the end of their life, most loyalists were satisfied with their choice between filial piety and loyalty, but Zheng Sixiao was different. He desperately wanted to join the resistance in 1275 , but his mother's illness and death interrupted his ambitions to engage in physical combat with the Mongol forces. After mourning his mother for the entire compulsory period, Zheng spent the rest of his life in political and social seclusion out of intense devotion to the Song. At his death he regretted being the most "unfilial and disloyal" subject of the Song because not only did he not play an active role in loyalist resistance, but he had no heir to continue the family name and attend to the ancestral rites.

Because South China had never been under foreign rule the outlook of the Song loyalists is of particular importance to an understanding of the Chinese response to foreign conquest. Their collected writings, with the exception of Zheng Sixiao's Xinshi, are generally mild towards the Mongols and other foreigners who are called barbarians, barbarian caitiffs, chieftains, northern peoples, or northern visitors. In contrast, the Song imperial edicts of 1274-75, drafted by the erudite loyalist Wang Yinglin, contain much stronger language, referring to foreigners as swine, dogs, and snakes. The collected writings of the loyalists discuss alien rule in more subtle tones by the use of historical analogies. For instance, the virtues of Cai Yan and Su Wu, whose loyalty to the indigenous Han dynasty remained unchanged over many years, are alluded to in order to reinforce the loyalists' antipathy to the alien government. Some, but not all the loyalists, expressed ethnic and racial prejudices against foreigners, whom they considered incapable of ever behaving like Chinese. Their views contrasted to earlier traditional beliefs of culturalism, a conviction that foreigners could be assimilated into Chinese culture and civilization.

At the start of the resistance, it was the threat of an unprecedented foreign conquest and rule of all of China that motivated active loyalists such as Wen Tianxiang and Wang Lixin, as well as more obscure figures, who swore to die rather than be "contaminated by barbarian blood." There were 
also several who sought unoccupied territory on which to die or left instructions to be buried in other lands. Apart from Wen, both Empress Dowager Xie and Xie Fangde perceived early that the Mongol conquest, if victorious, would be an unprecedented disaster. In appealing for widespread support for the throne, the 1275 edict for the qinwang campaigns in fact emphasized that never before in Chinese history had the whole of China been conquered by a foreign people.

The yimin loyalists, however, had diverse views. Some, like Zhou Mi, simply lamented the change of dynasties but showed few fierce antiforeign sentiments in their writings. Others, like Lin Jingxi and Deng Mu, displayed heart-rending emotions about foreign rule, albeit using allusions rather than outright condemnation. However, in his Xinshi, Zheng Sixiao abused without restraint the Mongols, whom he regarded as inhuman, untrustworthy and insatiable. His racial views on foreigners call to mind scholars like Chen Liang, who earlier held similar opinions, and anticipated those of Fang Xiaoru (1357-1402). ${ }^{1}$ It is difficult to determine exactly how much ethnic and racial prejudice was in Song loyalism because we cannot be certain whether the loyalists' writings have survived intact from self-censorship in the Yuan and from the literary inquisitions in the Qing. One thing is certain: some racial and ethnic hostility existed among individual writers during and immediately after the Song conquest.

However, most loyalists who survived and lived under Mongol rule, including Xie Fangde before his martyrdom in 1289, were gradually impressed by the degree of sinicization in the Yuan dynasty and among its officials. Former Song officials, like Jia Xuanweng who was forced to live and teach in Hejian, modified earlier antiforeign sentiments as they became aware of the high standard of Confucian learning in North China despite centuries of foreign rule. Such warm sentiments towards northern Chinese acquaintances and scholars reduced somewhat the resentment southerners in general harbored against northern Chinese and foreigners, who they felt were better treated by the Yuan government. The Mongols' political reunification of the country also gradually mollified the loyalists. The mournful feelings about

1. On Fang Xiaoru, see Xiao Gongquan, vol. 4, 526-37, and Mi Chu Wiens. 


\title{
Chapter Seven
}

the Song demise, already waning, were further reduced as people regained opportunities to travel widely and as the cultural and scholarly traditions of the North and South became reintegrated. Except for a few loyalists such as Lin Jingxi, loyalists looked at reunification positively and thereby softened their antipathy to foreign rule.

After some years, loyalists such as Wang Yinglin compared the Mongol Yuan to the short-lived Qin dynasty. They became convinced of the permanence of Chinese culture and civilization through the transmission of Confucian teaching, and after a period of adjustment looked confidently to the future. In that respect, their feelings were not much different from some northern Chinese scholars who served the Yuan and felt that the foreign origins of the ruling dynasty were irrelevant; what was of crucial importance was the ruler's enlightenment. Thus in 1260, Hao Jing advised Li Tingzhi:

\begin{abstract}
At present, he who can employ scholars and practice the way of the Middle Kingdom should be regarded as the ruler of the Middle Kingdom. If scholars in this [favorable] time do not apply themselves, then the people will be subjected to the executioner's knife and abandoned in dejection; there will not be half a survivor left. ${ }^{1}$
\end{abstract}

The concept of legitimate or orthodox succession constituted the final component of Song loyalism. ${ }^{2}$ Traditionally it was regarded as Heaven's prerogative to grant the mandate of rulership to a dynasty, which must thereupon be worthy of it by carrying out benevolent rule. Only when rulers were evil and depraved was the mandate withdrawn and given to another imperial house. The Song collapse raised many unanswered questions. Since the Song

1. Hao Jing, 37.13a, in a letter to Li Tingzhi to convince him about Qubilai's enlightened rule.

2. For a survey and discussion of the concept of legitimate succession in Chinese history, with particular regard to the Song and Yuan periods, see Hok-lam Chan, "Chinese official historiography," 68-74, and Rao Zongyi, Zhongguo shixue shang zhi zhengtong lun, 28-42, 105-62. 
emperors were generally considered thrifty and benevolent rulers, the cause for the dynasty's collapse was perplexing to the loyalists. Xie Fangde blamed a lack of filial piety among officials during the last years of the Southern Song, but most loyalists, like their contemporaries and traditional historians, put the major responsibility on Jia Sidao. At the same time, they felt obliged to obscure their close relationship with Jia. Many key loyalist figures had been his protégés or at one time benefited from his patronage: they included Li Tingzhi, Liu Fu, Chen Yizhong, and Hu Sanxing. Zhou Mi's writings suggest that even he had been one of Jia's close friends. The loyalists also blamed the defectors and collaborators but they did not rail against those with whom they were personally acquainted. In their opinion, Jia and these renegades, and not the Song imperial house, were responsible for losing the mandate of Heaven.

The succession of the Mongol Yuan dynasty posed a problem of legitimacy to the loyalists. ${ }^{1}$ The conquest of North China by the Jurchens necessitated the removal of the Song capital to the southeast and the relocation of the Song court. With another ruler enthroned, the legitimacy of the Song continued in South China; in that respect the loss of the North, humiliating as it was, wàs not tantamount to losing the entire country to foreign rule. But after the defeat of loyalist resistance in 1279 , for the first time in history there was no Chinese-ruled territory. Fearing this impending situation Xie Fangde, Wen Tianxiang, and Empress Dowager Xie declared that never before had the Middle Kingdom seen total foreign conquest and hinted that in their opinion the Yuan, despite its military superiority, was not legitimate. Zheng Sixiao's remarks in the Xinshi were more direct and inflammatory. He rejected reigns by foreign rulers, together with those by women and usurpers, as illegitimate and equivalent to the rule of animals who pretended to be human beings. He argued that legitimate succession did not need to be based on territory; the Middle Kingdom should be treated as still in existence and legitimate despite the fact that its territory was totally occupied by foreigners. The for-

1. Surprisingly, there is relatively little on this topic among loyalist writings. Zhou Mi quotes his friend Chen Guo's theory of legitimate succession based on seven breaks and six continuations, but this framework covers only up to the Tang dynasty. 


\title{
Chapter Seven
}

eigners then controlling China should be considered illegitimate usurpers. He felt that since the Mongol dynasty was alien it did not have the mandate of Heaven and would be certain to disintegrate shortly.

By the late 1280s and 1290s it was evident that there was no hope for a revival of the indigenous Song. Most loyalists had, therefore, rationalized permanent alien rule. Their use of Yuan reign titles by that time indicates their acceptance of the dynasty's legitimacy. Certainly by 1300 the Song loyalists no longer formed a separate and visible social group, and were not much different from the larger sector of southern scholars, including many collaborators, in their perception of loyalty to the Song and changing attitudes towards the Yuan dynasty.

A question asked at the beginning of this study was whether the southern Chinese responded differently than their northern compatriots when the Jurchen Jin occupied North China in 1126-27. At the time the Jurchens had remarked that there were few loyalists in the Song compared to the conquest of the Liao. ${ }^{1}$ Emperor Shizong of the Jin (r. 1161-89) also commented on the different attitudes of northern and southern Chinese:

\begin{abstract}
Since antiquity, those among the natives of Yan [i.e., the Dadu region] who were loyal and honest have been few. When the Liao army came, they submitted to the Liao; when the Song came, they submitted to the Song; and when Our present dynasty [i.e., Jin] arrived, they submitted to Our present dynasty ... . [Thus] although they have undergone several dynastic changes, they have not been ravaged for these reasons. The southerners are unyielding and intransigent. Those who dare to speak and admonish frankly are many; [if through such conduct] one man is put to death, there will follow another who will still admonish. [This attitude] is highly admirable. ${ }^{2}$
\end{abstract}

1. Biography of Li Ruoshui, SS 446.13160-62.

2. Toghto, Jinshi 8.184. See also Yanai, 95. 


\section{The Transformation of Song Loyalism}

The Chinese literati under Jurchen rule cooperated with the new government because survival of tradition and culture was foremost in their minds and they hoped to use Chinese learning to "civilize" or transform alien rule. ${ }^{1}$ When the Mongols took over the government in 1234, North China had already been subjected to foreign rule for centuries, and northern scholars had become accustomed to foreign conquest. In addition, because the Jurchen Jin mistreated its Khitan and Chinese subjects, military and civilian officials found it easier on their moral conscience to submit to the Mongols. ${ }^{2}$ Some Song contemporaries wrote about the hopes of the northern Chinese to reunite with the Southern Song and noted their crushing disappointment during its collapse in 1276. However, by that time northern Chinese who had submitted to the Yuan or were born under its rule felt loyal to the Yuan and not to the Song, in spite of the common ethnic and cultural identity with the South. $^{3}$

This is not to say that there were no loyalists during the Mongol conquest of North China. Indeed, there were some who joined Daoist sects in protest and to preserve Chinese values and culture under Mongol dominance ${ }^{4}$ However, like northern scholars and generals under Jin rule, they

1. On northern scholars who wished to preserve tradition and culture, and therefore cooperated with Jurchen rule, see Peter K. Bol.

2. A primary reason for Jin defections to the Mongols was the general hatred of the Jurchens by their Khitan and Chinese subjects. See de Rachewiltz, "Personnel and personalities, " 142, and "Yeh-lü Ch'u-ts'ai." Hao Jing's Linchuan ji also expresses deep resentment of the Jin regime. After the collapse of the Jin, common people reportedly massacred large groups of Jurchens. See Zhao Yi, 20.589.

3. See, e.g., Zhao Mengfu's poem "Yue Fei's grave," in Zhao Mengfu, 4.42. Sun Kekuan remarks that Liu Yin, as a northern Chinese, was disappointed with the Mongol conquest which dashed any hopes of reunification with the Southern Song regime. Liu Yin was sympathetic to the Song, but his refusal to serve the Yuan was not related to loyal feelings toward the Song. See Mote, "Confucian eremitism," 262-79.

4. On these Daoist sects and their concerns with preserving Chinese civilization, see Chen Yuan, Nan Song; and Yao Congwu, "Jin Yuan." 


\section{Chapter Seven}

soon felt it more constructive to cooperate with the Mongol rulers in order to soften and transform alien rule into a more compassionate system. Compared to these northern brothers, the Song loyalists were more profoundly affected by the Mongol conquest and thus put up a relentless resistance for three years. But eventually they, too, adjusted to the idea of alien rule and a generation later they had come to terms with it. Their change of mind was helped by the high degree of sinicization they perceived as possible in their Mongol conquerors.

In spite of decreasing antipathy towards the Mongol dynasty, in each individual the essence and significance of loyalism to the Song remained unique and varied with particular circumstances. For instance, the martyrdom of Wen Tianxiang and Xie Fangde was inspired by different historical figures. To them, as to other loyalists such as Xie Ao, Zhou Mi, and Zheng Sixiao, loyalty and filial piety meant different commitments and resolutions. As a group, however, they realized that they were only stepping into the shoes of exemplary heroic figures of the past and would in this way attain some fame in posterity; they did not consider that they were setting a precedent with their loyalty to the Song.

\section{Impact of Song Loyalism on Later Generations}

Popular tradition tells us that the Song loyalists generally forbade their children to serve the Yuan dynasty and maintains that only with the establishment of the indigenous Ming dynasty did their descendants take up service. Biographies fitting this interpretation are easily found in sections of gazetteers dealing with loyalist personages. As shown in this study, however, these cases were the exceptions rather than the rule. Although many loyalists did not themselves reemerge from political withdrawal due to their commitment to the former dynasty, they allowed their children and pupils to accept official appointment in the Yuan government. Even Mou Yan, who never left his home for thirty-six years after the Song demise, saw nothing wrong with his sons and son-in-law entering Yuan service. The sons of the exemplary loyalists Xie Fangde and Wen Tianxiang also held office under the new government. While restricting themselves to political withdrawal or martyrdom, they perhaps saw it as their filial duty to ensure that the family did not lose its scholar-official gentry status. In this respect, they possibly even played an 
active role in arranging their sons' appointments through former colleagues like Liu Mengyan who had risen to high positions in the Yuan bureaucracy.

Although some yimin loyalists accepted office themselves due to poverty and other reasons, many others did not but continued to engage in teaching and scholarship. In that capacity they definitely influenced the young generation's attitude towards alien rule, sharing with them at the same time their own political experience before the Song demise. Their students and sons developed an admiration and nostalgia for the upright spirit of Wen Tianxiang and other exemplary loyalists. In this way the loyalists provided the younger generation with a bridge to the future as well as to the past. Through their offices and contacts with other Yuan officials in the 1290s and 1300 s, sons and pupils in turn helped the more stubborn loyalists come to terms with the new dynasty.

In subsequent generations Song loyalists existed only in the memory of stories told to the grandsons and young pupils of the loyalists. While they were influenced by the loyalist spirit, their loyalty was not to the Song but to the Yuan dynasty in which they were born, and under which they served. These men deeply admired the Song loyalists and wrote of their virtues and zeal, but their sympathy did not mean that they were anti-Yuan. ${ }^{1}$ Thus in the long run, the Song loyalists' impact on the younger generations lay essentially in the teaching and transmission of Confucian values and culture.

After the defeat of loyalist resistance in 1279, the Yuan was confronted with banditry and uprisings which were most rampant during the reigns of Qubilai and Toghon Temür. The unrest in the late 1270s and 1280s was particularly alarming in Fujian, Jiangxi, Guangdong, and Guangxi, which had in fact been centers of loyalist resistance under Wen Tianxiang and Zhang Shijie. ${ }^{2}$ Several uprisings claimed connections with the Song imperial family and one was led by Chen Diaoyan (fl. 1270-90), a former associate of Zhang Shi-

1. For example, the writings of Yang Weizhen and Tao Zongyi are pro-Song but not antiYuan. See Franke, "Some aspects," 118, 128-29.

2. For a list of these rebellions recorded in the annals of Qubilai in the YS, see Wan Sitong, Songji zhongyi lu, appendix.6-12; Chen Banzhan, Yuanshi jishi benmo, 1.1a-7b. 


\section{Chapter Seven}

jie. ${ }^{1}$ On that basis certain Ming and Qing scholars and modern nationalistic historians have hailed these rebellions as organized patriotic pro-Song activities. $^{2}$ Some even asserted that they were secretly planned by the yimin loyalists. $^{3}$ This claim is tenuous and uncorroborated by evidence. After 1279 most of the active participants in the loyalist resistance had died; the remnant loyalist forces were incorporated into the Yuan armies and the bandit groups simply dispersed as quickly as they had been assembled for short-term profit. Many such movements claiming to be pro-Song were in fact instigated by men who had taken up Yuan office but who later rebelled. Among the loyalists included in this study, there is only one or two who are said to have been participants in these later rebel movements. The uprisings of Chen Diaoyan, the She people, and several others invoking the Song banner were but isolated incidents operating without the support of the yimin loyalists. In fact, loyalists such as the Qingyuan scholar Shu Yuexiang condemned these bandits and outlaws who caused chaos and suffering.

The notion that these uprisings were related to the Song loyalist resistance might first have arisen because the Yuan government overreacted, suspecting without sufficient cause that the last Song pretender to the throne, Di Bing, had not drowned but had fled safely to Champa. After 1279 the Yuan court did not really fear a revival of loyalist resistance but wanted to prevent Song clansmen from being used as figureheads by rebel groups to instigate revolts. A fact overlooked by those who interpreted these uprisings as loyalist activities is that in South China more natural disasters occurred annually during Yuan rule than any other dynasty. ${ }^{4}$ Such calamities as floods and famine partially accounted for the rebellious mood of the times. To allocate

1. In 1283 Huang Hua organized a rebellion in Fujian, claiming to restore the Song. See Chen Bangzhan, Yuanshi jishi benmo, 1.3a. On the revolt of Chen Guilong and Chen Diaoyan in 1280-83, see SS 451.33274. Chen Biaoyan is said to have responded to Zhang Shijie's loyalist call in 1277 during the latter's siege in Zhangzhou.

2. Chen Bangzhan, Yuanshi jishi benmo, 1.6b; Wan Sitong, Songji zhongyi lu, appendix.12.

3. See Sun Kekuan's Yuandai han wenhua, 342, and his "Yuanchu Nan Song," 14.

4. Deng Yunte, 18-20. 


\section{The Transformation of Song Loyalism}

full responsibility to the Song loyalists is to misinterpret reality and create myths such as the "moon cake" campaigns to drive out the Mongols in the late Yuan. ${ }^{1}$

Although late Yuan rebel leaders (including Zhu Yuanzhang, founder of the Ming) often used the Song banner as the cause for revolt, few if any of the Song loyalists and their descendants included in this study can be shown to have taken part. ${ }^{2}$ It can be said that the Song loyalists did not play a military role after the defeat at Yaishan. In fact, in the late Yuan many individual scholars of the third or fourth generation under Mongol rule supported the Yuan despite the establishment of the indigenous Ming dynasty. The generation of scholars who experienced the collapse of the Yuan dynasty had not lived under Song rule but were led to admire Song loyalism through the writings of the loyalists. These men loyal to the Yuan included not only Mongols and Central Asians but also southern Chinese. There were many cases of Chinese gentry who recruited their tenants, family servants and slaves to repel rebellious movements.

The Yuan loyalists who survived dynastic collapse in 1368 lived a life-style very similar to that of the Song loyalists during the first generation of Yuan rule. Individuals such as Tao Zongyi (ca. 1316-ca. 1402), Yang Weizhen (1296-1370), and Dai Liang (1317-83) considered themselves subjects of the former Yuan and refused to serve the Chinese rebel leaders. ${ }^{3}$ What impressed these men the most about the Song loyalists, whom they

1. Legend and tradition wove the myth that in 1368 the Song loyalists instigated the Han race to rebel against the Mongols on the fifteenth day of the eighth month, i.e. the Mid-autumn Festival. This secret message was written on pieces of paper inserted in moon cakes. Moon cakes were traditional gifts to friends and relatives during the Mid-autumn Festival. See also Serruys, Mongols in China, 22.

2. On Zhu Yuanzhang's founding of the Ming, see John W. Dardess.

3. On Tao Zongyi's loyalist views, see Mote, "T'ao Tsung-i," 20-22. On Yang Weizhen and Dai Liang, see their biographies in Goodrich and Fang, 1547-53 and 1234-37. Some of these men treasured former possessions of the Song loyalists in order to inspire their own loyal spirit. These objects have included Wen Tianxiang's inkstone and Xie Fangde's lute. See Fu Lo-shu, "Yudai sheng yu haozhong." 


\section{Chapter Seven}

wrote about extensively, was their loyalty to the collapsing dynasty and not their antiforeign sentiments about Mongol rule. Thus they later declined to serve the Ming rulers. Men like Song Lian who entered Ming service, instead of showing exhilaration about the restoration of an indigenous Chinese dynasty, very often expressed in their writings a nostalgic sadness about the end of the Yuan dynasty and an uncertainty about the future of Ming rule. ${ }^{1}$ Even the Qing scholars Zhao Yi and Quan Zuwang commented on the large number of individuals who died for the Yuan cause or who refused to served the Ming government in spite of the different racial and ethnic background of the Yuan rulers. ${ }^{2}$ Quan felt that this phenomenon reflected the influence of Song loyalism and morality on the men of the Yuan, rather than an indication of the gratitude they expressed to the Mongol rulers for their arguably benevolent rule. The loyalty of these Yuan literati thus refutes the view that the late Yuan rebellions were the culmination of ethnic nationalistic resistance against an alien dynasty. In the transitional period between the Yuan and the Ming, scholar-officials influenced by Song loyalism were more affected by loyalty to the ruling house than loyalty to the Chinese race.

Recent scholars have in fact indicated that the racial factor during the dissolution of the Mongol Yuan was over-emphasized by Ming, Qing, and modern nationalistic scholars. They show that during the early Ming period there was neither blatant racial discrimination nor xenophobic sentiment expressed towards the Mongols, many of whom chose to stay under Ming rule rather than follow the Mongol court to Mongolia in 1368. ${ }^{3}$ In spite of the racial overtones in Zhu Yuanzhang's proclamation of succession to the Yuan, the founder of the Ming dynasty acknowledged the legitimate status of the al-

\section{See Qian Mu.}

2. Zhao Yi, 30.645-46 and 32.677-78; Quan Zuwang, waibian 18.907-08 and 18.908-09. On Yuan loyalists, see also Li Zefen, vol. 4, 109-56. A descendant of Chen Yizhong, Chen Da (fl. 1368), refused to serve the Ming and tried to drown himself ( $\mathrm{Li}$ Zefen, vol. 4, 156). On ethnic Mongols who preferred to stay in China under the Ming, see Serruys, Mongols in China, 34-46.

3. Serruys, Mongols in China, 54-62. 


\section{The Transformation of Song Loyalism}

ien dynasty. ${ }^{1}$ According to these scholars, it was the reckless Tumu Incident of 1449 (in which the Mongols inflicted a humiliating and catastrophic defeat on the Ming court) that intensified anti-Mongol feelings. ${ }^{2}$ This incident also led to a revision of the histories of the Song, Liao, Jin, and Yuan dynasties in order to deny legitimate status to all foreign governments of China. ${ }^{3}$

Although Song loyalism had some impact on the Yuan loyalists, it was during the transition from Ming to Qing that a large number of parallels may be drawn. The obvious one is that both the Song and Ming loyalists were confronted with foreign rule. As with the Song loyalists, the Ming loyalists also put up a fierce military resistance to the Manchu conquerors, but they received even more popular and local support than during the Song collapse and posed a greater threat to the succeeding dynasty. ${ }^{4}$ The Ming loyalist movement was much more widespread and involved many more personalities. While the Gujin tushu jicheng recorded almost seven hundred names and biographies of Song loyal subjects, over five thousand biographies of Ming loyal personages are included. ${ }^{5}$ We earlier discussed the dissent in leadership during the Song resistance which undermined its strength, but this cannot be compared in magnitude to the rifts and conflicts in the Ming loyalist movement.

Many martyrs and survivors of the Ming loyalist resistance compared themselves with the Song loyalists and looked to the Song for precedents and ideological support. It was alleged, for instance, that Zheng Sixiao's Xinshi

1. For the text of this statement proclaimed in 1367, see Meng Siming, quoting from Mingda zhengyao (1.17a-18a), 222. For a partial translation, see Wiens, 3-4.

2. On the historical background and details of this event, see Mote, "The T'u-mu incident of 1449." On its impact on anti-Mongol sentiments, see ibid., 271-72.

3. Hok-lam Chan, "Chinese official historiography," 96-105.

4. On Ming loyalist activities, see, inter alia, Frederic Wakeman, Jr.; Jerry Dennerline; and Lynn A. Struve.

5. Even allowing for the question of a higher degree of survival of sources on the Ming period, the figures for the Ming loyalists are still impressive. These biographies are in Chen Menglei, 735-63. 
was forged by Ming loyalists in order to spark loyalist resistance during the Ming collapse. If they were not responsible for the forgery, they certainly hailed its discovery and responded to its appeal to resist foreign conquest. In their writings, the loyalist personalities frequently referred to Song loyalist exemplars such as Wen Tianxiang, Xie Fangde, Xie Ao, and Zheng Sixiao. In particular, the antiforeign views of Wang Fuzhi and $\mathrm{Gu}$ Yanwu bring to mind Zheng Sixiao's strong statements about the inhuman nature of foreigners. ${ }^{1}$ Huang Zongxi was deeply moved by Xie Ao in his loyalist sentiments and by Deng $\mathrm{Mu}$ in his political thought. ${ }^{2}$

Lü Liuliang (1629-83) is an example of a "latent" loyalist who developed racist feelings against the Manchus after he had obtained a degree from the new dynasty. ${ }^{3}$ In that respect he was like Wang Yuanliang and Deng Guangjian who resigned after a period of service to the Yuan. Among the Ming loyalists, there were eccentric painters like Zheng Sixiao and poetry circles which lamented the end of the dynasty. ${ }^{4}$ Ming loyalists also moved to other parts of the empire in the course of their military resistance, the most noteworthy among them being Koxinga (Zheng Chenggong, 1624-62) who chased out the Dutch and continued his operations in Taiwan. ${ }^{5}$ Following the example of Li Yong from Dongguan, who went to Japan after the Song

1. See Wiens, 9-15. On Wang Fuzhi, see Xiao Gongquan, vol. 5, 636-40; and Ian McMorran. On Gu Yanwu, see Willard J. Peterson.

2. On Huang Zongxi, see de Bary. Huang Zongxi's Song Yuan xue'an, completed by Quan Zuwang, is a monumental work on the intellectual schools of the Song and Yuan. The Song loyalists discussed in this study are mostly classified under the following schools: Shuixin (juan 54-55), Longchuan (56), Cangzhou (69-70), Beishan (82), Shenning (85), Dongfa (86), and Sunzhai (88).

3. On Lü Liuliang, see Xiao Gongquan, vol. 5, 640-46; and Tom Fisher. Lü Liulang's preface and poem on the painting "Ruci jiangshan" makes a moving comparison between the Ming collapse and the Song demise. See Chen Dengyuan, 466.520-21.

4. See the symposium volume on Ming loyalist painters edited by Rao Zongyi, Ming yimin shuhua yantao hui jilu zhuankan.

5. On Koxinga, see Ralph D. Croizier. 
The Transformation of Song Loyalism

collapsed, the scholar Zhu Shunshui (1600-82) departed for Japan and Annam where he taught and served. ${ }^{1}$ As in the case of the Song loyalists, voluminous scholarship poured from the pens of the Ming loyalists; but unlike the relative freedom of expression during the Mongol period, strict censorship during the Qing proscribed many of their writings. Even in the midQing period Quan Zuwang still had to exercise caution when he wrote; his high praise of the Song loyalists disguised favorable statements about the Ming loyalists.

With regard to the changing nature of their loyalism, the Ming loyalists drew examples from the Song loyalists. One instance was the decision to reenter public service. While Gu Yanwu, Huang Zongxi, Wang Fuzhi, and Lü Liuliang did not actually take up appointments in the Qing, they encouraged their children, relatives, and students to do so. ${ }^{2}$ Although Huang Zongxi refused to participate in the Ming history project, he did not forbid his student, Wan Sitong, to take part; he actually made available his private library to ensure a thorough job. This accommodating attitude undermined their loyalism in the eyes of contemporaries, who criticized each other for less than adequate manifestations of duty to the former dynasty and ruler. In fact, the Ming loyalists were more strict in their demands of unchanging loyalty. For this reason many saw Song loyalism as more absolute and Song loyalists as more resolute than had actually been the case. For instance, Wang Yinglin, who was not criticized in his own time for being wanting in loyalty, came under fierce attack by the Ming loyalists.

During the last dynastic collapse in 1911 that ended the Chinese imperial system, a new set of factors changed the meaning of loyalism. Song and Ming paragons of loyalism became exclusively identified as ethnic and nationalistic heroes. ${ }^{3}$ Those who embraced traditional models of loyalism towards the former dynasty may have felt socially displaced, because loyalist

1. Ching, "Chu Shun-shui."

2. See He Guanbiao.

3. Zhang Binglin edited Wang Yinglin's Sanzi jing. On Zhang, see also Wiens, 18-19; and Li Runcang. 


\section{Chapter Seven}

sentiments to the Manchu rulers were not regarded in a positive light nor respected in the midst of China's turbulent struggle to enter the modern era. The eminent scholar Wang Guowei felt loyalty to the Qing which he had served, and in 1927 drowned himself in the former Qing palace grounds. ${ }^{1}$ This act, and those of others like him who showed a lingering loyalty to the Qing, have received traditional praise in the zhongyi biographies in the draft history of the Qing. Furthermore, the Song loyalists have been drawn upon as a source of inspiration in this century in the face of Western and Japanese imperialism as well as of the country's current political division. A case in point is Zhang Binglin (1868-1936), who highly praised the Song and Ming loyalists, expressing his antiforeign sentiments and nationalistic thought in his reminiscences of the erudite loyalist Wang Yinglin. Chen Yuan conveyed his nationalism as he annotated Hu Sanxing's work. At present in Taiwan, Wen Tianxiang and the exemplary loyalists are interpreted to have been more fiercely anti-Mongol than had really been the case. In the People's Republic, they are also observed to be praiseworthy men, but the nature of their loyalty and ethnic views are deemphasized to comply with the government's longstanding policy of stressing the country's ethnic complexity and of fostering harmonious relations among all ethnic groups. In fact, the landlord-gentry status of Wen Tianxiang, Deng $\mathrm{Mu}$, and other loyalists has been exaggerated and the limited visions of their loyalty to the Song dynasty criticized. Such an interpretation of loyalism to apply to situations of national significance other than dynastic change reflects a departure from the traditional concept of loyalty to a dynasty.

1. On Wang Guowei's loyalist feelings and suicide, see Schneider, 97-98. Chia-ying Yeh Chao argues that Wang's suicide was motivated by purity of ideal and general disillusionment with the times rather than loyalism to the Manchu regime. See her Wang Guowei, 7184. 


\section{APPENDIXES}

A. Songshi Biographies of Zhongyi Men (SS 446-55).

$\begin{array}{lccc}\text { SS } & \text { Loyalists (1273-1300) } & \text { Other Loyal Men } & \text { Total } \\ 446 & 0 & 20 & 20 \\ 447 & 0 & 14 & 14 \\ 448 & 0 & 25 & 25 \\ 449 & 0 & 38 & 38 \\ 450 & 16 & 1 & 17 \\ 451 & 11 & 0 & 11 \\ 452 & 7 & 43 & 50 \\ 453 & 0 & 45 & 45 \\ 454 & 41 & 5 & 46 \\ 455 & 2 & 10 & 12 \\ \text { Total } & 77 & 201 & 278 \\ \% & 28 & 72 & 100\end{array}$

Note that the 77 loyalists at the end of the Song appear in random order among loyal men of other periods in the Song.

B. Zhongyi Biographies Throughout the Dynasties.

The figures are tabulated from Chen Menglei et al., Gujin tushu jicheng, juan 706-763, vols. 311-316. Chen and his associates gleaned from various official and local sources the following numbers of biographical sketches of loyal men grouped according to the dynasties to which they directed their loyalty.

$\begin{array}{lr}\text { Shang } & 2 \\ \text { Zhou } & 77 \\ \text { Qin } & 4 \\ \text { Former Han } & 23 \\ \text { Latter Han } & 87 \\ \text { Wei } & 19 \\ \text { Shu-Han } & 0 \\ \text { Wu } & 14 \\ \text { Tsin } & 154 \\ \text { Liu-Song } & 27\end{array}$

$\begin{array}{lr}\text { Liang } & 18 \\ \text { Chen } & 7 \\ \text { Northern Wei } & 29 \\ \text { Southern Qi } & 18 \\ \text { Northern Qi } & 9 \\ \text { Northern Zhou } & 9 \\ \text { Sui } & 41 \\ \text { Tang } & 181 \\ \text { Latter Liang } & 5 \\ \text { Latter Tang } & 5\end{array}$


Appendixes

$\begin{array}{lrlr}\text { Latter Tsin } & 9 & \text { Song } & 684 \\ \text { Hou Han } & 2 & \text { Jin } & 179 \\ \text { Latter Zhou } & 27 & \text { Yuan } & 322 \\ \text { Liao } & 15 & \text { Ming } & 5074\end{array}$

C. Wen Tianxiang's Career Before the Resistance (SS 418).

$\begin{array}{llr}\text { Year } & \text { Position } & \text { Rank } \\ 1256 & \text { ranked first in list of jinshi } & \\ 1259 & \begin{array}{l}\text { chengshi lang (prestigious title) } \\ 1260\end{array} & \text { supervisor of Jianchang jun } \\ 1263 & \text { assistant staff author } & \\ 1264 & \text { judicial intendant of Jiangxi } & \\ 1267 & \text { secretary of the right (rev. of verdicts) } \\ 1268 & \text { judicial intendant of Fujian } & 5 \mathrm{~B} \\ 1269 & \text { administrator of Ningguo } & 5 \mathrm{~B} \\ 1270 & \text { director of military equipment } & \\ 1271-73 & \text { in retirement } & \\ 1273 & \text { judicial intendant of Hunan } & \text { 3B } \\ 1274 & \text { administrator of Ganzhou } & \text { 2B } \\ 1 / 1275 & \text { responded to qinwang campaign } & \text { 1B } \\ 6 / 1275 & \text { vice-president of Ministry of War } & \\ 9 / 1275 & \text { president of Ministry of War } & \end{array}$

Note the rapid rise from fifth to third rank and above after Wen's response to the Song court's appeal for the defense of the country.

D. Zhongyi Loyalists in Wen Tianxiang's mufu.

\begin{tabular}{|c|c|c|c|c|}
\hline $\begin{array}{l}\text { Name } \\
\text { Chen Jizhou }\end{array}$ & $\begin{array}{l}\text { Place of Origin } \\
\text { Ningdu (Jiangxi) }\end{array}$ & $\begin{array}{l}\text { Background } \\
\text { civil }\end{array}$ & $\begin{array}{l}\text { Rel. to Wen } \\
\text { colleague }\end{array}$ & $\begin{array}{l}\text { Martyrdom } \\
\text { killed, } 1277 \text { (with two } \\
\text { sons) }\end{array}$ \\
\hline Chen Longfu & Quanzhou (Fujian) & civil & cograduate & killed, 1278 \\
\hline Chen Xin & Raozhou (Jiangxi) & civil & follower & suicide, 1277 \\
\hline Chen Zijing & Ganzhou (Jiangxi) & civil & poet friend? & $1278 ?$ \\
\hline Chen Ziquan & Youxian (Hunan) & civil & follower & killed, 1277 \\
\hline $\mathrm{Du} \mathrm{Hu}$ & Tiantai (Zhejiang) & military & follower & captured/ill 1279 \\
\hline Fu Zhuo & Xujiang (Anhui) & civil & follower & suicide, 1277 \\
\hline Gong Xin & Anfeng (Anhui) & military & colleague & killed, 1277 \\
\hline $\mathrm{He} \mathrm{Shi}$ & Fuzhou (Jiangxi) & civil & cograduate & illness, $1280 ?$ \\
\hline Jin Ying & Jizhou (Jiangxi) & civil & landsman & illness, 1276 \\
\hline Li Zifa & Nan'an (Jiangxi) & military? & follower & $\begin{array}{l}\text { suicide, } 1279 \text { (with } \\
\text { family) }\end{array}$ \\
\hline
\end{tabular}




\section{Appendixes}

\begin{tabular}{|c|c|c|c|c|}
\hline Lin Dong & (Fujian) & civil & follower & killed, 1277 \\
\hline Lin Qi & (Fujian) & civil & follower & captured/ill 1278 \\
\hline Liu Bowen & Jizhou (Jiangxi) & military & landsman & killed, 1277 \\
\hline Liu Qin & Jizhou (Jiangxi) & civil & landsman & killed, 1277 \\
\hline Liu Shizhao & Jizhou (Jiangxi) & tailor & landsman & killed, 1277 \\
\hline Liu Zhu & Jizhou (Jiangxi) & civil? & landsman & $\begin{array}{l}\text { killed, } 1277 \text { (with } 3 \\
\text { sons) }\end{array}$ \\
\hline Liu Zijun & Jizhou (Jiangxi) & civil & landsman & killed, 1278 \\
\hline Luo Kaili & Jizhou (Jiangxi) & civil & landsman & killed, 1277 \\
\hline Lü Wu & Taiping (Anhui) & military & follower & killed, 1277 \\
\hline Miao Chaozong & Huai (Jiangxi/Anhui) & military? & follower & suicide, 1277 \\
\hline Peng Zhenlong & Yongxin (Jiangxi) & military? & brother-in-law & killed, 1277 \\
\hline Sun $\mathrm{Li}$ & Jizhou (Jiangxi) & civil? & $\begin{array}{l}\text { landsman, } \\
\text { brother-in-law }\end{array}$ & killed, 1277 \\
\hline Tang Ren & Nan' an (Jiangxi) & military & follower & illness, 1277 \\
\hline Wang Shimin & Jizhou (Jiangxi) & civil & landsman & killed, 1277 \\
\hline Wu Wenbing & (Fujian) & civil & follower & killed, 1277 \\
\hline Wu Xibi & Youxian (Hunan) & civil & follower & killed, 1277 \\
\hline Xiao Jingfu & Yongxin (Jiangxi) & civil & poet friend & killed, 1277 \\
\hline Xiao Mingzhe & Jizhou (Jiangxi) & civil & landsman & killed, 1277 \\
\hline Xiao Taofu & Yongxin (Jiangxi) & civil & poet friend & killed, 1277 \\
\hline Xiao Xing & $\begin{array}{l}\text { Nanxiong } \\
\text { (Guangdong) }\end{array}$ & military & follower & killed, $1278 ?$ \\
\hline Xiao Zi & Jizhou (Jiangxi) & civil & follower & killed, 1279 \\
\hline Xie Qi & (Fujian) & civil & follower & $1277 ?$ \\
\hline Xu Zhen & Wenzhou (Zhejiang) & civil & follower & illness, 1279 \\
\hline Xiong Gui & Xiangtan (Hunan) & civil & follower & killed, 1278 \\
\hline Yin Yu & Ningdu (Jiangxi) & military & colleague & killed, 1275 \\
\hline Zeng Feng & Jizhou (Jiangxi) & civil & $\begin{array}{l}\text { landsman } \\
\text { teacher }\end{array}$ & ill, 1277 \\
\hline Zhang Bian & (Sichuan) & military & colleague & killed, 1277 \\
\hline Zhang Tang & Changsha (Hunan) & civil & follower & killed, 1278 \\
\hline Zhang Yun & Jizhou (Jiangxi) & military & landsman & killed, 1276 \\
\hline Zhang Zhezhai & Taizhou (Zhejiang) & military & follower & killed, 1278 (with son) \\
\hline Zhao Fan & Hengshan (Hunan) & civil & follower & $1278 ?$ \\
\hline Zhao Shishang & Hezhou (Anhui) & military & colleague & killed, 1277 \\
\hline Zou Feng & Jizhou (Jiangxi) & military & landsman & suicide, 1277 \\
\hline
\end{tabular}

1. There are forty-four biographies altogether of those who died or were presumed to have died during or shortly after the loyalist resistance. Two surviors, Wang Mengying and Zhong Zhen, have not been included in this list. Xie Mengde has also been left out because the information is suspiciously mistaken for Xie Fangde.

2. This table was compiled from Deng Guangiian's Wen Chengxiang dufu zhongyi zhuan. Twenty-seven out of the forty-four men also have biographies in SS 454. Chen Longfu, 


\section{Appendixes}

Zhang Tang, and Zhang Yun are listed as having biographies but, in fact, only their names appear. SS 454 contains discrepancies in the characters used for Zhang Tang, Liu Zhu, and Chen Xin.

3. Place of origin: Most of the men came from Jiangxi; others were from Anhui, Fujian, Zhejiang, Hunan, Guangdong--places where the loyalists fought in.

4. Background: Most of the men joined Wen in 1274-78. Of these, twenty-eight had civil careers, fifteen had military backgrounds, and one was a tailor.

5. Relationship to Wen: There were twenty followers who independently joined Wen, twelve landsmen, five colleagues, three friends, two relatives, two fellow graduates in 1256.

6. Martyrdom: Twenty-nine were killed in battle, seven died of distress or illness, four committed suicide, four were presumed to have died of natural causes.

E. Loyalist Centers and Major Personalities.

Name

Before 1276

After 1276

Soc. Ser. Relatives/disciples accepted

(also active in) Yuan office/title

1. LOYALISTS ABROAD

Chen Yizhong chief minister

Chen Zhongwei official

Zeng Yuanzi official

Su Liuyi's sons officials

Qu Kui scholar

Li Yong scholar

Champa, Siam no no son sur. to Yuan

Annam no no sons, son-in-law sur. to Yuan

Annam no no brother, sons sur. to Yuan

Annam no no sur. to Yuan

coastal island yes no no

Japan, Annam no no son Chunsou sur. to Yuan

\section{DADU (BEIJING)}

Wang Qinghui imp. concubine

Wang Yuanliang official

$\begin{array}{ll}\text { Jia Xuanweng } & \text { official } \\ \text { Wu Jian } & \begin{array}{l}\text { chief minister } \\ \text { chief minister }\end{array} \\ \text { Wen Tianxiang } & \text { emperor } \\ \text { Gongdi } & \text { emp. dowager } \\ \text { Xie } & \text { emp. dowager } \\ \text { Quan } & \text { imp. relative } \\ \text { Yang Zhen } & \text { imp. relative }\end{array}$

$\begin{array}{lll} & \text { no no no } \\ \text { Hangzhou, } & \text { yes yes } & ? \\ \text { Luling, Raozhou } & & \\ \text { Hejian } & \text { yes yes } & ? \\ & \text { yes no } & ? \\ \text { Tibet } & \text { yes no } & \text { sons, brother, grandson served } \\ & \text { yes yes } & ? \\ & \text { yes yes } & ? \\ & \text { yes yes } & ? \\ \text { yes yes } & ? \\ \text { yes yes } & ?\end{array}$

\section{KUAIJI (SHAOXING)}

\section{Tang Jue scholar}

Lin Jingxi scholar

Wang Yingsun imp. relative

Zheng Buweng scholar

$\begin{array}{lll} & \text { no no } \\ \text { Hangzhou } & \text { yes no } & \text { brother served } \\ \text { Hangzhou } & \text { yes no } & ? \\ & \text { no no }\end{array}$




\section{Appendixes}

$\begin{array}{ll}\text { Luo Xian } & \text { eunuch } \\ \text { Chen Shuke } & \text { scholar } \\ \text { Quan Quanweng } & \text { scholar } \\ \text { Wang Yisun } & \text { poet } \\ \text { Wang Yijian } & \text { poet } \\ \text { Tang Yisun } & \text { poet }\end{array}$

4. WUZHOU AND JIANDE

\begin{tabular}{|c|c|}
\hline Xie Ao & poet \\
\hline Fang Feng & poet \\
\hline Wu Siqi & official \\
\hline Wu Wei & official \\
\hline Lian Wenfeng & poet \\
\hline Yan Lü & scholar \\
\hline Feng Guifang & scholar \\
\hline $\begin{array}{l}\text { Chai Wang } \\
\text { ( } 3 \text { cousins })\end{array}$ & $\begin{array}{l}\text { official } \\
\text { scholars }\end{array}$ \\
\hline Jin Lüxiang & philosopher \\
\hline $\begin{array}{l}\text { Fang Fengchen } \\
\text { (brothers): }\end{array}$ & official \\
\hline Fang Fengzhen & official \\
\hline Fang Fengjia & official \\
\hline He Menggui & offical \\
\hline Fang Yikui & official \\
\hline
\end{tabular}

5. LULING (JI'AN) Wang Yanwu commoner Zhao Wen scholar. Zhang Yifu commoner Deng Guangiian official Liu Chenweng official Liu Jiangsun scholar

\section{QINGYUAN (NINGBO)} Wang Yinglin official (son):

Wang Changshi scholar Hu Sanxing official Dai Biaoyuan official Liu Zhuangsun official Shu Yuexiang official Huang Zhen official Chen Zhu official

$\begin{array}{lll}\text { no no } & ? \\ \text { yes } & \text { yes } & ? \\ \text { no no } & ? \\ \text { yes yes } & ? \\ ? & ? & ? \\ ? & ? & ?\end{array}$

\begin{tabular}{|c|c|c|c|}
\hline $\begin{array}{l}\text { Hangzhou, } \\
\text { Jiande/Kuaiji }\end{array}$ & yes $n$ & & ? \\
\hline Hangzhou & yes $n$ & no & students, son served \\
\hline Jiande/Kuaiji & yes $n$ & no & students served \\
\hline Wuzhou & no $n$ & no & $?$ \\
\hline Hangzhou & yes $y$ & yes & $?$ \\
\hline & ? ? & $?$ & $?$ \\
\hline & ? ? & $?$ & $?$ \\
\hline & no $\mathrm{n}$ & no & no \\
\hline & no $n$ & no & $?$ \\
\hline & no $n$ & no & students served \\
\hline & yes $n$ & no & three sons served \\
\hline & yes $r$ & no & son served \\
\hline & yes $\mathrm{r}$ & no & $?$ \\
\hline & yes $\mathrm{r}$ & no & son served \\
\hline & yes $\mathrm{r}$ & no & $?$ \\
\hline & yes $\mathrm{r}$ & no & relative, friend served \\
\hline & yes & yes & ? \\
\hline & no & no & $?$ \\
\hline Dadu & yes & yes & $?$ \\
\hline & yes & no & students, son served \\
\hline & yes & yes & $?$ \\
\hline & yes & no? & students, grandson served \\
\hline & yes & no & son served \\
\hline Taizhou & yes & no & grandson served \\
\hline Hangzhou & yes & yes & yes? \\
\hline & yes & no & friend served \\
\hline Hangzhou & yes & no & $?$ \\
\hline & no & no & no? \\
\hline & no & no & three sons served \\
\hline
\end{tabular}




\section{Appendixes}

$\begin{array}{lllll}\text { Chen Yunping } & \text { scholar } & \text { Hangzhou } & \text { yes no } \\ \begin{array}{l}\text { 7. RAOZHOU } \\ \text { Ma Tingluan }\end{array} & \text { chief minister } & \text { Hangzhou } & \text { no no } & \text { son served } \\ \begin{array}{l}\text { (son): } \\ \text { Ma Duanlin }\end{array} & \text { scholar } & & & \\ \text { Cao Jing } & \text { scholar } & \text { Wuyuan } & \text { yes yes } & \text { yes yes } \\ \text { Hu Ciyan } & \text { official } & \text { Wuyuan } & \text { yes no ? } \\ \text { Cheng Chuweng } & \text { scholar } & \text { Wuyuan } & \text { no no ? } \\ \text { Xu Yueqing } & \text { official } & \text { Wuyuan } & \text { no no ? } \\ \text { Xie Fangde } & \text { official } & \text { Jianning } & \text { no no sons served } \\ \text { Xiong He } & \text { official } & & \text { no no ? }\end{array}$

\section{PINGJIANG (SUZHOU)}

\begin{tabular}{|c|c|c|c|c|c|}
\hline Zheng Sixiao & painter & Fujian & no & no & no \\
\hline Gong Kai & painter & Hangzhou & yes & no & many friends served \\
\hline \multicolumn{6}{|c|}{ 9. DONGGUAN (NEAR GUANGZHOU) } \\
\hline Zhao Bixiang & $\begin{array}{l}\text { imp. relative, } \\
\text { official }\end{array}$ & & yes & no & no \\
\hline Zhao Dongshan & imp. relative & & no & no & $?$ \\
\hline Zhao Shiqing & imp. relative & & no & no & $?$ \\
\hline $\begin{array}{l}\text { Li Chunsou } \\
\text { (brother): }\end{array}$ & official & & yes & no & son served \\
\hline Li Deming & official & & yes & no & $?$ \\
\hline Chen Geng & scholar & & yes & no & brother sur. to Yuan \\
\hline Zhang Heng & scholar & Wuzhou & no & no & $\begin{array}{l}\text { son Yuanji served; brother did } \\
\text { not }\end{array}$ \\
\hline Fang Youxue & official & Hangzhou & no & no & $?$ \\
\hline \multicolumn{6}{|l|}{ 10. HUZHOU } \\
\hline Gao Side & official & & no & no & $?$ \\
\hline Chen Cun & official & & no & no & grandson Wuyi served \\
\hline Wen Jiweng & official & Sichuan & no & no & son served \\
\hline Mou Yan & official & Hangzhou & yes & no & three sons served \\
\hline Qian Xuan & painter & & no & no & $?$ \\
\hline Zhao Mengfu & $\begin{array}{l}\text { imp. relative } \\
\text { official }\end{array}$ & $\begin{array}{l}\text { Hangzhou, } \\
\text { Dadu }\end{array}$ & yes & yes & $\begin{array}{l}\text { friends, seven of Eight Tal- } \\
\text { ents served }\end{array}$ \\
\hline
\end{tabular}

\section{HANGZHOU}

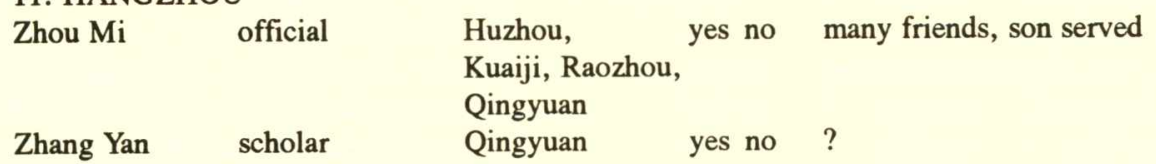




\section{Appendixes}

$\begin{array}{lllll}\text { Qiu Yuan } & \text { poet } & \text { Kuaiji } & \text { yes yes } & ? \\ \text { Bai Ting } & \text { poet } & \text { Qingyuan } & \text { yes yes } & ? \\ \text { Zhang Zhongshi } & \text { scholar } & \text { Huzhou } & \text { yes yes } & ? \\ \text { Wen Riguan } & \text { Buddhist monk } & & \text { no no } & ? \\ \text { Deng Mu } & \begin{array}{l}\text { Daoist philo- } \\ \text { sopher }\end{array} & \text { Kuaiji } & \text { no no } & \text { ? } \\ \text { Deng Wenyuan } & \text { scholar } & \text { Sichuan } & \text { yes yes } & ? \\ \text { Tu Yue } & \text { scholar } & & \text { yes yes } & \text { ? }\end{array}$

Notes:
Soc. $=$ Socialization with Yuan officials; Ser. = Service in Yuan government; Sur. $=$ Surrendered.

\section{F. Zhou Mi's Traveling Companions.}

\begin{tabular}{|c|c|c|c|}
\hline \multicolumn{3}{|c|}{ A. BEFORE 1276} & \multirow{2}{*}{ Yuan Service } \\
\hline Name $\quad 1$ & Dates & Comments & \\
\hline Zhao Mengjian & $1199-1267$ & poet, painter, imp. clansman & \\
\hline $\begin{array}{l}\text { Zhao Yuyin } \\
\text { (son): }\end{array}$ & $1213-65$ & official, imperial clansman & no \\
\hline *Zhao Mengfu & $1254-1322$ & painter, calligrapher, imperial clansman & 1287, high-rank \\
\hline $\begin{array}{l}\text { Yang Boyan } \\
\text { (son): }\end{array}$ & d. 1254 & father-in-law, scholar, official & no \\
\hline *Yang Dashou & fl. $1270-1300$ & wealthy Hangzhou family & $?$ \\
\hline $\begin{array}{l}\text { Mou Zicai } \\
\text { (son, grandson) }\end{array}$ & $\begin{array}{l}\text { d. ca. } 1266 \\
\text { ): }\end{array}$ & official & no \\
\hline *Mou Yan & $1227-1311$ & scholar, official & no \\
\hline *Mou Yinglong & $1247-1324$ & scholar, official & yes \\
\hline Wu Wenying & $1200-60$ & poet & no \\
\hline $\begin{array}{l}\text { Zhang Shu } \\
\text { (son): }\end{array}$ & fl. $1250-80$ & wealthy Hangzhou family & no \\
\hline *Zhang Yan & $1248-1320$ & poet & no \\
\hline Yang Zuan & d. 1268 & poet, father of Imperial Concubine Yang & no \\
\hline Shi Zhongshan & fl. $1240-80$ & poet, official & no \\
\hline $\begin{array}{l}\text { *Li Penglao } \\
\text { (brother): }\end{array}$ & fl. $1260-1300$ & poet, official & no \\
\hline *Li Lailao & fl.1260-1300 & poet, official & no \\
\hline $\begin{array}{l}\text { *Yuan Hong } \\
\text { (son): }\end{array}$ & $1248-98$ & official & $\begin{array}{l}1290 \text { s, adminis- } \\
\text { trator }\end{array}$ \\
\hline *Yuan Jue & $1266-1327$ & scholar, prose writer & 1290s, high-rank \\
\hline *Chen Guo & fl. $1270-90$ & scholar, official & no \\
\hline *Gao Side & fl. $1220-90$ & scholar, official & no \\
\hline $\begin{array}{l}\text { *Ma Tingluan } \\
\text { (son): }\end{array}$ & $1223-89$ & poet, scholar, chief minister & no \\
\hline
\end{tabular}




\section{Appendixes}

$\begin{array}{llll}\text { *Ma Duanlin } & 1254-1325 & \text { scholar, historian } & \begin{array}{l}\text { after 1300, edu- } \\ \text { cation officer }\end{array} \\ & & & 1290 \text {, ed. officer } \\ \text { *Wang Yisun } & 1232-91 & \text { poet } & \text { no } \\ \text { *Wang Yingsun } & \text { fl.1260-1300 } & \text { wealthy Shaoxing family, official } & \text { no } \\ \text { *Wen Jiweng } & 1236-1291 & \text { scholar, official } & \text { no } \\ \text { Liu Lan } & \text { d. } 1276 & \text { Daoist, poet } & \end{array}$

B. AFTER 1276

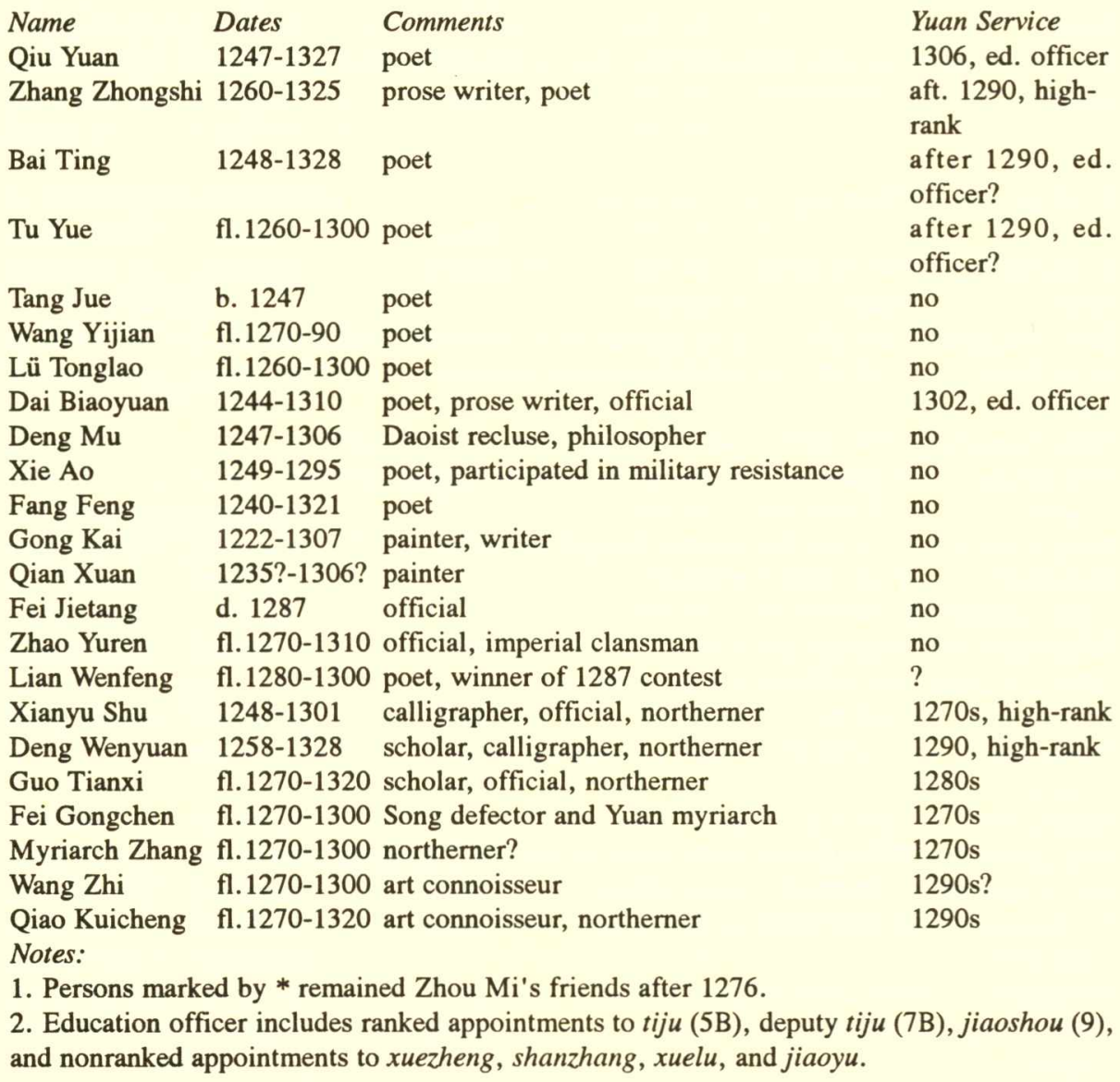




\section{BIBLIOGRAPHY OF WORKS CITED}

\section{Primary Sources}

Bai Ting白珽. Zhanyuan jingyu湛洲静哣. ZBZZ ed.

Bi Yuan晕流, comp. Xu Zizhi tongjian 績资治通爁. Taibei: Shijie shuju, 1962.

Chai Wang柴望. Qiutang ji秋堂集. SKQSZB ser. 5th ed.

Chen Bangzhan事邦醇. Songshi jishi benmo 宋史記事本末. Beijing: Zhonghua shuju, 1977. . Yuanshi jishi benmo 元史記事本末. 1888 ed.

Chen Botao 傮伯陶. Dongguan yimin lu虽党遗民睩. Jude tang ed.

Chen Li 邺彞. Dingyu ji 定宇集. SKQSZB ser. 2nd ed.

Chen Menglei 陳萝雷, et al. Gujin tushu jicheng 古今圆青集成. Shanghai: Zhonghua shuju, 1934.

Chen Shuke 掼恕可, comp. Yuefu buti樂府補題. ZBZZ ed.

Chen Yunping 陳允平. Rihu yuchang 日湖漁唱. CSJC chubian ed.

Chen Zhu泍着. Bentang $j i$ 本堂集. SKQSZB ser. 2nd ed.

Cheng Jufu程领夫. Xuelou ji雪楼集. Taibei: Guoli zhongyang tushu guan, 1970.

Cheng Minzheng程䑤政, comp. Song yimin lu宋遗民録. ZBZZ ed.

Dai Biaoyuan戴表元. Shanyuan ji 灲源集. SBCK chubian suoben ed.

Deng Guangiian 登光鹰. Wen Chengxiang dufu zhongyi zhuan 文丞相督府 忠義傳. In Wen Tianxiang's Wenshan xiansheng quanji. SBCK chubian ed.

Deng Mu每牧. Boya qin 伯手琴. ZBZZ ed. , comp. Dongxiao shiji 洞霄铣集. ZBZZ ed. , comp. Dongxiao tuzhi 洞霄圆志.ZBZZ ed.

Deng Wenyuan 整文原.Baxi ji 巴四集.SKQSZE ser. 3rd ed. 


\section{Bibliography}

Dengke lu登科睩. Yueya tang ed.

Dong Sizhang董斯张, comp. Wuxing beizhi吴舆侾志. SKQSZB ser. 9th ed.

Fang Feng方国. Yisu kao 夷佫考. Baoyan tang biji ed.

. Cunya tang yigao 存雅堂遗稿. Xu Jinhua congshu ed.

Fang Fengchen方逢辰. Jiaofeng wenji 蛟塞文集. SKQSZB ser. 4th ed.

Fang Xuanling 房玄龄. Tsinshu香書. Beijing: Zhonghua shuju, 1974.

Fang Hui 方目. Tongjiang ji 桐江集. Taibei: Guoli zhongyang tushu guan, 1970.

. Tongjiang xuji 桐江缜集. SKQSZB chuji ed.

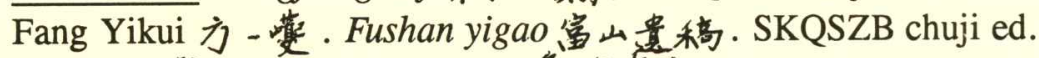

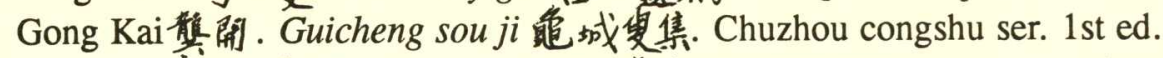

Gao Side 高斯得. Chitang cungao 耻堂存稿. SKQSZB supp. ser. ed.

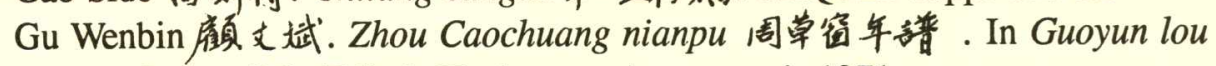
shuhua ji 2. Taibei: Hanhua wenhua gongsi, 1971.

Hao Jing 郝綬. Lingchuan ji 陵川集. SKQSZB ser. 4th ed.

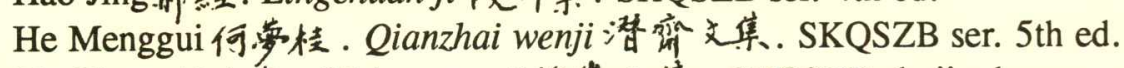

Hu Ciyan 胡次炎. Meiyan wenji梅索文集. SKQSZB chuji ed.

Huang Jin黄漂. Huang Jinhua wenji 黄金華文集. SBCK chubian ed.

Huang Zongxi黄宗堢. Mingyi daifang lu 明夷待劯绿. Beijing: Zhonghua shuju, 1955.

. Song Yuan xue'an 宋无等案. Shanghai: Shangwu yinshu guan, 1934.

Ji Yun 紀昀, et al. Siku quanshu zongmu tiyao 四库全書總目提要. Taibei: Shangwu yinshu guan, 1971.

Jia Sidao 賈似道. Yuesheng suichao悦生随抄. Shuofu 20.

Jia Xuanweng 家铉翁. Zetang ji 埧堂集. SKQSZB chuji ed.

Jiang Shiquan蒋士铨. Dongqing shu冬青樹. Taibei: Yiwen yinshu guan, 1971.

Jin Lüxiang 金履祥. Renshan ji 仁山集. CSJC chubian ed.

Li Penglao, Li Lailao李彭老，李菒老。Guixi eryin ji 遍溪二隐集。Jiangcun congshu ed.

Lian Wenfeng遇文圆. Baizheng ji 百正集. SKQSZB supp. ser. ed.

Lin Jingxi 林景暖. Jishan ji霖山集. Beijing: Zhonghua shuju, 1960.

Liu Chenweng 劉辰翁. Xuxi ji 缜溪集. SKQSZB ser. 4th ed. 


\section{Bibliography}

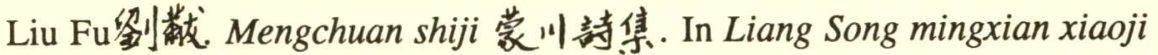
362. SKQSZB ser. 6th ed.

Liu Guan枊其. Liu Daizhi wenji 枊待制文焦. SBCK chubian ed.

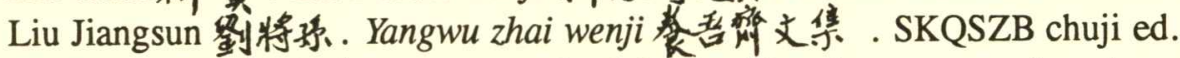

Liu Minzhong 经敏中. Ping Song lu平宗睩. Shoushan ge congshu ed.

Liu Yin噼因. Jingxiu xiansheng wenji 静修先生文集. SBCK chubian suoben ed.

Liu Yiqing 倒一清. Qiantang yishi錢堷倳. Wulin zhanggu congbian ed.

Lu Xinyuan陸心源. Songshi yi 守史翼. Taibei: Wenhai chuban she, 1967. Lu Xiufu陸季夫. Lu Zhonglie gong shu 陸忠烈公書. Qiankun zhengqi ed. Ma Duanlin、馬端稫. Wenxian tongkao 文雃通考. Shanghai: Shangwu yinshu guan, 1936.

Ma Tingluan.鳥廷鹤. Biwu wanfang ji 碧梧玩芳集. SKQSZB supp. ser. ed.

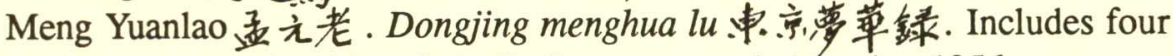
other works. Shanghai: Gudian wenxue chuban she, 1956.

Mo Youzhi 莫友之. Song Yuan jiuben shu jingyan lu宋无萑本毒絰眼睩 Taibei: Guangwen shuju, 1967.

Mou Yan牟峣就. Lingyang ji 陵淂集. Wuxing congshu ed.

Nianchang念常. Fozu lidai tongzai 佛祖痤代通載. Taishô Tripitaka, vol. 49:2036.

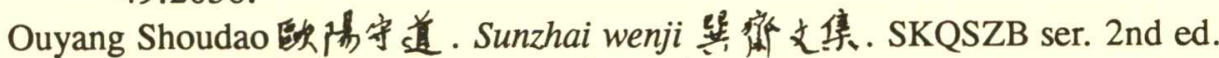
Ouyang Xiu卧陽修.Xin Wudai shi 新五代定. Beijing: Zhonghua shuju, 1974.

Pu Shoucheng蒲素客. Xinquan xueshi gao心泉學詩稿. SKQSZB chuji ed. Qiu Yuan仇逶. Jinyuan ji 金洲集. Wuying dian juzhen ban congshu ed. Shancun yiji 山村速集. Wulin wangzhe yizhu ed.

Quan Heng權衡. Gengshen waishi 庚中奴史. Xuejin taoyuan ed.

Quan Zuwang 全祖望. Jiqiting ji船埼亭集. Wanyou wenku ed.

Shi Nai'an施政底, and Luo Guanzhong 羅置中. Shuihu quanzhuan 水汻全 傮. Shanghai: Renmin chuban she, 1975.

Shu Yuexiang 鿭获徉. Langfeng ji閧国集. SKQSZB ser. 3rd ed.

Sima Guang间鳥光, comp., and Hu Sanxing 胡三省, annot. Xinjiao [Zizhi] tongjian zhu 新校资治通爁注. Taibei: Shijie shuju, 1972.

Sima Qian间、局透.Shiji 史㝇. Beijing: Zhonghua shuju, 1973.

Song Lian宋㴋. Song Wenxian gong quanji 宗文㭧公全集. SBBY ed. 


\section{Bibliography}

et al. Yuanshi元史(YS). Beijing: Zhonghua shuju, 1976.

Songji sanchao zhengyao 守、李三朝政要. Postscript Erwang benmo

by Chen Zhongwei 嘾仲微. CSJC chubian ed.

Su Tianjue罧天滔，comp. Yuan wenlei 元文類. Shanghai: Shangwu yinshu guan, 1936.

Su Zedong 辚濐串, comp. Songtai qiuchang 宋台秋唱. Jude tang congshu ed.

Tao Zongyi 陶宗儀. Nancun zhuogeng lu南村軗耕録. Beijing: Zhonghua shuju, 1980.

, comp. Shuofu嗾彩. Yuanwei shantang cangban ed.

Toghto 舵㙂, et al. Jinshi金史. Beijing: Zhonghua shuju, 1975. . Songshi 字史(SS). Beijing: Zhonghua shuju, 1977.

Wan Sitong 荡斯同. Nan Song liuling yishi 南安六陵量事. With Gengshen jun yishi. Taibei: Guangwen shuju, 1968.

. Songji zhongyi lu 宋季忠我绿. Siming congshu ser. 2nd ed.

Wang Feng王条. Wuxi ji 梧滛集. SKQSZB ser. 2nd ed.

Wang Fuzhi 王夫之. Songlun!宗斾. Beijing: Zhonghua shuju, 1964.

Wang Yanwu 王炎午. Wuwen gao吾汶稿. SKQSZB ser. 9th ed.

Wang Yi 王奕. Jiacun leigao 稼村颣稿. SKQSZB chuji ed.

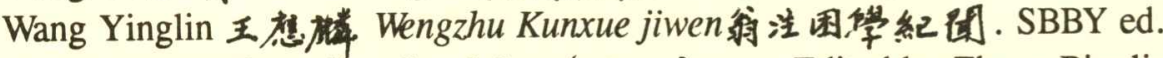
. Chongding Sanzi jing 重部三字砤. Edited by Zhang Binglin.

Shanghai: Hanwen zhengjie, 1933. . Siming wenxian ji 四明文獻集. Siming congshu ser. 1st ed.

Wang Yuanliang 江元量. Hushan leigao 湖山颣稿. Wulin wangzhe yizhu ed.

. Shuiyun $j i, \mathrm{k}$ 雲集. Wulin wangzhe yizhu ed.

comp. Wang Song jiu gongren shici 亡字萑宫人部部. App-

ended to Wang Yuanliang's Hushan leigao. Wulin wangzhe yizhu ed.

Wang Yun玉恽. Qiujian daquan ji 秋溜大全集. SBCK chubian ed.

Wei Shou 魏收, et al. Weishu魏書. Beijing: Zhonghua shuju, 1974.

Wei Zheng魏徽, et al. Suishu 陧書. Beijing: Zhonghua shuju, 1973.

Wen Tianxiang 文天样. Wenshan xiansheng quanji 文山先生全集. SBCK chubian ed.

Wu Wei 是渭, comp. Yuequan yinshe 月鼠㕫社 Yueya tang congshu ed.

Wu Zimu 委自牧. Mengliang lu萝梁绿. In Dongjing menghua lu. Shang- 


\section{Bibliography}

hai: Gudian wenxue chuban she, 1956.

Xia Wenyan 夏文着.Tuhui baojian 固掵寒签. Jiguge congshu ed.

Xianchun yishi 减淳道事. Shoushan ge congshu ed.

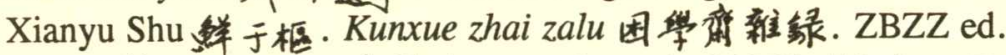

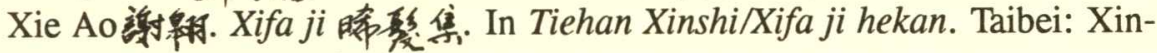

jiang shuju, 1975 .

, comp. Tiandi jian ji 天地明集. Appended to Xie Ao's Xifa ji.

Taibei: Xinjiang shuju, 1975.

Xie Fangde謝枋得. Bihu zaji 碧湖䌖靯. Shuofu 19. . Dieshan xiansheng wenji 愿山先生文焦. SBCK xubian ed. annot. Shi Zhuan zhushu 封傮注㧧. ZBZZ ed.

, annot. Wenzhang guifan 文章轨籍. SKQSZB ser. 11th ed.

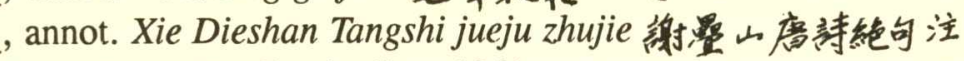

解. Hong Kong: Xuelin shudian, 1961.

Xiong He熊和Xiong Wuxuan xiansheng wenji 熊勿軒先生文集. CSJC chubian ed.

Xu Dazhuo 待.大煌. Jinyu lu嗉稌睩. Wangcui lou congshu ed.

Xu Yueqing竍日坬. Xiantian ji 先天集. SBCK xubian ed.

Yang Boyan 棉伯虽. Jiujing buyun 九絰補曂. Xuejin taoyuan ed.

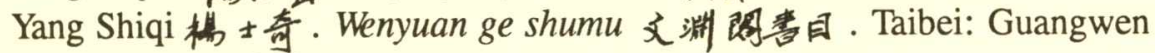
shuju, 1969.

Yao Silian姚思㵂, et al. Liang Shu梁. Beijing: Zhonghua shuju, 1973. Ye Shaoweng 妱翁. Sichao wenjian lu四朝聞見睩. CSJC chubian ed. Yuan Jue袁桶. Qingrong jushi ji 清客居士集. CSJC chubian ed. Zhang Hongfan 张弘籍. Huaiyang ji 淮倩集. SKQSZB ser. 3rd ed.

Zhang Yan 张类. Shanzhong baiyun ci 山中白雲呞. Jiangcun congshu ed. Zhang Yi 张明. Yaishan ji 尾偗. Hanfen lou biji ed.

Zhao Bixiang 趙必像. Fupou ji 㠅部集. SKQSZB ser. 8th ed.

Zhao Jingliang 趙景良, comp. Zhongyi ji 忠库集. SKQSZB ser. 9th ed.

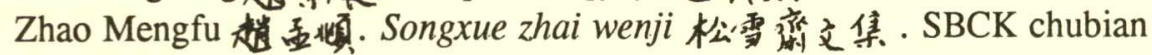
suoben ed.

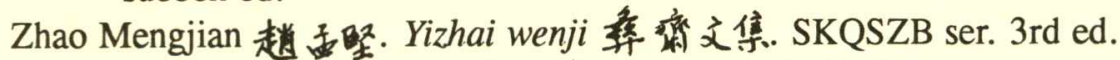

Zhao Wen趙文. Qingshan ji 青山集. SKQSZB chuji ed.

Zhao Yi 趙翼. Nian'er shi zhaji 廿二敦記. Beijing: Zhonghua shuju, 1963 . 


\section{Bibliography}

Zhaozhong lu 䀦忠睩 CSJC chubian ed.

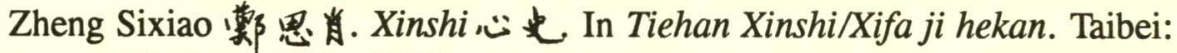

Xinjiang shuju, 1975.

. Zheng Suonan xiansheng shiji wenji 郸所南先生特集文集。

Appended to Zheng Zhen's Sanshan Zheng Jushan. SBCK xubian ed. Zheng Yuanqing 郸元度. Hulu jingji kao 湖録经籍考. Taibei: Guangwen shuju, 1969.

Zheng Yuanyou 鄚元祐. Suichang zalu遂昌雜睩 Baihai ed.

Zheng Zhen嗼震. Sanshan Zheng Jushan xiansheng Qingjun ji 三山鄭菊山

先生清焦集. SBCK xubian ed.

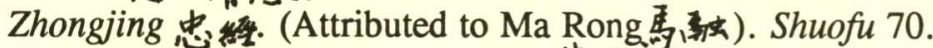

Zhou Mi 周密. Caochuang yunyu 草窗韵語. Lidai huajia shiwen ji 3.

Taibei: Xuesheng shudian, 1973.

. Guixin zazhi 発手雜裁 Jindai bishu ed.

. Haoran zhai yatan 浩然独雅强. SKQSZB supp. ser. ed.

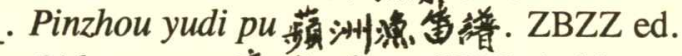

. Qidong yeyu弯事野部. CSJC chubian ed.

. Wulin jiushi 武林隽事. Biji xiaoshuo daguan ed.

. Yunyan guoyan lu 䨐烟遗眼睩.Baoyan tang biji ed.

1969.

. Zhiya tang zachao 志雅堂雅钞. Taibei: Guangwen shuju,

, comp. Chenghuai lu澄㥬绿. Rongyuan congshu ed.

, comp. Juemiao haoci jian 絶妙好词簙. Shanghai: Zhonghua shuju, 1957.

Zhu Cunli 朱存理. Shanhu munan 理㗅模隹. Taibei: Guoli zhongyang tushu guan, 1970.

II. Secondary Sources

Allan, Sarah. The Heir and the Sage. Taibei: Chinese Materials Center, 1981. Allsen, Thomas T. Mongol Imperialism: The Policies of the Grand Qan Mongke in China, Russia, and the Islamic Lands, 1251-1259. Berkeley and Los Angeles: University of California Press, 1987.

Anderson, E. N. Jr. "The boat people of South China," Anthropos 65 (1970), 248-56.

Bai, Shouyi. "Ma Duanlin de shixue sixiang" [The historiographical thought of 


\section{Bibliography}

Ma Duanlin]. In Bai Shouyi, Xuebu ji (Beijing: Sanlian shudian, 1961), 210-52.

Balazs, Etienne. Chinese Civilization and Bureaucracy: Variations on a Theme. Translated by H. M. Wright and edited by A.F. Wright. New Haven and London: Yale University Press, 1964.

De Bary, Wm. Theodore. "A plan for the prince: the Ming-i tai-fang lu of Huang Tsung-hsi." Ph.D. dissertation, Columbia University, 1953.

Beasley, W. G., and E. G. Pulleyblank, eds. Historians of China and Japan. London: Oxford University Press, 1961.

Beattie, Hilary J. "The alternative to resistance: the case of T'ung-ch'eng, Anhwei," in Spence and Wills, From Ming to Ch'ing, 239-76.

Bol, Peter K. "Seeking common ground: Han literati under Jurchen rule," Harvard Journal of Asiatic Studies 47:2 (1987), 461-538.

Brown, William Andreas. Wen T'ien-hsiang: A Biographical Study of a Sung Patriot. San Francisco: Chinese Materials Center, 1986.

Buell, Paul. "The Sung resistance movement, 1276-79: an episode in Chinese regional history," The Annals of the Chinese Historical Society of the Pacific Northwest 3 (1985-86), 138-86.

Cahill, James. "Ch'ien Hsüan and his figure paintings," Archives of the Chinese Art Society of America 12 (1958), 11-29.

. Hills Beyond a River: Chinese Paintings of the Yüan Dynasty, 1279-1368. New York: Weatherhill, 1976.

. An Index of Early Chinese Painters and Paintings: T'ang, Sung, and Yüan. Berkeley and Los Angeles: University of California Press, 1980.

Chan, Hok-lam. "Chinese official historiography at the Yüan court: the composition of the Liao, Chin, and Sung histories," in Langlois, China Under Mongol Rule, 56-106.

. "Chinese refugees in Annam and Champa at the end of the Sung dynasty," Journal of Southeast Asian History 7:2 (1966), 1-10.

. "Comprehensiveness" (t'ung) and "change" (pien) in Ma Tuanlin's historical thought," in Chan and De Bary, Yüan Thought: Chinese Thought and Religion Under the Mongols, 27-87.

. The Historiography of the Chin Dynasty: Three Studies. Wiesbaden: Franz Steiner Verlag, 1970. 
Bibliography

. Legitimation in Imperial China: Discussions Under the JurchenChin Dynasty (1115-1234). Seattle and London: University of Washington Press, 1984.

. "Liu Ping-chung (1216-74): a Buddhist-Taoist statesman at the court of Khubilai Khan," T'oung Pao 53: 1-2 (1967), 98-146. , and Wm. Theodore de Bary, eds. Yüan Thought: Chinese Thought and Religion Under the Mongols. New York and London: Columbia University Press, 1982.

Chan, Wing-tsit, tr. Reflections on Things at Hand: The Neo-Confucian Anthology. Compiled by Zhu Xi and Lü Zuqian. New York and London: Columbia University Press, 1967.

Chang, Bide, et al., comp. Songren zhuanji ziliao suoyin [Index to biographical materials of Song personalities]. 6 vols. Taibei: Dingwen shuju, 1976.

Chang, Carsun (Chia-sen). The Development of Neo-Confucian Thought. New York: Bookman, 1957-62.

Chang, Fu-jui. Les Fonctionnaires des Song: Index des Titres. Matériaux pour le Manuel de 1'Histoire des Song 5. Paris: Mouton \& Co., 1962.

Chang, Kang-i Sun, "Symbolic and allegorical meanings in the Yüeh-fu pu-t'i poem series," Harvard Journal of Asiatic Studies 46:2 (1986), 353-85.

Chao, Chia-ying Yeh. "On Wang I-sun and his Yung-wu Tz'u," Harvard Journal of Asiatic Studies 40:1 (1980), 55-91.

. Wang Guowei yu qi wenxue piping [Wang Guowei and his literary criticism]. Hong Kong: Zhonghua shuju, 1980.

Chao, Y.R. (Zhao Yuanren). Zaonian zizhuan [Autobiography: early years]. Taibei: Zhuanji wenxue chuban she, 1984.

Chen, Dengyuan. Guoshi jiuwen [Anecdotes of national history], vol. 2. Beijing: Xinhua shudian, 1962.

Chen, Gaohua, comp. Yuandai huajia shiliao [Historical material on Yuan painters]. Shanghai: Renmin meishu chuban she, 1980.

Chen, Yuan. Chen Yuan shiyuan xue zawen [Chen Yuan's miscellaneous papers on historical sources]. Beijing: Renmin chuban she, 1980.

. Nan Song chu Hebei xin daojiao kao [A study of new Daoist sects in Hebei during the early Southern Song]. Furen daxue congshu 8. Beijing: Jingcheng yinshu ju, 1941. 


\section{Bibliography}

Tongjian Huzhu biaowei [An exposition of Hu Sanxing's annotations on the Zizhi tongjian]. Hong Kong: Guangjiao jing chuban she, 1978.

Western and Central Asians in China Under the Mongols. Translated and annotated by Ch'ien Hsinghai and L. Carrington Goodrich. Monumenta Serica Monograph 15. Los Angeles: University of California, 1966.

Chen, Zhutong. "Yuandai zhonghua minzu haiwai fazhan kao" [A study of Chinese overseas expansion in the Yuan dynasty], Jinan xuebao 2:1 (1936), 125-49; 2:2 (1937), 123-48.

Ching, Julia. "Chu Shun-shui, 1600-82: A Chinese Confucian scholar in Tokugawa Japan," Monumenta Nipponica 30:2 (1975), 178-91.

"Neo-Confucian utopian theories and political ethics." Мonumenta Serica 30 (1972-73), 1-56.

Cleaves, Francis W. "The biography of Bayan of the Bârin in the Yüan Shih." Harvard Journal of Asiatic Studies 19:3-4 (1956), 185-303.

"The biography of the Empress Cåbi in the Yüan Shih," Harvard Ukrainian Studies 3-4 (1979-80), 138-50.

Croizier, Ralph C. Koxinga and Chinese Nationalism: History, Myth, and the Hero. Harvard East Asian Monograph 67. Cambridge: Harvard University Press, 1977.

Dagong bao. "Xinya yamen zhiyou." 17 August 1980.

Dardess, John W. "The transformations of messianic revolt and the founding of the Ming dynasty," Journal of Asian Studies 29:3 (1970), 539-58.

Davis, Richard L. Court and Family in Sung China, 960-1279. Durham: Duke University Press, 1986.

Demiéville, Paul. "Notes d'archéologie chinoise," Bulletin de l'Ecole Française d'Extrême-Orient 25 (1925), 449-67.

Deng, Yunte. Zhongguo jiuhuang shi [A history of relief in natural disasters in China]. Beijing: Sanlian shudian, 1961.

Dennerline, Jerry. The Chia-ting Loyalists: Confucian Leadership and Social Change in Seventeenth-Century China. New Haven and London: Yale University Press, 1981.

Farquhar, David M. "Chinese Communist assessments of a foreign conquest dynasty," China Quarterly 30 (1967), 79-92. 


\section{Bibliography}

Fisher, Tom. "Loyalist alternatives in the early Ch'ing," Harvard Journal of Asiatic Studies 44:1 (1984), 83-122.

Folsom, Kenneth E. Friends, Guests, and Colleagues: The Mu-fu System in the Late Ch'ing Period. Berkeley and Los Angeles: University of California Press, 1968.

Franke, Herbert. "Chia Ssu-tao (1213-1275): A 'bad last minister'?" in Wright and Twitchett, Confucian Personalities, 217-34.

. From Tribal Chieftain to Universal Emperor and God: The Legitimation of the Yüan Dynasty. München: Verlag der Bayerischen Akademie der Wissenschaften, 1978.

. "Some aspects of Chinese private historiography in the thirteenth and fourteenth centuries," in Beasley and Pulleyblank, Historians of China and Japan, 115-34.

. "Tibetans in Yüan China," in Langlois, China Under Mongol Rule, 296-328.

, ed. Sung Biographies. 3 vols. Wiesbaden: Franz Steiner Verlag, 1976.

Fu, Lo-shu. "Teng Mu: a forgotten Chinese philosopher," T'oung Pao 52:13 (1965-66), 35-96.

. "Yudai sheng yu haozhong" [Wen Tianxiang's jade-girdle inkstone and Xie Fangde's lute]," Gugong jikan 15:3 (1981), 1-22.

Fu, Marilyn Wong. "The impact of reunification: Northern elements in the life and art of Hsien-yü Shu (1257?-1302) and their relation to early Yüan literati culture," in Langlois, China Under Mongol Rule, 371433.

Gedalecia, David. "The life and career of Wu Cheng: A biography and introduction," Journal of the American Oriental Society 99:4 (1979), 60141.

Gernet, Jacques. Daily Life in China on the Eve of the Mongol Invasion, 1250-1276. Translated by H. M. Wright. Stanford: Stanford University Press, 1962.

Giles, Herbert A. A Chinese Biographical Dictionary. Leiden: E.J. Brill, 1898.

Gong, Yanming. "Yeping Yue Fei de zhongjun sixiang" [More on Yue Fei's loyalty to the sovereign], Zhongguo shi yanjiu (1981:4), 83-92. 


\section{Bibliography}

Goodrich, L. Carrington. The Literary Inquisition of Ch'ien-lung. Baltimore: Waverly Press, 1935. and Fang Chaoying, eds. Dictionary of Ming Biography, 13681644. 2 vols. New York and London: Columbia University Press, 1976.

Grodzins, Morton. The Loyal and the Disloyal: Social Boundaries of Patriotism and Treason. Cleveland and New York: World Publishing Company, 1956.

Gulik, R.H. van. Chinese Pictorial Art as Viewed by the Connoisseur. Rome: Istituto Italiano Per Il Medio Ed Estremo Oriente, 1958.

Haeger, John Winthrop. "1126-27: Political crisis and the integrity of culture," in Haeger, Crisis and Prosperity, 143-61.

. "The intellectual context of Neo-Confucian syncretism," Journal of Asian Studies 31:3 (1972), 499-513.

, ed. Crisis and Prosperity in Sung China. Tucson: University of Arizona Press, 1975.

Halperin, Charles. Russia and the Golden Horde. Bloomington: Indiana University Press, 1987.

Hawkes, David. Ch'u Tz'u: The Songs of the South. Oxford: Clarendon Press, 1959.

He, Ge'en. "Danzu zhi yanjiu" [A study of the Dan people], Dongfang wenhua 5 (1959-60), 1-39.

He, Guanbiao. "Lun Ming yimin zidi de chushi" [On the public service of the sons and disciples of the Ming loyalists], Dousu 42:1 (1981), 23-31.

He, Guanhuan. "Lun Songchu sanchao wujiang de lianghua fenxi" [Quantitative analysis of generals in the first three Song reigns], Shihuo 16:3,4 (1986), 115-27.

Hervouet, Yves, ed. A Sung Bibliography. Hong Kong: Chinese University Press, 1978.

Hightower, James Robert. The Poetry of $T^{\prime}$ ao Ch'ien. Oxford: Clarendon Press, 1970.

Holmgren, Jennifer. "Widow chastity in the Northern Dynasties: The Liehnü biographies in the Wei-shu, " Papers on Far Eastern History 23 (1981), 165-86.

Huang, Qinglian. "Yuanchu Jiangnan de panluan, 1276-1294" [Rebel move- 


\section{Bibliography}

ments in South China in the early Yuan], Zhongyang yanjiu yuan lishi yuyan yanjiusuo jikan 49:1 (1978), 37-76.

Huang, Xiaoguang. Xuxi ci yanjiu ji jianzhu [A study and annotation of Liu Chenweng's ci]. Taibei: Huagang, 1973.

Huang, Xiaomin. "Ma Tingluan ji qi yiwen" [Ma Tingluan and his lost writings], Shumu jikan 5:2 (1970), 43-66.

Hymes, Robert P. Statesmen and Gentlemen: The Elite of Fuchou, Chianghsi, in Northern and Southern Sung. Cambridge: Cambridge University Press, 1986.

Jian, Bozan. Zhongguo shi lunji [Essays on Chinese history]. 2 vols. Shanghai: Guoji wenhua fuwu she, 1947.

Jian, Youwen (Jen Yu-wen). "Gangzhou hezai" [Where was Gangzhou?] in Song Liao Jin Yuan shi yanjiu lunji. Dalu zazhi shixue congshu 3:3. Taibei: Dalu zazhi, 1970, 75-88.

Song huangtai jinian ji [Commemorative volume on the Song imperial lookout tower]. Hong Kong: Zhaoshi zuzong qin zonghui, 1960.

. Songmo erdi nanqian nianlu kao [On the route taken by the two emperors at the end of the Song]. Hong Kong: Mengjin shuwu, 1957. . "The travelling palace of Southern Sung in Kowloon," Journal of the Hong Kong Branch of the Royal Asiatic Society 7 (1967), 2138.

Jiang, Bingzhao. "Shezu zuyuan chutan" [Preliminary study of the tribal origins of the She people], Minzu yanjiu 1980:4 (1980), 39-45.

Jiang, Liangfu. Lidai mingren nianli beizhuan zongbiao [Dates of famous men across the centuries]. Taibei: Shangwu yinshu guan, 1970.

Jiang, Tiange. "Bian Zhao Mengjian yu Zhao Mengfu zhijian de guanxi" [On the relationship between Zhao Mengjian and Zhao Mengfu], Wenwu 1962:12 (1962), 26-31.

Jiang, Yixue. Lu Xiufu nianpu [A chronobiography of Lu Xiufu]. Taibei: Shangwu yinshu guan, 1977.

Jin, Shi. "Chongping Shanyuan zhimeng" [A reappraisal of the treaty of Shanyuan], Minzu yanjiu 1981:2 (1981), 30-34.

Jin, Yufu. Song Liao Jin shi [History of the Song, Liao, and Jin]. Hong Kong: Longmen shudian, 1966. 


\section{Bibliography}

. "Yue Fei zhisi yu Qin Kui" [The death of Yue Fei and Qin Kui], in Zhou Kangxie, Song Liao Jin Yuan shi, 415-18.

. Zhongguo shixue shi [A history of Chinese historiography].

Taibei: Hongshi chuban she, 1977.

Kamegei, Ryo. Bun Ten-sho. Tokyo, 1935.

Kao, Mu-sen. "Li K'an: An early fourteenth century painter," Chinese Culture 22:3 (1981), 85-101.

Kaplan, Edward H. "Yüeh Fei and the founding of the Southern Sung." Ph.D. dissertation, University of Iowa, 1970.

Kracke, E.A., Jr. "Family versus merit in Chinese civil service examinations under the empire," Harvard Journal of Asiatic Studies 10 (1947), 103-23.

. Translation of Sung Civil Service Titles. Matériaux pour le Manuel de 1'Histoire des Song 2. Paris: Mouton \& Co., 1957.

$\mathrm{Ku}$, Chieh-kang. "A study of literary persecution under the Ming." Translated by L. Carrington Goodrich. Harvard Journal of Asiatic Studies 3 (1938), 254-311.

Kuwabara, Jitsuzo. "On P'u Shou-keng," Memoirs of the Research Department of the Toyo Bunko 2 (1928), 1-79; 7 (1935), 1-104.

Langley, C. Bradford. "Wang Yinglin (1223-1296): A study in the political and intellectual history of the demise of Song." Ph.D. dissertation, Indiana University, 1980.

Langlois, John D., Jr. "Chin-hua Confucianism under the Mongols (12791368)." Ph.D. dissertation, Princeton University, 1974.

. "Chinese culturalism and the Yüan analogy: Seventeenth century perspectives, " Harvard Journal of Asiatic Studies 40:2 (1980), 355-98.

. "Political thought in Chin-hua under the Mongols," in Langlois, China Under Mongol Rule, 137-85.

, ed. China Under Mongol Rule. Princeton: Princeton University Press, 1981.

Lee, Sherman E., and Ho Wai-kam, eds. Chinese Art Under the Mongols: The Yüan Dynasty (1279-1368). Cleveland: Cleveland Museum of Art, 1968.

Legge, James, tr. The Chinese Classics. 5 vols. Hong Kong: Hong Kong 


\section{Bibliography}

University, 1960.

Li, An. Wen Tianxiang shiji kao [A study of Wen Tianxiang's activities]. Taibei: Zhengzhong shuju, 1972.

Li, Chu-tsing. The 'Autumn Colors on the Ch'iao and Hua Mountains': A Landscape by Chao Meng-fu. Ascona: Artibus Asiae Publishers, 1965. . "The Freer 'Sheep and Goat' and Chao Meng-fu's horse paintings," Artibus Asiae 30 (1968), 279-346.

. "The role of Wu-hsing in early Yüan artistic development under Mongol rule," in Langlois, China Under Mongol Rule, 331-70.

Li, Qingyai. "Shu Li Tingzhi" [On Li Tingzhi], in Zhou Kangxie, Song Liao Jin Yuan shi, 421-29.

Li, Runcang. "Shilun Zhang Taiyan de minzu zhuyi" [On Zhang Binglin's nationalism], Jindai shi yanjiu 1981:3 (1981), 256-85.

Li, Zefen. Yuanshi xinjiang [New interpretations of Yuan history]. 5 vols. Taibei: Zhonghua shuju, 1978.

Lin, Shuen-fu. The Transformation of the Chinese Lyrical Tradition. Princeton: Princeton University Press, 1978.

Liu, James T.C. (Liu Zijian) "Luelun Songdai wuguan qun zai tongzhi jieji zhong de diwei" [On Song military officials and their position in the civil bureaucracy], in Sôdai shi ronsô. Edited by Aoyama Hakushi Koki Kinen Kai. Tokyo: Seishin Shobo, 1974, 477-87.

. "Yüeh Fei (1103-41) and China's heritage of loyalty," Journal of Asian Studies 31:2 (1972), 291-97.

Liu, Zhaoyou. "Xinshi zuozhe kaobian" [On the authorship of Xinshi], Dongwu wenshi xuebao 4 (1982), 15-27.

Lo, Irving Yucheng. Hsin Ch'i-chi. New York: Twayne Publishers, 1971.

Luo, Xianglin. Pu Shougeng zhuan [Biography of Pu Shougeng]. Taibei: Zhonghua wenhua, 1955.

" "Song wangtai yu Songji zhi haishang xingchao" [The Song lookout tower and the sea route of the refugee court at the end of the Song], in Songshi yanjiu ji 9. Taibei: Zhonghua congshu, 1977, 99146.

Lü, Meique. "Wang Yinglin zhushu kao" [Wang Yinglin's writings], Gugong tushu jikan 3:1 (1972), 37-53; 3:2, 43-58.

McMorran, Ian. "The patriots and the partisans: Wang Fu-chih's involve- 


\section{Bibliography}

ment in the politics of the Yung-li court," in Spence and Wills, From Ming to Ch'ing, 133-66.

Meng, Siming. Yuandai shehui jieji zhidu [The system of social classes in the Yuan dynasty]. Yanjing Monograph 16. Beijing: Yanjing xuebao, 1938.

Morgan, David. The Mongols. Oxford: Basil Blackwell Ltd., 1986.

Mote, Frederick W. "Confucian eremitism in the Yüan period," in Wright, Confucianism and Chinese Civilization, 252-90.

. "T'ao Tsung-i and his Cho Keng Lu." Ph.D. dissertation, University of Washington, 1954.

. "The T'u-mu incident of 1449," in Chinese Ways in Warfare, edited by Frank A. Kiernan, Jr. and John K. Fairbank (Cambridge: Harvard University Press, 1974), 243-72.

Moule, A.C. "Hang-chou to Shang-tu, A.D. 1276," T'oung Pao 16 (1915), 393-419.

. Quinsai, with Other Notes on Marco Polo. Cambridge, London: The University Press, 1957.

, and Paul Pelliot, eds. Marco Polo: The Description of the Wrld. London: George Routledge \& Sons Ltd., 1938.

Needham, Joseph, and Wang Ling. Science and Civilization in China. Cambridge, London: The University Press, 1959. Vol. 3.

Pan, Bocheng. Fang Xugu yanjiu [A study of Fang Hui]. Taibei: Xin wenfeng, 1978.

Petech, L. "Sang-ko, a Tibetan statesman in Yüan China," Acta Orientalia 34:1-3 (1980), 193-208.

Peterson, Charles A. "First Sung reactions to the Mongol invasion of the north, 1211-17," in Haeger, Crisis and Prosperity, 215-52.

"P'u-ku Huai-en and the T'ang court: The limits of loyalty," Monumenta Serica 29 (1970-71), 423-55.

Peterson, Willard J. "The life of Ku Yen-wu (1613-1682)," Harvard Journal of Asiatic Studies 28 (1968), 114-56; 29 (1969), 201-47.

Qian, Mu. "Du Mingchu kaiguo zhuchen shiwen ji" [Reading the prose and poetry collections of early Ming officials], Xinya xuebao 6:2 (1964), 243-326.

Qiu, Shusen. "Deng Mu he tade Boya qin" [Deng Mu and his Boya qin], 


\section{Bibliography}

Yuanshi ji beifang minzu shi yanjiu jikan 3 (1978), 8-14.

Rachewiltz, Igor de. "Personnel and personalities in North China in the early

Mongol period," Journal of the Economic and Social History of the Orient 9 (1966), 88-144.

. "Some remarks on the ideological foundations of Chinggis Khan's empire," Papers on Far Eastern History 7 (1973), 21-36.

. "Yeh-lü Ch'u-ts'ai (1189-1243): Buddhist idealist and Confucian statesman," in Wright and Twitchett, Confucian Personalities, 189-216.

Rao, Zongyi. Jiulong yu Songji shiliao [Kowloon and historical sources on the end of the Song]. Hong Kong: Wanyou tushu, 1959.

. Zhongguo shixue shang zhi zhengtong lun [On orthodox succession in Chinese historiography]. Hong Kong: Longmen shudian, 1977. , ed. Ming yimin shuhua yantao hui jilu zhuankan [Special issue on the conference on Ming loyalist painters], Xianggang zhongwen daxue Zhongguo wenhua yanjiu suo xuebao 8:2 (1976).

Rickett, Adele Austin. Wang Kuo-wei's 'Jen-chien tz'u-hua': A Study in Chinese Literary Criticism. Hong Kong: Hong Kong University Press, 1977.

Rodzinski, Witold. A History of China. Oxford: Pergamon Press, 1979.

Rossabi, Morris. "Khubilai Khan and the women in his family," in StudiaMongolica: Festschrift für Herbert Franke. Edited by Wolfgang Bauer. Wiesbaden: Franz Steiner Verlag, 1979, 153-80.

. Khubilai Khan. His Life and Times. Berkeley and Los Angeles: University of California Press, 1988.

, ed. China Among Equals: The Middle Kingdom and its Neighbors, 10th-14th Centuries. Berkeley and Los Angeles: University of California Press, 1983.

Schirokauer, Conrad. A Brief History of Chinese and Japanese Civilizations. Orlando: Harcourt Brace Jovanovich, 1989.

Schneider, Laurence A. A Madman of Ch'u: The Chinese Myth of Loyalty and Dissent. Berkeley and Los Angeles: University of California Press, 1980.

Serruys, Henry. "A manuscript version of the legend of the Mongol ancestry of the Yung-lo emperor," in Analecta Mongolica. Edited by J.G. 


\section{Bibliography}

Hangin and U. Onon. Bloomington: Indiana University Press, 1972. . The Mongols in China during the Hung-wu Period (1368-1398).

Brussels: L'institut Belge des Hautes Etudes Chinoises, 1959. (Mélanges chinois et bouddhiques 11).

Shao, Hsun-cheng. "Historical significance of the curious theory of the Mongol blood in the veins of the Ming emperors," Chinese Social and Political Science Review 20 (1937), 492-98.

Shu, Zhenbang. "Hubilie yu Yuandai de tongyi" [Qubilai and reunification in the Yuan dynasty], Nei Menggu shehui kexue 1981:2 (1981), 100-05.

Spence, Jonathan D., and John E. Wills, Jr., eds. From Ming to Ch'ing: Conquest, Region, and Continuity in Seventeenth-Century China. New Haven and London: Yale University Press, 1979.

Struve, Lynn A. "Ambivalence and action: Some frustrated scholars of the K'ang-hsi period," in Spence and Wills, From Ming to Ch'ing, 32165 .

The Southern Ming. 1644-1662. New Haven and London: Yale University Press, 1984.

$\mathrm{Su}$, Wenting. Songdai yimin wenxue yanjiu [A study of the literature of the Song loyalists]. Taibei: Xuesheng shuju, 1979.

Sun, Fuhou. Dai Shanyuan nianpu [Chronobiography of Dai Biaoyuan]. Shanghai: Shangwu yinshu guan, 1936.

Sun, Guodong. "Tangdai zhongyang wenguan qianzhuan shijian yu fenqi tantao" [A study of the length of time for promotions and transfer of central officials in the Tang dynasty], Xinya shuyuan xueshu biankan 16 (1974), 329-52.

Sun, Kekuan. Menggu hanjun yu han wenhua yanjiu [Studies on the Mongol Chinese army and Chinese culture]. Taibei: Wenxing shudian, 1958.

. "Yuanchu Nan Song yimin chushu: buhe Menggu ren hezuo de nanfang rushi" [Preliminary study of the Southern Song loyalists in the early Yuan: the southern scholars who did not cooperate with the Mongols], Donghai xuebao 15 (1974), 13-33.

. Yuandai han wenhua zhi huodong [Chinese culture and activities in the Yuan dynasty]. Taibei: Zhonghua shuju, 1968.

. Yuandai Jinhua xueshu [Jinhua scholarship in the Yuan dynasty]. Taizhong: Donghai University, 1975. 


\section{Bibliography}

Tan, Qixiang, ed. Zhongguo lishi ditu ji [Collection of Chinese historical maps]. Shanghai: Ditu chuban she, 1982.

Tillman, Hoyt Cleveland. "Proto-nationalism in 12th century China? The case of Chen Liang," Harvard Journal of Asiatic Studies 39:2 (1979), 403-28.

Tu, Wei-ming. "Towards an understanding of Liu Yin's Confucian eremitism," in Chan and de Bary, Yüan Thought: Chinese Thought and Religion Under the Mongols, 233-77.

Twitchett, D.C. "Chinese biographical writing," in Beasley and Pulleyblank, Historians of China and Japan, 95-114.

Wakeman, Frederic, Jr. "Localism and loyalism during the Ch'ing conquest of Kiangnan: The tragedy of Chiang-yin," in Conflict and Control in Late Imperial China, edited by Frederic Wakeman and Carolyn Grant (Berkeley and Los Angeles: University of California Press, 1975), 4385.

Wang, Deyi. "You Songshi zhi tandao Mingchao ren de Songshi guan" [On Ming views on Song history according to Songshi zhi], Songshi yanjiu ji 12. Taibei: Zhonghua congshu, 1980, 501-25.

et al. Yuanren zhuanji zilian suoyin [Index to biographical materials of Yuan figures]. Taibei: Xinwen feng chuban gongsi, 1981.

Wang, Gungwu. "Feng Tao: An essay on Confucian loyalty," in Wright, Confucianism and Chinese Civilization, 188-210.

. "Power, rights and duties in Chinese history," Australian Journal of Chinese Affairs 3 (1980), 1-26.

. "Rhetoric of a lesser empire: Early Sung relations with its neighbors," in Rossabi, China Among Equals, 47-65.

Wang, Guowei. Guantang jilin [The collected writings of Wang Guowei]. Beijing: Zhonghua shuju, 1959.

Wang, Meng'ou, annot. Liji xuanzhu [Annoted selections from the Liji]. Taibei: Zhengzhong shuju, 1968.

Wang, Rongchu, annot. Xihu shici xuan [An anthology of the poetry of the West Lake]. Hangzhou: Zhejiang renmin chuban she, 1979.

Wang, Weiyong. "Nan Song yimin ci chutan" [A preliminary study of the $c i$ of the Southern Song loyalists]. M.A. thesis, Dongwu University, 1979. 


\section{Bibliography}

Wang, Yinghua. Caochuang ci yanjiu [A study of Zhou Mi's $c i$ ]. Taibei: Chinese Materials Center, 1978.

Watson, Burton. The Old Man Who Does As He Pleases: Selections from the Poetry and Prose of Lu Yu. New York and London: Columbia University Press, 1973.

Wei, Qingmang. "Yuan Shundi wei Songyi kao" [On Shundi of the Yuan as a descendant of the Song imperial house], in Zhou Kangxie, Song Liao Jin Yuan shi, 544-76.

Wiens, Mi Chu. "Anti-Manchu thought during the early Ch'ing," Papers on China 22A (1969), 1-24.

Wilhelm, Hellmut. "From myth to myth: The case of Yüeh Fei's biography," in Wright, Confucianism and Chinese Civilization, 211-26.

Wright, A. F., ed. Confucianism and Chinese Civilization. New York: Antheneum, 1965.

and D. C. Twitchett, eds. Confucian Personalities. Stanford: Stanford University Press, 1962.

Xia, Chengtao. Tang Song ciren nianpu [Chronobiographies of Tang and Song $c i$ poets]. Beijing: Zhonghua shuju, 1961.

Xiao, Gongquan. Zhongguo zhengzhi sixiang shi [A history of Chinese political thought]. Taibei: Zhonghua wenhua chuban she, 1954.

Xiao, Qiqing. "Yuandai de ruhu: rushi diwei yanjinshi de yizhang" [Confucian households in the Yuan: a chapter in the historical position of Confucian scholars], Dongfang wenhua 16:1-2 (1978), 151-78.

Xie, Hongxuan, comp. Xieshi wenxian jiabian [Literary remains of the Xie family]. Taibei: Xieshi zongqin hui, 1970.

$\mathrm{Xu}$, Bingyu. "Liao Song Yuan sandai funü jielie shiji yu zhenjie guannian zhi fazhan" [The records of virtuous women in the Liao, Song, and Yuan and the development of attitudes towards chastity and virtue], Shihuo 10:6 (1980), 241-53.

$\mathrm{Xu}$, Songshi. Yuejiang liuyu renmin shi [A history of the aboriginal peoples of Guangdong and Guangxi]. Beijing: Zhonghua shuju, 1938.

Yan, Jianbi. "Nan Song liuling yishi zhengming ji zhu cuangong fawei niandai kao" [Determining the six excavated Southern Song imperial tombs and the dates of their destruction], Yanjing xuebao 30 (1946), 27-50. 


\section{Bibliography}

Yanai, Watari. Yuandai meng han semu daiyu kao [The three social classes in the Yuan Dynasty]. Translated by Chen Zhe and Chen Qingquan. Shanghai: Shangwu yinshu guan, 1932.

Yang, De'en. Wen Tianxiang nianpu [A chronobiography of Wen Tianxiang]. Shanghai: Shangwu yinshu guan, 1939.

Yang, Ligui. "Zheng Sixiao yanjiu ji qishi jianzhu" [A study of Zheng Sixiao and annotation of his poetry]. M.A. thesis, College of Chinese Culture, 1977.

Yao, Congwu. "Cheng Jufu yu Hubilie ping Song yihou de anding nanren wenti" [On the problems Cheng Jufu and Qubilai had relating to pacifying the southern Chinese after the Song conquest], Wenshi zhexue bao 17 (1968), 353-79.

. "Hubilie ping Song yihou de nanren wenti [On the problems of the southern Chinese after Qubilai pacified the Song], Bianzheng yanjiu suo nianbao 1 (1970), 1-56.

"Jin Yuan Quanzhen jiao de minzu sixiang yu jiushi sixiang" [Nationalistic and compassionate thought of the Quanzhen Daoist sect during the Jin and Yuan], in Yao Congwu, Dongbei shi luncong. Taibei: Zhengzhong shuju, 1959, vol. 2, 175-204.

. "Tiehan Xinshi zhong de nanren yu beiren de wenti" [On the problems of the northern and southern Chinese in the Tiehan Xinshi], Shihuo 4:4 (1974), 109-26.

Yokota, Terutoshi. "Getsusen ginsha ni tsuite" [On the Yuequan yinshe], $\mathrm{Hi}$ roshima Daigaku Bungakubu Kiyo 14 (1958), 99-125.

Yoshikawa, Kojiro. Genminshi gaisetsu [An introduction to Yuan and Ming poetry]. Tokyo: Iwanami Shoten, 1963.

. Introduction to Song Poetry. Translated by Burton Watson. Cambridge: Harvard University Press, 1967.

Yuan, Ji. Cheng Xuelou pingzhuan [A critical biography of Cheng Jufu]. Taibei: Xinwen feng, 1979.

Yuanshi gangyao bianxie zu. "Guanyu Yuanshi yanjiu zhong ruogan wenti de chubu yijian" [On preliminary opinions about some problems in the study of Yuan history], Yuanshi ji beifang minzu shi yanjiu jikan 1 (1977), 8-15.

Zhang, Xincheng. Weishu tongkao [Study of forged books]. Shanghai: Shang- 


\section{Bibliography}

wu yinshu guan, 1957.

Zhao, Xinian, comp. Zhaoshi zupu [The Zhao family genealogy]. Hong Kong:

Zhaoshi zongqin hui, 1937.

Zheng, Liangshu. "Wen Xinguo gong zupu" [The clan genealogy of Wen Tianxiang], Gugong jikan 14:3 (1980), 53-68.

Zhou, Kangxie, ed. Song Liao Jin Yuan shi lunji [Essays on the history of the Song, Liao, Jin, and Yuan]. Hong Kong: Qiongwen shudian, 1971.

Zhou, Liangxiao. Hubilie [Qubilai]. Changchun: Jilin jiaoyu chubanshe, 1986. . "Lun Hubilie" [On Qubilai], Zhongguo shehui kexue xиebao 1981:2 (1981), 97-106.

Zhou, Zumo. "Hu Sanxing shengzu xingli kao" [On the birth and death dates of Hu Sanxing], Furen xuezhi 13:1-2 (1945), 113-16.

. "Songwang hou shi Yuan zhi ruxue jiaoshou" [On Confucian scholars who served the Yuan as instructors after the fall of the Song], Furen xuezhi 14:1-2 (1946), 191-214.

Zurndorfer, Harriet T. "Hsin-an ta-tsu chih and the development of Chinese gentry society (800-1600)," T'oung Pao 67:3-5 (1981), 154-215. 



\section{INDEX-GLOSSARY}

aboriginals, 114. See She and Yao.

accommodation, 106, 181, 241, 245, 247, 263

Ajirghan阿制罕, 34

amnesty, 33, 38

Anhui 安徰, 99

Annam安南, xiv, 11, 58, 65, 139-143， 191, 263

Anqing安 度, xiv, 31

Ao Junshan 教君善, 211, 224

appeasement, 13, 22

Arigh Qaya 阿里海牙, 28

atrocities, 41, 87

auditing regulation policy, 21-23

Bai Ting 白煡, 164, 213, 218, 226, 228， 233

Bai Xing 白行 (Yuluboli玉号伯里, Urlugbayli?), 175

bandits, $33,34,38,50,54,6 \mathrm{~J}, 71,100$, $103,106,115,174,180,257$

baoguo 韧闻, 96, 106, 207, 235

Bayan 伯颜, 28-29, 31, 34, 35, 39-43, 54, $63,105,146,151,226$

Beijing 北京. See Dadu.

bereavement, 88

Bian Juyi 逗居陪, 71, 117

Bianliang 深梁(Kaifeng), 12, 14, 115，
144, 172, 176

Bigan 比干, 112

biji 等陪, 196, 218, 233-235

biographies, 7-10, 61, 69-70, 82-91, 133, 194, 261

Bolot 卖 羅, 63

Boyi 伯夷 and Shuqi 叔弯, 96, 109, 127-128, 138, 156, 249;

Shouyang 首陽 mountain, 101

Buddhism, 99, 148, 155, 189, 213; monasteries, 150; monks, 24, 214; sutras, 207

Byan-sprin 1Can-skya (Yanglian zhenjia 㛫 遇真茄), 150-151, 214, 231

Cai Yan 蔡琰 (Wenji 丈姫), 156, 250

caitiffs (lu 噟), 157, 174

Cao Bin 曹林, 42n

Cao Jing 费棌, 185

censorship, 71-79; Qianlong rescript, 78. See Xinshi.

Central Asians, 159, 220

central bureaucracy, 103, 119

Chai Wang 紫望; son Xijun 希浚, 165

Champa卢城, xiv, 121, 141, 258

Changzhou 常州, xiv, 12, 32, 244; massacre, 34, 36, 199, 237

Chaozhou 潮州, xiv, 12, 54, 84, 119 


\section{Index-Glossary}

Chen Botao 陆伯陶, Dongguan yimin lu, 80

Chen Cun 傮存, 209; grandson Wuyi 恕 送, 211, 224

Chen Diaoyan 律吊眼, 257

Chen Geng 䏂哾, father Yixin 应新, 192

Chen Guo 鿇呙, 200, 204, 207, 230

Chen Li 侓標, 185

Chen Liang 啋亮, 158, 251

Chen Shuke 阵，恕可，153

Chen Wenlong 诤文埥, 32, 35, 47

Chen Yi 侓贸, 54, 115

Chen Yizhong 狰益中，27, 32, 35, 45, $47-55,60,63,67,119-120,126,141-143$, 157,193

Chen Yuan 传堭, 74n, 264

Chen Yunping 掼允平, 174, 182, 202, 218, 226-227

Chen Zhongwei 陆仲微, 65, 142; Erwang benmo 二王本戈，65-66，68， 73,85

Chen Zhongxin 豫、仲信, 211, 224

Chen Zhu奍著 (Siming 四明, Songxi yilao 松溪遗老), 102, 174, 179-182

Cheng Chuweng 程焚襍, 186

Cheng Jufu和锴夫, 126, 169, 212, 222224, 226, 246

Cheng Pengfei 暒鸧热，29

Cheng Yi 程硕, 95

Chizhou池州, xiv, 31, 43

Chu 楚, Songs, 160

Chunqiu 春秋, 148, 216

ci䳝, 202

class discrimination, 1-3, 125; Mongols
蒙与, Semu色目, Hanren 漢人， Nanren南人，2

commoners, 137, 157

conciliation, 38, 42, 133

concubines, 131, 143, 146, 206

Confucius (Kongzi 孔 子), 94

Confucianism, 39, 61, 189; classics, 74, 120, $124,144,158,174-175,177,183,191$, 207, 209, 223, 248-249, 252; concepts, 93-98, 113, 148, 257; Neo-Confucianism, 95, 214, 230, 234; scholars, 69, 101-102, $125,128,138,181,187$; withdrawal, 25, 139

culturalism, 1, 250

Dadu 大都 (Beijing), xiv, 11, 12, 31, 37, $39,62,89,109,112,125,128,139,140$, 169; loyalists, 143-149; Yan 菽, 148; Yuan capital, 20, 105

Dai Biaoyuan戴表元, 81, 83n, 175176, 206, 210, 217-219, 224, 227, 246

Dai Liang 戴良, 259

Daoism, 148, 189; nuns, 124, 144, 145; priests, 39, 99, 107, 135, 155, 202, 213214

Davis, Richard L., 4, 245

defectors, 19-20, 26-27, 33, 38, 42, 91, 93, $99,107,117,120,132-136,146,174,231$, 249

Deng Guangjian 登绉荷, 58, 66-67, 111, 132-136, 143-144, 149, 167-169, 194, 245, 247, 262; Tianhai lu, 64, 77; Wen chengxiang dufu zhongyi zhuan, 64-65, 69, 85

Deng Mu 登融牧, 206, 214-217, 262; Boya qin 修身琴, 216; Dadi mountain 


\section{Index-Glossary}

大滌山, 214; Jundao 青 道 and Lidao 夷道, 215

Deng Wenyuan 借文彩, 165, 210, 217, $224,226,228$

despotism, 216

Di Bing 常罗(Prince Ji吉玉, Prince Wei 街王), 28, 35, 45, 47, 56, 58, 64, $76,84,89,120,258$

Di Guoxiu 倠国秀, 48

Di Shi 帝是 (Duanzong 端宁, Prince Yi 董 王 ), 28, 35, 45, 47, 56, 84, 89, 119-120

Ding Daquan 丁大全, 22n, 24, 141

Dingiazhou 丁家洲 (near Wuhu 踩湖), xiv, 31-32

Dong Songchen薄宇医, 103

Dong Wenbing 茥枃, 28, 34

Dongguan事党，xiv, 11, 59，139，140， $143,164,208,262$

dongqing shu 冬一青樹; Dongqing shuyin 冬青樹引，153

Du Fu杜甫, 62

$\mathrm{DuHu}$ 杜湤, 50

Dusong pass 猲松公壂, 34, 36

Dutch, 262

dynastic collapse, 1, 8, 93, 146

educational officials: jiaoshou 教授; jiaoyu 教諭; shanzhang 山莀; tiju提臮; deputy tiju副掍鹪; xuelu䒚绿; xuezheng 䒯正, 180, 227-228

Eight Talents of Wuxing, 211-212, 222-224

elegies, 110

envoys, 34, 36, 100, 118-119, 122; Song entourages, 39-41

ethnicity, 1, 96, 105, 264 eunuchs, 22, 103

Ezhou鄂州, xiv, 12, 15, 29, 104, 116

family involvement, 99-100, 141

Fan Tianshun 范只顺, 44n

Fan Wenhu范文虎, 38, 117

Fancheng 样, 城, xiv, 12, 20

Fanyang 范陵, 120

Fang Feng 方圈, 157-166, 193, 208; Dongyang jun yimin 妻晹郎填民，157

Fang Fengchen 方夆辰，209 (Shanfang yimin 山度起民); brothers Fengjia 夆教 and Fengzhenc选振, 166

Fang Hui 方回, 41, 134, 185, 190, 211, $219,231,246$

Fang Xiaoru方孝需, 251

Fang Yikui 方一落, 166

Fang Youxue 方幼學，165, 192, 209

Fei Gongchen 费拱辰, Myriarch, 222， 226, 231

Fei Jietang 妻嘴堂，83, 207

Feng Dao 馮道, 94

Feng Guifang 凴桂芳，159

filial piety, 105, 108, 123-124, 126, 130, 168, $187,239,247,249-250,253$

Fonchow福州, xiv, 12, 36, 47, 55, 119, 121

foreign rule, 1, 137, 148, 177, 187, 215, 255 , 257

foreigners, 131, 157-158, 166, 172, 196, 219, 225,250

fortuneteller, 39, 123

Fozu lidai tongzai, 90

Franke, Herbert, 8, 16

Fu福, Prince, 40, 145, 210

Fuchai f差 terrace, 160 


\section{Index-Glossary}

Fujian福建, 28, 36, 44, 52, 99, 108, 121， 142

Fuzhou㜯州, xiv, 12, 53, 122, 245

Fu Zhuo 傅卓, 48

Gansu 甘禹，13

Ganzhou贑州, xiv, 12, 30, 53, 108

Gangzhou难州，xiv, 12, 56, 85

Gao Kegong 高克落，220, 226

Gao Side 高斯得, 200, 209

Gao Yingsong 高應.松, 39

genealogies and gazetteers, 38, 79, 82, 193

Gengshen waishi, 89

gentry, 99, 102

Gong Kai 䧆䧓, 8, 65, 117, 186, 189-190, 194, 208, 240

Gong Sheng㸃勝, 128, 249

Gongdi 若帝 (Xian 蒸, Duke of Yingguo 漓闻公), 28, 33-35, 40, 69, 81, 89, 105, $113,143,145,248$

Gu Yanwu顧炎武, 75, 262-263

Guanfu官富, xiv, 12, 84-85

Guangdong 事, 44, 54, 56, 58, 85, 99, 108, 121

Guangxi 西, 99

Guangzhou哾州, xiv, 12, 56, 84, 106, 140

Gujin tushu jicheng, 79-80, 261, 265-266

Guichi 贵池, 185

guilt, 107, 111, 147, 187, 228

Guo Tianxi 部天锡，220，226

Gusai mountain 孤寒山, 101

hagiography, 61

Haifeng 海啙, xiv, 12

Han 漠, dynasty (206 B.C.-A.D.220), 93-94

Han Tuozhou鲜低肯, 197, 230

Han Zhen 嫴震, 45n
Hangzhou杭州(Lin'an愳安), xiv, 11, 12 , 14, 84, 103, 139, 140, 144, 148, 181, 198, 204; collapse, 1, 34; floods, 28; lifestyle, 25-26; loyalist center, 212-222

Hanyang 漠陽， 29

Hao Jing 郝怒垔, 16-19, 31, 46, 252; Linchuan ji, 18n

He Menggui 何萝桂, 166, 209

Heaven, 29-30, 41, 71, 126, 214-215; mandate, 88,252

Hejian 河間, xiv, 111, 144, 148

Hengshan 㮀方

Hercules, 113

Hezhou 合州, xiv, 15, 52n

historiography, 4, 9, 18, 82, 87, 230, 243

Hong Kong 香港. See Kowloon.

Hu Ciyan 胡次炎, 185

Hu Han 胡翰, 73n

Hu Sanxing 乩三省，73-74，82，102， 117, 174, 178-180; son Youwen 幼丈， 179

Hu Yigui 胡一桂, 128n

Huai往, xiv, 1, 12, 14, 15, 16, 20, 26, 32, 44, 116, 140; Huaidong准事, 50; Huaixi 淮、西, 28, 31, 32

Huang, family, 86

Huang Jin落滀, 162

Huang, Myriarch黄蕾户, 146

Huang Zhen者, 震, 102, 174, 181

Huang Zongxi 黄宗若, 153, 159, 262263

Huangzhou樯, xiv

huayi 萧费, 247

Huazhou 化州, 85

Hubei 湖北, 99 


\section{Index-Glossary}

Hu-Guang、新虚, 30

Huizhou徽州(Anhui), xiv, 12

Huizhou 悪州(Guangdong), xiv, 12, 54, 135

Hunan湖南, 44, 99

Huzhou湖 州(Wuxing), xiv, 11, 12, 25,

$34,139,140$, 197; loyalist center, 205-211

Hymes, Robert P., 4, 245

imperial relatives, $21-22,36,48,55,76,85$, $88,146,150,180,190,192,222$

imperial mausolea (cuangong 㩰, 宫, ling

陵) , 15, 74, 81, 149-156, 204, 231, 258

Japan, 2, 84, 143, 158, 191, 262-263

Jia Sidao 賈似道，15-33，83，90, 104，

$116,126,133,141,166,174,178,199$,

230, 237; disgrace, 32, 45

Jia Xuanweng 家铉新, 36, 39, 49, 111, $125,143,148$

Jia Yi 買誼, 132

Jia Yuqing 责锫度, 36, 39

Jiagu Zhiqi 㚘崖之奇, 166-167

Ji'an吉安, 140

Jian Youwen 簡又文, 83-86

Jiande 建櫯(Yanzhou), 11, 139, 140, 157;

Chun'an 淁安; loyalist center, 166-167

Jiang Cai 善 才, 40, 50, 71, 117, 120

Jiang Dacheng 姜大戗, 208

Jiang Wanli 江莴里, 24, 43, 103-104,

171; brother Wanqing 萬顷，43

Jiang-Hu 江湖, 50; Jiangdong 江束, 123;

Jiang-Huai, 127; Jiangnan 江南, 1, 126;

Jiangxi 江曲 , 44, 51, 53, 99, 103

Jiangshan 江山, 165

Jiangxin ; 心, 47

Jiankang 建康(Nanjing), xiv, 12, 14, 25 ,
$31,34,199,237$

Jianyang建晹, 123

Jiaozhi 交趾(Tonkin), xiv, 15

Jie Xisi 揭倭斯, 109n

Jin 金, dynasty (1125-1234), 1, 13-15, 19, 40, 95, 166, 254; emperors: Shizong 世

宗, 254; Zhangzong 草宗, 89n

Jin Lüxiang 金敫样, 165

Jing荆; Jing-Hu制湖, 20; Jingnan 葫

南, 28

Jing'ao \#㴽, 56

Jinhua 金華 scholars, 162

jinshi 進士，102，113，119，122，163-164, $166,173,176,182,190,212$; 1256 examination, 102, 178-179, 184, 199, 228

Jizha季札 (surname Wu 吴); Prince Xu

徐君; Xujian ting 新知亭, 164

Jizhou 蒰州(Hebei), xiv, 219-220

Jizhou 声州(Jiangxi), xiv, 12, 25, 31, 53

Jizi 筫子, 112

Jurchen 女真. See Jin.

Kai Tak airport, 84

Kaifeng 群封. See Bianliang.

Kaiping 故乎. See Shangdu.

Khitan 觢丹. See Liao.

Kongkang 空抗, 53

Koreans, 158

Kowloon 九龍存，8, 55, 83-86, 140, 244;

Dayu shan 大㟪山, Erwang dian 二

王殿, Fotang men佛堂闰, Guanfu chang 官富场，Guta与垎; Houwang miao 侯王麻; Jin furen mu 金夫人

墓; Jiulong cheng 九散城; Song wangtai 守、王、瞢, 84-85

Koxinga (Zheng Chenggong 郸成功), 262 


\section{Index-Glossary}

Kuaiji 鿖楮 (Shaoxing), xiv, 11, 74, 81, $139,140,204$; loyalists, 149-156

Kuwabara, 75

Lamaist monks, 89, 145, 150, 152

landsman, 107, 114, 152, 155-156, 185

Langlois, John D. Jr., 4

Lantao Island, 85

legitimate succession, 41, 76, 79, 89, 188, $230,252-254,260-261$

Leizhou雷州, xiv, 12, 32, 56, 85

Leping 平, 183

Li Dehui 本㡖弾，28

Li Fei 李节, 30, 43

Li Heng 李夏, 56-57

Li Jue 李㕰, 48

Li Kan 李刑, 219, 226, 231, 234

Li Lailao 李莱老; brother Penglao善老, 154,200

Li Ling 李陵, 109, 111

Li Tan 李㻼, 19-20, 116; adoptive father: Li Quan 李全, 19

Li Tingzhi 李庭芝, 50,63, 178; detaining Hao Jing, 16-19, 30, 32, 37, 40, 252; resistance, 44-50, 60, 106, 115-119, 248

Li Yong 李用, 143, 262; sons Chunsou 春舅 and Deming 德明, 191-192

Li Zefen 李剘芬, 4

Lian Wenfeng 起文唝，164, 214, 240

Lian Xixian 廉. 希象, 18n, 34, 151; brothers Xigong 希竞 and Xixian 希婜, 220

Liangshu梁肁, 97

Liao 尞, dynasty (916-1125), 1, 13, 79, 255

Liao Yingzhong 㢊整中, 24

lienü zhuan 烈女傅, 129

Lin Jingxi 林景窚, 151, 155-156, 217,
252

Lin Kongzhai 林空栾, 100-101

Liu Ba 㔁岂, 36

Liu Bingzhong 制秉忠, 20

Liu Chenweng 銐辰永, 167, 169-172, 194, 208; Bingzi songchun、两子送春， 170-171; son Jiangsun 将 㐿, 172

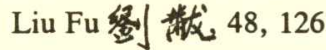

Liu Guan 㠹其，162, 240

Liu, James, T.C., 95-96

Liu Lan倒 漏, 202

Liu Mengyan 留萝来，34，40，107，112， $125-127,136,146,174,211,232,246$

Liu Shiyong 缴印页, 51, 121

Liu Yin 剧因, 82, 83n

Liu Zheng 倒整, 19-20

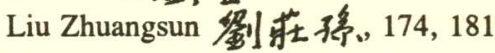

local contributions, 80-87, 100, 115

loyalism: life-style, 11; popular tradition, 910; military resistance, 1, 44-90; Ming, 260-263; Qing, 263; Song, 243-254; Yuan, 255-260

loyalist centers, 11,140

loyalist writings, 6-9; biographies, 10-12; martyrdom, 5; poetry, 8. See Wen Tianxiang, Zhou Mi

loyalty, absolute, 243; concepts, 93-98; definition, 5-6; loyal ministers, 24

Lu Xinyuan 陸心源; Songshi yi, 80

Lu Xiufu 婘秀夫, 34, 46-58, 65, 76, 86, $102,117,119-120,122,156,178$

Lu You 陸游, 14n, 156

Lugang. 港, 31

Luling 䧹陵, xiv, 71, 106, 139, 140; loyalist center, 167-173 


\section{Index-Glossary}

Lü Liuliang 号留良, 262-263

Lü Tonglao 号同老, 154, 221

Lü Wenhuan 员文焕，20,33，67，105，

$117,122,133-135,146,249$; relatives Shikui后市花，27，134-135; Wende 文德，

121; Wenfu文福, 27

Lü Wu 虽武, 50

Luo Xian 羅绕, 151

Luo Xianglin 羅香林, 83-86

Luzhou源州 (Sichuan), 19

Ma Nanbao、考南案，53n

Ma Rong、局辞; Zhongjing，忠经，94

Ma Shilong 㾋士静, 65n

Ma Tingluan禹廷霍，24-25, 103, 182185, 194, 200, 203,206, 246; son Duanlin

端悔 184-185; Wenxian tongkao 文战

真考, 184

Malaysia, 87

Manchu䓋洲. See Qing.

Manchuria, 13

Mangqutai 蒙国岱，38

Marco Polo, 37n

marginal loyalism, 91-92, 196, 241-242

marriages, 164, 179, 191, 210

martyrs. See zhongyi loyalists.

Meizhou梅州, xiv, 12, 53

Mencius (Mengzi 通子, 372-289? B.C.), $94,97,137$

Meng Gong 孟珙, 116

Meng Siming 蒙思明, 3

mercenaries, 59, 100, 107, 114

Miao Zaicheng 苗再城, 50n, 118

Mi 米, Woman, 86

Middle Kingdom, 124, 126, 156, 188

military officials: demotions, 26-27; discrim- ination, 22-23

Ming明, dynasty (1368-1644), 138, 256, 260; loyalists, 80, 261-263; scholars, 89, 176, 258; emperors: Taizu 太柤(Zhu Yuanzhang牛元璋), 2, 259-260; Chengzu 成祖 (Yongle永媓), 89n, 90

Mingshi 明史, 72

modern scholars, 2-4, 7-10, 89, 125, 258, 260

Mongolia, 13, 260

Mongols, 1, 2, 255, 259; army and navy, 1, 18-19, 38, 134, 259; conquest of Song, 1, 15-44. See Yuan.

Mote, Frederick W., 8, 75

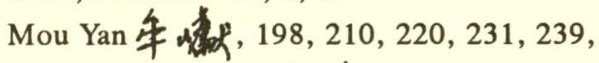
256; father Zicai $\} \ngtr$; sons Yinglong

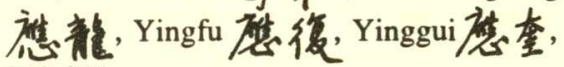
210-211

mufu 䓪庇, 114, 116

Muslims, 20, 89, 234

myth-making, 9, 42-43, 51, 87-91, 243

Nanjian南制, xiv, 12, 52

Nanjing 俑.亨. See Jiankang.

Nationalists, 75

Ningxia 等夏，13

North America, 86-87

Northern Qi 北脈, dynasty (550-577), 1n

Northern Song 北宇, dynasty (960-1127), 94; collapse, 14-15; emperors: Huizong 徽宁, 14, 40; Qinzong 䣄宗, 14, 40; Taizu 太祖, 42n; founding, 13

northerners (northern Chinese), 19, 124-125, $166,196,219,225$

obituary, 176-177, 237-239

opportunists, 132-133, 135

Ouyang Shoudao 的晹守道, 170 


\section{Index-Glossary}

Ouyang Xiu 原淂修, 94, 102

Ouyang Xuan 致淂去，70-71

painting, 186-190

People's Republic of China, 264

Peng Guodong 彭国楼, 75n

Pingjiang 平江 (Suzhou), xiv, 11, 12, 34,

$65,75,139,140,160$; loyalist center, 186190.

Ping Song $l u, 69$

poetry meetings, $81,104,153-154,162-165$,

174, 190, 203, 213, 233

political career, 137, 156, 203

poverty, 124, 155, 162, 179, 189, 191, 210,

$218,222,228,245-247,249$

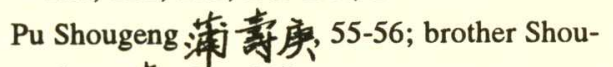

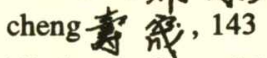

public-land reform, 21, 33

Qaidu海都, 31

Qaraqorum, xiv, 15

Qi 絧, Grand Historian, 110

Qian Xuan 琙量, 8, 211-212, 224

Qian Zhensun 钱镇㤝, 102n

Qiantang yishi, 66-67

Qianwan 济源, 55, 85

Qiao Kuicheng 篹成, 220

Qin 毒, dynasty (221-209 B.C.), 101, 177, 215,252

Qin Kui 秦本魚, 96

Qing清, dynasty (1644-1911), 3, 68, 75, $79,89-90,137-138,152,175,258,263-$ 264; censorship, 263

Qingyang Mengyan 青陽萝缹, 25, 146 Qingyuan 度光(Ningbo政波), xiv, 11, $47,73,81,121,139,140,204,218,244$, 245; loyalist center, 173-182 qinwang勤玉,30, 33, 44, 45, 59, 103-104， 107,251

Qiu Kui 开. 获, 96, 143

Qiu Yuan 仇遮, 154, 164, 213-214, 218， 227, 246

Qizhou 蕨州(Jiangxi), 31

Qizhou 㐿・州(Shandong), xiv, 12, 196, 225, 236

Qu Yuan 原原, 131-132

Quan 全, Empress Dowager, 28, 41, 81, 145

Quan Quanweng 全泉笴, 81,83, 152, 164

Quan Zuwang 全担望, 75, 80-83, 90, $137,152,164,175,244,260,263$

Quanzhou泉州, xiv, 12, 47, 54, 84, 121, 143

Qubilai Qaghan (Yuan Shizu 元世祖), 15, $16,38,40-41,67,76-77,112-113,133$, $144,146,151,252,257$

racialism, 156-157, 251, 260, 262

Rao Zongyi 镜宗蹎, 65, 83-86

Raozhou 镜州, xiv, 11, 31, 43, 139, 140; loyalist center, 182-186

recluse, 191

refugee court, 55-60, 83-84

Republican Revolution, 80, 263

resistance, 143, 159, 244; defeat, 9; dissent, 50-52; finances, 52-53; local and popular, 6, 53; military, 44-60; passive protest, 6, 190

reunification, 1, 148, 172, 196, 233, 251

Ruan Kesi 防克已，30, 44, 117

rulin, 69-70, 138

ruffians, 99, 113, 191

sahua 撒花，38 


\section{Index-Glossary}

Sangge 婪哥, 150

Sanjiang 三㲸, 67

Saturn, 113

scholar-officials, 1-2; life-style, 25-26

sexual relations, 131, 234

Shang 商, dynasty (1700-1050 B.C.), 96,

112, 131; Guzhu state 孤竹國, 96

Shandong 山事, 19, 196

Shangdu 上都, xiv, 15, 31, 40, 113

Shanyuan演牒, Treaty of, 13

Shaoxing 绍舆. See Kuaiji.

Shaowu 䂙武, xiv, 55

Shayang抄晹, xiv, 29

She 秴, 100, 130

Shi 史, lineage, 245

Shi Mengqing 史蒙㑡, 175

Shi Songzhi 妜㟯之, 22n

Shi Tianzi 长澤, 28

Shiji, 96-97; Sima Q1an 司馬透, 132n

Shijing 橦然, 124, 137

Shu Yuexiang 野岳样, 102, 217, 258

Siam (Thailand), 55, 141

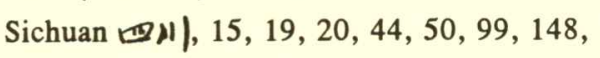
165, 183, 207

Siku quanshu, 75

Sima Guang 可馬光, 94, 178; Zizhi tongjian, 178

singing girls, 104, 131, 301

sinicization, 251, 255-256

sobriquets, 157, 158, 165, 166, 171, 176, $180,187,189,236,247$

Song 宗, dynasty (960-1276), 1, 25, 206. See Northern and Southern Song.

Song Jiang 宇. 江, 190

Song Lian 宇嚰, 162, 260
Songji sanchao zhengyao 守季潮政要, 65-66

Songshi 羊史 (SS), 24, 61, 68-73, 79, 87, 89, 91, 98-102, 106-107, 133, 137, 265-266

Song yimin $l u, 79$

Southeast Asia, 142-143, 193

Southern Song 南字, dynasty (1127-1276): capital, 1, 25; collapse, 1, 35-40; emperors: Duzong 宗, 20, 27, 28, 29, 69, 81, 83, 143, 201; Gaozong 高察, 14, 47, 95-96, 152; Lizong 理宗, 15, 69, 81, 102, 150; Xiaozong 孝宗, 152; founding, 14-15; morale, 31

Spanish Loyalists, 5

standard histories, 97, 139, 261

students, 22, 32, 40, 107, 139, 141, 181, 210,

257; National University, 165, 186, 198

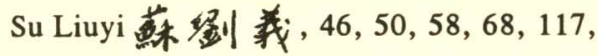
$121,141-142,182$

Su Wu 落武, 110, 156, 250

suicide, 10, 100-102, 106, 108, 123, 131-132

Suishu, 98

Suizhou 倩州, xiv, 116

Suzhou 落州. See Pingjiang.

Taigong Wang 太公望, 94

tailor, 99

Taishan 台山, 86

Taiwan, 86, 262, 264

Taizhou 秦州(in Huai), xiv, 50, 118

Taizhou 台州(in Zhe), 140, 174

Tan Rumu 就孺木, 75n

Tang 唐, dynasty (618-906), 109, 111, 206

Tang Jue 度玨, 151-155

Tang Yisun 店禁孜 154

Tangut 㶳项. See Xi Xia. 


\section{Index-Glossary}

Tanzhou渒州, xiv, 43

Taop匋, Mount, 155

Tao Qian 陶潜, 138, 163, 224, 249

Tao Zongyi 陶字,俄, 259

tea and salt monopolies, 33

Tian Dan田军, 97n

Tiantai 天台, 178

Tiao river 落水, 101

Tibet, 89,145

Tingzhou 汀州, 199

Toba 据咙. See Wei dynasty.

Tonglu 椆发，159

Tongzhou通州, 52n

tributes, 13-14, 34

Tsin 厸, dynasty (266-316); Eastern Tsin (317-420), 138

Tsinshu, 97-98

Tumu 土末 Incident, 251

Tu Yue 屠约, 213, 226-227

Twitchett, D.C., 61

Uighur, 172, 220

United Empire Loyalists, 5

Uriangqatai $\pi$ 良合名, 15; son Aju, 28, 71

Wan Sitong 藻斯同，79-80,89; Songji zhongyi lu, 79, 99, 132

Wang Feng 王透, 76n

Wang Fuzhi 王夫之, 75, 262-263

Wang Guowei 王团维, 90, 145n, 264

Wang Jiweng 王繶寉, 55, 107, 135

Wang Lixin 汪立倍, 43, 250

Wang Mang 王莽, 128

Wang Qinghui 王清密, , 143-145

Wang Xizhi 王载之, 221; son Xianzhi 都之, 220; Baomu zhi 保, 女誌, 220, 240
Wang Yanwu王。委、午, 71, 107-109, 167168,249

Wang Yijian 王易筧, 154, 221

Wang Yinglin王㤫被(Bohou伯覃， Junyi yimin浚侍索), 7, 32, 78， $82,102,173-182,248,250,263$; brother Yingfeng否圈, 175; son Changshi是 世, 174; grandson Housun 誨, 176

Wang Yingsun王莫抒。81, 151-152, 208, 217, 221, 237

Wang Yisun 王沂脬, 154, 202, 208, 226227

Wang Yuanliang 汪元量, 109, 143-149, 169, 173, 183-184, 208, 245, 247, 262

Wang Yue 王鈥, 24, 32-33

Wang Zhi 王芝, 220-221

Wang Zhu 王洙, 2, 88-89

Wei秏象, dynasty (386-534), 1

Wei Tianyou 䁛天佔，128

Weishu騩娄, 98

Weizi微子, 112

Wen Bi 文壁，103，111-112，135，191192,250

Wen Jiweng 丈及䈳，32, 202-203

Wen Riguan 温日觀，214

Wen Tianxiang 交天样 (Songrui宗瑞), $7-8,25,31,36,72,74,76,85-86,90-91$, $117,121-122,126,130,135,144,156$, $159,167,191,243,245,248$; military headquarters, 49-57, 102-115; writings: Ji Dushi 集杜待，62，66; Jinian lu纪年绿， 65; Wenshan xian sheng quanji 方山先 生全集, 61-69; Yinxiao ji 吟躋集, 62; Zhinan lu 指㣮, 62, 65; Zhengqi ge 正氮䭲, 110-111 


\section{Index-Glossary}

Wen Yanbo 文唐㙛, 174n

wenyuan 文, 138

Wenzhou 温州, xiv, 12, 34, 36, 44, 47, 118-119, 140, 141

women loyalists, 93, 129-132

Wu 武, King, 127

Wu Cheng 吴澄, 223

Wu Jian 繁, 35-36, 49, 149

Wu Jun 畓滛, 48

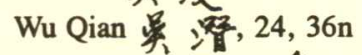

Wu Quanjie 虽全節, 217n

Wu Siqi 吴思率, 157-166

Wu Wei 采、渭, 163

Wu Wenying 品文英，201

Wuguang 䅂光, 96

Wuxing 員然. See Huzhou.

Wuyuan 㜞源(Huizhou, Anhui), 139, 182, 185

Wuzhou 䠛州, xiv, 11, 12, 28, 74, 139, 140; loyalist center, 157-166

Xi Xia 西夏, dynasty (1038-1227), 1, 13

Xia 夏, dynasty (2100-1700 B.C.), 96

Xia Gui 夏一贵, 20, 31, 41, 118, 134

Xiamen 廈塥 (Amoy), 84

Xiang river 湘汉, 101

Xiangyang 变淂xiv, 12, 34, 43, 104, 108,

117, 244; collapse, 19-20; Song reaction, 26-27

Xianyang 或陑, 171

Xianyu Shu 路于榞, 166, 219, 221, 226, 234

xiao, 95

Xiao Zizhong 蔽子中，211, 224

Xiaojing 考悢, 95

Xie Ao 㴬揭, 74, 153, 157-166, 193-194,

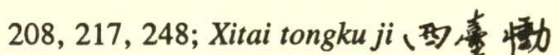

哭视, 159-162, 164

Xie Changyuan 新昌元, 173, 181

Xie, Empress Dowager 新太后, 9, 29-30, 32 , 34-35, 41, 44, 87, 105, 129, 134, 144, 232,248

Xie Fangde 謝枋得，8，31，68，72，74， $87,102,122-129,135,182,185,243,245$, 248,253

Xie Tang 新棌, 35, 36

Xie Xu 铸锗, 101

Xin Qiji 率衰疾, 14n

Xincheng 新城, 29

xingchao 行朝, 48

xing dudufu 行都督底, 52

Xingguo舆国, 53

Xinghua 策化, 55

Xinhui 新弇, 85

Xinshi 心史. See Zheng Sixiao.

Xin Wudai shi, 98

Xinzhou 信州, xiv, 31, 122, 140

Xiong Fei 熊飛, 59, 191

Xiong He 熊乐, 124

Xishe 汐社, 162

Xiushan秀山, 55

Xu Furen 培夫人, 130

Xu Heng 培衡, 82, 83n

Xu Qianxue 新乾等, 75n

Xu Xuejiang 許雪汉, 147, 208

Xu Yingbiao 待應镀, 40, 130, 156

Xu Yuan解菱, 109

Xue Yueqing 新月卯, 186, 195

$X u$ Zizhi tongjian, 68, 74, 89

Xu Zongren徐察仁，32

Xue Angfu蕈昂夫, 172 


\section{Index-Glossary}

Xunzhou循州, xiv, 12, 54

Yaishan 崖山, xiv, 12, 68, 80, 85, 109,

119-120, 139-141, 154, 191, 259; battle, 52, 56-59

Yan Baishi 隌百待, 75n

Yan Gaoqing 颜果卿, 111, 159

Yan Guang 影光, 159; Yan ziling, 160

Yan Guangda 器光大, 39n

Yan Lü 蕧侵, 159

Yanai Watari 箭内互, 3

Yang㛫,Imperial Concubine, 58, 201

Yang Boyan 楬伯掻, 198, 203; relative

Dashou 大受, 205, 235

Yang Weizhen 㛫維槕, 152n, 259

Yang Zhen 㛫镇, 145

Yang Zuan 㛫䍃, 201-202, 208; son Liangjie亮節; Yinshe 哈社, 201

Yangluo 晹道, 29

Yangzhou掦州, xiv, 12, 30, 41, 49, 116, 118, 140, 244

Yangzi 掦子(Yangtze river), xiv, 1, 12, 20,

$26,28,105,140$; crossing of, 29, 34

Yao傜, 59-60

Yao Congwu 姚從吾, 4

Yao Jiheng 姚際婳, 75n

Yao Shi 姚式, 211, 224

Ye Lin 宷. 林, 216

$y i$ 夷, 94

Yijing 易經, 148

yimin 遇贵成 (remnant subjects); centers, 137-

194, 244; definition, 5-6, 91, 93, 137-139,

248, 257

yimin逸民 (recluses); yinyi 隐冕, 125, 138-139

Yiwu義島, 200, 204, 237
Yiyang 戈淂, 123

Yiyin 伊尹, 94

yixian 案庭, 80

Yin Gu等, 117

Yingzhou 趴州, xiv, 28

yongwu ci 旌物理, 153

Yu Jiaxi 余苏慯, 75n

Yuan 元, dynasty (1271-1368), 1-5, 20, 125; collapse, 258-259; emperors: Chinggis Qan (Taizu 大祖), 19, 72; Möngke Qaghan (Xianzong 窓宗), 15; Qoshila (Mingzong 相宗), 89-90; Shidebala (Yingzong 菜 宗), 41; Toghon Temür (Shundi 順奠), 89-90, 257; founding, 20; service, 125 , 146, 180, 185, 222-228; social unrest, 2; Song conquest, 15-40. See Mongols, Qubilai.

Yuan Haowen 元好門, 82-83; Zhongzhou $j i, 149$

Yuan Jue 袁捔, 82, 175-176, 226-228, 239240; father Hong洪, 173-175, 180, 200, 204, 231, 246

Yuan Mei 袁枚, 75n

Yuanshi (YS), 69, 85, 133-134, 150

Yuan Yong 表铕, 173

Yudu零都, 53

Yue Fei 岳花, 14, 95-96, 105, 111, 118, 248

Yue Yi 祭效, 97n

Yuequan yinshe 月泉哈社。162-164, 213

Yuezhou越州, 160

Zeng Feng 曾国, 208

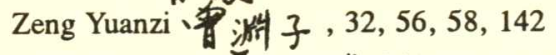

Zhang Binglin章蛃被, 264

Zhang Fuheng 张胙亭, 211, 224 


\section{Index-Glossary}

Zhang Heng 腲衡; brother Yuanji 元吉, 192

Zhang Hong 张㴬, 75n

Zhang Hongfan 暷弘籍, 28, 34, 54, 57$58,63,66,106,111,167$; father Rou 柔,

17, 28; son Gui 珪, 169

Zhang Jian一章地, 27, 32, 103

Zhang Jue 搏玨, 52

Zhang Liangneng 章良能, 197, 203

Zhang Ruoxu 张若虐，202

Zhang Shijie 張世倸, 34, 35, 51-58,63， $67,82,117,119-122,141,173,257$

Zhang Xun 张巡, 109, 159

Zhang Yan 很类, 154, 218; father Shu 榞, 201, 213

Zhang Yifu 很毅父, 167-168

Zhang Zhongshi 张仲宾, 210, 214, 217

Zhangzhou漳州, xiv

Zhang Zihui 浱子惠, 128n

Zhao Bixiang 琑必像, 59n, 190-193; relatives Dongshan 事, 山 and Shiqing 時 清, 191

Zhao Jin 趙首, 48

Zhao Liangchun 趙良漳, 44n, 209

Zhao Maofa 趙印络, 43, 71

Zhao Mengchuan 趙孟傳, 173

Zhao Mengfu 趙雷北具, 198, 211, 218， 221-226, 228, 232; father Yuyin 船, 198

Zhao Mengjian趙孟堅, 203

Zhao Wen趙丈, 168

Zhao Yi 趙翟, 90, 260

Zhaozhong lu, 66, 70

Zhedong 浙束, 54; regional government, 38; school, 80; Zhejiang 浙江, 34, 99,
163; Zhexi 浙西, 21

Zheng Buweng 鄅翁, 151-152

Zheng Sixiao 奠思消 (Sanjiao wairen 三教外人, Suonan所韩, 65, 186189, 194-195, 207, 250; father Zhen 震, 8, 186; Xinshi, 65, 67, 74-76, 83, 188, 250,262

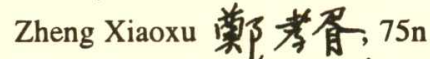

Zheng Yuanyou 奠陑祜, 76n

zhengtong 正統, 247. See legitimate succession.

Zhenjiang 鎮江, xiv, 31, 34, 49, 119

Zhenzhou 真州, 118

zhong, 94, 247

Zhong Jiyu䱋季玉, 117

Zhong Ziqi 金重卉期, 216

Zhongjing 忠縉, 94

zhongyi 忠義 loyalists, 5-6, 137, 244; other terms: chengjie 成節; jieyi 節善; sijie 死食; yishi 我士; zhongchen 㤂 居; zhonglie 忠烈; tradition, 93-136; zhongyi zhuan 忠莪偊 69

Zhongyi ji, 66

Zhou 周, dynasty (1050-221 B.C.), 96, 131, 138; Eastern Zhou, 124

Zhou, King 訧王, 112

Zhou Guanhua 周冠苹, 75n

Zhou Mi周密(Bianyang laoren弁晹老 人, Caochuang 草窇, Gongjin公理), 37n, 141, 153-154, 162, 183; dilemma, 222-228, father Jin轱, 197-199; Jia Sidao, 22; life before 1276, 25, 196-204; loyalism, 208-210, 228-242, 246, 248; son Yong 镂, 240; writings; 67-68, 76; Chenghuai lu, 206-207; Guixin zazhi, 85, 233; Juemiao 


\section{Index-Glossary}

haoci jian, 228-229; Qidong yeyu, 66n, 230; Shenzhong bian, 238; Wulin jiushi, 228; Yunyan guoyan lu, 221, 228-229; Zhiya tang zachao, 221

Zhou Wenying 周文莫, 121n, 131n

Zhu Shunshui 牛舜水, 263

Zhu Xi 生嘉, 95, 125, 132, 224, 234

Zhuge Liang 諸葛亮, 111

Zong Bing 宗炳; chenghuai guandao 澄嚎 徵道, 207n

Zou Feng 舴溷, 53

Zu Di 祖逖, 111

Zuozhuan 左傅, 137 


\section{ABOUT THE AUTHOR}

Jennifer W. Jay graduated with a B. A. and an M. A. at the University of British Columbia, where she first began graduate studies in Tang history. Upon obtaining a Ph.D. from the Australian National University in 1983, she taught Chinese history and classical language at the University of British Columbia. She has been at the University of Alberta since 1986, where she is now Associate Professor in the Department of History, teaching Chinese and world history. 


\title{
Other Books of Interest
}

\author{
Reminiscences \\ by \\ Nicholas Poppe
}

1983. vii, 330 pages. 28 photos, notes. person index. \$20.00. ISBN 0-914584-16-2.

"The book definitely deserves purchase and reading by all parties who deal with Mongolia, and will have interest for students of Soviet life, and, indeed, the whole human condition." Nongolian Suduies

Wu Tse-t'ien and the Politics of Legitimation in T'ang China

\author{
by \\ R.W.L. Guisso
}

1978. xii. 335 pages, illus.. maps, bibliography. glossary, index. $\$ 9.00$. ISBN 0-914584-11-1.

"This work is destined to become the standard work on this fascinating woman for years to come. With it, Empress Wu scholarship has come of age." Journal or Asian Sludies

\section{Buddhist Art of East Asia \\ by \\ Dietrich Seckel \\ translated by Ulrich Mammitzsch}

1989. viii. 411 pages, illustrations, maps, bibliography, index. \$40.00. ISBN 0-914584-97-9.

Widely acclaimed as the definitive work in its field, the book presents the reader with masterly descriptions of virtually every field of Buddhist art, including architecture, sculpture, painting, calligraphy, ritual implements, and much more.

Please send your orders, with prepaid check, to:

Center for East Asian Studies

Western Washington University

Bellingham. WA 98225-9056 